Thinking Locally: Provincialism and Cosmopolitanism in American Literature Since the Great Depression

A Dissertation presented to the Faculty of the Graduate School at the University of MissouriColumbia

In Partial Fulfillment of the Requirements for the Degree

Doctor of Philosophy

by Jason Arthur

Dr. Andrew Hoberek, Dissertation Advisor

December 2007 
The undersigned, appointed by the dean of the Graduate School, have examined the dissertation entitled

\section{THINKING LOCALLY: PROVINCIALISM AND COSMOPOLITANISM IN AMERICAN LITERATURE SINCE THE GREAT DEPRESSION}

$$
\text { presented by Jason Arthur, }
$$

a candidate for the degree of doctor of philosophy, English

and hereby certify that, in their opinion, it is worthy of acceptance.

\begin{tabular}{|c|}
\hline Associate Professor Andrew Hoberek \\
\hline Associate Professor John Evelev \\
\hline Professor Patricia Okker \\
\\
Professor Thomas Quirk \\
\hline Associate Professor Kristin Schwain \\
\hline
\end{tabular}


For Sara, whose fingerprints are all over this dissertation. 


\section{Acknowledgements}

My doctoral committee aided all aspects of the production of this dissertation. My advisor, Dr. Andrew Hoberek, saw this project through all its embarrassing potholes and dead ends. I would have never thought about most of what I've been thinking about for the past two years were it not for his expert advising. Drs. John Evelev and Pat Okker also read and provided helpful comments on multiple chapter drafts. Dr. Tom Quirk's sage advice on all things regional guided this project aright. Dr. Kristin Schwain also provided helpful feedback and advice.

Many other people read and critiqued portions of the manuscript, including Drs. Emma Lipton, Devoney Looser, Anne Myers, Donna Strickland. Dr. Jeffrey J. Williams was a consigliere; he read and responded to most of the chapters herein. Fellow graduate students Zak Watson and Crystal Lake also read a lot of the manuscript. Fellow contemporary regionalist, Dr. Douglas Reichart Powell was also a great inspiration, as was fellow friend Dr. James Andrew Miller.

I also need to thank those at the Harry Ransom Research Center at the University of Texas, at Austin, who were so accommodating and collegial while I was in residence down there. Their financial and archival assistance was vital to the completion of this project. Thanks especially to Patrice Fox, who helped me daily while I was in residence at the Center. 
Table of Contents

$\begin{array}{ll}\text { Acknowledgements } & \text { ii }\end{array}$

Introduction: "Local Affiliations in Twentieth-Century America" 1

Chapter One: "Specific Soil: James Agee and the Poverty of New Deal Documentary" 36

Chapter Two: "Pavement: Jack Kerouac and the Delocalization of America" 94

Chapter Three: "The Chinatown and the City: Maxine Hong Kingston and the Relocalization of San Francisco"

Chapter Four: "Old New England and the New Third World: Russell Banks and the Living Wages of Cosmopolitan Citizenship"

Epilogue: "War in the Middle-West: Jonathan Franzen and Local Affiliations in the Twenty-First Century

Notes

Works Cited

Vita 


\section{Introduction:}

\section{Local Affiliations in Twentieth-Century America ${ }^{1}$}

You have only to look at all the autumn art about death and at all the spring art about life to get an idea: we are so blindfold [sic] by local fact that we cannot even imagine this simultaneity. It is comfortable, and to quite some extent natural, and no doubt to some extent wise, to be local: and yet in for instance politics we flatter ourselves we are outgrowing it. (James Agee, Let Us Now Praise Famous Men, 219)

The cosmopolitan is local, and it is historical. (Robert Pinsky, "Eros Versus Esperanto" 86)

In Writers for the Nation: American Literary Modernism (1997), Barry Chabot recalls an often-overlooked link between T.S. Eliot and Van Wyck Brooks. The arbiter of cosmopolitan modernism and the arbiter of localist nativism respectively, Eliot and Brooks were acquainted as undergraduates at Harvard. ${ }^{2}$ In fact, when he turned down Brooks's offer to write reviews for The Freeman, Eliot expressed his memory of Brooks as the "prominent man of letters" at Harvard (qtd. in Chabot 16). Eliot's affable rejection of Brooks occurred in 1920, two years before The Waste Land and the Dial Award thrust Eliot onto the world literary stage. The Dial editors praised Eliot's "cosmopolitan vision", part of which reads: "there is nowhere in his work that 'localism' which at once takes so much of American writing out of the field of comparison with European letters" (qtd. in Chabot 16). Ironically, Brooks, who "was identified precisely with the 'localism' 
the editors had chastised when presenting the award to Eliot," received the Dial Award the year after Eliot (16). This curious contradiction indicates that there is an underexamined continuity between literary efforts to champion local affiliations and literary efforts to distance one's writing from specific locales. Indeed, before Brooks became disillusioned with the cosmopolitan affect of literary modernism, he had actually helped shape its development on American soil. The "preliminary moment" of modernism, as Chabot characterizes it, was dominated by the "tutelage of Brooks," the primary objective of which was "to rectify the individualism [Brooks] assumed to be characteristic of American life by propagating a set of values or concerns that could weld a disparate people into a vital community" (16-17). Thus, in some sense, the modernist innovations of Brooks's generation actually forecast the community-building social agenda of New Deal aesthetics. More importantly, these innovations developed out of an interest in "thinking locally," or reflecting on one's affiliation with the land that has failed to yield adequate forms of community.

In addition to claiming that the objective of modernism was to repair the splintering of community on American soil, Chabot argues that the First World War actually harmed the aesthetic development of American modernism. ${ }^{3}$ Going against the common argument that the horrors of the "Great War" actually engendered the radical innovations of modernism, Chabot claims that it "sapped young intellectuals and writers of their energy and especially of their optimism" (17). Normally, the War is considered an occasion for American writers to engage in cosmopolitan themes and viewpoints; it led to wide-scale expatriation and, as with The Waste Land, lent an air of global currency to texts that are otherwise assemblages of the "broken images" gathered from experiences 
with bankrupt locales. However, it is possible that the original plan for American modernism was not to embrace cosmopolitanism, but to put "young intellectuals" and literary talents to work reforming provincialism in America. ${ }^{4}$ Furthermore, these intellectuals and writers were to recognize that "local" America held for them a valuable model of affiliations and community building. As Chabot explains:

American literary modernism ... involves the recognition that even the seemingly fortunate are victimized by current economic and social life.... American literary modernism was primarily animated by efforts to repair this deficiency, to imagine conditions that would either restore to the national life the possibility that all citizens could enjoy access to functioning and supportive communities, or, failing restoration, at least provide something by way of a substitute. (2)

In other words, before being hijacked by the salons of Europe, modernism had a social agenda to bring wider attention to local issues and thereby to better represent the uneven development of economic and social progress in the U.S. ${ }^{5}$

In this dissertation, I will consider the legacy of thinking locally in mid-century and contemporary American fiction. More specifically, I will argue that the persistent interest in contemplating local affiliations bespeaks the fact that the long division between cosmopolitanism and provincialism is a myth. To rephrase Brooks's famous phrase, this myth creates a "useable present" wherein the codes that signify worldliness (or "cosmopolitanism") and the codes that signify strictly local literacy (or "provincialism") are held apart as opposites. This false polarity, which is "usable" primarily in the context of maintaining the geographic dimensions of economic 
disparities, makes one's economic situation appear to be an identity characteristic. Just as Sinclair Lewis's Babbitt personifies the uncultured middle class of the 1920s boomtown, the sharecropper personifies "the poor" of the 1930s rural zones. They are, as John Steinbeck was fond of calling migrant farmers in California, a "new race" of American. ${ }^{6}$ In both personifications, there is an assumption that the person being represented contains some engrained property that corresponds to his economic class. Indeed, Flannery O'Connor famously proclaims that fiction writers not only produce this conflation but also cherish it:

the fact that we will always have the poor with us is a source of satisfaction [to the fiction writer], for it means, essentially, that he will always be able to find someone like himself. His concern with poverty is with a poverty fundamental to man. (131)

This conflation of poverty as an economic situation and as some cosmic stamp on humankind is common to fiction in general. The assumption that both senses of poverty are located in rural zones is common to American fiction after the Great Depression. An unfortunate byproduct of Depression era attempts to represent the plight of rural poverty is thus fiction that represents poverty in a way that reifies a revisable situation into an elemental condition. I start this introduction with a brief discussion of American modernism because the long division comes to some degree from the aborted attempt to develop literary innovations alongside a social critique of the failure of American communities. As I discuss in the following section, before they were torn from their context, modernist forms of localizing and delocalizing American soil were intended to reveal the interdependence of local affiliations and global citizenship. 


\section{I}

Chabot's thesis about the preliminary localism of modernism in America is not as anomalous as it first appears. Recent academic debates about the innovations of U.S. modernism have started to uncover the importance of what I will call the "local affiliations" of modernist transformations of U.S. "culture.” Walter Benn Michaels and Susan Hegeman have been instrumental in shaping these debates, as both critics analyze the historical and regional conditions of pioneering cultural critics and modernists alike. Benn Michaels and Hegeman both expose more theory-driven scholarship about the exceptionalism of the so-called "modernist moment" as a fluke, or at least as a discussion of abstract literary innovations that have been torn from their historical conditions. A deliberately polarizing intervention into the mid-1990s culture wars, Benn Michaels's Our America (1995) analyzes U.S. modernism in the context of an early twentiethcentury debate between nativist and pluralist perspectives on American culture. Benn Michaels's revisionist historiography has since proven to be a launch pad for his multiproject argument with "identity politics." Nearly anyone who evokes Our America does so to disagree with one or all of Benn Michaels's anti-identity politics goals. However, Americanists such as Hegeman have since adopted its historical methodology. ${ }^{8}$ Our America thus signifies a turn in American literary criticism, from analyzing the methods and innovations of literary figures to historicizing them. It's no longer acceptable to explain, say, The Waste Land in a formalist vacuum. By the same token, modernist literary critics cannot simply explain The Waste Land as a product of Eliot's cultural context. Instead, after Benn Michaels, modernist critics have to explain The Waste Land 
as a cultural context, as what Hegeman calls a "terrain of culture." According to Hegeman, modernism "spatializes" the "culture concept."9

Chabot helps parse Hegeman's claim, suggesting that many American intellectuals and artists of the 1920s had struggled to ground modernist literary innovations in specific American places. Expanding on this observation, Hegeman adds the observation that these very intellectuals were wary of the likely possibility that their innovative patterns for thinking about America would be, as they in fact were, claimed solely by "the cosmopolitan avant-gardes of a few European capitals" (20). In response to this fear, the intellectual and artistic scene in New York in the 1920s develops a nonnostalgic mode of thinking locally, otherwise known as "nativism." Waldo Frank's Our America (1919) (from which Benn Michaels takes the title of his study) produced a way of thinking about the slippery concept of "culture" in America as something that, despite one's political leanings, is made up of mappable horizons. As Hegeman explains, Greenwich Village literati such as Frank, Randolph Bourne, Paul Rosenfeld, and Constance Rourke, team up with Columbia University anthropologist Franz Boas and his students (Ruth Benedict, Edward Sapir, Alfred Kroeber, and Ruth Margaret Mead), creating a middlecase status for "culture"- one that blends the capital-C "Culture" of Arnoldian cosmopolitanism and the lower-case-c of the localist social sciences. Though the Greenwich Village/Morningside Heights connection suggests that nativist perspectives on culture are somehow a New York thing, the literary and intellectual advances of Frank and Bourne owe a debt to the provincial South and Midwest. ${ }^{10}$ These urban intellectual groups in the 1920s make possible the critical narratives about the 
literary historical cohesiveness of "American" modernism and what immediately follows, namely documentary realism.

Tony Hilfer develops a similar historical grid in The Revolt from the Village (1969), when he implies that the reaction against the profound growth of Midwestern and Southern provincialism, especially after the First World War, played a big role in the anatomy of the East-Coast literary criticism of the period. This reaction is most sustained in the critical works of Brooks and H. L. Mencken, the first two East-Coast literary critics to turn their metropolitan gaze onto the inland "booboisie." ${ }^{, 11}$ Interrogating this division between East-Coast sophistication and mid-American provincialism, Brooks establishes, in his critical works, the organizing principle of most late nineteenth-century American literature scholarship. Brooks's principle is division. He asserts that American literary realism is divided between the vernacular realists, who revel to a destructive degree in the raw materials of uncultivated America (a case Brooks makes in The Ordeal of Mark Twain [1920]) and the cosmopolitan realists who do not accept the confines of American society (described in The Pilgrimage of Henry James [1925]). According to Hilfer, Brooks and "his associates [Mencken, Frank, and Bourne] saw cultural life in terms of a simple, stark dichotomy: the eternal opposition of the creative impulse to the acquisitive impulse" (112-113). The vulgar boosterism of the Midwest needed to be decried, and from a safe distance. This type of attention to the disparaged provincial zones of America offers an enduring model of criticizing the town from the city. As I explain in the following section, the writers I study revise and update this model of critiquing the "town" (or the un-reflexive local affiliation) from the "city" (or self-reflexive position). 
Due to the central position of "War" as an organizing rubric for mid-century fiction, discussions of the development of local affiliations normally stall after the 1930s. For instance, the last chapter of Tom Lutz's survey of regional fiction and cosmopolitan valuation, Cosmopolitan Vistas: American Regionalism and Literary Value (2003), is titled "After 1930: The New New Regionalism." Here Lutz briefly surveys contemporary fiction that echoes the Depression-era's "renewed desire for the rootedness of regionalism" (187). Citing some contemporary legacies of Depression-brand rootedness, Lutz recalls the usual suspects (including Dorothy Allison, Carolyn Chute, Kent Haruf, Cormac McCarthy, and Annie Proulx). Every writer in Lutz's list configures "the local" as that which is threatened by the whim of globalized capitalism. Lutz's most compelling claim about this twentieth-century conception of the local appears in a discussion of a figure whose status as a localist is virtually unheard of: Raymond Williams. Lutz discusses Williams as a critic and part-time regional novel writer who critiques "the provincialism of a metropolitan view of the country" (197, my italics). To a large degree, Lutz's conception of "the local" is the conception I adopt in this dissertation. Likewise, the rhetorical objective of the literature I study in this dissertation is of a piece with Williams's literary critiques of the provincialism of those who view the country from the city. The goal of such literature is to expose the local affiliations of cosmopolitan points of view, to dramatize the biased criteria through which the cosmopolitan mind evaluates unfamiliar "locals."

Reviving the communal and spatial preoccupations of the preliminary modernist moment, the writers I study develop ways of representing local affiliations without also reifying these relations into class-inflected identities. As is indicated by O'Connor's 
admission that "the fact that we will always have the poor with us is a source of satisfaction" occurs in a lecture often taught in university writing workshops, it is easy to argue that the misreading of class difference as identity extends into the present time. ${ }^{12}$ Rather than a discreet event, this problem is a long-term process that begins roughly at the New Deal's recession and is resolved only by means of rescuing the arrested social agenda of U.S. modernism. Thus the literary techniques I discuss in this dissertation all occur after the end of the Great Depression, during a period when American writers become remarkably self-conscious about their local affiliations. The reason why these writers worry over their relative locations, the reason why one's position in the process of representing American terrain starts to matter so much after the Depression, is because of the tension between the elitist cosmopolitanism of transatlantic modernism and the populist nationalism of New Deal localism.

New Deal regionalism differs in obvious ways from the regional project mounted by late-nineteenth-century "Atlantic group" periodicals. ${ }^{13}$ Consider first that the engineers of the first were the editors of elite periodicals and the engineers of the second were government agents and proponents of social welfare. This means that the ends are different. The documentary work of this second period highlighted "the raw stuff of the contemporary mass record," casting an empirical eye on the economic and social sources of regional difference and setting social justice as a standard for curating such difference (Kazin 381). New Deal social welfare projects also expanded the media through which regional difference could register. ${ }^{14}$ For instance, the Information Division of the Farm Security Administration (FSA) employed a dozen of the country's best photographers (including Walker Evans, Arthur Rothstein, Ben Shahn, Dorothea Lange, Marion Post 
Wolcott, Jack Delano, and John Vachon) and produced over 164,000 photographs of America's many regional and socioeconomic strata. This documentary approach abandons the ghettoizing techniques of the late nineteenth century, privileging infinite texture and facts over either the humorous presentation of stock characters or the mystifying adoration and purity of regional difference. It also, however, abandons the positive kinds of cross-cultural contact that accompany nineteenth-century regional writing, especially cosmopolitan "outsider" narrator, whose process of blending her rootless subjectivity into provincial culture becomes a process of balancing different perspectives on American culture at large. ${ }^{15}$

Concurring with most regional scholars, I understand regional fiction as a means of escaping the ether of "thinking globally," a return to the stability and density of solid ground. The way in which this impacts the representation of poverty is complicated. In contrast to regional fiction, Depression-era documentary turns the process of thinking territorially into a political process, making the act of thinking locally into a politically progressive, rather than conservative, pastime. With the Depression, the days of regional fiction about quaint and bucolic countrysides come to an end. Or, as Grant Wood's famous painting American Gothic (1930) indicates, the large-scale national trauma must register on the face of even the most archetypal, nostalgic imagery. Even Wood's most optimistic regional landscapes, such as Spring Turning (1936), are deliberate inversions of the real state of the drought-plagued Midwest. In short, Depression-Era visual art represented missing vitality (rather than the ever-present sentimentality) the nation's regions. Narratives or visual representations controlled by nostalgic affection for peoples, places, and folkways that have passed away are thus infeasible after the advent of the 
Great Depression. The rural peoples, places, and folkways of Depression-era regionalism (as represented within the pages of WPA guidebooks, FSA photo-essays, and FWP caseworker studies) are those that still survive, some just barely. Such urgent currency of subject matter produces a heightened interest in thinking territorially and, as in the breasts and thighs of Wood's Spring Turning, thinking of people themselves as territory.

In Chapter One, "Specific Soil," I discuss James Agee's reaction to the populist documentary efforts that established what Alfred Kazin refers to as the 1930s era of "national self-scrutiny" (378). To a large extent, the populist efficacy of the Works Progress Administration (WPA) and the elitism of high literary vision join hands in the wake of the Great Depression. Both the clinical prose productions of the WPA (such as the State Guidebook Series) and the modernist meditations on America (such as John Dos Passos's U.S.A. trilogy [1938]) are extreme forms of national autobiography. Both multiply the available methods of revealing local affiliations. ${ }^{16}$ After the recession of the New Deal, the localizing techniques of documentary prose become privatized, taken up by a modernist aesthete such as Agee, who updates localization techniques, making visible the point of contact between the documentarian and his subject and thus attempting to expose the conditions that produce the false conception of poverty as an identity trait.

In Chapter Two, "Pavement," I discuss how Jack Kerouac, founding member of the "Beat Generation," embraces Agee's iconoclastic vigor, but "delocalize" his narrative position. Rather than neglecting local affiliations, as other writers who come of age during the Second World War have the tendency to do, Kerouac multiplies them ad infinitum. In fact, in On the Road (1957), he goes so far as to represent transatlantic 
modernism alongside mid-century frontier nostalgia as a kind of provincialism. Through the character of Roland Major, a "Hemingwayan short story" writer trying to live a Parisian literary life amid broke bohemians in Denver, Kerouac devalues the retention of transatlantic cosmopolitan credentials in American communities. He enacts an absurd form of world citizenship, one based on what W. J. Lhamon later terms "deliberate speed," a mid-century aesthetic defined by its oscillation between "gregariousness and isolation" (85). Simulating the unanchored experience of the weightless flight of highway travel, Kerouac articulates a form of local affiliation that is incapable of shortsighted provincialism, incapable of mistaking a local condition as an essential condition. Writing about speeding from one side of the American continent to the other, Kerouac's persona affects a transcontinental reach that is both patriotic and cosmopolitan, as it both defines America and remains detached from any one part of it. In short, Kerouac unearths the proto-modernist notion that the fortunate are victimized by the wide-scale isolation of American communal bankruptcy. His fiction demonstrates that the cosmopolitan credentials that harden around self-proclaimed modernists only aggravate the primary deficiency of American life - what Chabot calls the inability to "enjoy access to functioning and supportive communities" (2). Kerouac's solution, a combination of community building and flight, is too unsophisticated to be considered cosmopolitan. It does, however, produce a liberatory form of conceiving of narrative identity formation. In Chapter Three, “The Chinatown and the City," I examine how Maxine Hong Kingston, who came of age in the West-Coast bohemian communities founded by followers of the Beats, critiques the gender politics of Kerouac's reaction against cosmopolitan modernism. As critics of Kerouac and the Beats often argue, it is 
problematic for white men to assume a "victimized" status in American society, as such a pose always (even if inadvertently) offends those whose racial or gender determinants leave them incapable of choosing or denying victimization. Kerouac's legacy is therefore inherently divisive. But Kingston demonstrates that Kerouac's ideal of the delocalized persona is worth saving, even if the cultural forms that it engenders are problematic. Her novel Tripmaster Monkey: His Fakebook (1989) continues Kerouac's argument that cosmopolitanism is a form of narrow-mindedness. Kingston criticizes the West-Coast bohemianism that sprouts in the furrow of Kerouac's narrative innovations, charging that the Beat-inflected "San Francisco Renaissance" denies the city its urban diversity and thus enacts a cosmopolitan form of provincialism. Kingston thus updates the technique of delocalization in order to interrogate the reigning West-Coast politics of representing local affiliation. Kingston's intervention into the masculine-dominated literary forms and traditions of her home region, the Bay Area, is what makes Kingston's fiction "multicultural." With such an origin, "multicultural fiction" can be seen as a corrective to the central contradiction of mid-century literary bohemianism, rather than as a purely political correction to the under-representation of minority writers. Kingston's delocalized treatment of urban space reveals the various cultural influences ingrained in San Francisco's unique makeup, the very influences that had been eclipsed by the dominant literary historical narrative about San Francisco. Thus, in addition to critiquing Kerouac's gender politics (no tough feat), Kingston continues an unfinished argument about the place of local affiliations in fiction about multivalent urban spaces.

In Chapter Four, "Old New England and the New Third World," I discuss Russell Banks's self-reflexive reaction to a recent masculine takeover of regional form. 
Specifically, I will discuss how Banks, like Kingston, redresses American economic injustices in spatial terms. Writing about the bankrupt rural zones of New England, Banks explores the virtues and limitations of focusing on the American region that is arguably the most damaged by the strain of modernism that neglects local affiliations. As a contemporary writer in deep dialogue with the localizing arts of American literary regionalism, Banks effectively revaluates the politics of thinking locally in American literature. His fiction reveals that provincial America has more to teach about the problems of globalization than do traditionally cosmopolitan zones. Basically, Banks demonstrates that the local affiliations fostered in the boondocks outlive the economic usefulness of such places. By examining what happens after modern capital abandons a small town, Banks articulates the contemporary value, indeed the cosmopolitan agenda, of small-town realism. Also, the fact that Banks is a white male writer is not unimportant. Indeed, his interest in local affiliations is on some level symptomatic of a trend among white writers: to represent the working-class masculinity integral to regional identity as though it were a form of ethnic identity. Indeed, the fact that white writers have learned to benefit from their regional "markings" is one possible explanation for why the politics of local affiliation have remained in play in American literature since the end of the New Deal. $^{17}$

Chabot makes this claim in a forthcoming book on contemporary American fiction. In a chapter titled “A New Regionalism in American Fiction,” Chabot evokes Richard Brodhead's argument about the cultural work of regional writing. He claims that what Brodhead saw occurring at the end of the nineteenth century, namely that the wellorchestrated appearance and disappearance of regional fiction in elite periodicals ensured 
that America's “diversities were ranged under one group's normative sway," has reversed itself in recent years (Cultures of Letters 137). Where "Brodhead sees immigrant fiction in the nineteenth century as emerging by means of adapting the conventions of the already flourishing Regional or Local Color genre," Chabot argues that the reverse pattern of derivation is now occurring; that is, that many contemporary white writers are producing a new regional literature, and that they are developing it partially by adapting to their own cultural locations and purposes the conventions of recent writing by African Americans, Asian Americans, and other minority writers. (Chabot 1$)^{18}$ In this passage, Chabot likens local affiliations to cheap tricks that help white fiction writers to be competitive. While I'm wary of the idea that white writers are this baldly opportunistic, I do agree that nonnormative patterns of affiliation are currently more valuable than, say, the putatively middle-class experiences explored in the fiction of Johns Updike and Cheever. It seems to me that this phenomenon is not simply a result of the much disparaged and celebrated "identity politics" of recent years. Instead, I think that the contemporary focus on the delicate architecture of local affiliations is largely the result of a crisis in realist technique that began during the privatization of New Deal aesthetics. Banks himself indicates in a forthcoming novel about the reach of social welfare in upstate New York in the 1930s, titled The Reserve (2008), that the roots of this contemporary phenomenon in white male fiction lie in the revised notion of masculinity enacted by the New Deal.

In short, the literature I investigate in this dissertation responds in distinct ways to documentary realism's brief reign. Furthermore, it all in some way oscillates between 
self-reflexive localization and selfless delocalization. Agee's labor-intensive documentary prose in Let Us Now Praise Famous Men (1941) and Kerouac's "spontaneous prose" in On the Road (1957) signify the two extreme stylistic possibilities that become available after the end of the New Deal. ${ }^{19}$ These two writers also dispel some of the myths to which even the best critics of American literature fall prey, namely the that the mid-century vortex of Cold War concerns draws in all of the literary and cultural work in its proximity. While I do not mean to trivialize the vast amount of scholarship on the influence of the Second World War and the Cold War on mid-century fiction, I do hope to suggest an alternative to war-centered rubrics, one that reveals the importance of local affiliations to American fiction after the Great Depression. Where Agee juxtaposes a high literary narrative sensibility against the impoverished subjects of documentary realism, Kerouac traces his encounters with rural and provincial America in the sloppy hand of a dilettante.

In each case, these writers straddle the line between documentary and vernacular writing. Their methods resemble to a small degree those of vernacular writing. Of course, vernacular writing simulates the language of everyday life; its elisions and phonetic spellings mimic the way people actually speak and think in the world. This kind of dialect is common to local color stories, or stories whose primary aim is to highlight the peculiarities of local folkways and thus to (intentionally or not) reinforce sectional division in America. ${ }^{20}$ According to this logic, certain geographical zones (such as rural hamlets or urban slums) have dialect, while others do not. ${ }^{21}$ What distinguishes Agee and Kerouac from vernacular writers is that they do not simulate the language and customs of everyday life in rural America. Instead, they dramatize the felt experience of 
encountering the raw materials of such simulations. For Agee, and to a lesser degree for Kerouac, to dramatize the encounter is to call attention to the key shortcoming of documentary prose, specifically that it affects no local affiliation whatever.

The documentarian is always oddly missing from his own representation. His position relative to the world he represents is thus that of a cosmopolitan detachment. With no local roots, the documentarian enacts the "conquering gaze from nowhere," which Donna Haraway claims allows any writer the scientific conceit "to see and not be seen, to represent while escaping representation. ${ }^{, 22}$ In the following section, I will discuss the recent academic debate over the virtues and limitations of "cosmopolitanism," a concept that even its supporters claim is dangerously close to affecting the same kind of detached accounting.

\section{III}

As the current debate about cosmopolitanism reveals, this effort to revise the relationship between cosmopolitan and localist paradigms is not being forged strictly on literary terrain. In one of the essays that sparked the current interdisciplinary debate about cosmopolitanism, "Patriotism and Cosmopolitanism" (1994), Martha Nussbaum argues that "home," or one's local attachments (particularly those associated with a particular country), ought to have no "special salience in moral and political deliberation" (3). ${ }^{23}$ Of the more than a dozen critiques of Nussbaum's argument, a single counterargument can be deduced, that choosing "world citizenship" is not the same thing as choosing to abandon local affiliations. Nussbaum's critics, who include Anthony Appiah, Benjamin Barber, Gertrude Himmelfarb, and Hilary Putnam, argue that the denial of local affiliations leads to the "thin gruel of contract relations" (31). In other words, 
cosmopolitan subjectivity fails to grip "the viscera" (34). As Barber explains, "[n]o one actually lives 'in the world of which the cosmopolitan wishes us to be good citizens.' Rather, we live in this particular neighborhood of the world ... Our attachments start parochially" (34). Barber thus forges a patriotic argument (much like that of Richard Rorty in a well-known op-ed piece, "The Unpatriotic Academy") that sings the praises of "American everyman" who "drinks in the immediacy and the immensity of the American landscape" the way Walt Whitman and Woody Guthrie might (35).

Counterarguments such as these ring out of tune with the resounding cords of global connections that occupied so many academics in the early 1990s. Regardless, they are prevalent within the academy, not to mention the fact that they originate at both political extremes. Indeed, not since Charles Pasqua and Laurent Fabius joined forces to oppose the European constitution have proponents of the right- and leftwing political extremes so unanimously opposed the same course of action. In one way or another, all of Nussbaum's respondents exploit a shortcoming that she herself admits, that cosmopolitanism "seems to have a hard time gripping the imagination" (15). She concedes that her approach is passionless, but claims that the "colorful" intensity of local allegiances, meaning education methods that place special importance on "local origins and group membership," are compassionless. ${ }^{24}$ By placing primary importance on one's tangible group memberships, thinking locally overlooks "[t]he accident of where one is born," which is to say that compassion is replaced by the "fellow feelings" of group membership. These fellow feelings, Nussbaum claims, engender the unfair boundaries that cause so many of the world's problems. ${ }^{25}$ 
Robert Pinsky partially agrees with Nussbaum, but he is more concerned with preserving the regional coordinates of affiliation than he is with replacing one type of allegiance to an abstraction with another. Trying to claim it as a substantive concept, rather than the ephemeral sentiment Nussbaum lets it become, Pinsky asserts that " $[t]$ he cosmopolitan is local, and it is historical" (86). In other words, the spirit of cosmopolitanism is fostered in specific historical and geographical conditions. Pinsky locates his manifestation of this "spirit" in Brooklyn in the mid-1940s, right around the time the Dodgers ended segregation in professional baseball. ${ }^{26}$ Brooklyn at that time was "a borough that was in certain ways to New York what New York was to the country: historic and raw, vulgar and urbane, many-tongued and idiosyncratic ... provincial enough to have its own newspaper yet worldly beyond measure" (90). Pinsky's scale of affiliations, wherein Brooklyn is New York's world in miniature and New York is the U.S.'s world in miniature, packs the cosmos into a specific locale. According to Pinsky, this is in line with the long tradition of American literary realism; it is "an act of the imagination [that] corresponds to reality" (90). Thinking about the home as the world helps the American artist to more accurately gauge the disappearance and reappearance of America's global microcosms, its compressions of the world. But, just as the Dodgers left Brooklyn, Pinsky reminds us that a locale's status as a slice of the world comes and goes independent of whether or not the local community wants it to come or go. "Culture," in the context of modern capitalism, is always "going, going, gone ... it is movement" (90). The literary figure is obligated to expose the fact that culture responds to delocalizing capital. Pinsky claims that this knowledge engenders a conception of belonging "that has the erotic appeal to counterbalance patriotism" (90). The artist who 
does not acknowledge the terrible transience of cultural vitality takes as his subject not reality but fantastic places that never existed to begin with. In short, Pinsky claims that cosmopolitanism is not an affect, but a non-nostalgic way of thinking about place.

Thus the result of the Nussbaum debate, as Pinsky represents it, is the realization that local affiliations have a longer lifespan than the actual locales in which they claim they originate. The writer who doesn't acknowledge this fact is labeled a "regionalist," by which those who use that label mean that the writer is romantically nostalgic about a place that no longer actually exists. But in recent years, opposition to globalization has, for better or worse, increased the cachet of "the local" as a site of resistance to global capitalism. In his essay, "The Global in the Local," Arlif Dirlik explains this new interest in the local by claiming that a "romantic nostalgia for the concretely (and, therefore, humanely) local" has established itself "against the abstractly (and, therefore, dehumanizingly) global" (21). The easiest explanation for this renewed interest in the local, then, is the economic explanation: as capitalism develops into its "global" phase, anti-capitalists resist, and their sites of resistance are the local zones not yet touched by the arms of multinational capital. "Romantic nostalgia," Dirlik implies, is simply the best way to mobilize anti-capitalist sentiments. ${ }^{27}$ In addition to being a "site of resistance to capital," the contemporary "concern with the local" comes from the assumption that it is "the location for imagining alternative possibilities for the future" (22). The "local," then, in Dirlik's conception, is that which is threatened by capitalism, that which "local movements" try to "save and reconstruct" (22).

In terms of political activism, the local is the site of resistance to progress. In terms of fiction, it is the raw material for nostalgia. As Dirlik continues his explanation of 
the unattractive connotations of the local, he reveals an important dialectic between localism and modernism:

Modernist teleology has gone the farthest of all in stamping on the local its derogatory image: as enclaves of backwardness left out of progress, as the realm of rural stagnation against the dynamism of the urban, industrial civilization of capitalism, as the realm of particularistic culture against universal scientific rationality, and, perhaps most importantly, as the obstacle to full realization of that political form of modernism, the nationstate. (23)

The local, then, appears in contemporary discourse alongside anti-modern critiques of industrial civilization. Those who champion the local do so in order to "reject[] as ideology the 'metanarratives' which have framed the history of modernization" (24). In other words, localism is nothing less than a denial of progress narratives as we know them. ${ }^{28}$ Dirlik names postmodern discourse as a partner of localism, in that both are antimetanarrative — both postmodernism and localism work against the idea that a coherent, totalized view of its subject is possible. The implication of this unexpected similarity between the local and the postmodern is that "the struggle for historical and political presence" of local groups has "dynamized this postmodern consciousness" (35). In other words, the local and the postmodern are allies; both stand in as evidence that there is no such thing as a unified world.

Anticipating an argument that Benn Michaels makes much more dramatically in The Shape of the Signifier (2004), Dirlik claims that the local and the postmodern find their truest expression in the "politics of difference." Such politics "presuppose[] local 
differences (literally or metaphorically, with reference to social groups) both as a point of departure and as a goal of liberation" (35). In other words, "difference" is to the art and politics of postindustrial America what "standardization" is to industrial America. The fiction that elevates cultural difference has the opposite cultural import at the end of the twentieth century than it did at the end of the nineteenth century. Rather than being marginalized (as was the case with late nineteenth-century regionalism), fiction that uncritically reproduces provincial affiliations and "situated knowledges" (to borrow another term from Haraway) is duly rewarded in the contemporary literary marketplace. ${ }^{29}$ In the following section, I will discuss the impact of the politics of difference on contemporary fiction.

\section{IV}

My chapters on contemporary fiction (i.e., Chapters Three and Four) address the idea of local affiliations in contemporary American literature, examining specifically Kingston and Banks's critiques of their era's uncritical approach to standardized multicultural progress narratives. There is a problem, Kingston and Banks both indicate, with the way such narratives get valued in America. As Kingston demonstrates through her protagonist's failure to gain more than a provisional acceptance into the dominant urban groups, the multicultural self is too often a "representative self," or a stand-in for the identity group that their racial features signify. As is made clear in the narrator's ambivalence in Kingston's famous memoir, The Woman Warrior (1976), or even in the generational conflict of Amy Tan's first novel, The Joy Luck Club (1989), Asian American writers complicate the "representative self" model. In Tan's popular novel, ethnic markers mask Tan's argument that Chinese-Americans are as estranged from the 
local affiliations of their racial identities as her middle-class white readers. Tan's text narrates the particularities of Chinese culture, but these localizing narratives occur in China. In America, Tan's characters choose their own fates and create new personas independent from the local affiliations that make them "Chinese." ${ }^{30}$ As I will argue in Chapter Three, Chinese-American writers on the West Coast take as their subject their estrangement from the local affiliations that normally serve as a prerequisite for membership into an identity group. The narrator of The Woman Warrior and June of The Joy Luck Club have their local affiliations imposed on them by their mothers and fathers.

For instance, Kingston's “memoir” Woman Warrior, which inaugurated the "multicultural recanonization," is very interested in the American preoccupation with buildings and building representations of one's local allegiance. ${ }^{31}$ Near the end of the book, Kingston recognizes the uniquely American need to set allegiances in stone: "Concrete pours out of [the American writer's] mouth to cover the forests with freeways and sidewalks" (204). The unique problem of the Chinese American writer is that what gets memorialized in her writing is the Chinese American writer's most tenuous allegiances. As Kingston explains of her first two books: "I felt I was translating a culture for everyone ... It felt like a burden to me" (qtd. in Skenazy 144). When she turns to fiction, with Tripmaster Monkey, she takes as the language of her novel the "language of the Sixties," when "people were finding vocabulary for psychedelic states or visions or social action" (145). This new vocabulary is more in line with her own life's local affiliations, as opposed to affiliations with familial lives that she has not lived. In short, Kingston both revises the way Chinese Americans imagine their local affiliations and criticizes the paradoxical provincialism that love of Kerouac's style helped to produce. 
Kingston appropriates techniques from Whitman, Kerouac, and other Anglo American literary figures in order to blend the Chinese-American identity struggle with Kazin's "spirit of social inventory." Michael Kowaleski claims that this fiction "embodies an ironic trans-Pacific consciousness that mixes Rilke, Kerouac, and Chinese legends of the Monkey King, none of them out of place on the foggy streets of San Francisco" (14). As I will argue in Chapter Three, this blending of influences is not strictly "postmodern," but a pragmatic way of making one's local and literary knowledge useful.

In short, Kingston paves the way for a racially diverse literary persona that is "representing," rather than "representative." Her protagonist's agency extends beyond the right to claim racial status. In effect, Kingston reveals that what's wrong with the racially diverse protagonist in American fiction is the same thing that's wrong, according to Agee, with the sharecropper in New Deal documentary: she is represented as being too in need of aid and visibility to speak for herself. She is counted, but she doesn't do any of the counting. While both the identity traits and the degree of need between the sharecropper and the diverse protagonist are different, the basic economy of subjectivity/objectivity remains consistent with the documentary model Agee and Walker Evans attacked. The diverse protagonist troubles Kingston because this character is expected to conform to a progress narrative wherein the protagonist learns how to embody comfortably a set of traits assumed to be inherently her own. The standard multicultural protagonist is, like Esperanza of Cisneros's House on Mango Street (1985), predestined to always discover the means of subjectivity, to always teach some unenlightened reader how she comes to embody her voice. Kingston problematizes this progress narrative, offering a protagonist who already has a voice. Tripmaster Monkey is 
thus a case study in what happens after such a voice is acquired, rather than a variation on the multicultural routine. Her protagonist, Wittman Ah Sing, complicates the standard multicultural protagonist protocol, refusing to become a precious success story or to "come of age" as an embodiment of his racial identity. In effect, Wittman does away with success altogether, and in its place he produces a process of self-enactment that privileges gestural identity and reduces the primacy of determinants like embodiment and locale. The fact that Kingston's breakthrough Chinese American protagonist is male is important, as it allows her to interrogate the gender politics of local affiliations. Her "beatnik chinaman" embodies the scripts of both Chinese American stereotype and Beat generation "locale."

As I argue in Chapter Four, masculinity is very much at issue in the persistence of local affiliation. As Chabot explains, "Brodhead's linkage of regional and immigrant genres at the end of the nineteenth-century" is very similar to the linkage being made now between regional and multicultural genres (2). Immigrant fiction in the nineteenth century emerges by means of adapting the conventions of regional representation. Chabot believes that "the reverse pattern of derivation is now occurring"; white male writers are engaging in regional representation in order to present "their own cultural locations and purposes" as though they are minority locations and purposes. In effect, white male writers are trying to "pass" as minority writers. Their local affiliations are being exploited as the markings of ethnicity. Russell Banks is self-reflexive about this masculine takeover of regional form. In Chapter Four, I will discuss Banks's unique use of local knowledge, specifically his ability to represent the most seemingly irrelevant blue-collar zones of New England as a microcosm of the limitations of globalization. Banks's narrative 
sensibility, most accurately described as that of a small-town storyteller, does not come across as romantically nostalgic. On the contrary, as is revealed through Banks's timbre, the origins of cosmopolitan credentials are local. It is not economic advantage or multicultural cachet that authorizes cosmopolitan affect. Instead, it is the ability to critique one's own local affiliations rather than to fall into the provincialism of critiquing the affiliations of others. In the following section, I will account for how we might think of the white male exploitation of local affiliations as something other than a reactionary model used simply to remain relevant in a literary marketplace that values diversity. I will discuss the origins of this model, as they are notable in the reception of Wright Morris, a mid-century writer whose career spans into the 1970s. He commonly considered as a marginal figure, a writer who deliberately chose not to write about the Second World War and the Vietnam War. However, when we read mid-century and contemporary fiction for its local affiliations rather than for its relationship to wars, Morris will become a major transitional figure.

\section{V}

As I've already indicated, I think that criticism about American literature in the second half of the twentieth century pays too much attention the relationship between pre-Depression forms of realism or modernism and "the War," be it the "Cold" or the "World" war. For instance, in Leopards in the Temple (1999) Morris Dickstein builds his canon of "postwar" fiction from an exclusively war-centered rubric. ${ }^{32}$ In a chapter entitled "War and the Novel: From World War II to Vietnam," Dickstein argues that the powerful dynamism in the literature of the 1940s to the 1960s comes from writers' reactions to American participation in war. In the basic arc Dickstein draws, the "prewar 
social consciousness" of the 1930s is replaced, via meditations on war, by a "postwar sense of the absurd" (34). Surveying the World War II novel, from its beginnings in the combat narrative to its afterlife in the existential Holocaust narrative, Dickstein makes a convincing case for why we might think that war carries American fiction from the documentary realist vigor of Dos Passos to the postmodern rigor of Pynchon.

Dickstein focuses the remainder of his survey on the well-worn notion that Cold War "containment" is the imposing monolith that American literature in the second half of the twentieth century struggles against. Emphasizing the revitalization of American letters by non-traditional "outsiders," or young rebels who thumbed their noses at containment, Dickstein claims Adventures of Huckleberry Finn to be the "ur-text" of the postwar novel, naming Huck the progenitor of Holden Caulfield, Sal Paradise, and other outsider-rebel protagonists of the "not-growing-up novel" (90). Consequently, according to Dickstein's paradigm, much of postwar writing "lights out for the Territories," embracing the libratory potential of physical mobility. Huck's famous decision thus offers Dickstein a handy way of extending the canonical tension between "flight" and American privilege into the contemporary period. As I will discuss below, Wright Morris's career offers another, largely overlooked, model for approaching "the Territories," which by mid-century standards is a phrase that means rural America.

Morris should be a key figure in discussions of literary responses to the uniquely American quality of rural life, or what James Cox (by way of Robert Frost) calls the "diminished thing. ${ }^{, 33}$ In his own period, dominated by war novels, Morris was marginally received, championed only by critics such as Granville Hicks who'd forsaken the urban intellectual centers (not to mention the communist party) for the clean 
simplicity of small towns. ${ }^{34}$ Morris has since been claimed as the key "Nebraska writer" by the University of Nebraska-Lincoln Center for Great Plains Studies. ${ }^{35}$ But Morris has a more complicated relationship to small town life than these critical models might indicate. For instance, in 1957 Wayne Booth claimed that "a highly sophisticated dialectic ... flows throughout Morris's works," a dialectic that moves between the "real" world of home and the "phony" worlds that one encounters away from home (qtd. in Wydeven, 10). In a 1959 essay titled "Mass Society and Post-Modern Fiction," Irving Howe categorizes Morris as a "post-modern" writer with an established "distance from fixed social categories," a writer whose work betrays "concern with the metaphysical implications of that distance" (433). A generation after Booth and Howe, G. B. Crump, in The Novels of Wright Morris (1978), rejects the dualism/distance paradigms as false dilemmas. Instead, Crump suggests, Morris focuses on the platonic division between settlement and relocation. Crump thus replaces one dualist paradigm with a paradigm that views Morris as a writer split between two motifs: the "still point" and the "open road." The still point, as Wydeven summarizes Crump, "is characterized by focusing on an object or event precipitating acts of consciousness"; the "open road" motif "is more linear, involving greater lengths of time, emphasizing action" (11).

Despite the myriad dualisms applied to Morris's work, he is mostly remembered as "a champion of rural virtues and pioneer values" (Wydeven 18). This characterization is inaccurate, a result of the fact that the war rubric obscures the value of fiction that does not touch war. Morris's oscillation between the "still point" and the "open road" generates an ambivalence about, rather than embrace of, the value of rural, mid-American affiliations. As Morris claims in his study of American literature, entitled The Territory 
Ahead (1958), very few virtues and values remain in provincial America. Indeed, the general "raw materials" of American life have diminished. By "raw material," Morris refers to the aspects of American nature that are not somehow fashioned by Americans. Literature written in this mode "resemble[s] some aspect of a natural force - a pond, a river, a demonic whale — rather than something cleverly contrived by man" (640). The enduring impact of such "raw" works as Walden, or Adventures of Huckleberry Finn, and Moby-Dick produced, by the mid-twentieth century, a "raw-material myth" that inspired an unquenchable interest in the "lumps of raw life" (641). The mid-century writer who wants to be in the tradition of Thoreau is instead in the presence of "homemade provincial wares [that] no longer startle and amaze the world" (642). In other words, a traditional white male preference for "the Territories" has become a preference for the specter of what no longer exists. ${ }^{36}$

Morris began his career aware of the dangers of the raw-material myth. His first publication was in the 1940 edition of James Laughlin's avant-garde New Directions in Prose \& Poetry. His subject matter and techniques of blending photograph and prose, originally located him as one who favored modernist defamiliarization over the fellow feelings of nostalgic localism. As Alan Trachtenberg claims, Morris's early photo-texts perfect the modernist exile's "perspective of being out of place, a seeker in quest of home" (64). ${ }^{37}$ This observation comes from Trachtenberg's essay, "Home Place," which discusses the different modernist principles of combination in Morris's two 1940s "photo-texts": The Inhabitants and The Home Place. Trachtenberg has written two articles about Morris's photo-texts, one in 1996 and one in 2006. In the interim, with the exception of an anomalous article titled "Wright Morris and the Jews," there have been 
no scholarly articles on Morris that were not published in the Midwest Quarterly. Even Oliver Pollack's "Wright Morris and the Jews" begins with the Midwest-centric claim that "the Midwest was a formative influence as rural and small-town Nebraska and ethnic diversity in Omaha frequently provided material for many of the essays, novels, and photographs produced from 1942 to 1985 " (18). The fact that Morris is discussed only by scholarly conversations self-identified as "regional" obscures his cosmopolitan techniques.

Nevertheless, his critics see only that Morris's writing bears "the stamp" of the plains. Chester Eisinger describes Morris thusly. Interestingly, Morris himself uses this metaphor of the stamp" to refer to his own style. Eisinger calls Morris's style "indigenous ... bearing the stamp of the plains" (330). Morris characterizes his style as bearing "the stamp of an object made on the plains" (qtd. in Hicks 1970, x). Notice the difference. Where the critic's evaluation claims Morris uses an indigenous voice, Morris's selfevaluation characterizes the "stamp" as an aspect of the "objects" the writer chooses. But recent critics, beginning with Trachtenberg, stress that Morris's style and method are not so simply local. They are instead "deceptively simple," a "merging [of] modernist interest in language with vernacular Midwestern usage" (Wydeven 19). Indeed, Morris described his own use of vernacular as "modified," a mimetic method that "permit[s] the intrusion of tones, moods, and qualities that ordinarily would be excluded from the vernacular" (qtd. in Wydeven 19). ${ }^{38}$

Morris’s first publication, "Inhabitants," was part of an effort of East-Coast literary publications to claim the New Deal documentary agenda. Laughlin created an "American Scene" section for his annual collection especially for the two "modernist" 
interpretations of rural America: Morris's "Inhabitants" and James Agee's "Colon" (a section from the forthcoming Praise). Far from a populist publishing house, New Directions was a curious venue through which to showcase American folkways. More curious still was the attempt to co-opt both Morris and Agee as members of the EastCoast literati. The contributor's note makes Agee, who was born and raised in Tennessee, sound like a New York-based intellectual: "James Agee is in New York City when he is not on his farm in New Jersey. He has worked for Time and Fortune and is the author of ... a book of poems published by the Yale University Press" (ix). ${ }^{39}$ Likewise, Morris's note begins with an odd, biographically inaccurate claim - "Wright Morris is properly a New Englander"- and ends on a similarly East-Coast centric tangent: "there is to be an exhibition of [his work] at the Kamin Bookshop in New York City in the near future" (xi). Morris had only moved to Connecticut two years before the New Directions publication. This small effort to skew the historical record, to claim Agee and Morris as modernists who, like Eliot, are successful transplanted into the cosmopolitan literati, is symptomatic of a larger literary trend that Hegeman notices among New York intellectuals in the 1920s, to filter local affiliations of provincial America through "cosmopolitan" lenses of East-Coast sophistication.

"Inhabitants" couples stark, unpopulated photography of rural America with impressionistic prose poems often written in vernacular. Morris's prefatory note begins: "The origins of technique lie in the dimensions of the material — when these dimensions exceed the response, a technique appears" (147). In other words, the patterns and tools of representing local affiliations come from the materiality of the locale being represented. In Morris's case, this thing is "An Aspect of American Folkways" (the subtitle of the New 
Directions version of "Inhabitants"). According to Morris, "[ $t]$ he land constitutes a Folkway museum, an Architecture of Americanism — the material retaining the composite Look, the word the composite mind. The problem of technique is to engage both the eye and the ear" (147). The technique Morris is trying to replace is that of "translation," wherein "the picture leans on the prose [and] the prose stiffens gallantly" (147). The problem with this old way is that the two media are in conflict- "each partaking of the other's weakness, sapping its strength" (147). More specifically, the photography stands in as raw material and the text stands in as the art wrought from such material. Morris urges artists to abandon this "lean-to" method. ${ }^{40}$ The "burden" of deciphering correspondence between the representation of raw materials and the literary product should be "the reader's alone" $(147) .^{41}$

It is Morris's composite of modernist and realist referentiality that attracts Laughlin to his work. In the editor's note written especially for Morris's "Inhabitants," Laughlin expresses optimism about the development of visual culture to complement the lyric register of localizing prose. He acknowledges, somewhat reluctantly, that "[i]t has been obvious for some time now that the photograph was destined to play a far greater role in literature than ever the simple art illustration did" (145). Alluding to Archibald MacLeish's essay on photography, "The Soundtrack-\&-Picture Form: A New Direction,” featured in the 1938 edition of New Directions in Prose \& Poetry, Laughlin claims something like editorial ownership of the idea of "fusion of photograph and soundtrack (words)" (145). ${ }^{42}$ With an impresario's pride, Laughlin reveals that all signs point to the "new directions" of photo-texts, art forms that produce a "third experience" independent from hearing words or seeing images. Not surprisingly, Laughlin plays up the modernist 
high-literary moments in Morris, claiming that his photo-poems "attempt[] to fix things in immobility, in the way that a great lyric can fix an ephemeral mood for all time" (146). Trying to make Morris a high modernist, Laughlin assures his reader that Morris is not doing ethnography. Morris "is working with forms," not people, "that at times become completely abstract" (146). Therefore, he has converted the social welfare agenda of WPA documentary work into a strictly literary agenda; he has abstracted it to a universal state. $^{43}$

The main reason why Morris is no longer thought of as a modernist is because he elides the subjects from within which mid-century modernists normally function. In fact, Morris clearly states this condition in his fiction. The title of his second novel, The Man Who Was There (1945), alludes to a central figure, a soldier named Agee Ward (whose first name Wydeven claims "is surely a mark of debt to James Agee" [57]), who never actually arrives. He only appears through the conjuring remembrances of tenuously related characters. For instance, in the opening chapter of the novel, the reader is introduced to a ninety-three year old woman who takes a train from Omaha to Colvin, California. En route she becomes confused, beginning to think that the man in whose charge her daughters have placed her, a Private Reagan, is in fact Agee Ward, the orphan boy whom both the old lady and the young private knew briefly when Reagan was a child. Accompanying this delusion is Herkimer's conviction that she is traveling East to a Pennsylvania town from her youth rather than West to the California town adopted by her daughters. This directional confusion becomes a staple of what I will call, in Chapter Two, the "delocalized prose" of mid-century. Combined with the replacement of the 
soldier with an orphan child, it is clear that Morris's real interest is the place-based determinants of memory.

Morris's early fiction alludes to war, only to diminish its significance. In his novel Works of Love (1949), Morris's narrator takes pains to announce that his central figure, Will Brady, "fought in no wars, and passed his life unaware of the great public issues" (4). ${ }^{44}$ Morris's narrator asks the obvious question: "why trouble with such a man?," why extend interest to a citizen unaffected by a larger national or global imagination? Morris deliberately eclipses national and cosmopolitan issues alike, so as to highlight the debilitating normalcy of most small communities in America. For further evidence that Morris despised the centrality of the war in literary texts, see his discussion of Truman Capote's success with In Cold Blood (1966). In it, Morris explains, "I was properly amazed to see the war slipped off on a siding in western Kansas to let the Capote Cold Blood express roar through to Holcolmb. For two or three minutes, that is, Capote had higher billing than Vietnam. On the exchange, Cold Blood went up as the war went down" (qtd. in Hicks 1970, xxxi). Morris's excitement at the brief celebrity of Capote's novel comes from his sense that such innovative novels as In Cold Blood (1965) continue in the long tradition of developing the American sense of place, a tradition that was unfortunately cut short by the roll back of New Deal programs.

In the following chapter, I will analyze the meta-documentary technique of James Agee, whose prose in Let Us Now Praise Famous Men answers Morris's call to abandon the "lean-to" method of correspondence between prose and photograph. Following Walker Evans's stark portraits of sharecroppers and their wares, Agee develops and redevelops a technique of representing local affiliations that emerges from the materiality 
of the point of contact between the self-reflexive maker of prose and the impoverished rural figures to whom he is assigned and with whom he eventually speaks. The reason why Agee "troubles with" such men and women is not to make their plight visible, but to expose the false polarity that grows from making documentary representations without also acknowledging the division between the cosmopolitan point of view and the provincial point of being viewed. 


\section{Chapter One:}

\section{Specific Soil: James Agee and the Poverty of New Deal Documentary Art}

Rather than ask, "What is the attitude of a work to the relations of production of its time?" I should like to ask, "What is its position in them?” (Walter Benjamin, “Author as Producer” 222)

The human capacity to injure other people is very great precisely because our capacity to imagine other people is very small. (Elaine Scarry, "The Difficulty of Imagining Other People” 103)

If I could do it, I'd do no writing at all here. It would be photographs; the rest would be fragments of cloth, bits of cotton, lumps of earth, records of speech, pieces of wood and iron, phials of odors, plates of food and of excrement. ... A piece of body torn out by the roots might be more to the point. (James Agee, Let Us Now Praise Famous Men 10)

In Patterns for America, Susan Hegeman describes James Agee and Walker Evans's documentary photo-book, Let Us Now Praise Famous Men (1941), as a precursor to "Cold War liberal" patterns of social commentary. Summing up the formal mechanics of Agee's prose, Hegeman notes that the text of Praise "works in two ways": it makes other documentaries seem "morally bankrupt, cruel, the stuff of kitsch" and it "develops a new project ... the exploration of the interior spaces of the liberal intellectual himself" (191). In short, Hegeman suggests that Praise models the type of introspection 
that Lionel Trilling later dubs the "liberal imagination." byproduct of its introspection, Praise makes New Deal documentary projects seem both sub-literary and unethical. Since the sharecroppers Agee claims to "praise" are mere tools for this introspection, Agee is "caught," as Hegeman puts it, in the class-inflected paradox of anti-communist liberalism (191). I agree that Praise represents a shift away from the unself-conscious, philanthropic documentary work of the 1930s. I also agree that Praise concentrates profoundly on class divisions. But I do not agree with Hegeman that Agee's documentary prose reveals his cold war liberal affiliations. Instead, Praise is best understood as a meta-documentary that — contrary to Hegeman's reading of its introspection as instancing a cold war retreat from politics - exemplifies a politically useful effort to resist the transformation of poverty into identity. Agee announces his meta-documentary form as "a swindle, an insult, and a corrective" to New Deal patterns of representing rural poverty (xi). The insult comes in the fact that Agee and Evans make painfully visible the deliberate boundaries placed between the "nominal subjects" of documentary art (i.e., sharecroppers) and the enlightened humanists who invade their privacy (i.e., documentarians). This obscurity helps Agee reveal the resemblance between his cosmopolitanism and his sharecroppers' provinciality, a resemblance that is elicited by the shared experience of the documentary encounter. Because he does not lump sharecroppers into an identity, but instead blends his identity with theirs, Agee does not isolate but expands the reach of economic trauma, making it everybody's business.

Hegeman's periodization of Praise demonstrates the shortcomings of relying too much on wars (cold or otherwise) as the framing events of literary-historical periods. Aside from his preference for introspection, Agee has very little in common with cold 
war liberals. Rather, he shares traits with pre-Depression modernists, especially his interest in self-conscious language acts that defamiliarize lived experience. What Hegeman's analysis of Praise overlooks is that the point of Praise is to dramatize the act of getting "caught," and thus to expose the potential of documentary prose to exploit rural poverty. As I will examine below, Agee firmly underscores these moments of being "caught." Rather than engaging in the typical cold war liberal disparagement of New Deal social consciousness, Agee embodies its shortcomings and elisions. More specifically, he "localizes" the very source of the problem cold war liberals have with New Deal patterns of social commentary. Hegeman's observation that Agee retreats into a kind of fractured, convalescent liberal self is thus only partially accurate. ${ }^{46}$ In the process of embodying the shortcomings of New Deal documentary, Agee exposes the class relations embedded in even the most populist Depression-era representations of local affiliations.

It has long been agreed that Praise is a difficult text to classify. As William Solomon notes, “Agee's remarkable achievement has been characterized in several different ways: as a realistic documentary; as a modernist masterpiece; as 'a quintessentially postmodern text"; and as the progenitor of a new, mixed genric category, 'postmodernist realism'” (86). ${ }^{47}$ In this chapter, I will examine Agee's meta-documentary technique, specifically his methods of localizing the site of contact between the documentarian and his subject. Agee indicates that this "site" is his focus when, in one of his numerous drafts of the introduction to Praise, he insists that the book is to have a triple-exposed "centre": 
Our subject as a whole might be mapped_-very sketchily_as follows: At the centre, every recapturable instant of those eight weeks spent in the middle south. ... At the centre again: ourselves and our instruments. ... Again at the centre, these three families, chosen with such pain to 'represent' their kind; which whom, for a while, we intimately lived, and whom we watched. (Agee 2005, 145)

By compounding the center of his text in this way, Agee pinpoints the overlap of himself, Evans, their "instruments" (i.e., "the still camera and the printed word"), and the three families. It is this overlap that produces documentary art and this overlap that will serve as the subject of Agee's meta-documentary. By localizing such moments, Agee exposes the way the "selfless" localization of documentary prose ("selfless" in the sense that the self of documentary prose is missing from the document) reinforces a counterproductive division between the detached perspective of the documentarian and the rooted identities of those whom he documents. As I will demonstrate below, Agee exposes the documentarian's cosmopolitan detachment as a source of the misperception that the very poor are irrevisably rooted in an identity category.

As for the impact of documentary work on post-Depression local affiliations, there's some dispute regarding whether New Deal documentary dissolves or reinforces the boundaries that result from allegiance to place. On the one hand, Alfred Kazin believes that the objective of New Deal documentary is to take large-scale "social inventory" of the national as a whole. In this sense documentary work is nationally unifying and therefore a correction to the provincialism of thinking about America as a collection of discrete regions. On the other hand, William Stott, in his study Documentary 
Expression and Thirties America (1973), reveals that documentary work reinscribes regional difference. According to Stott, documentarians aestheticize "localized information"; they represent America as an infinite set of place- and community-specific distinctions (110). As Stott replays it:

If one pursued the documentary method ... one found no entity to call America. Instead, there were regions, though again if one looked hard enough, the regions gave way and one had communities ... In short, documenting America turned up such an abundance of ... "localized information" that no generalization with teeth and vigor held. (110) So, where Kazin's understanding of the macro effects of documentary work yields an impression that, taken as a whole, documentary work is an autobiography of the U.S., Stott's understanding of documentary technique yields an impression that there is no U.S., just myriad micro-regions. Stott's assertion that documentary work makes it impossible to see America as a unified whole is evident on literary fronts, as in John Dos Passos's USA (1930-1936), which builds to the climactic realization that "we are two nations" (1157)..$^{48}$

Where Dos Passos is disheartened, even ashamed, to make this admission, Kazin celebrates the unification of the New Deal inventory of distinctions. This inventory constitutes "a living record of contemporary American experience" that inspires an era of "extraordinary national self-scrutiny" (378). Kazin thus finds the very "teeth and vigor" that Stott claims to be missing from broad-stroke generalizations. Kazin refers to documentarians as "explorers who went hunting through darkest America with notebook and camera, the new army of biographers and historians" (381). These conspicuously 
masculine record makers excavate "the raw stuff of the contemporary mass record," making regional difference, once in the periphery of artistic production, the center of production.

But Kazin is not unqualifiedly optimistic about documentary prose. His problem, the problem Agee addresses head-on, is that "all too often [documentary prose is] only a sub-literature, perhaps only a preparation for literature ... evidence of a need to retreat into the solid comfort of descriptive facts" (381). Fetishizing "descriptive facts," documentarians produce an audience too content to know the localized facts of poverty and class division in America to actually care about generating solutions (378). Though "social awareness," which is the way Kazin terms the objective of documentary work, provides the raw materials for doing away with the harmful polarities in America, it does not attempt depolarization. In other words, documentary work exploits a "need for the past," specifically a need to represent national trauma as a feature of the "past." By exploiting this need, the "comforting surface of that past" stands in as solution to the economic problems that perpetuate that trauma (385).

Kazin indicates, therefore, that documentary work reifies poverty into an image whose presence actually aids the psychological well being of those Americans who are not impoverished. Black and white photographs of sharecroppers send the message that economic problems are a thing of the past. This past tense places poverty beyond the responsibility of civic duty. In sum, Kazin applauds documentary work for providing "a register of the learning process," which is to say an organized textual locus for the reappraisal of one's relation to a wounded national culture (385). But "the sense of a grim awareness" that documentaries offer is ultimately sinister, as it makes poor people into 
what John Steinbeck refers to repeatedly in his journalism about migrant workers as a "new race" of Americans. ${ }^{49}$ These migrant workers, sharecroppers, mountaineers, and other "children of crisis" receive the brunt of Depression-era economic trauma. ${ }^{50}$ Lumping them all into an identity category isolates the trauma as a phenomenon that has limits, limits that quarantine children of crisis. As Michael Szalay explains in New Deal Modernism, the lion's share of Roosevelt's welfare initiatives was intended not for these visibly isolated people, but the "disembodied liberal abstractions" that make up the American middle class (21). Children of crisis, such as migrants, sharecroppers, and mountaineers, stand in as a visual antithesis of the invisible middle class. Thus, in full view of said affectionate class, the sharecropper confirms the New Deal class bias.

This reification of economic trauma through sharecropper imagery is what Agee wants to remove from documentary work. Though it presents its fair share of "grim awareness" and certainly is a "register of the learning process" (evidenced most completely in Robert Coles's designation of it as the exemplary text through which to teach "documentary work"), Praise exposes the foggy inhumanity of documentary work, dramatizing the tenuously ethical terms of entry and departure that all documentarians experience and most never address. ${ }^{51}$ Like Evans's spectral presence in the face of his portrait of Annie Mae Gudger (her real name is Allie Mae Burroughs), Agee becomes a central figure in his own document, a grown man on his knees sifting through specific soil, an emblem of the exploitive curiosity at the root of documentary form. Evans's portraits confirm the physical being of the sharecropper as well as that of the documentarian; his subjects stare at his camera. 
Thus the viewer of Evans's photography does not witness abject poverty or, as Dorothea Lange's viewer is invited to do, a "new race" contemplating her sad lot. Instead, the reader witnesses a moment of face-to-face contact, the complexities of which Agee's text tries to communicate. Evans's portraits of sharecroppers illustrate the agenda of Praise as a whole - to represent the encounter between the documentarian and his subject. His photograph of Annie Mae Gudger is the book's key image. WJT Mitchell describes this photo as the "Mona Lisa of the Depression." But it is misleading to consider the photograph, as Mitchell does, to be "an 'icon,' ... a pure aesthetic object, liberated from contingency and circumstance into a space of pure contemplation" (293294). This interpretation implies that Evans's portraits dehumanize sharecroppers, when in fact they are some of the only sharecropper photographs that haven't elevated their sharecroppers into an image of abjection. Dorothea Lange's famous photograph of the "Migrant Mother" is an iconized form of abject poverty.

In contrast to Lange's "mother," Evans's woman is unaffiliated. She is unremarkable, a nondescript female face fixed erect against wood siding. No connotative procedures locate her in relation to her family: she has the face of neither a mother, a daughter, nor a sister. Whoever she is, her one relation is to the physical nearness of the photographer, for whom she has consented to provide an eye level headshot. Her sebumbrowned hair is parted tight and neat to the right, specifically for the photo. Her collared pullover blouse is dingy, its fabric pattern small interlocking squares of darker and lighter hue. It is a blouse she wears daily, not for special occasions. The photograph itself is no special occasion. She peers thoughtfully into Evans's lens, squinting at the sunlight behind him, slightly straining the muscles in her neck. She takes seriously the act of 
being photographed, standing upright and alone. But, with her eyes pointed directly at the camera lens and her expression full of attention, she is very much in the presence of the photographer. Mitchell is right to call her the "Mona Lisa," but is wrong to say that it is because we "find her fatigue, pain, and anxiety beautiful" (294). Instead, Annie Mae Gudger is the Mona Lisa not because of her anonymous beauty but because of the scopic carnality of her relationship with the one representing her.

Juxtaposed against Dorothea Lange's “Migrant Mother," Evans seems conspicuously interested in documenting this relationship. Lange's photo is a stark contrast to Evans's, as it registers the opposite of cross-cultural nearness. Lange's mother is centered as intensely as is Evans's figure. But her relation to her family is intensified. Two exhausted children, at either side of mother, rest weary heads on her shoulders, making her a strikingly more dignified maternal figure. Her hair is not, like Gudger's, hastily pasted to her scalp or pulled awkwardly behind her ear. Parted calmly to the left, neither messy nor combed, the migrant mother's hair is left alone. She has not been prompted, or allowed, to prepare herself for the shutter snap. Though her clothing is more pitiable than Gudger's, with a sweater sleeve missing from the elbow down and a bundle of fabric that serves as both her leg covering and wrappings for a nearly eclipsed third child, a sleeping infant, this mother transcends poverty, as do many subjects of Farm Security Administration (FSA) photographs, through her very dignified acceptance of its markings.

Lange's mother's striking facial expression is contemplative, not of the children at her ears but of something silent and distant. With lines stretched across her forehead and fingertips lightly drumming her chin, the mother is pictured in a rare moment of 
introspection. Her thoughts are remote and complex, intensely focused on the ominous question of what to do with all these draping children. She appears unaware of the photographer. Photography itself is not a real, no matter how temporal, concern as it is with Evans's women. In this photograph, Lange has perfected the pose of a disparaged self-reflection. The success of such iconic FSA images betrays an underlying interest in seeing abstract acceptance in figures of abjection, figures in need of something more than the sustained observation it takes to capture such rare moments.

Evans's women prepare for their close-ups, as do most of his men. Mr. Woods covers his unsightly lesions with a bandana; the Ricketts children wipe their eyes and tie their hair behind their heads. Their faces are rudimentarily primped. Rather than captured in postures that connote the otherwise exclusively middle-class condition of introspection, Evans's farm families are allowed to participate in the production of their own display, to examine their position and momentary appearance relative to the camera equipment that litters their front yards. This seems to accomplish much less for the families than does Lange's orchestrated image of introspection. Lange's poor are pictured confronting the general fact of poverty, while Evans's only confront the morning sun and the presence of a photographer. Evans's photos thus negate the reconciliatory possibility that the very poor retain the capacity for introspection, but they make visible the very banalities and adjustments that occur at the point of contact. They imagine a distinctive gesture engendered by those so physically near to the site of cultural polarities. They inaugurate a literary documentary work whose objective is nothing less than to deny the assumption of poverty as an element of identity. 
This denial comes about through a marriage of modernist formalism and the regionalist representational scope. A good example of this is found in Agee's description of sharecropper clothing, which is simultaneously heavily descriptive and highly stylized. In his extended metaphor of overalls, which Jeffrey Folks calls "the tour de force" of Praise as a whole (par 9), Agee exposes how impoverished people become conspicuously beloved. He describes George Gudger's (real name Floyd Burroughs) overalls as the "map of a working man" and "uniform ... badge and proclamation of [American] peasantry" (234). The central passage reads as follows:

The texture and the color [of the overalls] change union, by sweat, sun, laundering, between the steady pressures of its use and age ... into a region and scale of blues, subtle, delicious, and deft beyond what I have seen elsewhere approached except in rare skies ... and some of the blues of Cézanne ... a fabric as intricate and fragile, and as deeply in honor of the reigning sun, as the feather mantle of a Toltec prince. (236-237) Moments such as these catch the light of hagiography that one expects from a book with the phrase "Praise Famous Men" in the title. But these moments are rare, as Agee is usually too critical of his reader and too obscenely self-critical to do the actual work of "praising." Though the overalls section demonstrates some connection between Evans's dispassionate photos and Agee's frenetic text, Agee rarely captions Evans. Likewise, Agee explains that Evans's photographs are not "illustrative" (xi). As Agee writes in his first preface, the photographs and the prose "are coequal, mutually independent, and fully collaborative" (xv). ${ }^{52}$ They are there to produce that "third experience" that James Laughlin established, via MacLeish's pioneering work with phototexts. ${ }^{53}$ However 
invested it is in conflating sharecropper garb, high art, and native royalty, the overalls section as a whole is neither hagiographic nor iconizing. With this rhetorical move, Agee channels W. E. B. Du Bois, who was the first to confront this tendency in sociological writing to elevate the high culture hues of destitute people. Du Bois often sardonically refers to black sharecroppers using the French word for sharecropper: "métayer."

In contrast to Du Bois's mocking highbrow affect, Agee begins his aestheticization of overalls with a nod to hyper-provincial language. He preemptively corrects any mispronunciations of the local variant of the "overalls," explaining that "[t]hey are pronounced overhauls" (234). This interest in dialect speech is almost comic, considering the extreme sophistication of Agee's narrative vocabulary. This one nod to dialect directly scolds the reader for thinking that "he has the fortified right" to someone else's slang (403). ${ }^{55}$ In addition to calling attention to the problematic nature of taking such interest in someone else's language, Agee makes a pun out of "overhauls." In his sole gesture at a vocabulary outside of his own, his one instruction on how to ride the shape of local speech, Agee makes the stable badge of rural poverty ("overalls") homonymous with a process of revision (an "overhaul"). The play on words here is analogous to Agee's attempt to renovate the ethical ambiguities of documentary form. ${ }^{56}$

In what follows, I will begin with a discussion of Agee as a transitional figure, distinguishing him from the generation of documentarians who come before him and the cold war intellectuals who follow him. I will argue that the main characteristic that distinguishes Agee's work from the work of both generations is its preoccupation with the mechanics of representing rural poverty. Therefore, section II will briefly examine the relationship between the wound-centered regionalism of New Deal documentary and the 
ethical complexities of poverty as a literary enterprise. Section III will discuss Agee's macro-level critique of New Deal documentary, a critique that takes the form of a commentary about the limitations of literary representation itself. Section IV will focus on one key micro-level revision, namely the inclusion of the "outsider" perspective in Agee's prose treatment, similar to that of Evans's photographic treatment, of sharecroppers. In section V, I will expand my analysis of Agee's inclusion of the outsider perspective, examining the virtues and limitations of his self-reflexive model of localization. In the final section, I will compare Agee's brand of localization to the brand that dominates most literary-historical accounts of post-Depression methods of representing rural poverty, that of Steinbeck's The Grapes of Wrath (1939). In this final section, I will suggest that, while they are not as influential as Steinbeck's, Agee's techniques influence the formal agenda of subsequent generations, namely that of the Beat Generation.

\section{I}

To think of Agee as an affiliate of the cold war, rather than as a (however ambivalent) New Dealer, is to underestimate the impact of New Deal aesthetics on the ever-evolving tradition of representing local affiliations in American literature. In effect, when they group Agee with other mid-century cold warriors, literary critics miss an opportunity to consider the thread of local affiliations running from the emergence of modernist innovations to the recent reemergence of regional fiction. More importantly, literary critics isolate themselves from film critics and art historians when they include Agee in their cold war bubble. For instance, film scholars such as Bill Nichols reveal the overlaps in documentary and avant-garde film aesthetics in the 1920s and 1930s. 
Similarly, art historians such as Erica Doss argue convincingly that documentary and regional art in the 1930s leads directly to the abstract expressionism of the 1940s and 1950 s. ${ }^{57}$ Literary critics, on the other hand, continue to ignore the confluences between modernist and documentary realist narratives in these same periods. Thus our fixation on the cold war vortex keeps us from participating in the interdisciplinary discourse regarding the confluences between documentary and abstract/avant-garde art.

On one point Hegeman's categorization of Agee as a cold war figure is accurate. She notes that he received a cool reception by other cold war intellectuals. Members of the anti-Stalinist east-coast literary establishment, chief among them Dwight Macdonald (Agee's boss at Fortune), claimed that Agee was too talented to work for commercial venues. ${ }^{58} \mathrm{~A}$ Yale Younger Poet such as Agee should not bow to the stuff of "middlebrow kitsch. ${ }^{, 59}$ Literary highbrows, Hegeman claims, welcomed the commercial failure of Praise, which sold few more than 600 copies in its first printing. This failure proved that commercial America was too debased, too used to the relative kitsch of New Deal art, to acknowledge Agee's deep critique of documentary aesthetics (177). Apparently, what was so great about Praise was that it exposed 1930s documentary "as being both condescendingly simplistic and somehow fundamentally untruthful as to the real relations between different people" (179). Hence, readers wanted nothing to do with the sanctimonious finger wagging of Praise and this lack of interest only reinforced the elitism of mid-century highbrows.

In addition to paralleling Agee's commercial failure (rather than his artistic goals) with his initiation to cold war intellectualism, Hegeman strikes another interesting parallel that helps us re-categorize him as something other than another cold warrior. In 
her discussion of why Agee attacks documentary form, Hegeman argues that documentary prose is to Agee what representational art is to Clement Greenberg: "Its contents are literally captionable: reducible to easy sentiments and categories, and therefore it is both antiart and politically suspect" (184). This parallel is useful in that it highlights the deep commitment that Agee and Greenberg both had not to the development of new aesthetics so much as to the critique of old ones. Without this recognition of the need for revision, the Agee/Greenberg parallel falsely implies that Agee prefers modernist difficulty for modernist difficulty's sake. As my analysis of Praise will show, Agee's difficulty serves the purpose of highlighting the ethically suspect nature of documentary work at large.

As I mention above, Hegeman overlooks the fact that being "caught" exploiting sharecroppers is precisely the rhetorical objective of Praise. One only needs to read the rhetorical question that punctuates its first part-"How was it we were caught?"- to realize that Agee's central focus is his own invasion of others' privacy $(72,81) \cdot{ }^{60}$ Indeed, in an article titled "Privacy as a Subject for Photography," Wright Morris claimed that "privacy is the subject [of Praise], and revelation, sometimes nearly intolerable, is the result. Here are the standards: let those who can meet them go about their work. Let those cannot, turn their cameras somewhere else" (qtd. in Wyndeven 105). What Morris calls "nearly intolerable" revelation, Hegeman calls "petulant insistence on representing in the face of its very impossibility" (191). She argues that cold war intellectuals embraced Agee's turgid self-reflexivity, because they "saw in Agee's anger and hand-wringing a model for their own ... position of self-imposed marginality" (191). This reading of Praise as the raw materials for the liberal imagination ultimately categorizes Praise as 
"forward thinking," a contradiction considering Agee's objective of revision. In sum, because they overestimate the magnetism of cold war politics, literary critics overlook the fact that the aesthetics of mid-century literature were based on a revision of New Deal patterns, in Agee's case the local affiliations that authorize documentary encounter. In contrast to Hegeman's innovative attempt to reconceive the cold war through Agee, I hold that the standard read of the cold war intellectual canon is probably still the most accurate. Arthur Schlesinger, Jr.'s The Vital Center (1949) is still the exemplary cold war liberal manifesto. Indeed, K. A. Cuordileone explains in Manhood and American Political Culture in the Cold War (2005) that Schlesinger's famous defense of liberal democracy is the "quintessential cold war intellectual work" (4). Where Agee's documentary prose juxtaposes the "polarization of images" produced by political discourse after the end of the New Deal, Schlesinger's history exploits them to support his anti-communist (i.e., his "cold war") agenda (vii). He gives the legitimacy of political science to the notion that there are "hard and soft" ways to oppose totalitarian communism. Those who view communism as no real threat are "soft," and those who see no difference between domestic and international communism are "hard" (vii-ix). ${ }^{61}$ The Vital Center thus transforms a critique of New Deal politics into an anti-Stalin leftist thought that uses "hard/soft dualism" to, as Garry Wills puts it, "set up the desired contrasts for a decade" (521). Agee is seeking to break down these very contrasts before they emerge. In this fundamental sense, he differs from Schlesinger and his cold war cohort, who replace the utopian radicalism of the previous generation of leftwing American intellectuals with a utopian centrism that figures anti-communism as the standard position of the American left wing. Cuordileone sums it up nicely: 
The new liberalism was thus suspicious of the naïve sentimental politics of progressive and Popular Front era leftists, its ranks bolstered by the defection of dozens of repentant ex-Marxists and formerly radical New York Intellectuals who, along with New Deal liberals like Schlesinger, promised deliverance from the left-wing orthodoxies of the past and endorsed a new anti-Communist liberalism suited to the imperatives of a cold war world. (2)

As Schlesinger himself puts it, the "fundamental enterprise" of the New Deal is "reexamination and self-criticism" (Vital Center vii). The next step, Schlesinger argues, is to carry the knowledge gained from the New Deal, specifically that democracy can check the excesses of capitalism without also being socialist in ideology, into an anticommunist form of liberalism. According to Cuordileone, Schlesinger claimed that "the pragmatic tradition" established by the New Deal "had too hastily been abandoned by Depression-era leftists for naïve utopian fantasies" (5).

Agee also criticizes the naïve utopian fantasies of the New Deal left. This is easy to do, perhaps too easy, Agee indicates. Maybe the real work of the generation following the New Dealers is to reappraise the manners and methods through which New Dealers localized their utopian fantasies. Maybe the codes that signify poverty need revaluation, lest they fix an economic class into a standardized identity category. In order to stave off this transformation of class into identity, Agee inverts these codes. He inventories the "wealth" of even the most destitute sharecropper, counting the fascinating particularities of their material presence. For instance, Agee devotes over fifty pages to describing a single sharecropper living quarters. In his description, Agee recounts major structural 
spaces (hallway, front bedroom, rear bedroom, kitchen, storeroom) and domestic essentials (furniture, fireplace, mantel, closet, beds, table, lamp). He also inventories the odors and "bareness" of the house as though they were possessions. The bareness is presented as a kind of posh minimalism made up of "exact symmetries" and discrete spacing that "gives each object a full strength" (137). The shelter also includes an "altar" (the house's one partition wall, at the center of which is the fireplace and mantel) and "tabernacle." The tabernacle is the one table's one drawer. As Agee reveals the contents, a surprising juxtaposition of baby toys and cloths and shreds of newspaper stories and photographs, he transcribes newsprint text as it appears:

\section{GHAM NEWS}

hursday afternoon, March 5, 1936

Price: 3 cents

in $\mathrm{G}$

(else

Thousa

are on d

througho

cording its (146)

In addition to such incoherent transcriptions, Agee describes photographs of labor strikes being broken up by police. But these shreds and photos are being saved not for their content. Indeed, as his transcriptions make clear, the newspapers in this house are found in shreds and used not for their articles, and possibly not even for their photographs, but for their everyday use value as wrapping paper for fragile trinkets (among them a swan 
figurine). Their provincial needs limit their use of even the basic means of cosmopolitan education.

Nevertheless, Agee presents his findings as objets trouvés, existing objects that he collects into an assemblage organized around the guiding principle of juxtaposition. Ethical ambiguities aside, this aestheticization of the bits and pieces of poverty puts oldschool modernist defamiliarization in the service of reconsidering local affiliations of the Depression's great subject. Through this invasion of privacy, Agee appears to follow (perhaps somewhat literally) Barry Chabot's conception of the objective of preDepression U.S. modernism, to "weld a disparate people into a vital community" (17). As they are entered into the public record, these raw materials of provincial memory establish a kind of community between Agee and the sharecropper family, who "yet love me, and I, how dearly, them" (165). Agee's aesthete sensibility defamiliarizes the way the reader of a documentary book looks at poor Alabama sharecroppers; he transforms his study of the wood grain under the tables of poverty into an inventory of abundance. He thus unsettles the sentimentalism readers normally fall into when considering rural poverty. Since Agee never announces the awful economic situation of his sharecroppers, he never allows his reader the easy lens of pity.

This modernist defamiliarization of the experience of reading documentary prose highlights the shared (if temporary) local affiliations between Agee's detached cosmopolitan perspective and the rooted provinciality of his subject. Aestheticizing the physical conditions of a subject as ethically sensitive as sharecropper domesticity, Agee anticipates the Godard dictum: "It may be true that one has to choose between ethics and aesthetics, but it is no less true whichever one chooses, one will always find the other at 
the end of the road" (qtd. in Sontag 235). In the following section I will discuss this aesthetics/ethics interaction as it comes to bear on the wound-centered regionalism of New Deal documentary art.

\section{II}

In "Poverty and the Limits of Literary Criticism," Gavin Jones argues that, in American social discourse, "the poor" have always "hover[ed] somewhere between a class and a race of people" (781). He also argues, alongside Elaine Scarry, that it is the job of literary work to account for this literally marginal status. Surveying the relevant sociology on the subject, Jones indicates that nearly every American generation since the Civil War has faced "pervasive political pressures" to "move[] issues of exploitation and inequality into the realms of identity, morality, and race" (769). In other words, social discourse on poverty tends to steer clear of discussing the revisable processes that lead to poverty, a tendency literature has an ethical responsibility to resist. Without such resistance, social discourse will continue to elevate the "rooted" traits of poverty, thus continuing to mark the poorness of poor people as an engrained identity trait.

Jones argues that, despite the obligation of literature to correct the conflations among poverty and identity, it is wrong to completely disassociate class from race and gender. Such unqualified boundaries come with their own definitional problems, as they make race and gender seem to be, in Jones's words, "insurmountable absolutes" and class seem to be a temporary condition that can be moved out of by sheer dynamism about mobility. In short, to disassociate class from the trinity of identity politics is to assume that class is strictly the result of one's ability to access mobility. It is common of novels in the first half of the twentieth century, from Theodore Dreiser to Ann Petry, to represent 
one's access to mobility as dictated by her gender and race. In effect, dissociating class from race and gender paradoxically reinforces the myth of mobility, a myth that allows for claims that failure to "move" from one class to another rests solely on the entrepreneurial initiative and/or the moral fitness of the one attempting to move.

Rather than falling to either of these fallacies, Jones suggests that literary critics think in terms of poverty and surplus instead of upper and lower classes. Interested in the way poverty registers, in its codes, sources, and processes, Jones claims that "[o]bvious problems emerge when 'the poor' are defined as a class in themselves, when poverty is treated something like an ethnic affiliation with transhistorical integrity" (770). In effect, Jones is taking issue with the Christian adage that "The poor will always be with us." The worst problem with "classifying" poverty as a transhistorical universal is that poverty becomes "an identity tangled in alleged cultural and psychological pathology"; it is both a product of essential identity and a product of behavioral identity (770). Poverty, Jones suggests, shouldn't be thought of as a product of anything. It's a confluence of material and ethereal factors, the combination of a physical location and economic standing. When unreflectively reviewing representations of poverty, middle-class audiences absorb this combination as if it were a single condition.

If "complicated" in the way that Jones suggests, poverty becomes prime fodder for non-exploitive literary projects. As Jones puts it, “concern with poverty has often generated the kind of linguistic crises that so attract literary criticism” (779). Jones argues that poverty engages the "in between-ness" that modernist literary figures focus on. Rather than thinking of its twilight hues, and thus thinking about poor people as patients etherized upon tables, Jones suggests that the in between-ness of poverty is prime 
material for literature. American realist writers such as Dreiser and Edith Wharton “explore poverty" as a:

temporal condition of transition yet a social location nonetheless, as a haze of shifting socioeconomic relations that never loses material shape, as the very inverse of "identity" but still a description of structural forces that make minority consciousness matter. (781)

Praise, which Jones views as a classic response to the Great Depression, is the latest in a canon of American literary works - including Herman Melville's Pierre (1852), Dreiser's Sister Carrie (1900), and Wharton's House of Mirth (1905) — that represent poverty as a kind of aesthetically and culturally significant confluence of material and social realities. Agee's "radical deconstruction of discursive techniques" represents "the apotheosis" of the tradition of literary responses to poverty (780). His complex method of representing his local affiliations as a documentarian on assignment is part of a series of literary responses to the "contentious position of poverty within U.S. political and social discourse - responses that avoid easy recourse to sentimental or melodramatic neutralization of the poor" (780). This neutralization not only diminishes the chances of poor people to improve their lot. It also constitutes a passive political violence against impoverished citizens, the kind of violence that Elaine Scarry claims is visited upon those whom are unfairly imagined.

In "The Difficulty of Imagining Other People," Scarry indicates that sentimental responses to poverty are akin to "injuries." Evoking a common ethical dilemma involved in appreciating, say, Les Misérables, Scarry remarks that "we come out of the opera, absorbed with compassion for those on stage, not seeing the cabdriver and horses who are 
freezing from their long wait to carry us home" (104). In other words, even while art inspires compassion, it displaces it, making the felt experience of art appreciation into a typically class-inflected experience. For art to overcome this misdirection of compassion, Scarry argues, representations of "others" must make explicit "the difficulty of picturing other persons in their full weight and solidity" (98). A main objective of literary representations should thus be to indicate the complexities involved in constructing verisimilitude. To fail to effectively represent "the reality of other persons" is to injure them. As Scarry explains, "The difficulty of imagining others is both the cause of, and the problem displayed by, the action of injuring. ... the injury itself makes visible the fact that we cannot see the reality of other persons" (102). When applied to documentary art in the 1930s, an art form focused almost exclusively on "injuries," Scarry's argument changes slightly. Since sharecropper documentary was so prevalent, and since it was prevalent as something more like information than like art, the sentimental responses that it evoked are based in part on the fact that the injury is already visible. In fact, the injury is all that is visible. Documentary art thus complies with Scarry's argument, striving to make injuries realities. At the same time, though, this wound-centric representation neglects the reality of the person who is injured. The injury is all we can see, for instance, of Dorothea Lange's “Migrant Mother."

Obviously, not all New Deal art is wound-centered. Documentarians and other writers employed by the Federal Writers' Project (FWP) did strive to reimagine the relationship between middle-class readers and impoverished subjects, if not also to correct the misdirection of compassion that Scarry's anecdote displays. Because New Deal documentarians take as their subject the aftereffects of the disappearance of 
constitutional safeguards against an inhumane economic system, their art is by default wound-centered. The injuries of economic depression are there to be documented, and the eerily particular portraits of New Deal documentary reveal what had remained, in the economically irresponsible 1920 s, an abstraction (i.e., poverty). In short, the objective of New Deal documentary art is to represent the abstraction of poverty as though it had "weight and solidity."

This agenda of representing poverty interacts in interesting ways with the New Deal's regionalist agenda. In an article titled "Regionalism in the Era of the New Deal," Lauren Coats and Nihad Farooq explain that the "regionalist thought" of New Deal programs "provided a testing ground for the efficacy of regionalism" (80). Specifically, the FWP "aspired not to the conventional literary goals of producing poetry and fiction, but rather to more socially, politically, and economically useful objectives," namely the production of broad-scale nonfiction portraits (in the forms of state guidebooks and oral histories) of everyday life throughout the U.S. (83). The result was "the nation's first autobiography," which promoted "regional self-awareness and introspection" (83). The central tenet of regionalism in this period is thus to produce "effective programs and policies" (74). The most enduring way in which New Deal regionalism realized these programs and policies was through "locat[ing] the national psyche [in] the hope of ultimately reviving, and in some instances creating an American folk culture" (76). While this approach does effect policy change, it does not clear up the obstacles between the middle-class reader and her ability to imagine the reality of the impoverished subject.

As I discussed it the introduction, the means and ends of New Deal regionalism are vastly different from those of what Richard Brodhead refers to as "heyday 
regionalism." Where heyday regionalism is engineered by literary periodicals and designed to define the upper class by presenting its opposite, New Deal regionalism as engineered by the federal government is designed to define poverty (not to mention reduce it). Due to its social welfare agenda, New Deal documentary regionalism abandons the local color techniques of the late nineteenth century, preferring the textures of deep description to the masks of stock characterization or regional purity. In contrast to regional fiction, then, Depression-era documentary turns the process of thinking territorially into a political process, making the act of localization into a politically progressive, rather than conservative, pastime. The rural peoples, places, and folkways of Depression-era regionalism (as represented in WPA guidebooks, FSA photo-essays, and FWP caseworker studies) are, like the people and folkways of heyday regionalism, those that still barely survive in the modern world. The difference is that, in the context of New Deal documentary, those who are documenting their strivings are also those who are pulling for the impoverished. But the problem with producing a documentary representation is that the representation abandons the one politically progressive element of regional convention: the outsider narrator. This convention forges a path (albeit a commonly exploited one) to cross-cultural contact. Therefore, in the process of distancing itself from the seemingly irresponsible conventions of the previous generation of regional representational conventions, New Deal regionalists lost the dynamic of high/low culture exchange, a dynamic that Agee and Evans reintroduce.

Until recently, literary critics have ignored the literary innovations that result from this appropriation of the latent efficacy of New Deal regionalism, tending instead to focus on the cultural work of "Popular Front" writing. ${ }^{62}$ The original objective of government- 
commissioned projects such as the Federal Writers' Project was to produce texts that were somehow "socially, politically, and economically useful" (Coates and Farooq 83). What they actually produced were mammoth nonfiction portraits (in the forms of state guidebooks and oral histories) of the everyday lives of America and its citizens. This impulse toward what Kazin has aptly termed the "spirit of social inventory" had two impacts on regional form: it promoted narratives that are self-aware and introspective about their local affiliations and it transgressed the standard limits of regional texts. ${ }^{63}$ For instance, multi-front documentary projects such as state guides are almost inconceivable as bound documents. This explosion of the bindings of regional texts is revolutionary, considering that the form originally took shape via short-form periodical publications.

It is tempting then to claim that New Deal regionalism is unique in its focus on national autobiography. However, Bill Brown argues that regional fiction has always been in the business of producing national self-knowledge. In the elite literary periodicals of the nineteenth-century "every region of the nation was reproduced as knowledge that could be incorporated ... into the nation's knowledge of itself" $(2003,86)$. The motivations for this kind of incorporation are well documented, always conceived as a response to anxieties about the coming age of globalization. Even Brown blames the first "wave of globalization in the U.S.," (which he explains as an aggregate of late nineteenth-century immigration, middle-class travel, and international trade) for "provok[ing] a romance of the local and an insatiable desire to know about innumerable locales" (86). While it sounds like a variation on an old theme within regional scholarship, Brown's conception of regional fiction as a genre that translates place into knowledge indicates that this romance is not strictly exploitive but part of an effort to 
introduce globalized scales of thinking territorially. In the following section, I will discuss how Agee engages this effort in his self-reflexive meditation on the logistics of doing documentary work.

\section{III}

In the published version of his preface, Agee explains the objective of the original assignment: "to prepare, for a New York magazine, an article on cotton tenantry in the United States, in the form of a photographic and verbal record of the daily living and environment of average white tenant farmers" (ix). These, the conditions of production and coordinates of the product, give a sense of the limitations of the version of sharecropper life the reader will find. What is important is that Agee is frank about these limitations. A reader might easily predict the biases of a documentary project commissioned by Luce Industries and limited to "whites only." The question of what to expect from a book written after its publishing venue had rejected it, as Praise had been, is also fairly predictable. But a book that announces the limits of the project, and the nature of the institution that set those limits only to abandon the project, is more unpredictable. Having been stripped of its institutional backing, Praise may be the only New Deal-era documentary written without a guaranteed publisher. This is oddly liberating for Agee, allowing him to elide small talk and, revealing taboos in a straightforward manner, producing a reader-writer dynamic wherein the reader is hearing confession rather than receiving a disinterested "verbal record." Interestingly, Agee's lack of a private sector publisher produces the anti-autocratic conditions of production enjoyed by New Deal documentarians. 
No matter how critical he is of Depression-era documentary, Agee envies the working conditions of Works Progress Administration (WPA) employees. In November of 1937, Agee writes a letter to his former boss at Fortune, Archibald MacLeish, ${ }^{64}$ wherein he asks what MacLeish thinks the management of Life (the magazine MacLeish transfers to) might think of hiring a writer/photographer combo whose work is produced under "immunity" from the forty-hour workweek $(1937,2)$. Agee explains that, based on their experience in Alabama, he and Evans have decided that they are "ideas-men"; they should be able to work out story ideas "from the ground up [and] submit a given piece of work not according to [a] deadline but when we considered it finished" (2). Agee here is requesting the work conditions conducive to producing loose, baggy documentary projects such as Praise.$^{65}$ As Agee explains it, the normal conditions of production at a private publishing enterprise such as Fortune stifle creativity. Specifically, the "detailed and repeated modification of an idea to the reactions of an editor can seriously damage not only the given idea but the faculty for getting and developing ideas" (2 italics mine). In effect, Agee is asking for the very same "free to do what they wanted" working conditions that WPA documentarians enjoyed (Stott 105).

While he enjoyed the conditions of documentary production, however, Agee was ambivalent about the standard documentary product. This ambivalence evolved through his years at Fortune, where Agee wrote an exposé on the New Deal's most effective agency, the Tennessee Valley Authority (TVA) ${ }^{66}$ In the exposé, published in 1933, Agee first alludes to the reification of rural poverty. The mission of the TVA was nothing short of fixing the backwards infrastructure of the American South, specifically its poor management of river erosion and flooding and its systematic segregation from 
electrification. As Agee refers to it, the TVA was a "social-industrial-agrarian scheme" with the big (and largely successful) agenda to industrialize the vast region that is the Tennessee Valley. According to Agee, the arts and culture projects associated with the TVA isolate the "Tennessee mountaineer" as an identity in need of visibility. According to the logic of the TVA, mountaineers "are of that incomparably pure American stock which produced such men as Lincoln and Chief Justice Marshall and, for that matter, Cordell Hull" (635). ${ }^{67}$ The TVA "has a deep but realistic respect for what it calls the native culture of that valley and ... the mountaineer is a part of TVA's plans" (635). This embrace of the organic patterns of rugged individualism treats mountaineers as the "raw materials good and ill from which TVA prepares to fashion a civilization" (635). Thus the mountaineer becomes a personification of the revolutionary idea that "[m]an must learn to cooperate with his surroundings instead of disemboweling and trampling and hoping to discard them" (635).

The TVA revolutionized the farm system, developed new procedures for averting flooding, and optimized the Valley's vast resources. However, according to Agee, figures like the mountaineer and the sharecropper emerge as icons of poverty, helping produce the idea that "the poor" are an identity group. Agee dedicates himself to defamiliarizing icons like the sharecropper and the mountaineer, detailing their temporality and capacity to be uniquely present as something other than a stand-in for an abstract concept. This makes the politics of Praise hard to pin down. Admittedly a "non-conservative Southerner" and a "Communist by sympathy and conviction," Agee is something of a Popular Front writer ${ }^{68}$ But he actively subverts moments that might be mistaken as secret winks to fellow travelers. For instance, the epigraphs to Praise include a citation of the 
last lines of the Communist Manifesto, as they were popularized by the Popular Front"Workers of the world, unite and fight. You have nothing to lose but your chains, and a world to win." Rather than an earnest epigraph, this sloganized translation of Marx is the first sign of Agee's "swindle." ${ }^{, 69}$ As Agee explains in a footnote, the quote is in the service of a pedantically complex "sonata form" that Agee hopes his text will take. Hardly revolutionary, the quote is merely a sonata's "second theme." The "first theme" (and facing epigraph) is a quote from King Lear, wherein Lear, in a rare moment of introspection and pathos, directs the rich to "Expose thyself to feel what wretches feel" (III.IV 34). The two epigraphs, the first canonical and literary and the second idiomatic and political, juxtaposes elitist and populist literacy, stripping both of cultural capital and political inflection. Basically, the reader of Praise is not to celebrate prior allegiances, but to see them as new.

Agee's interest in musical form is likewise modernist, interested in formal signals that are strictly emotional and asemantic. This interest in music is evident in Agee's periodic references to Beethoven, not to mention his periodic references to the very futility of "writing at all" (10). In one passage, he alludes to Beethoven as the best ligament to bind the wood grain of an impoverished shack to the highbrow cultural knowledge: "the grain near these knots goes into convulsions or ecstacies such as Beethoven's deafness compelled" $(128) \cdot{ }^{70}$ This interest in musical form is reminiscent of Pound's call for modernist poets "to compose in the sequence of the musical phrase, not in sequence of a metronome" ("A Retrospect"). But Agee's attention to music has the opposite effect than imagism; it does not isolate images into aesthetic objects, but allows localized description of rural poverty to resonate as art in the ears of those who wouldn't 
normally consider more than the sights of poverty. Agee's writing is thus a less-thanideal medium — see his preference for photographs and unmediated artifacts—-for transferring his localized experience of the sights and sounds of poverty into the mind of his reader. Agee's insistence on accompanying this plight with classical music also recalls how fundamentally silent the rest of Depression-era documentary art is, how ominous and haunting black and white FSA photographs are. Agee wants to score this haunting, to make a pattern of negotiating the presence of spectacular poverty that might actually be useful to those who haunt and those who are haunted by the fact of division between documentary poverty and its readership.

But without a reader with some knowledge of documentary form, Agee's project itself becomes hermetic, a strictly textual blend of cosmopolitan and provincial signals. As a "corrective" to documentary art, the reader "will be wise to bear the nominal subject, and his expectation of its proper treatment, steadily in mind" (x, my italics). Readerly expectations and a knowledge of the "proper treatment" of sharecroppers in New Deal documentary art are thus crucial to understanding the full impact of Praise. Also crucial is the fact that, in the context of documentary art, "proper treatment" is always a matter of representational conventions through which sharecroppers (again the "nominal subject") are treated as subject matter. Never, Agee sardonically indicates, is the documentarian or his reader concerned with the actual physical welfare of the sharecropper, at least not until after the picture of his sad lot has been materialized.

Agee's method of materializing the sharecropper differs from "proper treatment" in that it comes from the haunting introspection that occurs at the point of contact between the documentarian and his disparaged subject. ${ }^{71}$ This technique differs from 
ethnographic posturing; Agee's complex effort of "praising"—not capturingsharecroppers involves a transparently high literary mode of narrative introspection. His combination of literary knowledge and local knowledge (or the knowledge of groundlevel experience) tears at the fabric of realist representation. Writing his record with the poet's pen, Agee produces an almost aural manifestation of the split between the empowered encountering self and its impoverished subject. Praise thus becomes a commentary about the limitations of literary representation itself. The shame and fascination Agee so prominently dramatizes makes visible the otherwise silent transition of the documentary subject into an icon for leftist struggle.

As many critics discuss, Praise is structured so as to resist the idea of a cohesive political message. Indicating his interest in asserting the ephemeral nature of the document, Agee clogs the first hundred pages of Praise with a series of digressions and false starts. A "Preface" is followed by a "Preamble," and neither of these sections do the work of orienting the reader. In fact, both take pains to make sly jokes about documentary work. In the Preface, a section that, according to his notebooks, Agee revised obsessively, he retains two very disorienting phrases: "nominal subject," which refers to the three Alabama sharecropper families that make up the documentary subject of Praise, and "on loan from the federal government," which refers to the leave Evans took from the FSA to accompany Agee to Alabama. These two phrases consistently appear in every version of the preface, suggesting that Agee was deliberately trying to seem flip toward the era's most serious documentary subject. In the case of the government loan wisecrack, Agee evokes the funding of documentary projects not as 
compensation but as the very credit-based exchange that helped produce the Great Depression. $^{72}$

Taking such pains to construct a dismissive affect, Agee clearly subverts audience expectations of documentary work. He goes so far as to label his whole manuscript as "a swindle, an insult, and a corrective" (xi). Without the inclusion of "corrective," Agee's preface would seem simply hostile and self-defeating. These subversive signposts are the first hint that Agee intends to reconstitute his audience's position relative to what Agee refers to as "a book about 'sharecroppers,' ... written for all those who have a soft place in their hearts for the laughter and tears inherent in poverty viewed at a distance, and especially for those who can afford the retail price" (11). Again evoking money, here the consumer dollars that grease the "free market," Agee makes clear his intention to revise the way readers value documentary work. Readers are forced to acknowledge, from the start, their own position in the asymmetrical material reality of economic disparities. This sets them up to understand that they are somehow agents in the strange cycle of being poor, representing poverty, and imagining poor people through a documentary representation of poverty at large. Because Praise is an aborted outgrowth of the Luce corporations, rather than a standard Federal One documentary work, the reader cannot automatically assume it to be part of a wave of social justice. ${ }^{73}$ As I mention above, the fact that phrases such as "nominal subject" and "on loan from the federal government," which dehumanize both the subject and agent of documentary work, survive extensive revision indicates that Agee does not want his preface to orient his reader, but to engage her understanding of the genre's codes. 
Nearly one hundred pages into the text, after the refrain of "How was it we were caught?" overtakes the initial voyeuristic preface, Agee begins his prefatory work anew (81). This time, he restates his documentary objective explicitly. The point of Praise is: to make a number of physical entities as plain and vivid as possible, and to make a few guesses, a few conjectures; and to leave to you [the reader] much of the burden of realizing in each of them what I have to make clear of them as a whole: how each is itself; and how each is a shapener. (97) In other words, localization is the name of the game. Agee's job is similar to the job of the WPA documentarian, to document "physical entities." But the reader's job is different. Cooperation, not compassion, is the expectation Agee places on his reader. The odd construction of a noun agent out of the past participle of "shape" introduces the idea that documentary work is always co-authored by the documentarian, his subject, and his reader.

In this process of deferring to the reader this "burden of realizing" the meaning of his representation, Agee dramatizes the central physical task of the documentarian: to invade privacy. Agee moves about the houses of his sharecroppers "as they would trust me not to," sifting through "the most delicate wounds, the most dedicated objects" (120, my italics). This apposition of wounds and "dedication"-meant here in the sense of ceremoniously handing property over to public use — communicates the key political stance of Agee's localizing technique: that which needs healing should be public property. This differs from the WPA version of "public access," since Agee's dedicated objects are not facts, figures or monuments, but very private objects. Those responsible for caring for these wounds, this public property, are those to whom the object is 
"dedicated" (i.e., the reader). Calling the reader to assume responsibility for the sharecropper's private property turns the sharecropper's house into a construct of privacy within public property (not unlike a public restroom), and the documentarian a depraved cruiser: "I planted my obscenities in the cold hearts of every mirror in foreknowledge ... permitted nothing to escape the fingering of my senses" (120-121).

However voyeuristic he may seem in this section, Agee insists that the documentarian's meanderings about the material reality of poverty lack "open sexual desire" (121). There is "no restiveness, nor despair: but the quietly triumphant vigilance of the extended senses before an intricate task of surgery ... not for shame of the people, but in fear and in honor of the house itself, a knowledge of being at work" (121, my italics). In short, Agee is far from indifferent to the ethical ambiguities of his work. His respect for his subject is manifest through his awareness that, no matter how sensual and unbefitting a gentleman his rummagings through privacy become, he is "at work." He retains all the surgical skill and professionalism of a documentarian whose job it is to fix the physical world in print. In fact, he is so acutely attuned to the work of localizing his environment that his "verbal record" picks up even the low-frequency steady pacing of the workday and the unsolicited pinings for pleasure that alight awkwardly upon one who is at work.

The characteristics of localization, as Agee retrieves them from WPA procedure, are: (1) Sentences are additive, which basically means that they hold a set of observations made up of compounded centers, or objects without verbs; and (2) objects are uncommon, often invisible, "signs and relics" of place. ${ }^{74}$ For instance, nestled between 
the house and the earth of a sharecropper homestead, Agee catalogues the detritus that literally falls through the cracks of everyday life:

bent nails, withered and knobbed with rust; a bone button, its two eyes torn to one; the pierced back of an alarm clock, greasy to the touch; a torn fragment of pictured print; an emptied and flattened twenty-gauge shotgun shell, its metal green, lettering still visible; the white tin eyelet of a summer shoe; and thinly scattered, the desiccated and the still soft excrement of hens. (130)

Agee indicates later that these "discoveries" are as valuable to him not as imagistic aesthetic objects but as "the earliest and profoundest absorptions of a very young child" (132). Representing them as near as possible to the state in which they were discovered, Agee reunites the byproducts and minutiae of domesticity with the dawning of childhood introspection. By calling these discoveries the absorptions of a child, rather than the findings of a documentarian, Agee saves the banalities of the sharecropper's foundation from its status as a plaything for the reader. In other words, Agee's acquisitive childishness gets reified in the place of the material existence of poverty.

Given this, it seems as though Hegeman's evaluation is valid. Agee decenters his sharecroppers so much that he makes his text a large-scale act of liberal navel gazing. While Agee's introspection is the star of Praise, it is the introspection of an encountering self rather than what Hegeman refers to as the "liberal intellectual" self (191). This distinction is important, as it makes clear Praise's status as a "corrective" to the tendency of documentary work to fix poverty as an inescapable identity category. As I'll discuss in the next section, this failure of documentary work is largely the result of the absence of 
documentarians from their own representations of the people of rural poverty. Continuing from Agee's observation about the inclusion of the Tennessee mountaineer in the TVA, Agee and Evans try to de-isolate the central figures of rural poverty. Together, they present images of sharecroppers that reveal their "full weight and solidity" as unique individuals but do not also present sharecroppers as stand-ins for the abstract notion of "poverty." Their methods of doing this, though distinct, are similar in that each includes some aspect of the "outsider" perspective. As I will argue in the following section, this juxtaposition of the rootless point of view and the rooted provincial figure, as pictured in Evans's sharecropper portraits, reveals the simple point that the poor do not always have to be poor.

\section{IV}

According to Hegeman, the sharecropper is the "most enduring icon of the period's cultural politics" (126). His image, in Kazin's words, "haunted the imagination" as an anthropomorphic stand-in for an otherwise incalculable national trauma (382). Like the disparaged figures of previous eras of regional art, the sharecropper is perpetually jeopardized but always also beyond the reach of civic duty. Unlike them, he is not endangered. Where disparaged figures of nineteenth-century regional writing vanish thanks to industrial progress, the sharecropper only multiplies. In short, the sharecropper offers an image of poverty that is memorable to the point of being perceived as a unique species of person. He is a representative of a class of poverty that has no civic support system. As exemplified in George Sessions Perry's sharecropper novel, Hold Autumn in Your Hand (1941), which won the National Book Award the same year Praise was published, the sharecropper does not share the ambitions for cooperative progress that his 
New Deal advocates promote. Sam Tucker, Perry's protagonist, refuses the federal and industrial compensations offered him. He prefers the plow to the factory, to check the sky for rain rather than his watch for lunchtime. Thus the fiction of the day represents the Southern sharecropper as one who will not recognize valid aid as such. ${ }^{75}$ Documentary work about the sharecropper similarly anticipates a welfare state that solves the "problem" of the sharecropper by not including him in its future. ${ }^{76}$ The sharecropper thus remains an isolated figure in documentary work. With arms akimbo, he contemplates his future alone, thus standing in as a visual antithesis of the invisible liberal middle class.

Agee and Evans's reimagining of the sharecropper flips this visibility/invisibility binary. They bring the "outsider," and thus cross-cultural, perspective to documentary work. Dramatizing the point of contact between the documentarian's cosmopolitan cultural capital and his subject's rural poverty, Praise affects a nearness to the site of cross-cultural contact that is absent from other Depression-era documentary work. For instance, Evans's photographs of sharecropper faces create an intersubjective link between the artist and the subject. Most sharecropper photographs come from the Information Division of the FSA, which adopted a goal of "introducing America to Americans.” Directed by Roy Stryker, a former Columbia University economics professor, the Information Division was the documentary arm of the FSA mission to preserve and promote American agriculture. Their assignment was to create a "visual analogue" to "the activities of the government in helping destitute farmers" (Rosenblum 379). However, on one of the Agency's first assignments, Arthur Rothstein manifested the deceptive potential of photographic illustrations of social welfare when he photographed a bleached steer skull that he had planted on the "cracked earth" of the 
South Dakota Badlands. ${ }^{77}$ For political opponents of the New Deal, this orchestration of desolate agriculture was evidence that government sponsored documentary efforts had no interest in reality.

Evans agreed with these rightwing accusers, "maintaining that for images to be true to both medium and event, situations should be found, not reenacted" (Rosenblum 382). From an interview with Evans, Stott discerns that, for Evans, "documentary" is synonymous with "stark record":

Any alteration or manipulation of the facts, for propaganda or other reasons, [Evans] considers "a direct violation of our tenets." He was shocked when his FSA colleague Arthur Rothstein was found to have moved the cow's skull, because "that's where the word 'documentary' holds: you don't touch a thing." (269)

But Evans was alone in this purist insistence on veracity (not to mention hypocritical). ${ }^{78}$ He was employed at the FSA for only two years, spending most of that time "on loan" to Agee and Fortune. His FSA photos were anomalous portraits of interiors, urban architecture, folk craft, and popular artifacts, nothing like the popular narrative scenes of rural poverty in many other FSA photographs. ${ }^{79}$ Evans was thus the New Deal documentary photographer "least in sympathy with the social implications ... [and] the bureaucratic restrictions of the project" (Rosenblum 383).

Margaret Bourke-White was another ambivalent documentary photographer. In fact, unlike most other prominent photographers of her generation, she never cashed a government check. Working exclusively for top Luce magazines (Fortune and Life), Bourke-White is remembered as an enterprising photographer of most every major 
national and international event in her lifetime (including extensive comparative work on American and Soviet industry, the European front of World War II, and the Korean War). Her first major publication, however, You Have Seen Their Faces, features some of the most mawkish and staged photographs of sharecroppers on record. The inaugural phototext of Depression-era farm poverty, Faces, for which her then husband Erskine Caldwell wrote the text, is decidedly theatrical when compared to Praise. Replete with "bizarre angles and in operatic lights," these photos are composed of orchestrated moments of the repugnant and the spectacular (Stott 270). According to one Life magazine article about her work, Bourke-White was "brutal" and determined to get "exactly the picture she wanted" (qtd. in Foner 125-126). She often organized, lit, and posed her subjects. According to the article, she "brutally" posed starving Sikh refugees, ordering them "to go back again and again" for a photograph whose final effect is seemingly affectless (126). Occasionally dismissed now as a photographer whose self-indulgent techniques were intended "to pep up the content, to wheedle the viewer into emotion by making it seem that what he looked at was fresh ... and not what it was: a sentimental cliché," Bourke-White has been vilified as a shrewd opportunist of poverty, especially when contrasted against Evans's seeming unautocratic efforts in Praise (Stott 270). Unlike Bourke-White, Evans "uses ... poverty to demonstrate how much [the impoverished] possess," how "all they touch, and all that touches them, is permeated with their being" (275).

But what looks like optimism is actually Evans's purist dogmatism. Evans has as glib a consideration for reality as has Bourke-White. The best of his Praise photographs, portraits of domestic interiors, borrow techniques from architecture photography. As 
demonstrated in the above discussion of Evans's sharecropper portraits, Evans's photographs of others highlight the conditions of encounter. Evans does so in a way that makes visible not the sharecropper herself, but the palpable boundary of estrangement between her and the beholder. Agee's conception of this boundary is different from Evans's. He places the documentarian's "encountering self" ${ }^{80}$ at the center of the document, erasing the conceptual gap between the agent of social welfare and its ostensible recipient. ${ }^{81}$ Another way to say this is that Agee makes documentary art local to the documentarian's experience. He puts William Carlos Williams's modernist dictum, "no ideas but in things," in the service of constructing a palpable "contact zone." abandons the agenda of mere awareness, which Agee feels is the most limiting aspect of documentary work. For instance, while the wish to "convey even some single thing as nearly as possible as that thing is" sounds like the wish of a documentarian, Agee's use of the word "convey" indicates that he intends to dramatize the process of materializing the thing (205). This overemphasis on the process of making a representation makes Praise both an elitist counterpoint to social welfare and a nexus of modernist formal properties and New Deal regional politics.

In the following section, I will survey the ethical ambiguities of this nexus, then demonstrate how Agee dramatizes the site of contact between the sharecropper and the documentarian. The remainder of my analysis of Praise will center on Agee's textual encounter with sharecroppers and the various corrections to documentary form that the dramatization of such an encounter engenders for a supposedly empirical genre. Since he directly confronts readerly expectations that had grown from the popularity of New Deal documentary, Agee's radically localized prose and his digressions into meta-commentary 
reveal Praise as a "contact zone," a textual site of contact between the cosmopolitan documentarian and the disparaged sharecropper wherein the "official rules" of such an encounter are questioned and revised. My argument, then, is that, by exposing himself in his document, Agee exposes the capacity of documentary protocols to produce poverty as an aspect of identity. As I'll discuss in the final section of this chapter, Agee's project ultimately fails; it doesn't set the agenda of postwar literary production as effectively as does Steinbeck's Grapes of Wrath. Nevertheless, his localization of the site of contact opens the possibility that such polarities as cosmopolitan detachment and provincial rootedness can be recognized. It's important to note here that, while Praise doesn't influence mid-century fiction as much as Grapes, it reemerges in 1960 as an important text for the white, middle-class managers of the civil-rights movement. Basically, Agee humanizes disparaged figures and blurs the line between cosmopolitan and provincial extremes long before the "age of great dreams" produces the cultural forms that might put his example to tangible use. ${ }^{83}$ The irony is that, prior to the "Freedom Summer" of 1961, Agee had little influence on literary or political modes of thinking about the relations of poverty. ${ }^{84}$ In addition to Agee's own difficult modernist objectives, what keeps Praise from being influential in the 1940s and 1950s is the fact that Steinbeck's The Grapes of Wrath proved so useful as both a literary and political master narrative for thinking about poverty.

\section{V}

Agee wasn't the only young writer to spend the summer of 1936 on assignment writing about the children of crisis in America. Steinbeck was hired by the San Francisco News to write a series of articles about migrant farmers in California's agricultural plains. 
Partly by virtue of the difference between their subjects and partly by virtue of their competing aesthetic ambitions, these two writers produces vastly different representations of those who suffer most the hardships of the cosmopolitan/provincial divide in America. Agee's subjects are by definition immobile. Steinbeck's, on the other hand, are by definition mobile. If either ceases to be one or the other, then he ceases to be within the scope of each writer's assignment. At opposite ends of the mobility/immobility continuum, Praise and The Grapes of Wrath differ on all points but this: each writer simulates the states of being (on the one hand immobile and on the other mobile) in their very style. Each writer's mode of expression mimics his subject's position in the production of iconic representations of rural poverty in the Depression era.

As I will demonstrate in this section, Steinbeck's choice to fictionalize his migrant farmers has the effect of racializing their poverty. Because he is essentially writing a "road novel," Steinbeck confronts the dilemma of choosing which aspects of his characters' identities can effectively be "mobilized." His choice to repeatedly underscore the Joad's adaptable agility suggests (1) that migrant farmers don't need social welfare and (2) that they consider their permanent relegation to the status of unskilled labor source to be a source of pride. This sympathetic portrayal, especially its agenda-setting popularity, foils much of the depolarizing work Agee and Evans hoped their metadocumentary book would accomplish.

Channeling the stoic managerial virtues of Tom Collins, who ran a federal migrant labor camp in California's central valley, The Grapes of Wrath provides a seamless transition from the New Deal era of documentary efficacy to the postDepression return to modernist formalism. It has also proven to be a model for 
subsequent generations of writers who fictionalize the plight of need-based continental migration. ${ }^{85}$ Steinbeck's position as a transitional figure is well documented. He spent roughly the same weeks that Agee spent in Hale County, Alabama, touring the Hoovervilles and Little Oklahomas of rural California. But Steinbeck was lucky where Agee was unlucky. Whereas Agee's text would not be published for five years (and even then it would sell poorly), the fruits of Steinbeck's weeks on assignment ran almost immediately, in seven installments in the San Francisco News (October 7-13, 1936). More importantly, Steinbeck's experience seeing destitute migrant farmers led him to a longtime friendship. Looking for favorable publicity, Collins obliged Steinbeck's initial need for material for his article series. He spent much time driving Steinbeck up and down California's agricultural valleys in an old bakery truck, explaining the lay of the land to Steinbeck. This experience with an official interlocutor stands in great contrast to Agee's experience, wherein his company was his subject (and occasionally Evans).

As opposed to the novel, which arguably runs counter to the social welfare agenda of the newspaper articles, Steinbeck and Collins produced a heroic journalistic defense of white migrant laborers' right to property. In the article series, Steinbeck refers to the farmers as a "new race." This label seems to suggest that, when denied the safeguards of constitutional rights, all have-nots are othered out of the realm of normal Americans. Throughout both The Harvest Gypsies and The Grapes of Wrath, Steinbeck represents his farmers as having lost their dignity. But it is not this loss of dignity, but instead the loss of inherently deserved property, that makes them a "new race" of people.

Drawing on his road tours and his unlimited access to Collins's Resettlement Administration reports, Steinbeck followed Collins's argument that white migrant 
workers are a race of "displaced Jeffersonian yeomen who needed and deserved their own small plots of land" (Wollenberg 140). ${ }^{86}$ In other words, they were a unique kind of poor, the kind whose very nature indicates that they deserve to own property. This special category of poverty is, Steinbeck's articles suggest, the result of the fact that the commercial protocols established during the Gold Rush discouraged small farm ownership in California. ${ }^{87}$ As far as Steinbeck is concerned, it is the job of New Dealers to promote the removal of these protocols, which should not apply to a displaced laboring class made up of white American families. California agricultural laborers were no longer made up of imported foreigners, but were instead "white labor ... American labor [that] will insist on a standard of living much higher than that which was accorded the [sic] foreign "cheap labor"' (The Harvest Gypsies 56). The racist overtones of Steinbeck's proclamations that white Americans would not accept the standard migrant status as a "peon class" are obvious here. Indeed, according to Charles Wollenberg, Steinbeck's message is that only "white Americans could successfully resist conditions which had regularly been imposed on non-whites and immigrants" (141). But this is both racist and a legal matter of fact. Since the completion of the transcontinental railroad, California had imported and exported a steady stream of foreign labor, from Chinese to Japanese to Mexican and finally Filipino. A not-so-ancillary benefit of this particular, pre-white American, labor is that it was afforded no constitutional rights.

Contrary to Steinbeck's optimism regarding the resolve of white family men, whom he assumes to be rugged individualists, the Okie migrants he championed were in fact "less willing to organize and unionize than the Mexican and Filipino" laborers (Wollenberg 144). In addition to idealizing the pride of white laborers, Steinbeck's 
representation of migrant farmers did the explicit work of racializing their poverty. Steinbeck repeatedly describes property-less migrants in racial terms. Even in the first installment of The Harvest Gypsies article series, Steinbeck claims his farmers' "blood is strong": "[t]hey are descendents of men who crossed into the middle west, who won their lands by fighting ... [t]hey are gypsies by force of circumstances" (22). Multiple times Steinbeck refers to migrant farmers as a "new race." It might be expected that racializing specifically white American groups of impoverished people would have the effect of "lowering" these groups to a level normally occupied by foreign labor. However, in Steinbeck's work, racialization of white men is a way of asserting that, when deprived of both land ownership or the vote, all persons in America are potentially racially other. It is private property, the yeoman's distinguishing characteristic, that Americanizes and deracialized men. It is arguable that this argument about property is the political message of The Grapes of Wrath, it would certainly be the political message of a New Deal manager such as Collins.

In the end, The Grapes of Wrath does not bring about much change in public programs. These idealized white farmers are never provided with the land that has been denied their yeoman's blood. What the novel does affect is a shift in the way American writers after the New Deal will approach the subject of poverty. As Michael Denning claims, a "grapes of wrath" master-narrative dominates the twilight years of Popular Front literary production. ${ }^{88}$ According to Denning, literary representations of poverty that are published after 1940 have to contend with two antithetical historical events: the end of the New Deal and the beginning of the grapes of wrath master narrative. By July 1939, the WPA is swallowed by the Federal Works Agency and renames the "Works Projects 
Administration" (the word "Progress" implied too "radical" an agenda) (Harris 129-130).

Likewise, the runaway popularity of Steinbeck's novel, and John Ford's 1940 film adaptation, represents a moment of transition wherein New Deal politics are privatized and New Deal aesthetics of localization abandoned. ${ }^{89}$ Considering Agee's reservations about New Deal documentary, one might assume Agee would be optimistic about this transition. But the opposite is true; Agee hates Ford's adaptation. He even interrupts his own revisions of Praise to draft an incendiary review of the film. ${ }^{90}$

Agee's problem with the rise of the "grapes of wrath" master narrative is not its privatized center, but its erasure of gritty local affiliations. Praise meditates on the static point of contact between sharecroppers and the representational agenda that would characterize sharecroppers as icons of poverty. The "grapes of wrath" master narrative, on the other hand, functions under what Michael Szalay calls a "comforting distance between cause and effect" (166). Basically, the "grapes of wrath" master narrative replaces the messy details of local affiliations with the exciting process of fleeing those affiliations. In the process of fleeing, the migrant workers assume a position as permanently homeless, an alternate race of people who operate under an entirely independent set of cultural codes but who look, to hateful racist eyes, like any other minority. As one of the first of many Californians claims of the "Okies": "They ain't human. A human being wouldn't live like they do. A human being couldn't stand to be so dirty and miserable" (221).

Agee argues that this master narrative begets a sentimentalist populism that replaces efficacy with inert consent. In the case of The Grapes of Wrath (the novel and the film), neither the reader nor the viewer has to bother at all with the discomfort of 
impoverished local affiliations, or with the "cooperation" involved in transforming such knowledge into a coherent message. Instead, she simply has to passively approve or disapprove of what happens to the Joads as they are en route to California. Basically, Agee doesn't like this narrative logic because it proposes too simple an answer to too complicated a question, an answer that its reader does not help to produce. The reader just awaits the solution, as though she were waiting for Tom Joad to reemerge as the revolutionary hero he promised to become.

But Steinbeck is uninterested in the material realities of migrant men such as Tom Joad. He wants Tom to exist as a pure idea, a pure sense of delocalized masculine virtue. As Szalay argues, Tom's disappearance from the novel is a rhetorical universalization of Tom's stoic masculinity (162). Additionally, Tom's disappearance impacts all the sites of class struggle within the world of the novel. Consider Tom's famous words to Ma:

I'll be all aroun' in the dark. I'll be ever'where ... Wherever they's a fight so hungry people can eat, I'll be there. Wherever they's a cop beatin' up a guy, I'll be there ... I'll be in the way guys yell when they're mad an'I'll be in the way kids laugh when they're hungry and they know supper's ready. An' when our folks eat the stuff they raise an' live in the houses they build—why, I'll be there. (419)

After this heroic, masculine effusion of the public and private sites of class struggle, Agee's brand of self-reflexive prose, which dramatizes the contact between cosmopolitan artists and the denizens of immobile poverty, seems fussy and esoteric. Something tangible is at stake with the Joads. What is even more tangible in Steinbeck's prose is that the Joads are actively moving, of their own accord, toward a solution, even if this 
solution means the sacrifice of their oldest born to the gods of social justice. The reader thus need not worry about his position in the plot, nor about being hoodwinked or "caught" in the awkward position of identifying with an unflattering personal need, namely that need to know that poverty is real and is really far away from him. By comparison, then, Praise looks unnecessarily complex. Its twining of highbrow aesthetics and grim realities seems (and is) deliberately anti-congenial to its readership.

For these reasons, The Grapes of Wrath becomes the successor to New Deal literary paradigms. It abandons documentary form and in the process it abandons the central "freedom" from logistic and representational boundaries. This freedom is replaced by an utter allegiance to a narrative logic of migration that only understands "freedom" in terms of the temporarily besieged "free" human spirit, personified in Tom Joad. As a replacement of the WPA agenda, the "grapes of wrath" master narrative thus underplays, or outright abandons, the point of contact between cosmopolitan writers and their impoverished subjects. Like the impressionistic chapters of The Grapes of Wrath, or even like the fact that Steinbeck's lived experience with migration occurred primarily in the passenger seat of Collins's bakery truck, this new narrative abandons the weight and solidity of documentary form. Its bird's eye view of migration is a welcome relief from the worm's eye view of immobile poverty offered by documentary work.

Through both his explicit response to the documentary tradition and his implicit critique of the "grapes of wrath" master narrative, Agee expresses hostility toward the kind of representation that never asks its reader to occupy any subject position he doesn't already know about and feel comfortable occupying. His review of John Ford's adaptation appears in the first pages of the journal that would become the major portion 
of Praise. In it Agee challenges those who take the film seriously to "get out and see how many tires are flat" on Route 66 (Agee 1940, 5). ${ }^{91}$ In other words, Agee calls to mind the fact that critical acclaim regarding the film's "adaptation of reality" ignores the absence of the kinds of ground-level snags that would have been included in the a true adaptation of reality. ${ }^{92}$ Likewise, Agee argues that Ford white washes the crass characteristics of Steinbeck's Joads into lovable characteristics, thus promoting a large-scale embrace of poverty. It makes what is repugnant about poverty into something huggable. ${ }^{93}$ Thus begins the transformation of poverty into an identity category. ${ }^{94}$

Lovable as all get-out, Ford's Joads hit the open road with all of American popular culture to cheer on their migration. According to Agee, of all the popular attempts to elevate poverty, The Grapes of Wrath has gained "so special a place in history, and so special a reputation, that it seems a symbol for them all" $(1940,6)$. The fact that Agee is making these poignant observations in his journals to Praise is more than a convenient coincidence. It indicates that Agee developed his self-reflexive version of documentary prose in explicit response to the delocalization he saw occurring in popular cultural manifestations of rural poverty. The problem for Agee is that migration narratives eliminate the local sites of contact, which is to say that they eliminate the potential of a readership to imagine its real relation to rural poverty. If only to show its unmediated venom, I reproduce here the heart of Agee's invective against this new narrative logic:

I submit that there is quite as much unreality in Grapes of Wrath as in Gone with the Wind (sight unseen), and that it is of a far more poisonous order, being more near the centers of human living, pain and dignity, and 
therefore more insulting to them, and being also so successfully disguised as "reality," that it deceived even its creators. I suggest that it is virtually worthless in any direct way, but endlessly interesting as an encyclopedia of flaws, substandards, inadequacies, self-deceptions, deceptions of the public, opportunities impaired for the future, and, at very best, of painful disappointments. It may be well more interesting, for those with the special taste for it, to watch and analyze as an elaborate, flawlessly false and logical and vulgar, collective dream: general America's dream of a lot of things about itself. (6-7, italics mine)

A burgeoning film snob, Agee laments the prominence of uncomplicatedly sentimental "moving pictures," especially those that "move" the question of poverty to a subordinate position in relation to a fantastic plot arc. ${ }^{95}$ But the prominence of The Grapes of Wrath is especially discouraging to Agee because it has the power to make "nearly all leftwingers ... so happy, indeed, that they can (literally) overlook—or still worse, seem to forgiveany number of [the film's] merely non political gaffs" (6). In short, the film makes audiences lazy, even if lazy with the right politics. It erases the need for intervention, for benevolent intruders like Agee himself.

Additionally, migration, under the logic of the "grapes of wrath" master narrative, is synonymous with disenfranchisement. Worse, it decreases the tragedy of this disenfranchisement, as Steinbeck's Okies are so enterprising. As a superhuman "new race" of poor, the Joads take matters into their own hands. They migrate independent of welfare accommodations, as they have the agility to transfer from one labor practice to another, to pick up the business of revolution as though it were farming or mechanics. In 
fact, the only sign of government sponsorship in The Grapes of Wrath, California's Weedpatch camp, is "sanitary" to the point of existing in the novel as a utopia—an ideal place from which to criticize the real world, a place that never itself exists in the real world. The film thus produces impoverished people who are simply too enterprising for their own good.

The migratory narrative of The Grapes of Wrath, no matter how closely it resembles the facts of Dust Bowl migration and desolation, thus undermines the "progress" of New Deal documentary art. Agee's fear, at least as he expresses them in the pages of his Praise journal, is that The Grapes of Wrath signals the dawn of the art of "sentimental liberalism" that is indifferent to the life of documentary art and too comfortable with the cosmopolitan/provincial polarity. According to Agee's review, this new sentimentalism "so unqualifiedly heartens all those who plug so hard and care so much for the development of 'documentary' films [that] the increased arc of "reality"' is replaced by the increased vocabulary of sentimental fantasy that might usher into existence a version of reality akin in idealism to Gone with the Wind (6).

Of course, reviewers such as Agee, who rushed to judge Steinbeck as sentimental, are in effect more than comfortable with the polarity. They are downright reinscribing the polarity. Agee was not the only one down on The Grapes of Wrath. According to Denning's review of its reception, Steinbeck's novel was considered "an emblem of middlebrow kitsch to New York intellectuals" (259). Embodying the “"documentary impulse' of representing 'the people,"” but representing only a mythic everyman, The Grapes of Wrath actually further polarizes American culture. It becomes what Szalay refers to as a "high-water mark in twentieth-century American sentimentalism" (167). 
Despite the New Yorkers' pessimistic conceptions of The Grapes of Wrath, the novel is not solely a text of sentimental liberalism. It engages the giant facts of foreclosure and farm land denuded of topsoil in the same dramatic way that Pare Lorentz's Resettlement Agency films had. The problem that Agee sees with The Grapes of Wrath is that its plot presupposes that there is no valid political action that can be taken by any but the superhuman poor (viz., Casey and Tom). There are no depolarizing gestures in this type of fictionalization, as there is no solution to the problem, save movement and disappearance. As we will see in the following chapter, Jack Kerouac develops a similar attitude toward movement and mobility. Much like the roving serpent of loaded down old jalopies that Steinbeck's farmers become, Kerouac represents a generation of white middle-class males who must move at all costs. When they attempt to establish local affiliations, they become vagrants, pooled together and nudged back to the road. In short, Kerouac develops Steinbeck's master narrative into the current conception of the "road novel." In the final section of this chapter, I will briefly discuss how Agee's own hyper-localized prose previews the emergent need for this form of delocalization.

\section{VI}

In contrast to the sloganizing populism that ends the film version of The Grapes of Wrath (Ma remarks: “We're the people! We go on!") or even the reluctantly compassionate populist heroinism that ends the novel (Rosasharn breast feeds a starving stranger), Praise closes with one last modernist gesture toward the importance of formalized sound. ${ }^{96}$ But, unlike the structural "sonata form" of Praise as a whole, sound here does not score or give aesthetic dimensions to the document. Instead, it actually emerges as an alternative subject—one that puts to use the ground-level depolarization of 
documentarian and subject. As sound becomes the subject of Agee's text, rather than its structure, documentarian and subject alike enter into a pact of mutual listening.

The final section of Praise is titled "On the Porch 3." From this stable position of "the porch," Agee and his subject hear a mysterious call in the wilderness, which Agee confusingly calls a communicative gesture that is "not only beyond possibility but irrelevant to it" (414). What is curious is not the mysterious sound per se, nor is it Agee's weird characterization of it. Instead, the curious bit is that Agee is not alone when he hears it. He and the unnamed porch companion listen to the sound together, mutually recognizing the defamiliarizing peripheries of their painstaking attempt to relate to one another: ${ }^{97}$

All the darkness in near range ... as far as we were able to hear was strung with noises that were all one noise, and to this we had become so accustomed that this new sound came out of silence, and left an even more powerful silence behind it, so that with each return it, and the ensuing silence, gave each other more and more value, like the exchanges of two mirrors laid face to face. (408)

This is the sound of the periphery that structures the site of contact between the documentarian and his subject. It is the atmospheric white noise of nature to which both parties have grown desensitized. Together, Agee and his subject-turned-companion analyze the ethereal subtleties of the structuring periphery, as though it were strange music in need of notation. Via "mutual listening," the two become "one hollowed and listening ear," jointly absorbing pure form (i.e., a sound that has no body to speak from or reflect upon) (409). This final section, singular in both its use of the pronouns "we" and 
"us" and its gesture at an ether beyond Agee's radically localized point of contact, amplifies the fact that what has been so troubling about documentary work (in addition to its ethical contradictions) is that it is so isolating. Praise lays bare the local affiliations that mark points of separation between the documentarian and his subject. Why now discover a new relation to the subject, that of joint recognition, if not to indicate that even the most self-reflexive documentary work has pronounced limits?

The mysterious sound connotes an agency independent from companionate listening, one that facilitates the fact of coexistence. It is a sound "so entirely itself, without regard for us" that is "more alien to us because it is alive and conscious and within our near perspective of kinship" (411). Agee's self-reflection here is, in the final section of Praise, finally coupled with his subject in something like a kinship. In the presence of a mysterious agency desperately seeking its own companion, Agee, Agee's companion, and the reader alike realize that such companionship is precisely what has been missing for the over 400 pages of the Praise manuscript. Moreover, Agee's multiplication of questing subjectivities sets his own project into much needed relief. This moment inaugurates something that readers who have made it this far into Praise might have considered impossible for Agee: an admission that his inability to represent the "actual" constitutes no great loss. When he is not alone, Agee can relax into the "frightening joy of hearing the world talk to itself" (414)—very similar to Kerouac's pleasure at living lost within "the immensity of it all" (On the Road 309). Agee and his newly acknowledged companion can "lay thinking, analyzing, remembering ... until at last we too fell asleep" (416). These — the last words of Praise — offer a surprising deference to the world that exists beyond the documentarian's grasp. Agee's sustained 
ambivalence regarding the project of documenting sharecroppers is thus compensated at last by the chance to share the "frightening joy" that elsewhere haunts Agee's embodied documentary stance.

This mutual listening calls to mind what Ann Douglas describes as Kerouac's "poetics of intimacy." It couples the encountering self and a companion and creates a narrative economy wherein the narrator needs not worry over his relation with his subject. As opposed to Agee, whose self-reflexive documentary nearly exhausts itself with preambles, prefaces, and false starts, Kerouac's literary narrative begins with the briefest of introductions. Where Agee's writing is labored, an artful simulation of the real conditions of documentary encounter, Beat writing is easy, a seemingly effortless dramatization of its encountering self. Kerouac dwells in the structuring periphery Agee and his sharecropper hear in the final evening on the porch together. In other words, Agee and Kerouac go together in my study not just because they represent opposite versions of localizing aesthetics, but also because they reveal two otherwise invisible elements of the post-New Deal literary landscape. Where Agee's prose makes visible the missing encounter of documentary work, Kerouac's prose reveals the unstable nature of specific soil in a world where delocalizing forces, such as mid-century automobile culture, are redefining the fundamental types of local affiliations available to Americans.

By pointing out that Agee ends his self-reflexive documentary book with a testimony to mutual listening, I am not trying to suggest that Agee predicts Kerouac's aesthetic agenda. Instead, I end with the ending of Praise because this ending punctuates the fact that Agee intends for his book to be publicly useful. Unlike the floating liberal thinkers of the cold war, Agee is not finally a figure untethered from public life. If 
anything, it is public life that is untethered from the kinds of local affiliations that selfreflexivity helps to manifest. Agee positions his encountering self as a coworker in what appears to be the impossible task of figuring what the hell is happening to class divisions in America. In that case, when scholars like Hegeman and Alan Spiegel think of Agee as a pioneer of the moods and methods of cold war introspection, they are not only lumping him into the ever-expanding pool of writers who help support the war rubric. ${ }^{98}$ They are neglecting the fact that the lessons learned from New Deal models of public life, and not the lessons learned from the Cold or Second World Wars, impact the way key cultural terms of the rest of the "Century of the Common Man" get understood. ${ }^{99}$

Susan Faludi makes a similar argument in Stiffed: The Betrayal of the American Man (1999). Using journalist Ernie Pyle as an example, Faludi suggests that to remember figures such as Pyle or Agee as products of the Second World War is to eclipse the New Deal models that inform these figures' agendas. Just as Agee produced some of the most influential film criticism of the mid-century, Pyle wrote columns about battles of the European front. ${ }^{100}$ In this sense both are remembered primarily as mid-century public intellectuals. More specifically, both are remembered as public intellectuals who are firmly grounded in the decidedly unanchored international political and cultural struggles of the mid twentieth century. But such conflations obscure the historical record. So much so, Faludi suggests, that they represent the daunting terms of discourse, such as "postwar masculinity," as a kind of mass epidemic inherited directly from the battlefields of Normandy. As Faludi explains, "[t]he model [of masculinity] Ernie Pyle limned in his columns" did not come from the battlefields so much as from "the Great Depression, while touring small-town and rural America chronicling the quiet struggles of Alabama 
sharecroppers" (20). If anything, then, the war of note that laid the tracks of mass change in mid-century political and cultural discourses, as it is displayed in Pyle's and Agee's work, is Roosevelt's war on poverty. This war brought about the renewed interest in the cracks and crevasses of the particular, corporeal sites of economic class struggle. It occasioned what Scarry would call a "generous imagining" of poverty as something wholly other than a race or a class of people, a dynamic produced in part by the reflexes that the meager local conditions cause when beheld by one not of those conditions.

Where the war on poverty, Agee suggests, exploits this interest in particularity, the Second World War pulverizes it. Mid-century American culture falls in love with the chorus lines of superhuman soldiers whom Faludi calls the "anonymous, duty-bound young men" who sired the baby boom. (16). Agee does not recognize this superhuman anonymity in the common man. In fact, he never recognizes that there is such a thing as a "common" man. George Gudger's overalls are of a piece with the best Cézanne canvas, the cloak of a remarkably uncommon and haunting person whose physical depth resists easy classification as "poor." In this sense, Agee's representations of rural sharecroppers likewise exploit interest in particularity, in that he aestheticizes it. What is important is not just to recognize this exploitation, but also to acknowledge that, like William Whyte's concept of the "organization man," the logic of Agee's representation of hyper-specific sharecroppers reflects a curious cultural logic in mid-century America- the negative correlation between individual particularity and economic value. In the following chapter, I will examine Kerouac's response to this dominant mid-century cultural logic. 


\section{Chapter Two:}

\section{Pavement: Jack Kerouac and the Delocalization of America}

Time is the essence of the undertaking, time to live into the land and absorb it; still more time to cure the reading public of its preference for something less than the proverbial bird's-eye view of the American scene, what you might call an automobile eye view, something slithering and blurred, nothing so sharply discriminated that it arrests the speed-numbed mind to understand, characters like garish gas stations picked out with electric lights. The one chance of persuading the young reader to make these distinctions for himself would be to whet his appreciation on the best regional literature of our past so that he may not miss the emerging instance of his own times.

(Mary Austin, "Regionalism in American Fiction” 107)

Trying, let us say, to represent, to reproduce, a certain city street, under the conviction that nothing is as important, as sublime, as truly poetic about the street in its flotation upon time and space as the street itself. ... You abjure all metaphor, symbol, selection and above all, of course, all temptation to invent, as obstructive, false, artistic ... you try to give the street in its own terms: that is to say, either in terms in which you (or some imagined character) see it, or in a reduction and depersonalization into terms which will nearly as possible be the "private," singular terms of that asphalt, those neon letters, those and all other items combined, into that 
alternation, that simultaneity, of the flat blank tremendously constructed chords and of immensely elaborate counterpoint which is the street itself. (James Agee, Let Us Now Praise Famous Men 208)

Yes, zoom. (Jack Kerouac, On the Road 182)

In "Regionalism in American Fiction" (1932), Mary Austin predicts that the careful localization strategies of regional writing will become increasingly less popular as American culture literally starts to speed up. In effect, the American reading public in the 1930s will settle for "less than" the sharp, inclusive geography of "American scene" fiction, as this public begins to prefer the "automobile eye view," or the point of view that corresponds to the "speed-numbed mind" of modern society. Fiction of the nature Austin predicts is normally considered a feature of mid-century, post-interstate system America. However, Austin sees it coming from a distance. Likewise, Agee foresees and is as bothered as Austin about the perpetual state of distraction of the American reader. His advice to young writers - "give the street in its own terms"-is to use the subject matter that fuels popular interest in speed and mobility as a way of reinventing the anti-modern modernist sensibility, the mental activity of which requires a fair amount of sluggish meditation.

This agreement between Austin and Agee echoes the root-level resemblance of regionalist and modernist writers in the Depression era, a resemblance I discussed in Chapter One. It also signals the fact that what undoes the popularity of regional and modernist aesthetics alike at the mid-century is not the Second World War, but the fact that concepts of time and time's relation to experiential reality change thanks to the 
650,000 new miles of pavement laid down by New Deal work programs. Where "time is the essence" for writers such as Austin and Agee's, both of whom are from a generation of writers whose formal influences draw them closer to the ground of specificity (not to mention closer to the early rather than middle twentieth century), time is essentially a non-issue for writers like Jack Kerouac, who propel themselves, with the sheer narrative dynamism of their highway mimesis, through what John Tytell calls the "embalming insecurities" of the 1950s (12).

Yet Kerouac's fiction, as well as the literary offerings of most of the Beat Generation, is reminiscent of Agee's iconoclastic vigor. Kerouac, like Agee, has a bone to pick with documentary aesthetics, especially with its polarization of cosmopolitan detachment and provincial affiliation. As we will see below, Kerouac is similar to Agee in that he blends detachment and affiliation into a single subject position. He is unlike Agee in that he writes fiction that enacts an absurd form of world citizenship, one based on what W. J. Lhamon later terms the mid-century aesthetic of "deliberate speed." Lhamon applies this phrase to a slate of visual and literary artists who, at mid-century, rebelled against stale polarities. ${ }^{101}$ Deliberate speeders are "always telling and denying a story, always catching and freeing a connection, encouraging and discouraging an interpretation" (128). The object is to enact a narrative logic that resists polarization. The resistance comes vis-à-vis a revolutionary, what I'll define as "delocalized," approach to representing identity.

The identities of the characters in Kerouac's fiction are derived from a set of multiple simultaneous local affiliations. His heroes are hobos with names like "Mississippi Gene," a character in On the Road (1957) who hasn't been to Mississippi in 
years as he's been "crossing and recrossing the country every year ... only because he had no place he could stay in without getting tired of it because there was nowhere to go but everywhere, keep rolling under the stars, generally the Western stars" (28). Characters such as this are appealing to Kerouac because they are incapable of shortsighted provincialism, incapable of mistaking a local condition for an essential condition. In speeding from one side of the American continent to the other, Gene acquires a transcontinental reach that is both patriotic and cosmopolitan as it simultaneously inventories America and reduces the capacity of Americans to be affiliated solely with any one part of the country. This is a deliberate, albeit naïve, attempt to free Americans from their roots and thereby repair the national culture's inability to build sustainable communities. Kerouac's solution to this American epidemic is to combine community building and flight from community into a single act.

In this chapter, I will discuss Kerouac's urge for depolarization vis-à-vis delocalized identities. Kerouac's delocalization techniques stand in stark contrast to Agee's localization techniques. Where Agee presents at length the site of contact between the rooted subjects of documentary art and the detached agents of imaginative art, Kerouac obscures the sources of American identity. His narrative voice expresses multiple, simultaneous affiliations with the American continent, enacting the very "blurred" automobile's eye view that Austin so forlornly (and accurately) predicted would dominate fiction production in the U.S. Yet, despite their differences, Kerouac and Agee alike try to overcome the counterproductive byproduct of New Deal documentary (i.e., the problem of representing economic conditions as though they are identity traits). Where Agee focuses on the "roots" of the problem (i.e., the supposed division between 
the cosmopolitan observer and the provincial observed), Kerouac considers the "routes" of the solution (i.e., the literary and figurative lines that span provincial and cosmopolitan zones alike).

Marco Abel has already established the relationship between Kerouac's "lines of flight" from identity and the aesthetic theories of Gilles Deleuze. In his article, "Speeding Across the Rhizome: Deleuze Meets Kerouac on the Road" (2002), Abel draws the parallels between Kerouac's literary objectives and the Deleuzean ideal of "rhizomatic" art. According to Abel, Kerouac's style “demarcates a new form of writing: not the slow, deliberate sentence of the dominant modernist tradition, but the speedy, visceral, combinatory, over-exuberant conjunction of words that form sentences radically different from their predecessors" (232). Such sentences indicate that Kerouac's technique of delocalization and Deleuze's conception of "minoritarian politics" share a goal: "to relate to other social assemblages not based on knowledge but [on] desire" (240). I agree with Abel's argument to some extent. Kerouac envisions a mode of belonging to marginal social groups that is based solely on what the one seeking entry does not know about the group. Ignorance is a virtue for both Kerouac and Deleuze because it clears the way for visceral expressions. But rather than continue to point up the readymade parallels between Kerouac's neo-romantic literary form and Deleuze's aesthetic theory, I find it more productive to examine how Kerouac untangles local affiliations from identity and, in the process, reveals provincialism and cosmopolitanism as kindred sensibilities.

In Chapter One, I demonstrated how Agee attempts to make visible the point of contact that enables readers of documentary prose to pity its impoverished subjects. Here, I will demonstrate how Kerouac usurps the likelihood that readers will pity the children 
of crisis that Kerouac writes about (including shiftless hobos and Mexican migrant workers). Because of his objective of multiple simultaneous local affiliations, Kerouac's narrator assumes an identity that has equal standing among downtrodden and discriminated Americans. This assumption has led to much discussion of Kerouac's racial and gender essentialism. It is well known that Kerouac is open to the criticism that his narrative innovations presuppose a white, middle-class freedom to circulate and selfidentify. ${ }^{102}$ Indeed, his narrator's motivating interest in going on the road is to assume the kind of idealized poverty that transcends the cosmopolitan/provincial polarity with the simple assertion that "Everything belongs to me because I am poor." ${ }^{\text {"103 }}$ According to this assertion, world citizenship is the reward for abandoning local ties. This assumption that there is a wealthy kind of poverty — a poverty based on the freedom from local ties that one does have rather than on material possessions one does not have- has become the most enduring ethical problem of On the Road, a novel where homeless orphans are envied as cosmopolitans and a white, middle-class narrator compares himself to "an old Negro cotton-picker" and a "Mexican" on the same page (97). The novel is dismissible by many because it fails to analyze itself as ethically problematic, fails to contribute anything but the most counterproductive of gestures in the direction of diversity in America. By including naïve middle-class affections for the "less fortunate," Kerouac externalizes the very processes that incensed Agee about the consumption of documentary prose.

Additionally, as Abel argues, in order to continue our critique of Kerouac's wholesale appropriations, "we need to ask questions different in kind from the ones that have been asked thus far. Instead of asking, 'How has Kerouac represented gender or race 
relations in his fiction?' we need to ask 'What kind of gender, race, or class relationships has he invented?'” (246). In a sense, I will ask such questions in this chapter. The short answer is that Kerouac has invented a narrative form for what Elaine Scarry refers to as the "weightless" subject position (105). Kerouac's most famous narrator, Sal Paradise of On the Road, achieves his weightlessness while under the influence of road travel. Such narrative weightlessness is an "alternative strategy" for achieving "equality between self and other" (Scarry 105). This strategy knocks down the inequalities of identity not by "trying to make one's knowledge of others as weighty as one's self-knowledge"-which is to say not the way that Agee does- - "but by making one ignorant about oneself, and therefore as weightless as all others" (105). As I will argue below, the contrast between Kerouac's narrator's self-ignorance (a byproduct of “deliberate speed") and Agee's weighty, documentary self-awareness sets up the aesthetic scale in which contemporary American fiction writers still fight against the provincial/cosmopolitan polarity. ${ }^{104}$ I will begin by examining Kerouac's broader significance to both post-Depression and cold war issues, moving to a discussion of the inclusive and engaged form of cosmopolitanism that Kerouac produces from his narrator's lack of official local knowledge. This ignorance is what allows Kerouac's vision of equal access world citizenship to develop. Kerouac, who, according to Beat generation lore, was a poor driver, constructs a road novel with a narrator who is a novice of the road trip. Sal misunderstands the local dilemmas that accompany road travel, dilemmas similar to those delineated in Steinbeck. Partly as a result of Sal's ignorance, On the Road represents movement West as essentially indistinguishable from movement East. Sal's inability to tell whether he's going east or west is an important geographical component to the type 
of depolarization Kerouac envisions. In subsequent sections, I will analyze "the road" as a key corresponding symbol to delocalization, arguing that Kerouac develops the road trope as a way of rejecting the regional provincialism and modernist cosmopolitanism of previous generations. Ultimately, Kerouac tries to reveal the contour lines that link all Americans. In the process, he both exposes the false polarity between provincialism and cosmopolitanism in America and showcases what by today's standards is an aggressively naïve politics of identity.

\section{I}

Kerouac's ideal subject matter is the entire American continent and everyone on it. In other words, Kerouac's subject matter is the exact opposite of Agee's subject matter - the specific point of contact between the documentarian and his subject. Agee produces a disorienting sense of lived experience, a sense that defamiliarizes the division between those who are cosmopolitan and those who are provincial. Kerouac, on the other hand, directs the reader to what is American rather than who is American, at what Kerouac calls "the immensity of it" rather than at the disorienting textural depth of an individual encounter. His delocalization of identity reveals the contour lines, rather than stereoscopic depth, of separate identity groups in America. ${ }^{105}$ Thus Kerouac's fiction avoids the fixation on difference that usually motivates fiction writers who strive to include multiple cultural locations. Through sustained interest in the immediacy and the immensity of American diversity, rather than a sustained interest in difference per se, Kerouac invents new relations among American economic classes and racial groups, relations that amplify the resemblance among all things American. 
In literary historical terms, Kerouac's type of fiction, which downplays the importance of the kind of complex introspection Agee demands from his reader, rises to prominence as documentary protocols decline. Beat writers inhabit the structuring periphery that encroaches on Agee in the final passage of Praise. Kerouac's narrators peek onto stable settings as infrequently and with as much diffidence as Agee's documentarian attends to what is beyond the sharecropper's porch. For instance, at one point in On the Road, Sal sneaks into a "four-room shack" reminiscent of the sharecropper shelters Agee describes throughout Praise. He observes that " $[\mathrm{t}] \mathrm{here}$ were no screens, just like in the song, "The window is broken and the rain is coming in"' (99). He thus treats this tenant shack, inhabited by a Mexican family of migrant farmers in the San Joaquin valley, as a reference point for a popular song that traffics heavily in ethnic stereotypes, “Mañana” (1947) by Peggy Lee. ${ }^{106}$ Doing this, Sal answers Agee’s earnest encounter with rural poverty, replacing sustained observation with the kind of referential thinking common to youth culture. Sal's comparison of the shack to an exploitative popular song indicates his position as a middle-class white kid encountering poverty for the first time. The irony is that Sal's reductivism is as earnest as Agee's complexity, perhaps more so, considering that Kerouac doesn't shy away from dramatizing the very class divisions Agee's prose tries to simultaneously expose and deride.

In a nutshell, Kerouac's fiction is about getting away from the very complex local affiliations that Agee obsessed over. This agenda can be seen even in Kerouac's "Essentials of Spontaneous Prose," wherein the writer explains the "image-object" he uses to "set up" the conditions for spontaneous prose should never take precedence over the thousand words of "sketching" that such images and objects inspire ("Essentials" 72). 
Where Agee wants "the street in its own terms," Kerouac relishes the displacement offered by such paved means of flight. The difference between Agee's placement and Kerouac's displacement, then, is that the first affirms the material conditions of (or "localizes") the material reality and the second sets itself in motion and never reestablishes a local affiliation.

Obviously, no one place is permanently inhabitable for a narrator whose last name is Paradise, a narrator who makes believe that he circulates freely above cultural division, never to be snagged by the details that spell the differences of people. This means that Sal's perspective often appears ignorant of cultural division, certainly, as in the scene of the migrant shack, ignorant of any civic duty he may have to repair such divisions. No corresponding economic need propels Sal to cross and recross the U.S. The goal is to flee the very cramped spaces that Agee and others of the documentary era so earnestly occupy, to liberate encountering selves from the "either/or" choice implied in the cosmopolitan-provincial juxtaposition that Agee's revisionary documentary technique depends on, even as they essentialize the "porches" that they "zoom" past.

For instance, the final paragraph of the novel, one long and much memorized sentence of 171 words, demonstrates Kerouac's penchant for depolarized thinking and reasserts his argument that the objective is to, whatever the cost, by God keep moving. Sal reflects on what has amounted to the melancholy experience of multiple transcontinental road trips. Beginning with the ambitious introductory phrases, "So in America, when the sun goes down," Kerouac shows Sal's enduring naïveté (309). The first half of the sentence is an accretion of prepositional phrases that indicates that Sal's seen a lot and absorbed little: "in America ... on the old broken-down river pier ... over 
New Jersey ... in one unbelievable huge bulge over to the West Coast ... in the immensity of it ... in Iowa ... in the land where they let the children cry" (309). Taking this twilight inventory, Sal recaps the tension among being "in" "on" and "over" various parts of the country, the tension that drives the plot's forward progress. He speeds his imagination from the east coast where he is to the west coast where he has been, peeking down at the inland prairie regions, remarking with an air of wisdom that it is "the land where they let the children cry." In addition to being one of the least intuitive ways for a seasoned traveler to finish the sentence "Iowa is the land where ," this piece of acquired local knowledge evokes the image of children in mock pain, the pain of not wanting to go to bed rather than the pain of going to bed hungry. On the Road indulges such insatiable, childish desire. The knowledge of the country that this indulgence yields includes the fact that there are giant roadblocks (the size of Iowa) that shackle Sal and his friends to harsh unpleasant responsibilities. Sal recoils from this standard moral, blurting out a half-formed, very non-standard, rhetorical question: "don't you know that God is Pooh-Bear?" This question, likely a ventriloquial consolation for the crying children of Iowa, stands in the place of the earnest discovery that Sal's travels were supposed to have yielded. America itself is a child. "Complete night" comes like a mother and "darkens all rivers, cups the peaks and folds the final shore in," covering land the way a mother might cover and tuck in a child's bed (310). This is the consolation (or punishment) for trading one's local affiliations for a smattering of multiple local affiliations.

Kerouac was not always so interested in shedding his local affiliations. Before the success of On the Road, he had written a series of manuscripts that have come to be known as his "Lowell novels." With the exception of Visions of Gerard (1963), 
Kerouac's Lowell novels are the product of a literary project that predates the publication of On the Road (1957). Including The Town and the City (1950), Maggie Cassidy (1959), and Dr. Sax (1959), these novels (which were published after On the Road but written before its publication) are rooted in the culture and geography of Lowell; they shed the light of local color on Kerouac's hometown. Furthermore, they resemble the "village rebel" novels of Sherwood Anderson and Thomas Wolfe (after whom Kerouac modeled his pre-delocalizing narrative style). The specific place is important to the degree that it serves, in the words of the narrator of Winesburg, Ohio, as a "background on which to paint the dreams of [the village rebel's] manhood" (153). In short, Kerouac's Lowell novels sketch the childhood and adolescence of a writer/narrator whose appropriate fruition is to take place, as is George Willard's, while on the road of flight from a stable home. $^{107}$

This particular pattern of development leads to Kerouac's aesthetic interest in the fleeting aspects of surfaces, in the boundary that separates one object from another. Unlike Agee's documentary thing, which is the result of sustained observation, Kerouac's delocalized thing is all surface; it changes shape and refracts different dimensions at the liberty of a beholder in motion. In short, to abandon local affiliations is not to abandon locale, but to imagine the democratic availability of the surfaces that make up a specific locale.

The very title On the Road supposes the road to be a kind of stabilizing surface, positioning (or even "prepositioning") the narrator to be "on" it. The road itself becomes a locative surface for Kerouac, as well as for many other mid-century American writers. ${ }^{108}$ It is a kind of transcendent soil that makes the rest of America seem like a 
fluctuating mess. Only from the road is one properly placed to have any of vision of America en masse. The road, then, as I discuss at length in section III, is to postDepression writers like Kerouac what the river is to post-Civil War writers like Mark Twain, a place from which to criticize the social mores of provincial America.

Whenever Sal momentarily drifts from the road, he experiences a profoundly disorienting panic. For instance, after waking up the third day of his first journey across the country, Sal experiences an intense and textured defamiliarization amid a commonplace motel setting. This experience, which Kerouac marks as a danger, is similar to the kind of experience Agee hopes to inspire in his reader. Sal describes this "one distinct time in my life" as follows:

I didn't know who I was-I was far from home, haunted and tired with travel, in a cheap hotel I'd never seen, hearing the hiss of steam outside, and the creak of old wood of the hotel, and the footsteps upstairs, and all the sad sounds, and looked at the cracked high ceiling and really didn't know who I was for about fifteen strange seconds. I wasn't scared; I was just somebody else ... halfway across America, at the dividing line between the East of my youth and the West of my future. (17) ${ }^{109}$

The silent panic of being alone amid unfamiliar banalities, what Agee terms as a perverse form of "being at work" on letting the materiality of an unfamiliar place engulf your sense of self, is precisely the kind of experience Kerouac hopes to avoid (Praise 121). This moment of estrangement from himself is thematically similar to other mid-century models of alienation, the most influential of which being Jean Paul Sartre's Nausea ${ }^{110}$ As opposed to the heady estrangement of Sartre's first-person narrator (Roquentin), Sal's 
estrangement comes from the mere fact that he has temporarily stopped moving. $\mathrm{He}$ attempts to retreat from this estrangement and reconnect with the delocalized identity that the road allows, the identity of the homeless hitchhiker. In short, the first circumcontinental trip in On the Road, begins with a deliberate denial of Agee's method of depolarization, a pronounced flight from the horrifying self-realizations that result from sustained contact with a rooted affiliation. This doesn't mean that Kerouac doesn't share Agee's depolarization objective. As is evident even from the above passage, Sal confronts this "dividing line" in America. The difference is that he chooses to think in spatial rather than interpersonal terms. He answers Agee's weighty observation by enacting the weightless project of flying from local affiliations. In the following section, I will discuss a preliminary step in confronting the dividing line, the development of a "counter-urban" cosmopolitan stance, a stance that is not anti-urban but that exposes the dividing forces of urban intellectual forms.

\section{II}

As an episodic narrative whose significant moments occur in both established urban centers such as New York and San Francisco and Old West commercial boomtowns such as Central City, Colorado and Cheyenne, Wyoming, On the Road enacts an equal-opportunity, naïve cosmopolitanism that does not recognize the geographical hierarchy of American places. In fact, Kerouac's narrator is contemptuous of his native, urban east coast, whose pretensions draw lines of division among even fellow New Yorkers. But this narrator lacks the faculties to beat intellectualism at its own game. Instead, Sal is compelled to be in the shadows of life forces whose instincts and desires trump big intellects. In short, Kerouac's narrator is prefers instinct-driven frontier figures 
to urban sophisticates. However, no matter how radiant his counter-urban prejudice becomes, it is a misinterpretation to conclude that Kerouac's hostility toward urban sophistication means that he is indifferent toward the provincialism and moral hypocrisy of the commercial West. On the contrary, Kerouac criticizes all forms of provincial short sightedness and hypocrisy, especially those forms that exist in New York itself.

Sal's primary reason for leaving "the East of my youth" for "the West of my future" is to escape the cold and pervading culture of sophistication in the East (17). In the opening pages of the novel, Sal evokes a stark contrast between Dean, the embodiment of the West, and Sal's New York friends:

All my other current friends were "intellectuals"-Chad [Hal Chase] the Nietzschean anthropologist, Carlo Marx and his nutty surrealist lowvoiced serious staring talk, Old Bull Lee [William Burroughs] and his critical anti-everything drawl—or else they were slinking criminals like Elmer Hassel [Herbert Hunke], with that hip sneer; Jane Lee [Joan Vollmer] the same, sprawled on the Oriental cover of her couch, sniffing at the New Yorker. Dean's intelligence was every bit as formal and shining and complete, without the tedious intellectualness. And his "criminality" was not something that sulked and sneered ... it was Western, the west wind, an ode from the Plains, something new, long prophesied. (10)

It is this critical thinking, or "intellectualness," that Kerouac's narrative most resists, preferring instead an "intelligence" whose objective is the Whitmanian virtue of comprehension rather than the Arnoldian virtue of critique. Dean's covetousness of eastcoast intellectualism actually reveals its status as a posture. Dean desires not a manner of 
cosmopolitan inquiry, but a set of tricks. What makes Dean different from the New York friends is his lack of interest in winning arguments, or in even acknowledging disagreement. He is "the west wind" both because he has no localized home—Dean "was actually born on the road" (3) - and because he has no firm perspective through which to critique the continent that, following the logic of counter-urrban cosmopolitanism, is his default home.

Dean is enamored of sophistication- - "a young jailkid all hung-up on the wonderful possibilities of becoming a real intellectual" (6). He understands that the moves that make up intellectual life potentially have a useful street-value. Dean thus easily learns to "talk in the tone and us[e] the words ... that he had learned from 'real intellectuals,", revealing east-coast cosmopolitanism as routinized and superficial. Because the onus is not on one's ability to negotiate local affiliations, but on his ability to sound a certain way, Dean uses intellectual moves as though they are driving moves. Through Dean, Kerouac reveals New York cosmopolitanism as a form of provincialism, an affect that normally needs oriental couch covers and New Yorker magazines in order to function. Dean is never indoctrinated as an east-coast cosmopolite; he merely adds its "terms and jargon" to the manic pastiche of gestures that passes for his personality (6). His initial allure is thus, according to Kerouac, his ability to mobilize the scavenged trappings of sophistication. ${ }^{111}$ Devoid of self-reflection, beyond humiliation, and unaware of his greater naïveté, Dean is a desirable alternative to the east-coast sophisticates. A road-wary trickster is especially desirable to a narrator who, as I will discuss in the following section, is ill prepared for the local dilemmas of road travel.

In his attempt to point up the resemblance between the cosmopolitan detachment 
and the provincial bias of New York, Kerouac attracts obvious criticism. Most famously, conservative mid-century critic Norman Podhoretz renounces Kerouac's fiction as an affront to New York intellectualism. ${ }^{112}$ Podhoretz lambastes Kerouac and the rest of the "Know-Nothing Bohemians" as barbarians and philistines who are "hostile to civilization" and amenable only to "primitivism, instinct, energy, "blood"” (307-308). As pushovers for "mystical doctrines, irrational philosophies, and left-wing Reichianism," the Beats have none of the discerning, intellectual rigor of either Podhoretz's cohort or previous generations of homegrown American bohemians (308). For instance, Podhoretz contrasts the Beats with the literary bohemians of the 1920s (who include Sherwood Anderson and Ernest Hemingway). The latter group, according to Podhoretz, is characterized by its "repudiation of the provinciality, philistinism, and moral hypocrisy of American life" (307). Where the "typical literary figure of the 1920s was a midwesterner who had fled from his home-town to New York or Paris in search of a freer, more expansive, more enlightened way of life," the mid-century bohemian writer does not seem to have the least interest in running away from provincialism (307). I agree with Podhoretz that the Beats do not follow the standard trajectory of moving from rural zones to urban, cosmopolitan zones. However, the Beats are not anti-intellectual. Or, more accurately, what looks like anti-intellectualism is, in Kerouac's fiction, a valid exposure of the provincial allegiances of traditional zones of disinterested intellectual culture. Kerouac avoids New York intellectualism by both avoiding New York and by avoiding the smug postures that accompany its intellectual crowd. In so doing, he avoids the fallacy that cosmopolitanism has a home base. 
As opposed to an exclusive urban-centered cosmopolitanism, the cosmopolitanism Kerouac seeks is inclusive, conversant with styles and spheres of interest that exist outside of the city. As competing literary sensibilities, both the urban and the counter-urban models are similar in that each is detached from any recognizably rural local affiliation. But the urban form alone consists of what Amanda Anderson calls "Arnoldian disinterestedness," by which she means a complex of postures and evaluative means that signify worldly cultivation. This mode stifles the "reciprocal intersubjective dimension" of cosmopolitan relations (110). In other words, being preoccupied with presenting one's self as one who is acquainted with "the best of what is known and said" in the world leads the Arnoldian urbanite away from the types of cosmopolitan relations that aren't merely the result of cosmopolitan self-presentation. Without this intersubjectivity, cosmopolitanism is simply a complex of knowledge and a pattern of isolated gestures that never facilitates exchange and that thus never actually absorbs any cultural traits to which the self-consciously "worldly" individual is not already congenial. Urban cosmopolitans thus attain disinterestedness, meaning that they do not transcend local affiliations so much as exclude them from their interest. The hyper-inclusion of the Kerouac model, on the other hand, implies that the cosmopolitan can be at home anywhere within the diverse American body politic, not just in those zones that contain likeminded cosmopolitans.

Kerouac's narrator in On the Road has the intersubjective self-reflexivity that makes inclusive cosmopolitanism possible. The opposite of disinterested, Sal is hyperexcited to be around "mad" people, the very type of people that exclusive cosmopolitans dismiss as uncultured. His motivation, not unlike Whitman's, is voyeuristic. Sal's 
observation of others activates his agency and encourages the behavior of "people who interest" him, as he has always "shambled after" them (8). He follows Dean Moriarty (Cassady) and Carlo Marx (Ginsberg) as they "danced down the streets like dingledodies," remarking with characteristic enthusiasm that "the only people for me are the mad ones, the ones who are mad to live, mad to talk, mad to be saved, desirous of everything at the same time, the ones who never yawn or say a commonplace thing" (8). This naïve hero worship glorifies the very "madness" that eventually betrays Sal. But, considering that Sal mentions in the opening pages of the novel that Dean eventually "put[s] me down ... on starving sidewalks and sickbeds," the hero worship takes a cautionary tone (11).

By the logic of Sal's cosmopolitanism, the goal is not to be "mad," but to be in the presence of madness. Ann Douglas argues that this voyeuristic subject position is Kerouac's enduring writerly modus operandi. The writer affects the position of the disinterested cosmopolitan in that he wants "to record rather than precipitate, to watch the fabulous, divinely inexplicable doings of a world he never made" (2007, xi). Though his novels do function as what Kerouac himself referred to as his "contemporary history record," the record differs from the documentary records of the Depression in that its object of study is madness and intimacy and not the site of intimacy's production (viii). Kerouac's ideal subjects are those who neither "say a commonplace thing" nor care too much about the common places they inhabit (On the Road 8). Due to this interest in mad subjects, Kerouac's relationship to locale might be considered insignificant or an authorial afterthought, especially since the manic living and omnivorous desire the Kerouac admires exists in the city as well as on the frontier. But, as I will discuss in the 
following section, Kerouac is interested in locale to the extent that the road itself can be considered a locale. Obviously, the road is a key mediating force in On the Road; it is a non-place-specific localizing force that determines where Sal is in relationship to his desires and who Sal is in relationship to where he is on the map.

\section{III}

As I've described in the first two sections, the process of enacting a counter-urban form of cosmopolitanism affords Kerouac a rarefied view of the contour lines among urban and rural provincial sensibilities in America. Therefore, though Kerouac's narrative techniques differ radically from Agee's documentary techniques, both do the work of depolarization. Agee's method of exposing false polarities, his self-conscious metadocumentary, differs vastly from Kerouac's fictional coming of age narrative. However, the two do share a point in common. Both achieve a defamiliarization of some key intercultural territory. Where Agee defamiliarizes the site of contact between the documentarian and his subject, Kerouac defamiliarizes the roads that connect urban and rural zones.

Rather than trying to find himself, Sal is in the process of getting away from himself. In the opening sentences of the novel, the reader learns that Sal has "split up" with a wife he never again mentions and that he has "just gotten over a serious illness that ... had something to do with the miserably weary split-up" (3). Putting this experience of being "split" behind him, Sal moves to "the part of my life you could call my life on the road" (3). This post-breakup road-trip format has become a common trope of contemporary road prose; William Least Heat-Moon's memoir Blue Highways (1983) comes to mind. But, where the bachelored Least Heat-Moon uses his split as an occasion 
to explore the scenic byways of America, Sal chooses the biggest, straightest

thoroughfare on the pre-interstate highway map (Blue Highways 1). ${ }^{113} \mathrm{He}$ is not seeking solitude, but a much shorter path to another identity.

In his initial contact with the road, Route 6, Sal's boyish expectations are foiled. The standard masculine mythos of the "open road" and the American "wilderness" are nowhere to be found. In other words, Kerouac follows Agee's advice; he gives "the street in its own terms," suggesting that the literal, transcontinental lines that link Americans are not made of transcendental terrain, but of generic pavement that is indifferent to the fate of men. The material that links provincial and cosmopolitan zones in America is thus shown to lead nowhere in particular, which is to say that the new type of roads emerging in the mid-century need travelers who are not linked to idealized notions of mobility.

Sal's initial expectations are a veritable index of idealized notions of mobility. He plans to hitchhike west in a barrage of virile gusto. He winds up failing miserably and buying a bus ticket to cover his losses. Sal thus begins a process of "discovering" that the West that he had learned about in school does not exist. As I will examine in the section following this one, the actual mid-century West is shallowly self-referential and nostalgic. It threatens Sal's fantasy of himself and his gang as the inheritors of the "outcast" group identity made popular in nineteenth-century local color writing about the West. ${ }^{114}$ The other kind of nostalgic posturing Sal discovers in the West, stylistically the polar opposite of local color nostalgia, is an atavistic modernist cosmopolitanism (in the character Roland Major). Sal's reaction to these two disparate postures (frontier masculinity and modernist cosmopolitanism) reveals a key objective of On the Road: to erase nostalgic regional markings and to recommit cosmopolitanism to the job of 
increasing the frequency and gravity of cross-cultural contact. Kerouac's critique of both frontier nostalgia and modernist disinterestedness indicates that the goal of delocalization is to occupy neither identity. The goal, instead, is to never actually need to arrive at a stable identity. For the reader this goal is made manifest in Sal's manic gropings toward the horizon. His affection for what is immediately perceivable, his unsophisticated impersonations of flight— - seen in frantic non-sequiturs like "Yes, zoom" (182)— constitute the stylistic innovations in literary realism realized by Kerouac's admittedly unrealistic agenda.

Kerouac's objective is revealed through his narrator's misunderstanding of the road itself as an artery of effortless conveyance. Much like the Mississippi River in Adventures of Huckleberry Finn, the road in On the Road becomes a key terrain upon which the novel's narrator is allowed to experience the world as it is unmediated by social codes. ${ }^{115}$ It is a multi-faceted terrain: a cultural symbol of the postwar American's freedom to circulate independent of any official agenda, a democratic thoroughfare that privileges private conveyance and public transportation alike (though the former more so than the latter), and the basic path of late 1940s intercontinental regional migration. It is also, as the successor of Huck's river, a symbol of infinity and propinquity, conceptually threading the disparate regions of the continent into some form of contact with one another. The road is a means of escape, a source of cultural literacy, a producer of community, and the approximate locale of the new New World sublime. Though Sal's road never becomes a utopic space from which to critique the surrounding society, as Huck and Jim's river becomes, it facilitates Sal's learning experience, becoming the 
center of his burgeoning awareness of an America wherein local affiliations are disappearing. ${ }^{116}$

But Kerouac does not simply replace the river with the road as the emblematic thoroughfare of masculine escape. Sal's shoddy preparations to get away from his middle-class safety leave him in a perpetual state of "vaguely planning." Unlike Huck, whose one proficient literacy is the river (he reads it, predicts its behavior and its capacity to facilitate clean escape), Sal has no hands-on familiarity with the road. The opening pages of the novel demonstrate a disconnection between the abstractions of travel that Sal has learned from reading books - its cartographic apparatus and its romantic significance - and the actual pavement that he must carry himself across. After "poring over maps of the United States" and "reading books about the pioneers," Sal falls in love with a "long red line called Route 6" (12). He decides at leisure to hitchhike the entire length of this virtual contour line across America. But in order to get to Route 6 from Paterson, New Jersey, Sal finds that he has to hitchhike north up the entire length of the Hudson Valley to the Peekskill Mountains (12). When he reaches Route 6, Sal finds it black, deserted, and indifferently awaiting a frightening thunderstorm that comes down Bear Mountain to soak him. A driver sees Sal sulking and belches that "there's no traffic passes through 6" (13). This gruff bit of local knowledge punctuates Sal's colossal navigational gaffe and his naïve romanticization of the road as a simple connecting line. What he thought was a main artery of America is actually indifferent pavement whose origin in the East offers none of the brassy send-off he'd fantasized would score his departure. Defeated, Sal rides the bus back to New York. To add insult to injury, Kerouac 
puts him with "a delegation of schoolteachers" whose "chatter" locates him as a besieged schoolboy who has failed to flee the clutches of "sivilization" (13).

Eventually, both roadmaps and pavement, the abstract and concrete representational extremities of the road, fail Sal. The novel's primary terrain thus loses its universalizing and particularizing edges alike. This prohibition against extremes ostensibly blocks the road from replacing the river as a key American metaphor. The road is unavailable as both a large-scale literary symbol and a localized modernist "thing." It is strictly perceptual, deconceptualized by Sal's discomforting initial experience with it. It thus becomes, at least in Part One of On the Road, the location of Sal's learning process. As Sal thinks aloud on the page (exposing his missteps as well as successes), the road is slowly delocalized as a concept.

Sal is the opposite of a pioneer. His complete lack of local knowledge and prior ground-level experience with the road leave him incapable of territorializing, historicizing, or locating in any traditional sense the continent he is soon to cross and recross. He knows maps well and travels west not to discover territory or the promise of future prosperity, but to experience life as one who is other than middle-class. His lack of local knowledge is not a sign that Sal needs experience, not an indication of the kind of experience that Sal will have, but an indication of the kind of comprehension Sal prefers to glean from texts. Sal is a bad navigator not because he doesn't read atlases, but because he reads atlases for emotional and not semantic content. For instance, when reading his maps and pioneer books in his aunt's apartment, Sal does not retain the information and explanations he finds in them. Instead, he commits himself to "savoring 
names like Platte and Cimarron" (12). Sal prepares himself for travel by learning the names of rivers, treating names themselves as though they have topographic contours.

For instance, in response to Major's histrionic invitation to savor cosmopolitan vistas - "Ah, Sal, if you could sit with me high on the Basque country with a cool bottle of Poignon Dix-neuf, then you'd know there are other things besides boxcars"- $-\mathrm{Sal}$ explains, "It's just that I love boxcars and I love to read the names on them like Missouri Pacific, Great Northern, Rock Island Line" (41). This declaration of love for rail-line names stenciled onto boxcars, like the "savoring" of river names, bypasses the masculine ethos of pioneer and industrial America, of the territorializing efforts of those virile men who moved West and erected a nation. Such efforts culminate for Sal in the names of the rivers and states that their records and companies sustain.

This is the new surface, or new interest in surface, that Kerouac's delocalizing strategies prepare the way for. The boxcars feature decontextualized language whose emotional meaning is derived from the catalogue of places that Sal passes in a flash, a catalogue that recounts and verifies one's position as "on the road." The very scale of boxcar language, the size of its letters, likewise excites Sal. It presupposes all of America as its intended audience. It also implies a horizontal relationship with a reader running at equal speed on comparably endless rails, released from inertia and the profound inactivity of stable homes and specific soil. Boxcar language transforms the names of states into moving, unruly, shuffling letters on an America-sized map. In this way, Sal answers the betrayal of the apartment road map by finding the living cartography of America, wherein the signifiers of place know no borders. Where the localized world of blackened arteries at the foot of Bear Mountain was ominous and threatening, here it is playful and inviting. 
The inclusion of "Rock Island Line" in Sal's catalogue evokes the very place where, earlier in the novel, Sal crosses the Mississippi River. Crossing from Rock Island, Illinois to Davenport, Iowa, Sal notes, "for the first time in my life I saw my beloved Mississippi River, dry in the summer haze ... with its big rank smell that smells like the raw body of America" (15). He assumes an automatic ownership he never feels for the road (especially not while driving), ${ }^{117}$ counting the river as "my beloved," an ownership that indicates that river literature is necessary to the development of Kerouac's new narrative of lighting out. As the location of well-seasoned and prepared myths of the American landscape, the river represents that manifestation of liberty that, when applied to the road, duped Sal at the foot of Bear Mountain. Noticing its "big rank smell that smells like the raw body of America," Sal indicates that the river has become a grand memento mori, to be acknowledged and passed over (15). Thus Kerouac demonstrates the pedagogical and literary historical implications of road travel by throwing an ignorant narrator onto indifferent pavement. In the following section, I will discuss how Sal's ignorance of the road is compounded by a related ignorance of what actually constitutes the mid-century American West and what Sal does to compensate for the dual betrayal he feels at being met with commercialized frontier culture.

\section{IV}

In On the Road, Kerouac displays a deliberately post-New Deal frontier economy, an economy of free market "revitalization" efforts. ${ }^{118}$ Kerouac's West is overrun by a renovated "Wild West," an unsavory consumer spectacle of repackaged frontier lore supplied by corporate sponsored chambers of commerce. This is not the wilderness alternative to east-coast sophistication that Sal hoped he'd find. As is always the case in 
Kerouac's world, the goal is a disappointment when compared to the journey. Sal's journey to the West concludes with "'" $t]$ he greatest ride in my life," an all-night ride across the prairies of Nebraska on flatbed truck, under a tarpaulin with an agreeable band of fellow male hitchhikers (24). The truck is driven by two fun loving brothers whose job it is to transport farm machinery from Los Angeles to Minnesota. On their trips back, "they picked up everybody on the road" (26). Everybody includes "farm boys" from Montana and North Dakota following the harvest, "city boys," high school football players, from Ohio hitchhiking to L.A. for fun. Finally, there was Mississippi Gene, who is traveling with a silent blonde boy who "seemed to be running away from something" (25). Sal loves Gene, partially because he helps the boy run from his trouble and partially because he is happily delocalized.

By "crossing the recrossing the country every year ... only because he had no place he could stay in without getting tired of it because there was nowhere to go but everywhere," Gene exemplifies a kind of ideal subject position for Sal (28). Having "nowhere," and thus "everywhere," to be emerges as Sal's desired condition. As with the "Everything belongs to me because I am poor" motto, Gene's condition of being "everywhere" because he has "nowhere" to be once again allows Kerouac to assert the wealth of the disenfranchised. This is different from implying that poverty is an identity category in that the identity of Gene and, periodically, Sal comes from their movement.

However, Sal does attach racial tags to Gene and thereby suggests that his status as roving hobo is akin to status as a racial minority. With no shortage of problematic connotations, Sal announces that there is "something of the wise and tired old Negro in him" (28). But this announcement is less a conflation of race and class as it looks. 
Considering the negation of place ("no place" and "nowhere") in Sal's description of a character whose first name is ostensibly the name of an American state, Sal's racialized description of Gene contributes to his delocalization of his identity. The "Mississippi" in Gene's name, like the "Negro" Sal's description of his demeanor, is an empty signifier. It presumes to "locate" the distinguishing characteristics of one who has literally been in motion for years on end. More than any self-conscious region or self-conscious racial figure, Gene represents the ideally "wild," evasive figure that Sal hopes to find in the West. He finds him, instead, in the liminal of the flatbed truck, a simultaneous nowhere and everywhere.

Accordingly, Sal disapproves of what he finds in Cheyenne, namely "Wild West Week":

As the truck reached the outskirts of Cheyenne, we saw the high red lights of the local radio station, and suddenly we were bucking through a great crowd of people that poured along both sidewalks. ... Big crowds of businessmen, fat businessmen in boots and ten-gallon hats, with their hefty wives in cowgirl attire, bustled and whoopeed on the wooden sidewalks of old Cheyenne; farther down were the long stringy boulevard lights of new downtown Cheyenne, but the celebration was focusing on Oldtown. Blank guns went off. The saloons were crowded to the sidewalk. (32-33)

Sal immediately recognizes "to what absurd devices [the West] had fallen to keep its proud tradition" (33). ${ }^{119}$ The localizing devices are capitalist, contrasting with the federal programs of a decade earlier, whose localization techniques were designed to produce a living record of the region and thus to revitalize that portion of the bold politic. The 
legions of WPA artists and documentarians whom Kazin and Stott saw scouring the West in the 1930s have, by the time Sal reaches Cheyenne, disappeared and along with them the promise of New Deal welfare. What replaces them are "fat businessmen in boots and ten-gallon hats." In addition to their obviously vast political differences, the key difference between New Deal and capitalist versions of localized revitalization lies in the audience's position in the production of regional identity. In theory, the audience and producer of WPA work is the same, since all WPA labor (that of the artist and of the bridge-builder alike) is compensated the procedural labor of autonomous community building; everyone pays for revitalization and everyone is paid. ${ }^{120}$

The audience of Wild West Week, on the other hand, is positioned as a set of consumers. The irony is that they, too, constitute an autonomous community reproducing itself. Businessmen pool together into raucous crowds of money-spenders siphoning libations from Oldtown saloons. Their boots, ten-gallon hats, and wives in cowgirl costumes produce the signs of a "Wild West" landscape. But they are not producers in the same sense that WPA citizens are producers. They are barely even citizens, since their relation to the region (and by extension the nation) is mediated strictly by capital. They are in the West only insofar as they can buy that fact. Local affiliations unmediated by capital are things of the past. In the present of the early 1940s, there are only the performances of prior models of affiliations. Being in the Wild West is a matter of participating in a special week-long occasion, rather than of inhabiting a special place. Even the location of Wild West Week, in "Oldtown" rather than in Cheyenne's actual downtown, casts its projection of "Western" identity as part of a spectral past. The businessmen like the saloons and boots and the rest of it because they can afford to, not 
because these things have any bearing on their identities as Cheyenneans. They aren't even Cheyenneans, especially not to Sal, who sees them in their single unit as a crowd in the same way Guy Debord sees the society of the spectacle at large: "a negation of life that has invented a visual form for itself' (Debord 14).

The "Wild" of "Wild West Week" is thus supremely ironic. When Sal remarks that the "fat burpers" are "wild as ever," he does not mean they are feral or uncultivated, but that they are temporarily unrestrained from their middle-class proprieties. Even Sal goes a little "wild," spending five of his remaining seven dollars buying drinks for himself and Montana Slim. One is "wild" in Cheyenne to the extent that he can afford to be, just as one is "Western" to the extent that he can dress appropriately. Every condition is reduced from an expression of localized identity to a consumer exchange operation. For instance, when Montana Slim emerges from a saloon with a postcard he has just written to his "Paw," he makes the "strange request" that Sal "find a mailbox and put it in" (34). It is clear from this strange request that, during Wild West Week, even intimate familial communication threatens to join the ranks of impersonal economic exchange. Regardless, Slim's handwritten note is "tenderly polite" (34). When juxtaposed against the histrionic texts that make up Wild West Week, this note resonates with a kind of singular authenticity, the kind of honesty that is missing from the new Wild West. Of course, this rare authenticity is found only on a type of surface (in this case a postcard) that is designed to travel cross-country. Writing is once again represented as ambulatory, the one site of authentic expression in the West.

In short, the Wild West exists for Sal not in the West but on the flatbed that heads west over the prairie. In motion, "farm boys" and "city boys" alike yell back and forth 
their stories of misadventures in rural and urban American life. Doing this while speeding toward the West, these tender utterances of migrating men symbolize the frontier freedom that no longer exists. In setting their voices into overdrive, Kerouac delocalizes the local knowledge of the personal narratives that make up the colorful characters that an easterner traditionally expects to encounter in the West. In the same way that state names on boxcars delocalize the boundaries separating states, the place-based reminiscences of the hitchhikers delocalize the boundaries separating the personal experiences that contribute to individual identity.

Unlike the businessmen in the geographical West, the men and boys with whom Sal has lain across the prairie have rich pasts and futures. Their stories are varied and of a piece with Hart's “The Outcasts of Poker Flat” and Cather's Otto Fuchs, rough-andtumble hired men with big scars and bigger hearts. They are the very Western types whom the fat businessmen ape, but who are no longer anchored to their eponymous regions.

The West itself is no longer a recognizable region. It has been lost to private "revitalization" programs that sell frontier local color in exchange for the creative agency of its citizenry. Frontier fraternity and liberty, as exemplified by Mississippi Gene, have been evacuated from "the West." Even the stable signifiers of "Westerness" differ radically from Sal's preconception of the West. Chad King (aka Hal Chase), is described as the Western visage - “the beauty and grace of a Western hotshot who's danced in roadhouses and played a little football" (37-38). He is also an anthropologist specializing in "Plains Indians" (37-38). ${ }^{121}$ This ironic professionalization of the "Western hotshot" into one who studies, rather than violently subdues, Native Americans further simplifies 
the disappearance of traditional local affiliations in the American West (in this case a good kind of disappearance).

Even when Sal finally reaches his Denver cohort, it is thoroughly anti-rugged and stratified by a "war with social overtones," a petty social status feud between those (i.e., King and Major) who are responsible and gainfully employed and those (i.e., Dean and Carlo) who are unreformed bohemians and "underground monsters" (39). In the end, then, the idea that the West is still Wild is replaced by the depressing realization that the same petty social distinctions Sal thought he was fleeing from exist also in the West. This omnipresence of what is undesirable, as I will discuss in the following section, leads Kerouac to interrogate the available forms of literary cosmopolitanism available to midcentury writers who want to expatriate themselves from the enclosure of modern capitalism. Kerouac provides his protagonist with two choices: bohemianism or Eurocentric modernism. Both of these choices presuppose an unappealing indifference toward the sources of undesirable social distinctions. In the following section, I will look closely at how Kerouac evokes the contrast between these two lines of flight from commercial realities, ultimately demonstrating that the effort to parse the virtues and limitations of each alternative actually produce a new, post-New Deal method of negotiating the ethnic and class divisions still haunting the American West (divisions that are obscured by a prevailing logic that designates the urban East as cosmopolitan and the frontier West as provincial).

\section{V}

Sal wants to be affiliated with bohemians because they are neither conspicuously attached to a specific locale (i.e., provincial) nor pretentiously worldly (i.e., 
cosmopolitan). The problem is that his economic status establishes his affiliation among the "professional" strata of the Denver gang. His first and most important interaction with another writer occurs within this stratum, with Roland Major, a pretentious cosmopolitan Europhile who comes across as a wet blanket in the West. Major's cool sophistication and smug leading questions provoke Sal, producing awkward moments that expose Sal's technical limitations with argumentation. When Major explains that "there are other things besides boxcars," Sal responds, "I love boxcars and I love to read the names on them like Missouri Pacific, Great Northern, Rock Island Line” (41). A naysayer of naïve bohemianism, Major is the mouthpiece of cosmopolitan modernism. He embodies the exclusivity that Kerouac's formal politics so aggressively counteract. A “Hemingwayan short story" writer trying to live a Parisian literary life amid broke bohemians in Denver, Major is a caricature of the wrong kind of cosmopolitanism. He refuses to allow unwashed Beats into his "swank apartment," preferring instead to savor old wine in the company of his own fictional creations. Sal's unflinching naïveté in his response to Major does not (nor is it designed to) convince the high-art aficionado to love boxcar language. Beat narratives never argue with nor, in contrast to Agee, actively denounce a competing style. Instead, they flail their tender and illogical principles without blushing. This innocence, which in the presence of sophistication looks like sophomoric amateurism, originates here in Sal's defense against (rather than reaction to) sophistication. Major's brief but meaningful presence in the novel brings to the surface the mode of transatlantic cosmopolitanism, based on detachment and sophistication, that Kerouac and the Beat project at large hope to eradicate from American letters. 
Major's European cosmopolitanism is a complex of techniques for detachmentincluding disinterestedness, objectivity, critical reason, and aesthetic free play—that allows one a certain manner of distance from one's subject. A detached cosmopolitan, Major makes believe that he transcends situatedness. But situated in the American West, Major has to defend his cosmopolitan credentials. He dons hyper-particularized postures of cultivation, calm, and aloofness that deliberately disassociate him from the undesirable American West. As an expatriate marooned in Denver, writing stories about expatriates marooned in Denver, Major distances himself from the real conditions of his life. Indeed, his postures of aloofness constitute the whole of his character. His paradoxical cosmopolitanism, as one simultaneously so worldly and so limited in the attitudes through which he can express this worldliness, results in a confused Eurocentrism. Major announces a Hemingwayesque dislike of "arty types" but is himself nauseatingly arty. In short, Major exemplifies how foolish detached cosmopolitanism looks within the context of actual community building.

But Major is more than a straight man. His mock invitation to Sal, to "sit with me" in France, is a counterpoint to the sincere provocations that propel Sal west. Major, like Sal a struggling writer, fails precisely where Sal succeeds. His calls for companionship, for someone to "sit with," are always fictional, and therefore for Kerouac can never constitute good fiction. ${ }^{122}$ His affinity for old-world culture, filtered through his disdain for "arty types," is sustained in a fiction that is content to be dissatisfied. His work in progress is, like Sal's, "about a guy who comes to Denver for the first time" (41). But, whereas Sal's is about a man elated to be in the West, Major's protagonist is a besieged humanist named Phil who, alongside a "traveling companion ... a mysterious 
and quiet fellow called Sam," seeks a tolerable and suitably Eurocentric culture (41). Of course Phil finds only "arty types ... all over America, sucking up its blood" (41). This narrative of besieged humanism builds to a banal epiphany: "Sam, they're here, too," meaning that the wrong kinds of people are all over America (41). The same might also be said of Sal's America, just not by Sal. Indeed, one way to think of On the Road is as a novel about cultural failure in America as told by a narrator whose aesthetic sense doesn't recognize failure as such. The success of Sal's narrative then lies in its ability to lead by example, to model a way of seeing that precludes cosmopolitan disdain for humdrum America.

Major contents himself with a type of cosmopolitanism that looks like separatism. He never lends a hand to the Denver group's attempts to produce a desirable world, preferring instead his bubble of fantasy. On a weekend trek to the mountain, Sal and the gang spend an evening with high-end tourists watching Beethoven's opera Fidelio in a newly renovated "polished" opera house in Central City, Colorado. Central City is a former mining town turned ghost town that, like Oldtown in Cheyenne, the "Chamber of Commerce types of the new West decided to revive" (51). Walking to the opera house, Major declares to Sal, "just look at this old town. Think how it was a hundred ... eighty, sixty years ago; they had opera" (51). Major disregards the renewal efforts that have again produced opera in Central City, taking instead the Miniver Cheevy perspective of always thinking of the value of the past. Though Sal is no champion of corporate revitalization projects, he has at least learned how to see contemporary America uncolored by romantic conceptions of its past. He also knows how to score contemporary America with creative expression. In response to Major, Sal repeats Major's own 
epiphanic slogan: "but they're here" (51). Sal's ability to salvage some street-value for even Major's labored imitations of Hemingway trumps Major's inert aestheticism, which renders him a symbol of stagnant irrelevance.

Kerouac dramatizes the burgeoning cultural agency of the Denver bohemians in direct contrast to Major's stationary aestheticism. After the opera, Sal and the others work to transform a Central City "miner's shack" into a suitable party locale (52): I took off my duds and joined the boys in the cleaning. It was an enormous job. Roland Major sat in the middle of the front room that had already been cleaned and refused to help. On a little table in front of him he had his bottle of beer and his glass. As we rushed around with buckets of water and brooms he reminisced. "Ah, if you could just come with me sometime and drink Cinzano and hear the musicians of Bandol, then you'd be living. Then there's Normandy in the summers, the sabots, the fine old Calvados. Come on, Sam," he said to his invisible pal. "Take the wine out of the water and let's see if it got cold enough while we fished." Straight out of Hemingway, it was. (52-53)

This scene exposes Major's inflexible cosmopolitanism alongside bohemian adaptability. Major's sophistication is finally exposed as parasitic, a type of reminiscence that is reducible to childish petulance. His vision of the past is composed in the very space cleared by the diligent efforts of those whom Major thinks culturally lazy. Stationary amid hurrying buckets and brooms, Major muses about "Cinzano," "sabots," and "Calvados." His proclivity for these hyper-particularized European liquors (Cinzano is a brand of Italian vermouth and Calvados is an apple brandy from the French region of the 
same name) and garb (sabots are wooden shoes) is represented here as a roadblock in the way of actual community building. Eurocentric local knowledge, in Kerouac's estimation, is thus toe-stubbing bric-a-brac in the miner shacks of the new bohemian West.

Even the footwear Major alludes to is impractical. Sabots are the western European name for the wooden shoes worn over other footwear for the purpose of navigating sodden ground. This reference calls to mind Sal's equally curious choice of footwear: cloth huaraches, which Sal explains were "not fit for the rainy night of America” (13). Both Sal and Major have conspicuous affinity for shoes that signify cultures not their own, a shared interest in transcending their respective affiliations via physical points of contact, their feet. But Major's reference to European shoes contrasts with Sal's romantic attachment to Mexican footwear. Where sabots would be strictly ornamental in the paved world of On the Road, would in fact prohibit foot travel, huaraches are designed for foot travel. Both Major and Sal seem to acculturate based on tenuous affection for cultures they exoticize. However, Sal's relationship with his moccasins does not proceed without levity. When lampooned by his flatbed brethren, Sal concurs that "they were the silliest shoes in America" (30). But at least Sal has a utilitarian excuse for his otherwise exoticist interest in Mexican footwear: "I didn't want my feet to sweat in the hot road" (30). Sal's acculturation is always in the service of movement, of facilitating his search for delocalized Americans. Major's affection for Europe, on the other hand is strictly nostalgic and derivative: "Straight out of Hemingway it was," Sal says of Major's one-man show of companionship, which contrasts with the intersubjectivity that comes with Sal's inclusive version of cosmopolitanism (53). 
Though Major's efforts to imagine himself as a deracinated Hemingway hero seem to have more of a demonstrable conclusion than does the Central City party Sal and others construct, the part does have a cultural function. Because they are not governed by the stationary principles of Major's retrogressive amusements, and because they are not aimed at any preconceived concepts of socialization, the party renders the principles that govern "partying" indistinguishable from the particularities of the experience that lets one know he is at a "party." For instance, Sal observes that "[t]here was no music, just dancing. The place filled up. People began to bring bottles" (53). By dancing without music, the partiers initiate an action normally considered to be reaction to some external rhythm, some music. Though it sounds like I'm making much ado about a seemingly throwaway observation, dancing without music is a dramatization of the delocalized identity Sal is attracted to. The dancers suggest that group of people who inhabit makeshift spaces of their own creation will will action into being before there is any legislating form to regulate the gestural limits of the action. Like the novel itself, this party divorces itself from literary historical precedents and patterns of thinking about cultural difference in America. In direct contrast to Major's expat-cosmopolitan sensibility, which features "musicians of Bandol" and specific kinds of alcohol, Sal's party is evacuated of the musical accompaniment that dictate dance moves. It is also freed of sundry specifics; Kerouac abstracts the nature of libations and attendance into "bottles" and "people." Even the miner shack itself disappears as a localizing force-it is the "night" that gets "more and more frantic," not any specific place (54).

But, as all parties have their problems, this cultural ideal is doomed. Though the Central City party delocalizes its members and expels nostalgic cosmopolitanism from 
the novel, it also eclipses the labor of its own creation. As everything drifts into the abstract (anonymous people, "bottles" of nonspecific alcohol, undetermined dancing, the "night"), Sal is seized by the same crippling failure of perception set upon him during the disastrous encounter with the abstract "red line" of Route 6. As a space of pure celebration, the mining shack is disorienting. In much the same mood as the realization that Route 6 is made up of crude materials that don't correspond to his excitement about it, Sal realizes that the party is "a great big fraternity-type party ... with banging beerbottles and roars" (54). In other words, what was momentarily sublime is now ridiculous. Teenage opera house ushers, who did not help create the party atmosphere, "just grabbed girls and kissed them without proper comeons" (54). The life of Central City itself is anthropomorphized in a bawdy epicurean character with the ironically localized name Denver D. Doll. He greets everyone with the same well wishes, "Merry Christmas" and "Happy New Year, m'boy" (though it is summer). These greetings conflate all types of celebration into one cosmic holiday party that has no corresponding occasion. Though it seems as though Sal would welcome such a happy delocalization of the concept of celebration itself, Denver D. and the ushers rope Sal back into the real world. They reassert a central theme of the novel, that the labor of production, or the journey to the goal, is more valuable than the product or goal.

Kerouac's reason for subverting Sal's good time in the West is clear here in a way that it isn't in the Bear Mountain episode. The party fouls of Dever D. and the ushers remind Sal that delocalized identity must never take root. The Central City party amounts to little more than a reminder that Sal is an ambivalent member of a privileged class, a class that inhabits impoverished shacks for amusement. This is more troubling than the 
previous reality check. At the foot of Bear Mountain Sal at least looks like a child of crisis, despite the fact that he can afford to (and does) take a bus to Chicago the same night. In Cheyenne, Sal is an indignant observer of a touristic spectacle. As a reaction, Sal tries to adopt the perspective of the "Indians," on the side streets of Oldtown, "who watched everything with their stony eyes" (35). But in Central City, Sal can't help but see himself as one of the fat businessmen. Having rejected Major's cosmopolitan blinders, Kerouac's narrator has nowhere to retreat to when delocalization clears the way for the unwanted reminder of the fact that delocalized identity is a class privilege. Just as Sal's metonymic self-alignment with his favorite children of crisis - the migrant Mexicans whose shoes he wears and the stoic Native Americans whose eyes he shares - is an appropriation, the "heroic" transformation of the miner's shack is another capitalist renovation. It only serves those who are entitled to circulate to and from America's sites of poverty. In other words, Kerouac recognizes the complicity between post-New Deal capitalist revitalizations and his own self-interested document of vast America.

\section{VI}

This recognition is obviously disconcerting, as it means that social class is to some degree inescapable. The delocalized identity here, in the witching hour of Central City, seems to be an unrealizable fantasy. Indeed, in the same year that On the Road was published, Kenneth Rexroth issued an argument that the only way to transcend the markers of social class in America was not to delocalize but to "disaffiliate." Rexroth's article, "Disengagement: The Art of the Beat Generation" (1957), defines disaffiliation as process of "divorce" from American society (Rexroth 35). As exemplified by Rexroth, an elder Beat with whom Kerouac never sees eye to eye, and Gary Snyder, the disaffiliated 
artist is not delocalized but relocalized. His identity is the result of a deep acquired knowledge of Asian and indigenous American cultures. His goal is to enliven the indigenous energies of the American West by transforming the West into a version of the East. (I will discuss this Sino-centric West in the following chapter.) Kerouac tries his hand at disaffiliation in Dharma Bums (1958), the novel that follows On the Road, but even there Kerouac prefers to tell his story from a place of ignorance and naïveté rather than of deep acquired knowledge.

For Kerouac, as well as for Agee, the key to depolarization in American is not divorce, but a form of marriage. Agee marries the documentarian to his subject, as one merges into the position of the other. In the process, Agee exposes the otherwise hidden evaluative processes that lead one to see another as poor and yet another as wealthy. He makes visible the resemblance among the stationary materials that add up to one's identity, and thus he defamiliarizes the evaluative process. Kerouac disengages his characters from their material reality, setting them in motion before taking stock of their identity traits. This technique is necessary for Kerouac's narrator, whose objective is to tell the story of a poor kid (Dean) who has everything. Thus, in Central City Sal evokes fond mental arrangements of Dean and Carlo, arrangements that rescue Sal from his realization that he is just another member of a frat party. He knows that the real Dean and Carlo would "be out of place and unhappy" in the frat-party atmosphere and thus he envies and reveres them all the more (54). In a state of despair, Sal blends these two bohemian figures into a messianic figure sent to oppose the "mad drunken Americans" of Central City: 
They were like the man with the dungeon stone and the gloom, rising from the underground, the sordid hipsters of America, a new beat generation that I was slowly joining. (54)

The "man" of this simile is likely Florestan, the imprisoned hero of Fidelio, the opera Sal just watched. This coupling of Dean (the "west wind") and Carlo (the New Yorker), accompanied by the novel's first mention of the phrase "beat generation," suggests that the Beat agenda is to update the tragic solitude of classic imaginative literature, to make it match the needs of the mid-century male. In contrast to the makeshift nature of Central City, wherein old buildings are polished into opera houses and old shacks dusted into party halls, this Beat Florestan lives among "dungeon stone," foreshadowing Ginsberg's character's "Voice of the Rock" (in which mode he writes Howl). Carlo speaks in a mock prophetic voice that "'You'll all go flying to the west coast and come staggering back in search of your stone"' (130). ${ }^{123}$ Never one for wanderlust, Carlo insists, "Why don't you sit down and relax? Why do you jump around so much?" (130). His dedication to deskbound identity, married to Dean's transience, produces the very model of the rugged and committed artist that Sal had hoped to find in the West. Sal's status as a voyeur here thus encourages the production of the ideal delocalized identity. The ideal Beat, on the other hand, remains Sal, who wills such ideals into existence.

Putting the Cheyenne and Central City episodes into dramatic relief, this delocalized "sordid hipster" represents the fantasy Sal builds to compensate for having been duped by indifferent pavement. The difference between this and previous versions of Sal's inflated idealism is that its raw materials are actual people, its result something akin to a superhero. Where Sal's encounter with Route 6 is a corrective to his 
mystification of the road, Sal's mystification of Beat subjectivity is a reaction to the deflating fact that all the West really has to offer middle-class white boys is a place for frat parties. The party demystifies Central City, making it appear to Sal as what it has been from the start, another Cheyenne.

The heroic, if not also homoerotic, Dean/Carlo Superman image is obviously compensatory, Sal's way of saving himself the embarrassment about having adventured West just to erect a frat party. As the "underground monsters that season in Denver," Dean and Carlo represent something other than a flânuer looking for fun. Dramatizing their early friendship, Kerouac narrates a curious ritual that Dean and Carlo engaged in for hours, a conversation "machine" that "began with an abstract thought" and oscillated toward commonplace subjects that then folded back into even more tedious abstractions: “"When you borrowed that nickel to make up the check for the chicken-fried steaks ... you said "Carlo, this is the last time I'll impose on you," as if, and really, you meant that I had agreed with you about no more imposing"' (49). Ever the voyeur, Sal watches such exchanges, which rescue "abstract point[s] forgotten in the rush of events" (48). The couple does not counteract the chaotic and painful world around them with any traditionally masculine ideals like honor, courage, or endurance. They do not even argue. In fact what they do resembles the "consciousness raising" (CR) of the Students for a Democratic Society (SDS) movement. CR groups induced political ideas from intense discussion of personal experience, developing a set of politics out of the improvised discussion. ${ }^{124}$ Yet Sal still merges Dean and Carlo into a mythopoeic emblem of masculine virtue, a fantasy that grows from the confused tension between the lived experience of Sal's virgin voyage west and the abstract ideals that inspired the voyage. In 
the process, it becomes clear that Kerouac's essentialism is a byproduct of the fact that his novel is first and foremost a cautionary tale about the pitfalls of conflating the democratic urge to belong everywhere and the privilege to relocate at whim.

Consequently, Sal decides he needs a job, if only to, in the words of Lear via the epigraph of Praise, "expose thyself to feel what wretches feel.” In the following section, I will demonstrate how Kerouac's representation of Sal's attempt at a stationary work-life reveals that such empathy is impossible without the class and ethic divisions that Sal refuses to acknowledge.

\section{VII}

In the two major episodes of Part One that have to do with work (as opposed to the Cheyenne and the Central City episodes, which have to do with amusement), Sal becomes an armed night watchman in San Francisco and a migrant worker in the San Joaquin Valley. In the first episode, Sal assumes the role of a law enforcer; in the second he assumes the role of the law's victim. This combination of experiences perfects Sal's status as a delocalized narrator. In his attempt to root somewhere, to be some type of person, Sal's preference for being on the road, near his fantasies and away from actual people, becomes clear. For instance, when he is a night watchman, he randomly draws his gun on "queers" in bar restrooms and fantasizes about shooting out jewelry store windows. Reflecting on his burgeoning sociopathic behaviors, Sal declares: "The time was coming for me to leave Frisco or I'd go crazy" (73). All told, Sal's first transcontinental journey is a failure. He cannot embrace much more than his fantasy of Beat men who've shed their embarrassing class affiliations and rooted themselves to the stones of a West that doesn't actually exist. As he watches a drunken Roland Major (who 
has come to San Francisco to work for a newspaper) insult the father of Sal's old friend Remi Boncœur, Sal thinks,

How disastrous all this was, compared to what I'd written [Remi] from Paterson, planning my red line Route 6 across America. Here I was at the end of America—no more land—and there was nowhere to go but back. (77-78).

This is a far cry from the "nowhere to go but everywhere" omnipresence of Mississippi Gene. It is because Sal has friends that he cannot be Gene. More importantly, it is because Sal is so interested in getting from A to B, from the East of his past to the West of his future, that he fails in San Francisco. He is simply too goal-oriented to achieve the hobo sublime.

On his way "back," Sal takes up with Terry, a Mexican single mother with whom Sal spends the most time in one place, fifteen days in the San Joaquin Valley. The chapter presents all the proper setting and character ingredients of local color stories (85-102). The scenery is idyllic and the people rich in ways of thinking and feeling that are distinctive to their particular region. But the road keeps Kerouac from bringing the San Joaquin Valley plot, not to mention the romantic subplot with Terry, to fruition. For instance, walking hand in hand through "Arcadia," a residential suburb of Los Angeles, Sal and Terry are passed and jeered by high school students streaming down the road in cars. ${ }^{125}$ Sal explains:

I hated every one of them. Who did they think they were, yaahing at somebody on the road just because they were little high school punks and their parents carved the roast beef on Sunday afternoons? Who did they 
think they were, making fun of a girl reduced to poor circumstances with a man who wanted to belove. (88)

Now that Sal has abandoned the road to pursue a long-term relationship, he feels jeered at by more privileged travelers. In a sense, he has solved the problem he discovered in Central City, as he is no longer in the position of horizontal alignment with careless, tactless party boys. He is now the object of their derision, as high school kids on their way to a soda fountain berate and laugh him. Their freedom from accountability leads Sal to a stance as uncharacteristic as that of a gun-wielding security guard, that of hating innocent fun. Like the fraternity boys who ruined Central City, these passersby locate Sal against his will, situating him in an unfavorable reality. They also reinforce the fact that Sal does not want to be conversant with all spheres of interest. He wants to stay away from middle-class adolescence, an identity category dangerously similar to his old Paterson identity. What is ostensibly innocent fun—all they really said was "Yaah! Yaah! We won! We won!"- -becomes, when filtered through Sal's white guilt, an act of making fun of the less fortunate. His biting retort, that these students are spoiled by Sunday dinners prepared for them by their parents, demonstrates that to some extent Sal has known all along what he looks like to the foot traffic he zooms by from the Red highways of America. Kerouac finally in this scene reveals the class politics of the road, which his narrator has internalized so well as to assign motives and personal histories to carloads of happy teenagers. By taking up with Terry, Sal no longer has to feel the guilt of these class politics, as he becomes, so far as the high schoolers are concerned, another Mexican to pass by. But this temporary relief from class guilt only increases the problem, as Sal is 
not a Mexican and has no intention of assuming the local dilemmas that it would mean to live life as a Mexican.

Nevertheless, Sal enjoys his temporary affiliation with Terry. When he and Terry later run into the same teenagers at a soda fountain, Sal imagines that "all the kids ... saw that Terry was a Mexican, a Pachuco wildcat; and that her boy was worse than that" (89). Terry has a son, but he is not with her and Sal at the soda fountain. Her "boy" here is Sal, who enjoys being in white America with a Mexican. The reference to "Pachuco wildcat" refers to the Mexican subculture involved in the recent "zoot suit riots" in LA. This is a typical move, as Kerouac often aligns his narrator with ethnic identities that, to middleclass suburban kids, seem dangerous. In the novel's most infamous passage, Sal actually claims that he is a Mexican: "They thought I was a Mexican, of course; and in a way I am" (97). The "way" in which Sal is a Mexican is through the very eyes that he has abandoned, those of white teenagers and those of law-enforcing white men.

In Sal's world, one becomes ethnically or racially "other" when he no longer looks at that other but looks out from her perspective. As a "Mexican ... in a way," Sal "forgot all about the East and all about Dean and Carlo and the bloody road" (97). He plays father to little Johnny while Terry sits "mending clothes"; he becomes "a man of the earth, precisely as I had dreamed I would be, in Paterson” (97). Playing Circe to Sal's Odysseus, Terry transforms Sal from a wandering traveler into a rooted, if not domesticated, figure.

When Sal finally abandons Terry, it is not because she is Mexican and/or he is white, or any other reason based on race or ethnicity. He leaves because his staying threatens to turn Terry into a reified peasant, a figment of Sal's fantasy of becoming "a 
man of the earth." The rooted existence Sal has with Terry is always going to be exploitive. Even if Sal does all the right things a father and husband could do, he would still look like he "went native," like a white kid who'd hatched some plot in his aunt's apartment to go west and become a man of the earth. In sum, the Terry chapter and the security guard chapter (the two longest chapters of the novel) are seemingly anomalous episodes of rootedness that actually sharpen the contrast between Sal's ideal of delocalized identity and the very stabilized places, occupations, and identities that these two chapters have him assume. Sal says things like "I am a Mexican" because the language and conditions of stable observation are foreign to him. As someone with the proclivity to observe motion and observe while in motion, or "shamble after" what interests him, Sal brings to the surface the fact that in order to sound sophisticated or correct regarding racial and ethnic distinctions one's observations must be buttressed to some extent by identity categories that Sal can't help but see as fluid.

This is why, when in a bind, Kerouac creates confused iconic figures like the Beat superman. He has no idea in which identity category to place the emerging Beat generation. This is why Sal must imagine Beat Supermen. While Sal's efforts to not fall into identity categories come across as patronizing, Kerouac's effort to present a narrator who tries and fails to be "colorblind" confirms the presence of a hierarchy of those who are authorized to speak about identity categories. As a white man seeing America for the first time, Sal's perspective is clearly feckless. His naïveté places him far down on the hierarchy of racial enlightenment. By exposing Sal's low position on this hierarchy, Kerouac reveals the structure of legitimacy that accompanies the emergence of identity politics. Indeed, as I discuss in the following section, Sal's obsolescence, and possibly 
also the obsolescence of the mid-century white male explorer, is foreshadowed in the final episode of his first circum-continental road trip.

\section{VIII}

In the closing pages of Part One, as Sal is 365 miles from his aunt's home in Paterson, he meets "the Ghost of the Susquehanna," an eccentric old white man walking west along the Susquehanna river. The old man insists he is walking east and that he is "headed for Canady" (105). The ghost of the Susquehanna is "a semi-respectable walking hobo," a demystified and particularized old man. In this sense, he stands in stark contrast to the mystical old men and supermen whom Sal imagines in Central City. ${ }^{126} \mathrm{He}$ is not demonstrating some mystic truth by walking in the opposite direction of his proposed destination. He is simply confused about which direction he is walking in, and his remarks enter into the story not as wisdom but as misunderstanding. Sal names him "ghost" because he "haunts ... the entire Eastern wilderness on foot" (104). Though Sal and his traveling companion try to explain to the "ghost" that he is heading the wrong way, the old man's confusion is never corrected. Instead, the ghost inadvertently corrects Sal's misconception that "all the wilderness of America was in the West" (105):

No, there is a wilderness in the East; it's the same wilderness Ben Franklin plodded in the oxcart days when he was postmaster, the same it was when George Washington was a wild-buck Indian-fighter, when Daniel Boone told stories by Pennsylvania lamps and promised to find the gap, when Bradford built his road and men whooped her up in log cabins. (105)

In other words, there is as much American wilderness in Sal's own backyard as there is in the West, maybe more. The differences Kerouac draws between the East and West at the 
beginning of the novel thus continue to disappear. Whereas on the flatbed to Cheyenne Sal learns that Western freedom is no longer a feature of the West, but of movement west, here Sal learns that historical richness and wilderness is a feature of the East. The basic lesson of Sal's misunderstanding of the West still holds significance as a formal principle. The West still functions as an almost prelinguistic terrain, or space whose scale of signification corresponds to an in-progress mythology rather than to a bound volume of history. The East, on the other hand, is storied to capacity, crowded with the great names of America's founding. Unlike the proper names and place names of the East, the West is made up of nouns that - like the place names on the sides of boxcars - move as though they were verbs.

This sense of moving frontier materiality bespeaks a sense of geography that is in the process of reversing itself. At the beginning of the novel, there is the stuffy east coast to be escaped from and the "empty-headed" West to fly toward. Everything in the middle was the ideal terrain of road, which means that the majority of the American continent appears to be a zone of movement, a route from one American zone to another. This conception of the majority of America as a zone of movement promotes Kerouac's push for a delocalized version of American identity. Indeed, this is generally how people understand the Beat's stylistic legacy. This economy of movement and stasis is what most tangibly links the Beats to subsequent generations of innovative countercultures.

The point of closing the first part of On the Road with the Ghost of the Susquehanna is to reaffirm the central lessons of delocalization: rote memory must to give way to lived experience and local knowledge must come from interaction with locales rather than from official knowledge about them. When one gets out of a car and 
walks around, the elemental differences between "East" and "West" start to disappear. Even historical narratives change. The cast of historical figures remains the same, but Washington and Franklin live in a wilderness far from the locations of their historical feats. Dislocated thusly, these founding fathers become virile youths. In short, Kerouac closes the first part of On the Road with an appeal to a patrilineal mythopoesis, or the cast of old boy American mythmakers as young men. No matter how much progress Kerouac makes in the direction of delocalizing American identity, indeed how much his style predicates such a new imagination, his achievements at the level of style are always undone by the very localizing assumption that he, the youthful male writer, is always already at the center of America.

Regardless of how effective any argument about Kerouac's blunted multicultural message might be, Kerouac will never be read under the rubric of "multicultural fiction." For some reason, and that reason is the subject of the following chapter, Kerouac's idealism regarding delocalization is so naïve that we can’t look past its failures to be smarter about race and gender. We can't see Sal's declaration that "I'm a Mexican" as carrying any significance beyond that of blatant fetishism or appropriation. We can't believe that a white male writer so interested in seizing the compass points of America and American literary history might have helped imagine non-formulaic models for representing multicultural experience. ${ }^{127}$

Of this current critical attitude about On the Road, Abel explains that "[t]he novel's particular stylistics is often viewed ... either as a condemnable aestheticizing of social relations that ideologically conceals the 'true' conditions of American reality, or as a subversive poetics that initiates the dawn of a new, progressive, freer age" (231). Abel 
sees both sides of this argument as essentially the same, as they both speak from the same "tradition of literary criticism that views language representationally" (231). Likewise, I think that One the Road is as invested in diversity as any other legitimate "world literature" should be. Kerouac's radical allegiance to desire, indeed his exchange of localized identity for desire, renegotiates place and time into a kind of collective social assemblage that is comparable to global community, or at least presupposes such a community. Abel calls this aspect of Beat literature, this transformative desire, a "minoritarian politics." This phrase is derived from Deleuze and Guattari's concept of "minor literature" and its main objective is to be provocative, to tag a white male writer with a derivation of the word "minority." Speaking of the glass ceiling Kerouac hits when evaluated for his treatment of race and gender, Abel claims the moralistic logic of identity politics is to blame for the fact that Kerouac is considered a racially insensitive writer. However, while Abel asserts that the objective of "minoritarian politics" is to "circumvent" the very identity politics that the phrase evokes, he doesn't do much to explain why such a circumvention is desirable, aside from the fact that it makes Kerouac look like an edgy and subversive, rather than a racist and conservative, writer.

Both the content of Kerouac's personal politics and the content of his fiction have a lot of unresolvable problems. But one masculinist problem that Kerouac does not have is the enterprising use of place for "richness" and stability, place as a setting through which to pilot an old fashioned "soul search." Because the Kerouac who wrote On the Road preferred bohemian collectivity to individuality, all local knowledge is filtered through a desire for what Deleuze calls a "collective assemblage of enunciation"-a howl from a flatbed truck full of rovers stripped of their stable identities and speeding across 
the Great Plains at night (18). As a metaphor of Kerouac's very style of writing, the moving community symbolizes a weightless syntax, free from the inertia of local decisions and revisions. Just as the flatbed howlers hover over the boundaries between counties and states, the words on the page of On the Road seem governed by a law of grammar that has been modified by the aesthetic of deliberate speed. ${ }^{128}$ Its utterance along lines of flight vibrates with a disobedience that transcends the rigid hierarchies of identity politics. In the final section, I will preview the argument I make in chapter three, which examines Maxine Hong Kingston's recent renovation of Beat style, a renovation that winnows the aesthetic freedoms of Kerouac's style from its naïve identity politics and communal ambitions. In the process of separating aesthetic innovations from political shortcomings, Kingston uncovers a contradiction between the bohemian communal urge and the urge to delocalize identity.

\section{IX}

It goes without saying that the ambulatory communal dynamic in On the Road is homosocial. Indeed, much of the production of Beat literature is done in (or in hopes of) an all-male bohemian context. As Michael Davidson discusses in Guys Like Us (2004), the Beats seek a strictly masculine "literary bohemia" that was held together by a "collective plural" identity that acted as a prophylactic against the mid-century atmosphere of heteronormativity (86). In other words, the Beat version of literary bohemia is a paradox, as it is both progressive and all male. The "progress" that the Beats seek, at the expense of an equal distribution of gender representation, is an alternative to the elitist trusteeship of the New York literary scene. The motivation for homosocial bohemianism, as Davidson explains it, is to get away from the "pressure of East Coast 
sophistication and privilege" more than it is to get away from women (86). In other words, the Beat literary movement is inspired primarily by an interest in fleeing what is arguably the founding infrastructure of dichotomizing cultural logic in American letters: New York literary institutions. ${ }^{129}$ This does not mean that the gender exclusivity notable in Kerouac is insignificant. On the contrary, the homosocial component of Beat literature explains a lot about the methods through which a mid-century literary movement disassociates itself from the legitimating forces of its literary engines. Much like Agee had to abandon the confines to Fortune magazine before he could produce his large-scale work of textual depolarization, Kerouac and the Beats needed to flee New York City before they could produce a communal form of depolarization.

However, the logic of Beat bohemia leads to interior division within the anti-New York movement. Bohemianism operates under an anti "all-consuming" group dynamic, a seductive force that replaces individuality with togetherness. ${ }^{130}$ This doctrine was eventually rejectied by Kerouac, who often lived an isolated and somewhat monastic daily life. David Savran discusses the tension within the concept of bohemian togetherness. Describing the "bifurcated evolution of the white hipster," Savran explains that the typical Beat persona is a "divided self" (4). He "is at once a victim of the repressive and conformist society of which he is a part and a potentially violent, if directionless, opponent of that society" (49). This "divided self" is the "godfather" to both 1960s revolutionaries and current reactionary partisans of the so-called "Patriot movement" (4). Normal Mailer's 1957 essay, "The White Negro," attests to the accuracy of this internal division that occurs as the Beat movement broadens out to a full-scale counterculture. According to Mailer, the hipster is best characterized as "equally a 
candidate for the most reactionary and most radical of movements" (Mailer). Of course, Mailer's prediction proves true; in the 1960s, Kerouac becomes a reactionary creep and Ginsberg a flower child. In this sense, it seems that the process of detaching from the polarizing forces of New York provincialism engenders its own type of polarization. Indeed, as Kingston will demonstrate in fascinating ways, the Beat project of creating a bohemian social group is doomed to reinforce the cosmopolitan/provincial division precisely because its shape is determined by what it is not.

As screaming counterparts to the "organization man," the Beat bohemian joins up with other like minds, loses his individuality, and increases his mobility. Like the organization man, he has kinds of relationships and does kinds of work that are essentially "interchangeable." He is part of the emerging subjectivity that most confounds Jane Jacobs in her 1961 opus, The Death and Life of Great American Cities:

There are people who seemingly can behave like interchangeable statistics and take up in a different place exactly where they left off, but they must belong to one of our fairly homogenous and ingrown nomad societies, like Beatniks ... or the peripatetic junior executive. (136)

In short, they are completely free from local affiliations; they can circulate to whatever locale wants and accommodates their "work." But, as I'll discuss in the next chapter, bohemianism that assumes a gender requires an urban home base. In other words, the west-coast manifestation of the Beat movement translates Kerouac's combined denial of sophistication and embrace of portable group identity into a bohemianism that overcomes New York provincialism only to erect provincial dimensions all its own. As I'll explore at length in the next chapter, this contradiction in all-male bohemianism impacts the 
evolution of Chinese American literature in interesting ways. Kingston and Frank Chin, classmates at Berkeley in the early 1960s and later archenemies in a culture war over Chinese American literary expression, debate the historical and cultural precedents of gender exclusivity and the impact of delocalized narrative techniques on racial identity.

Kerouac's impact on recent multicultural fiction is thus largely stylistic. Because Beat literary criticism is so content-centered, this aspect of the legacy often flies under the radar of official literary history. It may be that Ken Kesey is to blame for this contentcentered approach to Kerouac. In 1964, he "revitalized" a major Beat master-plot when he asked Neal Cassady to drive him and his friends from San Francisco to New York. The trip, made in a Day-Glo painted school bus, is the LSD-infused revision of On the Road that was famously memorialized in Tom Wolfe's Electric Kool-Aid Acid Test (1968). Wolfe's "new journalistic" account of the trip elevates the event as nothing less than the ushering in of a new generation of wandering American deviants. For instance, he describes the division of labor (i.e., the choice of Cassady as driver) as though Kesey were staging the comeback tour of the "secret hero" of the Beat generation. Because he drives a school bus, Cassady's position in the trip dramatizes the division between the Beat generation and Kesey's. School bus drivers are mock authority figures with a fixed place on the social ladder. Those they convey are ostensibly less powerful but literally on their way to better things. Indeed, the point of the trip to New York was to make a publisher's party to celebrate the release of Kesey's second novel, Sometimes a Great Notion (1964).

Kesey's symbolic use of Cassady's driving is the result not of malicious intent on Kesey's part, but of the spectatorial affection that followers of Kerouac and Cassady 
often have for these founding members of the Beat generation. Wolfe echoes this affection when he first encounters Cassady. Wolfe wonders at the feet of a shirtless brakeman juggling a sledgehammer, "Who is that?" When he is told, "That's Cassady," Wolfe remarks that "[t]his strikes me as a marvelous fact" (15). The affection is notable elsewhere in the 1960s, for instance in the tender deference Ed Sanders shows toward Kerouac during the infamous 1968 episode of William F. Buckley's “Firing Line.” As an extremely drunk and hostile Kerouac harangues Sanders's "hippie" politics and lifestyle, Sanders's responds sincerely: "You're a great poet, it's your fault" (qtd. in Lerner). ${ }^{131}$ This exchange makes clear that the transition from Kerouac's generation to Kesey's, what Steven Watson refers to as the shift "from Beat to Beatnik," was not smooth.

What translated was not the innovative narrative technique of delocalization, but a kind of countercultural pose, a sincerity that insists on a deep sense of belonging to ideals perceived to be "Beat." It is in this sense that beatniks and hippies are, to paraphrase Kerouac, "billshitters." Their claims of sincerity betray an interest not in the innovations of literary movements that have preceded them, but in trying to provide accurate representations of themselves. ${ }^{132}$ Historian David Farber calls this disregard for the useful styles of the immediate past as a turn toward "the idea that Americans had "lifestyles"" (55). The word, which first appeared in Webster's International Dictionary in 1961, became a key feature of the very west-coast bohemia that grew from the Beat generation. The word is a portmanteau, employing the word "style" as an increment of "life," an attachable and separable entity that one can acquire and shed. As Farber notes, the word suggests a degree of "free choice," a degree of freedom from commitment (55). In other words, the concept of "lifestyles" introduces free-market selectivity to the formation of 
identity. It exploits the hard-won freedom from local affiliations, misunderstanding this freedom as an identity characteristic that one must acquire in order to gain acceptance into an ironically provincialized bohemian cultural formation.

In sum, the delocalizing aesthetic Kerouac pioneers in On the Road is reterritorialized by the following generation. ${ }^{133}$ Where Kerouac's narrative technique multiplies the grounded affiliations of the narrative voice and produces a directional confusion that depolarizes the normal lines of territory in America, the social congregations around such an aesthetic agenda undo most of delocalization's counterprovincial advances.

In any event, it is arguable that if the Beat "movement" were to stop anywhere, it may as well have been the Bay Area. Despite the obvious contradiction of giving delocalization a home, San Francisco is a somewhat appropriate setting. It is a city whose two-dimensional street design and three-dimensional topography produces its own microcosm of delocalized experiences. As Jacobs explains:

San Francisco is a city with many natural visual interruptions in a gridiron street pattern. San Francisco's streets, in general, are regular gridiron arrangements in two-dimensional plan; however, in three-dimensional topography they are masterpieces of visual interruption. The many abrupt hills constantly make separations between the nearby scene and the distance ... This arrangement greatly emphasizes the intimate and immediate street scenes, without sacrificing the clarity of gridiron organization. (496-497) 
The intimacy and immediacy of San Francisco topography matches Kerouac's aesthetic agenda. But, as I will discuss in the next chapter, in the process of setting up this home, west-coast writers neglect the narrative technique through which a writer represents the impulse to perform such an unlikely narrative gesture as representing the entire American continent at once. Without this interest in representing the impulse to represent the unrepresentable, the so-called San Francisco Renaissance neglects the project of negotiating multiple local affiliations. San Francisco writers become too convinced of their ideal position to be convincing. If anything, they make Kerouac's scatterbrained attempt to be everywhere at once seem to be the agenda of a realist. Indeed, the closer we get to the everyday globalization of Internet connectivity, the more of a realist Kerouac becomes. 


\section{Chapter Three:}

\section{The Chinatown and the City: Maxine Hong Kingston and the Relocalization of San}

\section{Francisco}

It seemed like a matter of minutes when we began rolling in the foothills before Oakland and suddenly reached a height and saw stretched out ahead of us the fabulous white city of San Francisco on her eleven mystic hills with the blue Pacific and its advancing wall of potato-patch fog beyond, and smoke and goldenness in the late afternoon of time. (Jack Kerouac, On the Road 169-170)

San Francisco's streets, in general, are regular gridiron arrangements in two-dimensional plan; however, in three-dimensional topography they are masterpieces of visual interruption. The many abrupt hills constantly make separations between the nearby scene and the distance ... This arrangement greatly emphasizes the intimate and immediate street scenes, without sacrificing the clarity of gridiron organization. (Jane Jacobs, The Death and Life of Great American Cities 496-497)

San Francisco is so homelike to me; and I would live there someday. (Jack Kerouac, Journals 784) 
San Francisco has become an Asian city. To speak, therefore, of San Francisco as land's end is to betray parochialism. (Richard Rodriguez, "Late Victorians" 28)

In the previous chapter I surveyed the narrative technique "delocalization," which I define as a form of narration that multiplies the positional affiliations of a narrative voice. In this chapter, I will survey how this technique, as developed in the prose of Jack Kerouac, is incorporated into recent multicultural fiction. Specifically, I will examine how Maxine Hong Kingston recontextualizes the technique in her one novel, Tripmaster Monkey: His Fakebook (1989), which is set in San Francisco in the 1960s. ${ }^{134}$ In Tripmaster Monkey, Kingston reveals the central paradox of Beat Generation literary history: that those influenced by Kerouac's innovative, delocalized narrative style take root in a specific place (San Francisco). Through revealing this paradox, Kingston makes a literary-historical argument about the incongruities between the Kerouac's aesthetic agendas and the cultural biases of the Beat-inflected literary movement that came to be known as the "San Francisco Renaissance," a movement that sprouts in the furrow of Kerouac's national success. Michael Davidson, a literary historian of the so-called "Renaissance," argues that the literary productivity of the Renaissance is fostered by "urban spaces in which alternative communities and constituencies are formed." $" 135$ In contrast to this claim about the mutual benefits of urban spaces and bohemian movements, I will argue that, thanks to the representation of the San Francisco art scene presented in Tripmaster Monkey, the relationship was not so congenial. In the effort to build a bohemian community in the West, the spokesmen of the Renaissance obscure the 
urban dimensions of the movement, preferring to represent San Francisco as a utopian nonplace rather than a racially diverse urban space. Kingston combats this provincial logic, specifically its anti-urban ethos. She represents the ground-level interaction between a "marginal man" (more on this term later) and a city that is both a specific urban space and a transhistorical, international zone of literary and cultural reference.

At the helm of what Yunte Huang calls the "multicultural recanonization," Kingston's writings have attracted voluminous scholarship that rates and evaluates her alongside other writers, multicultural and canonical alike (141). ${ }^{136}$ Her memoirs and her fiction have helped define the multicultural category as a category of American literature that uses individual character identity to negotiate the tensions among variously situated group identities. What has yet to enter the discourse surrounding Kingston's pivotal role in the multicultural redefinition of the American canon is any discussion of the social materiality that prompts the rise of, in this case, Chinese American fiction on the West Coast. Aside from explaining the proliferation of Chinese American offerings as a kind of parallel phenomenon to the Civil Rights Era, critics tend not to envision the publication spike as anything less than a collective seizure of equal rights. ${ }^{137}$ In this chapter, I will examine how Kingston's intervention into the dominant literary forms and traditions of her home region, the Bay Area, is what makes Kingston's fiction "multicultural." Furthermore, this intervention casts "multicultural fiction" as a corrective to the central contradiction of mid-century literary bohemianism: the urge for both communal identity and freedom external determinants on identity. "Wiittman Ah Sing,” Kingston's protagonist in Tripmaster Monkey, negotiates this contradiction by wanting both the 
freedoms of delocalization — namely the freedom from local affiliations and the freedom to choose the content of his identity - and the freedom to express his racial identity.

Kingston's interaction with Kerouac's narrative innovations is recognizable at various points throughout the novel. Her narrative voice, like that of Sal Paradise in On the Road (1957), follows the whim of an unpredictable and socially exiled protagonist in whose flights of fancy the narrative voice itself gets caught. Indeed, Kingston's narrative voice often mimics the naïve gropings characteristic of a Kerouac narrator. For instance, Kerouac-ean platitudes - "Good and bad, the world was exactly as it should be"-and sloppy modifier constructions - "the most beyond girl in the world"-are notable throughout Tripmaster Monkey (Kingston 16). Furthermore, in her treatment of a Chinese American seeking entry into the Beat-inspired bohemia, Kingston resolves the contradiction between the liberatory quality of Keroauc's sub-literary allowances and the apparent restricted access to such allowances.

In short, Kingston demonstrates that Kerouac's technique is useful to minority writers, even as the cultural forms that grow from it are not. This is surprising, considering that it is common knowledge that Kerouac tokenizes racial identities. Even Kingston's Wittman rails against Kerouac's having diminutized the "twinkling Chinese" in his fiction. However, Kingston's treatment of Kerouac validates Maurice Poteet's neglected argument about Kerouac's "bilingualism" and "ethnicity." The gist of Poteet's argument is that Kerouac's experimental style helped him to:

build bridges to and from a number of inner and local realities which might not 'become' American at all. In other words, spontaneous writing and effect are one answer, at least, to an ethnic situation that in many ways 
resembles the 'double bind' of psychology: if a writer cannot be himself in his work (a minority background) he is lost; if he becomes an 'ethnic' writer, he is off on a tangent. (qtd. in Charters, xxv) ${ }^{138}$

Poteet's suggestion that Kerouac is an immigrant from French Quebec is somewhat overstated. Though he grew up speaking a French-Canadian dialect, he was born and raised in Lowell, Massachusetts. Furthermore, the charge that Kerouac is an "ethnic" writer is hard to swallow, considering that Kerouac's portraits have been adopted as the all-American visage. Regardless of whether or not Poteet's argument is valid, his articulation of the difficulty of being an "ethnic writer" is helpful in the context of Kingston's prose. As will become clear below, the struggles Poteet attributes to Kerouac are similar to the struggles Kingston attributes to her "beatnik chinaman," Wittman. But she resolves the double bind of her protagonist's identity by locating the source of his identity trouble in the cultural materiality of the city at the "end of the road."

As she indicates by naming her Chinese American male protagonist "Wittman Ah Sing," Kingston intends to combine the white, male artist in the American West, the "Whitmanian tradition" that cropped up on the West Coast in the 1960s, and the multicultural persona as it continues to develop. ${ }^{139}$ Wittman's artistic agenda mirrors that of "the poet that his father tried to name him after" in that both enliven the correspondence between the "simple separate person" and public places in America (161). The "Ah Sing" part of Kingston's protagonist's name is a conjoined reference to both the Whitman poem just alluded to ("One's Self I Sing") and the name of the "Heathen Chinee" from the popular late-nineteenth-century local color poem by Bret Harte (that name being “Ah Sin”). ${ }^{140}$ This reference to frontier local color, with its 
questionable racial politics and humor about ne'er-do-well antiheroes, calls up both Harte's "pioneering" accounts of the seedy side of the life on the West Coast and Wittman's precarious status as a racialized Western "type."

The conjoined reference also signals the reader to Kingston's complex referential logic, which exposes the conspicuously masculine status of the various forms of "freedom" in the West. ${ }^{141}$ The form of freedom most dominant at the time period wherein Kingston set her novel is that of "Beat Bohemia." Wittman wants to be such a bohemian, but his interest changes as the essentialist politics of the group begin to emerge. For instance, at an LSD party Wittman admires a man for asking a "far-out" and "advanced question" that gets to the moral philosophy at the heart of the cosmopolitan worldview all the trippers are trying to pose as: "How do you reconcile unity and identity?" (105). As Wittman earnestly ponders this mock dilemma, a "hippy girl" interrupts to marvel at his double-eyed profile and epicanthic fold (105-106). Kingston here is parodying the oscillation between what Martha Nussbaum would call the "abstract universalism" of cosmopolitanism and "ethnocentric particularism" of provincialism. ${ }^{142}$ As the asker opens up the horizon of inquiry, the tripper closes in on Wittman, making his specificity a liability. Joined in this way, the asker's question and the tripper's observation together illustrate the cosmo-provincialism of West-Coast bohemia. Michael Davidson calls this internal split within communal identity a feature of a "California Orientalism" that has been around since the first "anticoolie" laws were passed in 1862 (Davidson 2004, 76). ${ }^{143}$ California Orientalism, according to Davidson, is a tradition of displacing the exotic, seductive, and irrational impulses latent in Manifest Destiny onto Chinese American men. Because of the persistence of California Orientalism, Wittman's particular kind of 
visibility remains an absolute roadblock that deters his joining any pre-established bohemian cultural forms.

In what follows, I will first discuss Kingston's reclamation of the urban realities of San Francisco, specifically her representation of urban space as literary space. Through dramatizing her marginalized artist's aesthetic interaction with the city, Kingston motivates a turn to both a post-New Deal public arts model and a post-Kerouac delocalization strategy. Like the partiers in the Central City episode of On the Road, who dance despite the presence of music, Wittman's observations of San Francisco's urban materiality express a will to communal expression that precedes any preexisting expressive form. In light of this parallel urge in Kerouac and Kingston, Kingston's critique of Kerouac's racial politics starts to appear deceptively simple. However, to date, Kingston's critique is only acknowledged as an obligatory reaction to Kerouac's latent racism. As my analysis in section II will show, Kingston's treatment of Kerouac in Tripmaster Monkey is a recontextualization of Kerouac's descriptions of the city dwellers whose marginalism Kerouac covets. Kingston's recontextualization thus continues the process of delocalization, rather than wagging a finger at its bad behavior. Kingston does, however, criticize bad behavior, but not that of Kerouac as much as that of the engineers of the San Francisco Renaissance. In section III, I will discuss how Kenneth Rexroth, the San Francisco Renaissance's great impresario, and other Renaissance practitioners mystify San Francisco to a point that its urban diversity disappears. Kingston critiques such white washing of San Francisco, such efforts to present the city as a lands-end utopia. In other words, Kingston points out that the ethos of the San Francisco Renaissance misinterprets Kerouac's delocalization technique, which emphasizes the 
particularities of the local without also expressing singular allegiance to one locale.

Erasing urban realities and rendering San Francisco into a zone of idealist bohemia, San Francisco Renaissance practitioners prove themselves to be provincial. Kingston corrects this provincialism by emphasizing the realist ethos of delocalization. In section IV, I will discuss Kingston's urban realism, arguing that she posits a positivist representational agenda that reinscribes the urban realities of the "Bay Area." Section V will examine the importance of "city fiction" as a nexus of traditional and multicultural conceptions of the self. In the final section, I will analyze Kingston's vision of the "final stage" of delocalization, as it takes the form of a one-man theatrical performance. Kingston's turn toward this "stage" both translates Kerouac's continent-sized canvas into a tangible terrain of self-fashioning and asserts the identificatory value of public arts. Wittman's bold assertion of presence at novel's end represents masculinity as a kind of pose rather than a preexisting biological condition. In short, Kingston enacts delocalization in order to do away with the false notion that both gender norms and Asian American identity have a stable foundation.

\section{I}

Michael Kowalewski claims that Tripmaster Monkey is a novel that "might counter the charge that urban fiction cannot somehow be "regional"" (14). In this section, I will demonstrate the validity of this key claim. I will do so by discussing Kingston's method of representing San Francisco as a simultaneously urban and literary environment. Kingston has indicated in interviews that the primary intention in Tripmaster Monkey is to juxtapose the delicate architecture of literary knowledge against the harsh realities of the minority eye-view of urban space. The organizing question for 
Tripmaster is, according to Kingston: "what use is a liberal arts education?" (qtd. in Skenazy 143). The goal is thus to find out what social good comes from "people that were created by books," to unlock the civic life of those with the most "embodied cultural capital" (140). ${ }^{144}$ Kingston's protagonist, arguably the best-read character in recent American fiction, is thus a "one-man show" of literary retention. He uses the tools of literary reference to expose the urban realities of San Francisco.

By limiting Wittman's application of his literary genius to a specific place, Kingston revisits an old argument about the influence of geography on the deracinated writer, an argument Kerouac left unfinished in On the Road. In Kerouac's novel, stable locales are consistent sources of disorientation for Sal Paradise. ${ }^{145}$ Where Kerouac indicates this disorientation in order to reassert his argument that the ideal state of being is a state of being in motion, Kingston asserts that the Chinese American artist must always in some sense be someone other than who his training tells him he is. Where he wants to be is another matter. According to Kerouac's literary geography, San Francisco is a "pivot point" (more on this concept in section III), the point of transition where one directional agenda transforms into another. It is, for those present at the dawn of the Beat generation, simply the place where one turns around. When forced to remain in San Francisco, the "end of the road," Kerouac's characters lose their minds. ${ }^{146}$ By confining Wittman's journey primarily to the city of San Francisco, Kingston takes up the thread of Kerouac's argument that San Francisco causes random sociopathic impulses, making it an inescapable condition of her protagonist's psyche. ${ }^{147}$ However, though he cannot flee the local origins of his crazy impulses, Wittman's knowledge that San Francisco is not 
the edge of the continent does save him from reinforcing the racist pathologies suffered by Kerouac's protagonist.

Kingston begins her story of Wittman with the sentence: "Maybe it comes from living in San Francisco, a city of clammy humors and foghorns that warn-omen, o-omen ... but Wittman Ah Sing considered suicide every day" (1). This grey atmosphere evokes the classic ennui of the disillusioned urban male; the sounding "o men" of the foghorn winks that such suicidal languor is conspicuously male. Under the weight of these classic dolors, Kingston's protagonist's brain wants to "fly far apart in the scattered universe" (1). These suicidal tendencies are common to urban male protagonists. But the abrupt violent imagery Kingston uses evokes the full weight and solidity of Wittman's somatic presence - it establishes his carnality rather than his invisibility. Readers have to think of his "blood, meat, disgusting brains, mind guts," before we can think about his “skin arrangements" (Wittman's name for one's racial status) $(1,11)$. In short, we have to envision Kingston's version of the Chinese American artist by first piecing him back together. $^{148}$

A couple pages into the novel, Wittman ponders the Golden Gate Bridge, specifically its status as a popular suicide destination. He has observed some such suicides and recalls that that they "take the side of the bridge that faces land. And the City. The last city. Feet first" (4, my italics). If Wittman were to jump, he'd "face the sea. And the setting sun. Dive" (4). This commitment to the sea instead of the "last city" signifies a refusal to credit "end-of-land sadness" (a phrase repeated often in Kerouac's San Francisco sketch, “The Railroad Earth” [1957]), as the motivation for Wittman's 
suicidal tendencies. Indeed, San Francisco is obviously the "first" not "last city" of Asian America.

By producing dolorous conditions for her Chinese American artist, Kingston juxtaposes the dual themes of urban disillusionment and racial marking. Kingston furthermore historicizes Wittman's disillusionment by highlighting the fact that Wittman is the member of a generation of Chinese American that has no material relation to his built environment. The fact that Wittman, a third-generation immigrant, is materially detached from the labor of production in the city is evident in the fact that Kingston mentions twice in the first chapter alone that Wittman had no hand in "building the city" $(1,4)$. However, as a classically besieged humanist, Wittman precedes to build his own city from the materials he, a liberal arts trained graduate from Berkeley, has at hand: deep pools of literary allusion and the audacity to think of himself as an artist.

One of the peculiarities of living within the pivot point of America is the unique everyday encounter with literary "airs": "The air of the City is so filled with poems, you have to fight becoming imbued in the general romanza" (20). Wittman's own brand of romanza is aimed at a girl who wore "a leotard and tights like an old-fashioned Beat chick" (20). While trying to "make" this chick, an former classmate and fellow Chinese American beatnik named Nanci, Wittman imagines "making the scene on the Beach, like cruising in the gone Kerouac time of yore" (20). Kingston steers this scene from its almost inevitable status as sappy nostalgia by alluding to the one positive and enduring form of intimacy that sprung from the Beat movement West. Escorting Nanci to a bookstore in hopes that she will stumble upon his one-act play, published in "an artistic avant-garde far-out new magazine," Wittman mingles his romantic encounter with the 
reader-writer intimacy of "homemade books ... mimeojobs, stencils, and small-press poetry that fit neat in the hand" (20). This is a reference to small press publishing that introduced the world to poems like Howl and Kaddish. Kingston heightens the intimacy of small-press publication, turning her would-be romance to what Davidson refers to as the unique "urban spaces" of the San Francisco Renaissance, "in which alternative communities and constituencies are formed" (1997, xii).

But the Beat chick abandons Wittman because he throws a fit when she tells him "You sound black. ... I mean like a Black poet. Jive. Slang. Like LeRoi Jones. Like . . . like Black" (32). This evaluation enrages Wittman, who fires back: "Huh? Monkey see, monkey do?" (32). Even his members of own racial group are denying him access to the "urban spaces" that were apparently so readily available to the San Francisco Renaissance milieu. When he's not trying to pick up chicks, Wittman searches desperately for these supposedly freely available urban spaces. But, alone, he discovers only odd city scenes. As he walks to Golden Gate Park, Wittman sees "[a]n old white woman ... sitting on a bench selling trivets ‘@ 1/2 dollar ea.,' which a duck and bunny pointed out with gloved fingers" (4). The old woman has no eyes, but "eye sockets ... wide open" (4). Wittman turns away, only to catch sight of "a pigeon and a squatting man, both puking" (4). These images seal the aesthetic for the morning, as the narrator indicates that Wittman's walk “was turning out to be a Malte Laurids Brigge walk" (4). Like the eponymous hero of Rilke's novel, Wittman "let[s] it all come in" (4), which is to say that his "poetic ego" like that of any existential flâneur, "assimilates all of life in its gargantuan, phantasmagoric creation of self' (Mackin 518). The atmosphere-setting reference to Rilke is significant for a number of reasons. As opposed to the Bay Area 
"bohemian" poets Wittman aspires to join, Rilke is an actual "Bohemian poet": he was born in present-day Prague before the dissolve of the Bohemian Kingdom. The novel alluded to, The Notebooks of Malte Laurids Brigge, represents an earnest version of the ironic existential malaise that Kingston uses to begin her novel. Kingston even parallels her San Francisco with Rilke's Paris by mimicking Rilke's novel's opening words: "So this is where people come to live; I would have thought it is a city to die in. I have been out. I saw: hospitals. I saw a man who staggered and fell” (3).

Giving content to Wittman's Chinese American identity by absorbing the sights and sounds of the city the way high-art poets would, Kingston creates two distinct experiences of public space in San Francisco: one thick with literary allusion and one thick with descriptive local information. Together these two allow Kingston to envision a post-New Deal the type of value-added public space, a model of injecting literary and artistic value into urban space that had not yet been envisioned, due to the provincial biases of New Deal arts programs on the West Coast. ${ }^{149}$

Kingston is deliberate and humorous in revealing the confluence between Wittman's street knowledge and his knowledge of the Western canon. For instance, Wittman hears in the cables of the Municipal railway (or "Muni") a sound similar to Beckett's mantra “I can't go on, I'll go on.” Kingston deepens the Beckett allusion through Nanci, an actress who admires Beckett because he is the only playwright who writes plays wherein "it doesn't matter what a ... character looks like" (23). Ham, Clov, Nag, and Nell don't belong to the world of corporeal identity, but to its Endgame (1957). Though Beckett's presence in the bus cables echoes Wittman's malaise at being a "racinated" poet ${ }^{150}$ Kingston is sure not to imply that her protagonist is on a level with 
great men of letters. Instead, these men are on a level with other forms of referential information. A line from Rilke or Beckett and the local fact that "the Orpheum [was] once 'the best vaudeville house in the West"" mean the same thing to Wittman (7). Both are synaptic occurrences that happen on a public bus to nowhere. In this spirit of the horizontal partnership of the literary and the local, Kingston delves into asemantic listing exercises that locate aspects of Wittman's character in his physical surroundings. For instance, as Wittman rides the Muni down Market Street, the narrator lists the places passing through the window: "The Embassy, the Golden Gate, U. A. Cinema, the Paramount, the Warfield, the St. Francis, the Esquire" (7). These are all theaters and their presence together suggests both the site of performing Western literary knowledge and Wittman's ultimate aspirations for a stage for his own hybrid art.

In short, Wittman's Muni ride down Market Street calls up an assemblage of literary and local references told on the surfaces of the San Francisco cityscape. Just as Kerouac finds the raw materials of his aesthetic in the large-scale letters stenciled to the sides of moving boxcars, Kingston finds a cultural and historical depth in the semiotics of a city in motion, a city that represents both the beginning and end of the American continent. This spirit of inventory locates the literary hues of daily life. When Wittman reads Rilke aloud while riding the bus, the Rilke passage runs for more than a page of the novel and describes the nauseating stillness of a bourgeois family dinner. Filling the silence of public space with a description of the silence of bourgeois domesticity, Wittman fills otherwise vacuous public space with a literary version of the lives of the inhabitants of that public space. Wittman is met with the same brand of complacency that he recites; everyone ignores him (8-9). This complacency, this passive acceptance of 
artistic eccentricity, is what Wittman decides has become of "Walt Whitman's 'classless society' of "everyone who could read or be read to"" (9).

Regardless of the apathy of the public, reading aloud inspires interest in transforming San Francisco's public spaces into literary spaces. He hopes some passenger will "write the board of Supes and suggest that there always be a reader on the route" (9). He hopes to begin a "tradition that may lead to a job as a reader riding the railroads throughout the West"

through Fresno- Saroyan; through the Salinas Valley—Steinbeck; though Monterey_Cannery Row; along the Big Sur ocean, Jack Kerouac; on the way to Weed-Of Mice and Men ... through the redwoods_-John Muir; up into the Rockies-The Big Rock Candy Mountain by Wallace Stegner.

This interest in translating cultural capital into an actual job is pervasive throughout the novel. Even while applying for unemployment, Wittman insists that his file read that he is a playwright (239).

More importantly, and notable in light of the above roll-call of male writers of the American West, Kingston indicates that to translate cultural capital into the means of earning a living is to level the hierarchy of literary value. Cast as soundtracks to their corresponding places, Saroyan, Steinbeck, Kerouac, Muir, and Stegner earn a status parallel to that of Rilke and Beckett, as writers who texture public interaction with physical surroundings and introduce the people to the vital living ground of their daily lives. Similarly, Wittman finds an unlikely literary companion while wooing the woman (Taña) who becomes his wife. As part of her initial reaction to Wittman's off-kilter 
personality, Taña recites a kitschy local color poem, “The Men That Don’t Fit In,” by frontier balladeer Robert Service. At this, Wittman marvels at the apparent uselessness of his English major credentials, "[f]our years of Chaucer and Shakespeare, Milton, and Dickens, Whitman, Joyce, Pound and Eliot, and you shoot me right through the heart with Robert W. Service” (113). Taña's middlebrow literacy makes Wittman's humanities training into a form of kitsch. It dissociates Wittman's generation from the bohemian generations that come before the 1960s: "Bloomsbury did not recite Robert Service. Neither did Gertrude Stein's Paris salon. Neither did the Beats. But Wittman Ah Sing's friends ... his generation-did" (113).

By coupling the lover of Rilke and the lover of Service in marriage, Kingston produces a situation that interrogates the quotidian use value of literature, that weighs literature alongside other public services and social rites. Beginning with Wittman's roll call of public reading material, Kingston uses her novel to rethink the literature of the American West not as some racist conspiracy threatening Asian Americans, but as a natural resource, an organic canon whose chaff can be winnowed out, a task exemplified by Wittman's decision to “refuse to be a reader of racist Frank Norris. He won't read Bret Harte either, in revenge for that Ah Sin thing" (9-10). Kingston thus democratizes literary knowledge; she places the terrain of high literary fiction and poetry in the hands of a literary savvy civic citizen.

Ironically, Kingston's critics read this liberatory reclamation of the city as an elitist turn. Kingston claims to have expected a serious literary audience to welcome her innovative use of literary allusions and high modernist tropes. On the contrary, actual audiences complain that the novel's myriad allusions are "only available to very literate 
people" (qtd. in Skenazy 143). Kingston responds by reminding her audience (a group of students and professors at UC Santa Cruz) that it didn't feel excluded by the esoteric cultural references in The Woman Warrior or China Men, references far more difficult to ferret out than her googleable literary references in Tripmaster Monkey. The reason is obvious. Readers of Kingston's memoirs can chalk up their confusion to ethnic difference — as one audience member echoes, "if you're not Chinese American, you don't have to feel like you should have known the allusions" (144). Kingston claims that the Tripmaster Monkey allusions are there to enfranchise the reader of canonical literature. "But the way you're all talking," Kingston responds, "it seems like I put those allusions out there to give you pain" (144). Regardless of whether Kingston is earnest when she says that she assumed Wittman's cultural capital would be parallel to her reader's, her method of blending literary allusions with local knowledge gives her protagonist's cultural capital some "street value." In short, by dramatizing the way a "marginal man" uses literacy of the Western canon, Kingston models a method of gaining a ground-level literacy of a disorienting city.

The point of this complex literary project is to reclaim city space as democratic social space, which Philip Fisher defines as particularly American brand of public space, a "homogeneous, cellular medium of life" that somehow "solved ... the problem of identity" (62). The choice to inhabit this space as opposed to the fruitful space of "ethnic memory" that Kingston had inhabited when writing her award-winning memoirs, seems counterintuitive, especially considering how commercially and critically successful Woman Warrior and China Men are. ${ }^{151}$ But Kingston explains that writing Tripmaster was "a great relief. In the first two books, I felt I was translating a culture for everyone. 
... It felt like a burden to me. ... [with Tripmaster I] wanted to use everything that I know, to use the [American] language at the hardest level that I can work it" (qtd. in Skenazy 144). Thus, democratic social space, as homogeneous as it is, is a far more appealing horizon for a writer who wants to interrogate and find a place within American language rather than to translate same dead culture into a language recognizable as “Asian American.”

Furthermore, in Tripmaster Monkey, Kingston historicizes her interest in "American language," explaining that the language of the novel is the "language of the Sixties" when "people were finding vocabulary for psychedelic states or visions or social action" (qtd. in Skenazy 145). This new vocabulary begins, Kingston argues, with Walt Whitman: "I feel very much in that tradition ... showing people how 1960 was using the language of the 1860 s ... we don't remember [that] Whitman said, 'Look to the East, that's also your motherland"” (145). Choosing such "facts" of literary history to build her story and her fictionalization of American language, Kingston lands firmly in the realm of positivist inquiry, by which I mean that her fiction negotiates the verifiability of racial traits. This proves fruitful both as a relief of the "burden" of writing out the nightmares of her ancestral past and as a way of making visible the unofficial realities of Chinese American experience in a city many of whose own inhabitants want to view as unbearably dreamy.

Wittman's observation of the literary hues of San Francisco's urban materiality is, in the beginning of the novel, a consolation tactic. However, when viewed in the context of Kerouac's fictionalization of the marginalized urban types that he covets in his fiction, arguably urban types similar to Wittman himself, this projection of Rilke into public 
space takes on new significance. Kingston's method of representing the artist in the city resembles Kerouac's to some extent. Kingston takes unique advantage of this resemblance, both critiquing Kerouac's racial politics and recontextualizing his descriptions of the marginal city dwellers. In the following section, I will discuss a specific case of recontextualization, an uncredited, versification of Kerouac's prose.

\section{II}

Soldiers, sailors, the panhandlers and drifters, [no] zoot-suiters, the hoodlums, the young men who washed dishes in cafeterias from coast to coast, the hitch-hikers, the hustlers, the drunks, the battered lonely young Negroes, the twinkling little Chinese, the dark Puerto Ricans, [and braceros and pachucos] and the varieties of dungareed Young Americans in leather jackets who were seamen and mechanics and garagemen everywhere. (Tripmaster Monkey 69)

Near the beginning of the third chapter of Tripmaster Monkey, Wittman thinks of the above passage from Kerouac. He cringes on cue at the lame racial slur "twinkling little Chinese." The phrase inspires pangs of betrayal and indignation in Wittman, a writer trying very hard to be Beat: "Et tu, Kerouac" (70). The two words "twinkling 
little" remind Wittman, a Chinese American poet and playwright, that he will never gain more than a tokenized acceptance into the Beat generation. He will never be what he wants to be, one of "Kerouac's people, tripping along the street" (69). ${ }^{152}$

Every article that I've seen address this section of Tripmaster Monkey nods at Kingston's nod at Kerouac's racism. I've even seen an entire dissertation chapter devoted to analyzing Kingston's battle against Kerouac's "poem" and the "process of inscribing collective identities" that it enacts (Durso vii). As such, in Kingston scholarship, Kerouac stands in as the primary force of racial essentialism. But, just as every scholar who references the above "Kerouac poem" fails to investigate its source in Kerouac's writing, this approach to Kerouac's influence on Kingston overlooks the key role he plays in the plot and style of Tripmaster Monkey. Furthermore, the charge that Kerouac "inscribes collective identities" is overstated. Kingston deliberately highlights the essentialism of the Kerouac passage.

Originally not a poem at all, but a sentence from Kerouac's first novel, The Town and the City (1950), the passage depicts a small-town adolescent's reaction to seeing Time Square for the first time. Kingston transliterates the passage into verse, turning it into a lyric inventory of marginalized types. Kingston's versification deliberately isolates what is deplorable about Kerouac's passage. She breaks the passage into lines that pair the non-racially-specific groups, such as "soldiers" and "sailors," and "panhandlers and drifters," and that isolate to separate lines the racialized figures of the passage. As such, "the battered lonely young Negroes, / the twinkling little Chinese" become barbs in the eyes of the reader (69). Kingston also adds bracketed words and phrases to Kerouac's passage, updating it for the 1960s West Coast: "[no] zoot suiters" (the zoot suit having 
been out of fashion sense the mid-1940s) and "the dark Puerto Ricans [and braceros and pachucos]" (border slang for migrant farmer and Americanized Hispanic, respectively) (69).

Kingston's critics show no interest in the fact that Kingston deliberately relocates Kerouac's observation from Times Square to the San Francisco Tenderloin. They merely partner with Kingston's narrator's indignation toward this sorry excuse for a "poem."153 Part of the reason why critics don't bother to find out the original context of the quotation is because Kingston is so effective at introducing it as a fictional textual artifact. The effect is that the passage becomes a sample of Kerouac's words even if they were not his words to begin with, as, indeed, they are not Kerouac's words for those who find them only in the pages of Tripmaster Monkey. If they are Kerouac's words, the Kerouac whose words they are is a member of Kingston's fictional world, he is "Jock Kerouac," the macho phallus of the mid-century literary scene Wittman can't join (70). However, as I will argue below, Kerouac functions in Kingston's text as something far more than a writer of what Patricia Keefe Durso refers to as "negative script of collective identity" (191). Rather than a writer whose bad behavior Kingston criticizes, Kerouac is a writer whose swaggering prose style describes the underground realities of the West Coast and the East Coast in the same breathe. Kingston winnows out the essentialism of Kerouac's style, talking back to his problematic passages as a way of correcting his flip racializations. Essentially, she revives the delocalized subjectivity captured in On the Road, the very subjectivity quashed by the provincial aesthetics of the San Francisco Renaissance. 
In fact, before the advent of bohemian provincialism, the delocalized subject was common to Asian American writing. Long before Kerouac hits the road, Filipino poet Carlos Bulosan maps out some curious and intricate relations among movement, territory, and cultural capital in the American West, all of which build to the assertion that, in America, it is criminal to both have cosmopolitan credentials and assert a local affiliation. In his memoir, America is in the Heart (1943), Bulosan tells the story of emigrating to the U.S. from Binalonan, a small town in the Pangasinan province of the Philippines. Bulosan wanders up and down the West Coast as far north as Alaska and as far south and San Diego. When forced to stop and remain stationary (in a Los Angeles TB ward), he acquires all the Western literary/cultural education he'd been lacking. But for Bulosan, this literature remains oddly foreign to the land that surrounds him. It's almost as though the civilization of the American West doesn't want to know of the fruits of Western civilization. This disconnection of the literary products of "the West" from the literal American West is the seed of illogic from which grows Bulosan's Marxian politics. ${ }^{154}$ The predator/prey economy he begins to see in the American West limits Bulosan's use of both Western cultural capital and the local knowledge he acquires from his meanderings up and down the coast. As an Asian lacking actual capital and trying to relocate to a country that sees him strictly as a "coolie," or faceless laborer, Bulosan delineates the special brand of provincialism that exists in the West.

By the time Kingston comes of age as a writer, this discourse on West-Coast provincialism obviously complicated by bohemian migration. In the wake of Kerouac and Ginsberg's national popularity, the Bay Area becomes the epicenter of Beatnik wannabes, a phenomenon noticeable in Tripmaster Monkey. Coming upon a woody 
station wagon with Ohio plates and bumper sign reading "North Beach or Bust,"” Kingston's narrator remarks "Poor bastards. Too late. They crossed the country to join the Beatniks" (26-7). This "Renaissance" engenders a new form of provincialism. The bohemian social spheres that emerge in San Francisco assert a hermetic group collectivity that is largely homosocial. Kerouac's gesture toward a language of post-regional America is thus translated into gestures that express fidelity to a fixed group identity. In other words, Kerouac's passion for boxcar-scale signification transforms into a passion for bumper-sticker slogans.

Wittman had long hoped to join this "gang of poets" that he'd watched gather around the City Lights Pocket Book Shop during the Howl obscenity trial. He had assumed that these might possibly be the "others of his kind" in San Francisco (21). He took hope from the fact that " $[t]$ here had been a Chinese-American guy who rode with Jack and Neal ... Victor Wong" (21). Of course, Kerouac dimunitized Wong, referring to him in Big Sur as “"Little Chinese buddy Arthur Ma”" $(89,91) .{ }^{155}$ According to Derek Parker Royal, the real sting of Kerouac's racial slurs is that " $[\mathrm{w}]$ hat professed to be an expression of anti-establishment sentiments turns out to be ... nothing more than another apology for the status quo.... the white all-American poet, is trapped within the same master narratives from which he attempted to free himself" (151). Royal rightly notices that Kerouac "exoticizes" and "romanticizes" non-white figures and in doing so "marginalizes those very subjects with which he desires to identify" (151). The "twinkling little" characterization inspires in Wittman a series of counter-epithets for Kerouac: "Big football player white all-American ... twinkling little Canuck ... I'm the American here" (70). ${ }^{156}$ Wittman then swears off his affair with the Beats: "Fuck 
Kerouac and his American road anyway" (70). In the midst of acknowledging the racist logic of Kerouac's form of cross-racial appreciation, Kingston names "his American road" as a suspect in his racist logic.

"The road" is the enduring terrain on which Kerouac's narratives are (pre)positioned to take place. By the 1960s, the road trope had transformed into a mechanism for one-way relocation from the East to the West. Much of Kerouac's cultural cachet was being pushed into the cities and seclusions of the West, namely San Francisco and Big Sur. It's fitting, then, that Kingston relocates his description of the members of the Times Square underground, making a description of those "others" of the San Francisco's Tenderloin where Wittman is walking when the Kerouac line occurs. As it originally appears in The Town and the City, the Kerouac passage reads as follows: He stood on the sidewalk in thin drizzle falling from dark skies. He looked about him at the people passing by — the same people he had seen so many times in other American cities on similar streets: soldiers, sailors, the panhandlers and drifters, the zoot-suiters, the hoodlums, the young men who washed dishes in cafeterias from coast to coast, the hitch-hikers, the hustlers, the drunks, the battered lonely young Negroes, the twinkling little Chinese, the dark Puerto Ricans, and the varieties of dungareed young Americans in leather jackets who were seamen and mechanics and garagemen everywhere. (361)

This is Keroauc's first description of the Times Square underground, made up of the very socially disparaged figures who inspired the "beat" tag and possibly the Beat style. ${ }^{157}$ Kingston's relocation of Kerouac's description of the Times Square scene is of a piece 
with a large-scale relocation of the Beat scene to the West Coast. Even before the Renaissance, the Beats were being pushed West. Just as Kingston places a description of Times Square in the Tenderloin district of San Francisco, highlighting the problematic racial politics of Kerouac's word choice, the editors of Grove Press made Kerouac relocate from New York City to San Francisco the more elicit, and potentially libelous, episodes from The Subterraneans (1958). ${ }^{158}$ In this sense, Kingston is reproducing a commonplace cultural logic of the 1950s: to get the Beats as far away from New York as possible.

What is interesting is how easy it is to relocate Kerouac, how little damage such uprooting and replanting of his prose does to its meaning. The reason for this is partially explained again by a passage from The Town and the City, from the paragraph Kingston skips over in her transliteration:

It was the same as Scollay Square in Boston, or the Loop in Chicago, or Canal Street in New Orleans, or Curtis Street in Denver, or West Twelfth Street in Kansas City, Market Street in San Francisco, or South Main Street in Los Angeles. (361)

This interchangeability of American places is, in essence, the one lasting effect of Kerouac's prose. As Elizabeth Wheeler claims, Kerouac's writing epitomizes a midcentury trend toward abstracting America's sense of place. However, it is very important to note that, even in the midst of wiping out localized distinctions, Kerouac does not also eschew the representational demands inherent in constructing a sense of place. Instead, he tries to represent a sense of place that applies to America as a whole and not just to somewhere in particular. 
San Francisco offers both Kerouac and Kingston a special occasion for considering an omnipresent sense of place. As Wheeler indicates, "Wandering the streets of San Francisco, Sal has an ecstatic vision of being everywhere all at the same time" (250). In the passage Wheeler refers to here, Sal finds himself "frozen with ecstasy" on the sidewalk of Market Street: “I looked down Market Street. I didn't know whether it was that or Canal Street in New Orleans: it led to water, ambiguous, universal water, just as $42^{\text {nd }}$ Street, New York, leads to water, and you never know where you are" (172). Kingston takes over Kerouac's delocalized sense of place, examining the enduring presence of San Francisco as a lodestone attracting those who are also attracted by delocalization.

In sum, San Francisco is the site of the dialectical clash in the discourse on thinking territorially in America - the site of the clash between "the regional" and "the urban." As historian David Farber claims, the Bay Area is "the first and the biggest and the most photogenic" major relocation sight of 1960s counterculture groups (169). Its many "freaks and shock troops" congregated "over a few city blocks or a few acres of countryside ... trying to make a world out of it, a place where all the old rules were up for grabs" (169). As the destination of "hippie" movement, San Francisco in the 1960s became a veritable reservation of the nation's disaffected (and mostly white) youth. As demonstrated by Ed Sanders's unwavering affection for the fallen and reactionary Jack Kerouac of the late 1960s, hippies believed themselves to be in direct lineage with the Beats. ${ }^{159}$

In fact, the unofficial "hippie anthem," "San Francisco (Be Sure to Wear Some Flowers In Your Hair)," represents a wholesale commercialization of Kerouac's 
geography of movement. The song's bridge verse- - All across the nation such a strange vibration / People in motion/ There's a whole generation with a new explanation / People in motion"- reifies Kerouac's aesthetics of motion, heralding the dawn of a multitude of hitchhikers using On the Road as a roadmap. Considering its apposition with "people in motion," their "new explanation" is implied to be that of some clichéd form of Kerouac's message, something like "go with the flow." Indeed the commercialization of Beat aesthetics has been well- documented. ${ }^{160}$ But studies of Kerouac's pop culture afterlife never seem to recognize the contradiction between a literary style that emulates movement and multiplies local affiliations and the appropriative cultural posture that, in Farber's words, "takes over a few acres." I say "appropriative" because the conception was lifted solely as a ploy to increase the number of like minds in the Bay Area. John Phillips's wrote "San Francisco (Be Sure to Wear Some Flowers In Your Hair)" to boost the attendance of the 1967 Monterey Pop Festival. The song's well-known lyrics are simple, memorable, and ultimately express a crucial contradiction in the way delocalization takes root in the Bay Area. Considering its status as a promotional song, designed to attract attendees, the famous opening line, "If you're going to San Francisco / Be sure to wear some flowers in your hair," rings as a finicky pronouncement of the city's dress code. Likewise, the song's last line- "Summertime will be a love-in there"betrays a kind of provincial self-interest. The term "love-in" is hyper-insular, almost to the point of cannibalism. Hippies are to be close, in mind and body. Their impulse is not to be in motion, but to reroot among like minds, to choose the makeup of the family that they will then smother and be smothered by. 
Kerouac was notably vehement in his opposition to the 1960s "progressive" notion of lifestyle choice. But Sanders was right, it was Kerouac's "fault." His embrace of America's lines of flight from identity, his audacious wish to be a Mexican or "an old Negro cotton-picker" (On the Road 97), introduced the baby boomer generation to the notion that they do not have to be who their parents say they are. This protean notion of identity is essentially cosmopolitan. It's ironic, then, that the site of this revolution in identity formation would take such a provincial shape. In the following section, I will examine the impact of provincial-cosmopolitanism in San Francisco literature. I will begin by looking at how the Beat presence in the region impacted its relationship with the masculine tradition of westward expansion. I will then examine Kingston's fiction, in terms of its correspondence with Kerouac's prose style and its ultimate rejection of San Francisco provincialism. The baseline question of what follows, then, is how writers in the second half of the twentieth century think of the Bay Area as a region. As mentioned above, delocalization retains a key realist "manner" of representation, even if it does jettison the "matter" of realist representation. Of the many ways that Kingston revolutionizes San Francisco fiction, the most important is her treatment of the city as a city. Male writers often want to think of San Francisco as a foggy lands end, a mystified and self-contained non-place. Kingston rejects this mystification by injecting a new premium on material reality. This rejection is, as I bear out in the following section, nothing short of a rebellion against the conventional understanding of San Francisco as the city at the end of the road. 
Jack Spicer once claimed this of San Francisco writers: "We are a coast people. There is nothing but ocean behind us" (qtd. in McCuller 44). More recently, Michael Davidson has claimed that 1960s San Francisco writers took as their subject "the ground of numinous presence," as opposed to the ground of urban materiality (qtd. in Hamalian 1996, 222). In short, these writers ignore the fact that they inhabit a city, trying instead to inhabit Kerouac's mystification of San Francisco as the "fabulous white city" divided among "eleven mystic hills" (169). The hills are mystic because there is nothing but fog and sea to their west, nothing but the western limit of Kerouac's mental geography. By suggesting that San Francisco is a utopian nonplace, rather than a diverse urban environment, Beat-inspired bohemian communities erase the representational entry point for non-white artists who are native to the area. They construct a provincial logic that shuts out writers, such as Kingston, who had come of age in the 1960s Bay Area. ${ }^{161}$ In another often-cited passage about the exceptionalism of American West, from A Thousand Plateaus (1980), Gilles Deleuze and Félix Guatarri update this romantic ideal of the frontier, including the East that is latently present in the West. Deleuze and Guatarri argue that the American West is the planetary hotspot for "deterritorialization." The following paragraph appears often in literary scholarship about the Beats and the American West. I quote the majority of it here so to provoke a launch point for my argument about bohemian provincialization in the West: ${ }^{162}$

[E]verything important that has happened or is happening takes the route of the American rhizome: the beatniks, the underground, bands and gangs, successive lateral offshoots in immediate connection with an outside. ... directions in America are different: the search for arborescence and the 
return to the Old World occur in the East. But there is the rhizomatic West, with its Indians without ancestry, its ever-receding limit, its shifting and displaced frontiers. There is a whole American "map" in the West ... America reversed the directions: it put its Orient in the West, as if it were precisely in America that the earth came full circle; its West is the edge of the East. ... America is the pivot point and mechanism of reversal. (19) This neo-romantic conception of spatial and textual terrain in America is, ironically, a result of the fact that countercultures and innovative cultural forms counterintuitively take root in Western urban zones such as San Francisco. Considering the premium that Beat literature places on multiplying local affiliations, it is easy to notice how counterintuitive this solitary local affiliation seems. Deleuze and Guatarri's metaphor of the American West's as a "pivot point" is helpful here, since a "pivot" is both a hyperspecific location (a "point") and a zone of pure movement. Relative to that which is turning around, such as Sal and Dean in On the Road, the pivot point is the thing whose anchored stasis produces a centrifugal reversal. The pivot point is the axis of internal rotation, the thing that facilitates movement but cannot itself be moved. From this complex form of rootedness, this rootedness that facilitates rootlessness, comes a special case of provincialism. In the mid-century, however, this centrifugal force becomes a centripetal force and San Francisco becomes a kind of flypaper for the delocalized subject.

A good way to begin describing West-Coast provincialism is to review East-Coast provincialism, specifically the perception New York literary critics have of West-Coast writers. In the wake of the New Deal, New York's literary gatekeepers started to defend 
their canon against the generation of "California writers" who had come of age during the Depression. In the earliest scholarship about this generation of California fiction, Boys in the Back Room (1941), Edmund Wilson systematically reduces the value of California writers. His system consists of asserting that California writers try and fail to write like Hemingway. Indeed, Wilson claims that California-based fiction, both that written by natives such as William Saroyan, Hans Otto Storm, and John Steinbeck and that by nonnatives such as James M. Cain and John O'Hara, is monotonously derivative of Hemingway's style. Furthermore, their bodies of work do not "carry weight proportionate to the[ir] bulk" (57). Even considering this chauvinistic selection policy and outmoded gatekeeper-inflection, Wilson makes a useful observation about disorienting effect that "the West" has on those from "the East": "All visitors from the East know the strange spell of unreality which seems to make human experience on the Coast as hollow as the life of a troll-nest where everything is out in the open instead of being underground" (57, my italics). By assuming a collective reaction to the West, Wilson endorses the cultural trusteeship that New York literary engineers had enjoyed since the heyday of the "Atlantic group." By accusing the West Coast of having no underground, Wilson attempts to deny it the cultural depth of the East.

Kenneth Rexroth, who despised East-Coast literary critics such as Wilson, agrees that California is depthless but argues that this lack of depth is not a bad thing. Rexroth echoes Wilson, asserting that there is "nothing underground about" the city $(1957 \mathrm{~b}, 179)$. Like the city's trolley cars, San Francisco's literati expose themselves and the machinery of their conveyance. The means of production in San Francisco, Rexroth claims, are widely available to whomever can spot them. Lawrence Ferlinghetti, the exemplary 
figure of San Francisco's do-it-yourself avant-garde, remembers that Rexroth "maintained that we had all fled West to escape the dead hand of the East Coast literary world" (Ferlinghetti). Indeed, Rexroth played impresario to massive East-to-West relocation. His unique way of representing San Francisco as simultaneously more democratic (i.e., less "underground") and otherworldly than the East Coast inspired, to some extent, the large-scale relocation of so many of America's most innovative poets.

Rexroth insisted that what is most special about the city is its peculiar relationship to the East-Coast literary establishment. According to Rexroth, the city's inhabitants bypass the commodification of talent and therefore live free from the "dense crust of custom" under which cities such as New York and regions such as the South produce their art $(1957,179)$. San Francisco does not suffer from such "surface phenomena" as custom (179). There is no fixed system of talent, no standard affective responses through which to handle literary products. Rexroth reasserts this San Francisco exceptionalism in his unofficial role as gatekeeper for West-Coast literature. For instance, in his afterword to Frank Norris's McTeague (1899), a novel whose mining theme expresses a complex relationship to the "underground," Rexroth explains that San Francisco is "a city mercifully spared the westward radiation of the great light from Plymouth Rock" (1964, 347). ${ }^{163}$ Repelled by the American work ethic and its ties to religious fundamentalism, Rexroth poses as a bohemian separatist. Like the "lost" generation who accompanied Gertrude Stein and Alice B. Toklas (both native to the Bay Area) to their Parisian literary salon, Rexroth prefers to exile himself from the American scene. If not for his capacity to think of San Francisco as an international zone, Rexroth confesses that "I would leave the United States for someplace like Aix en Provence—so fast!" (1957, 180). Living in San 
Francisco, Rexroth indicates, is akin to living in a foreign country. To further this analogy, Rexroth claims to "feel like I ought to get a passport every time I cross the Bay to Oakland or Berkeley" (180). This echoes Stein's now famous quote about Oakland"there is no there there" (289). ${ }^{164}$ Compared to Stein's great renunciation of local affiliations, Rexroth rings a little provincial, as though he engineered the San Francisco Renaissance in part because he couldn't bring himself to cross the Bay Bridge. Despite this affected physiological provincialism, Rexroth is blind to his need for specific soil. $\mathrm{He}$ chooses to think of the poets of the San Francisco Renaissance as "“disaffiliated,"” by which he simply means that their poetry escapes the clutches of East-Coast sophistication $(180) \cdot{ }^{165}$

Rexroth began cultivating this nativist pride long before Ginsberg's Howl transforms it into a sermonic pronouncement for a generation of disaffected youth. In an essay titled "Regionalism Makes Good: The San Francisco Renaissance," Linda Hamalian addresses Rexroth's relationship to New Deal politics. She claims that it is a mistake to think that the East-Coast Beats (i.e., Kerouac and Ginsberg) brought literary revolution to the West Coast. To assume, as many do, that Ginsberg's performance of Howl at the Six Gallery Reading in October 1955 is the inaugural moment of the San Francisco Renaissance is to overlook that the Renaissance began as a regional movement nearly thirty years earlier, when Rexroth, new to the Bay Area, wrote an essay titled "The Possibilities of an Intelligent Regionalism in California" (Hamalian 214). In the essay, Rexroth argues that writing of a "regional nature" will enliven a declining reading public, especially those citizens traditionally considered "too poor or too illiterate" for national periodicals to market themselves to (Rexroth qtd. in Hamalian 214). In short, Rexroth's 
efforts to reform the production and distribution of creative writing on the West Coast reveals that he conceived of "democracy in dynamic terms," the same terms "Walt Whitman had articulated more than fifty years earlier in Democratic Vistas" (216). ${ }^{166}$

Hamalian's refined understanding of the San Francisco Renaissance follows Davidson's history of the same literary moment. ${ }^{167}$ However, neither Hamalian's nor Davidson's accounts consider that Rexroth's regional aspirations likely derive from the fact that he was employed by the WPA at the time he arrived at San Francisco. The essay Hamalian alludes to was written (under a pseudonym) for a WPA-run magazine titled Material Gathered on the Federal Writers Project. Rexroth's pro-regionalism stance was thus influenced by a populist publication whose stated aim was to promote public literacy via internalizing regional paradigms. When not under the influence of such populist politics, Rexroth is less interested in developing a literate public sphere and more interested in having the specific soil of San Francisco appear transcendent.

For instance, in his celebration of the godfather of public sphere poetics in America, Rexroth applauds Whitman's ability to transform the localized detail into the universal symbol. In a review of Leaves of Grass, Rexroth claims that Whitman "found cosmogony under his heel, all about him in the most believable details of mundane existence" (qtd. in Hamalian 220). This sentiment, which Hamalian claims is "the background for what came to be known as the San Francisco Renaissance," represents a separation of "American soil" from democracy (220). Like all arcane modernist aesthetes, Rexroth demonstrates an interest in materiality linked to an interest in universals, or (as indicated by his choice of the word "cosmogony") the "universe" itself. Davidson recognizes this same universalizing use of materiality in San Francisco 
Renaissance poetry, claiming that the poets of this movement took as their subject "the ground of numinous presence" (qtd. in Hamalian 222) ${ }^{168}$ Poet Diane Wakoski likewise claims that the San Francisco Renaissance depoliticized "Whitmanian" aesthetics. In an essay titled "The Birth of the San Francisco Renaissance: Something Now Called the Whitman Tradition," Wakoski argues that the combination of autobiographical voice and precise observation of the material world endows the San Francisco poets with that elusive quality wherein cosmopolitan aspirations transform local affiliations into the sublime moments notable in such poems as "Crossing Brooklyn Ferry." In sum, once out from under the "constraints" of the New Deal politics, Rexroth et al in San Francisco discard the social justice agenda but retain the regional boundaries, which is another way of saying that their view of themselves as standing on the pivot point of politics and art erects the bulwarks of a provincialism. In effect, this overestimation of San Francisco as exceptional terrain create a West-Coast version of East-Coast literary establishment.

Hamalian reminds us of the necessarily multicultural nature of even the most provincialized pivot point. She claims that " $[w]$ ith the emergence of the West Coast as a literary center, a kind of 'multiregionalism' took over, which perhaps formed a prototype for the current multiculturalism (with the old boys network short circuited)" (228-229). Though it is necessary to think about San Francisco as the kind of nexus of cultural paradigms that engenders the multicultural moment, this conception of West-Coast exceptionalism overlooks two important problems. First, rerooting anywhere contradicts the delocalizing aesthetics that brought the deracinated multitude together in the first place. Second, lost in this conception is the simple observation that the engineers of the San Francisco Renaissance only recognize masculine models of artistic expression. ${ }^{169}$ 
One of the primary characteristics of this all-male "cultural theater" (to use Ginsberg's words) is a refusal to acknowledge the real-time grit and gambles of living in a city. San Francisco has emerged from the mid-century as something similar to what Wheeler calls an "Open City," a uniquely utopian urban space that is "based on joy and interracial understanding rather than violence, urban dread, and old griefs" (164).

This mystifying, seemingly apolitical mode of regionalizing urban space, which develops in the wake of Rexroth's discourse, ignores crucial sites within the very region the San Francisco poets call home, namely the segregated enclaves that exist in the San Francisco cityscape, the kinds of enclaves that have been featured in American novels set in the Chinatowns of America from Louis Chu's Eat of Bowl of Tea (1961) to Fae Ng's Bone (1993). Wheeler claims that fictionalizing these enclaves establishes a "diaspora [sic] sense of place" wherein "a sense of 'home' [is] situated not in one place but triangulated among multiple sites" (177). This is the minority response to the cosmoprovincialism of Rexroth's "cosmogony." In this sense, then, the Chinese American fiction that grows separately but in concert with the official San Francisco Renaissance literature and discourse is actually more "numinous" than San Francisco Renaissance poetry, as it represents social space that simultaneously contains more than one reality. It is China and America at once, as it involves (especially notable in Chu, Ng, and Amy Tan's work) multi-generational negotiations of the Chinese immigrant's relations to place. ${ }^{170}$ More importantly, these multiple intersecting senses of place, when embodied in a single text, exemplify a realist point of view that grounds what might otherwise be taken for rootless cosmopolitan subjectivity in a rational relationship with a specific place. As I argue in the following section, Kingston's writing, especially her engagement 
with the street-level confluences and incongruities of urban space and literary space, represents a stronghold of the realist tradition in America. The cultural mysticism people read into Kingston's prose, what Mary Gordon calls her "impossible" quality, is a misreading based on the false dilemma that Asian American writers are always representing two places at once, the living ground of their America and the floating atmosphere of their silent heritage land (Gordon ix).

\section{IV}

Huang has criticized Kingston for stooping to such a traditional American literary register as realism. By buying into urban realism, Huang claims, Kingston enacts the "deeply rooted linguistic positivism of the Western literary tradition" (142). This positivism "perpetuates itself in the wake of multicultural recanonization" and "prevents the formation of radical, transnational models of American literary studies" (142) ${ }^{171}$ In short, Huang and other transpacific Asian American studies scholars argue that Kingston furthers the cause of American literary conventions, subordinating Chinese literary conventions to a secondary status. This divided allegiance produces "textual fractures" in Asian American realism, or incongruities between the practice of American codes of representation and allusion and the use of heritage cultural knowledge. According to Huang, these incongruities "haunt [Kingston's] realist claims" (5). I believe the opposite is true, that Kingston's complex commingling of literary allusion and local knowledge supports her realist claims and that her realist claims are internationalist. In this section, I will begin by defining "positivism" as a habit of realist representation. I will then examine Kingston's reclamation of the literary trope of the "marginal man" walking in the city. 
Huang claims that "the generic preference for realist, personal narratives [in Asian American literature] is too obvious to miss" (144). However true this may be, Huang's apposition of "realist" and "personal" is outdated. If anything, unless it is ethnographic, the contemporary "personal narrative" is too abstract a genre to be associated with realist representation. One needs only to look at Kingston's own surreal "memoirs" to see that realism and the personal narrative have parted ways. Nevertheless, Kingston's own cohort criticizes her for writing in the Western, Christian tradition of autobiography. In the polemical introduction to The Big Aiiieeeee!: An Anthology of Chinese and Japanese American Literature (1991), Frank Chin and others remind readers that "every Chinese American book ever published in the United States of America by a major publisher has been a Christian autobiography or autobiographical novel" (xii). Thus Kingston's choice of genres signifies that she is "reborn in acculturation and honorary whiteness" (xii). But these charges overlook the fact that Tripmaster Monkey is not autobiographical. If anything, its realism stems from a positivist ethos that Patricia Lin argues "anthropoligizes" rather than "novelizes" the US. This brand of positivism "exposes the constitution of everyday or taken for granted realities" (335). Thus, thinking about positivism as too "Western" ascribes ethnocentric lines of division and entitlement to a representational trope that might actually be the best tool for announcing the unique presence of Asian Americans in the American city. In short, to think of Kingston's positivism as a whitening technique is to overlook the cosmopolitan impulse at the root of even the most localizing urges toward fact-finding.

I understand "positivism" as an approach to a subject matter, a preference for objects over social texts. Positivists stress the importance of "things" because they think 
American character takes shape in response to what Americans know about the material world. They seek a deep relationship to material conditions, one that (in Bill Brown's words) is "irreducible to ownership" $(2003,13)$. This pseudo-scientific relationship to the material world runs the risk of mistaking literature for a transcribing device that records what is there to be perceived. The main fallacy of positivism is thus the assumption that knowing how things work is as good as having control of the means of production. A positivist argument can, for instance, demonstrate how inequality is perpetuated through the rhetorics of diversity. The problem is that this demonstration is, for the positivist, an adequate consolation for the fact that inequality exists. In short, positivist representation tends to overemphasize facts.

Kingston is not a "positivist writer" per se. But she does value the catalogues and indices of social space over any large, clean claims one might make about what takes place on such space. Her impulse is to fact-find via a method not unlike her novel's protagonist's namesake. The sheer amount and complexity of what Kingston presents is of a piece with the evocative literary material of Whitman's catalogues in "Song of Myself." The problem is that the logic of multicultural recanonization counts Kingston's findings as an externalization of her essentially Chinese American identity. In short, misreadings of Kingston begin with an assumption that her positivist work ethic is actually a racially particular species of knowledge.

Like many Chinese Americans engaged in the project of representing the city, Kingston focuses her attention on the everyday details gathered from ground-level experience. ${ }^{172}$ In fact, peripatetic meandering is arguably the primary trope through which Asian American writers represent cities. The Asian American protagonist walking 
around the city was a key feature of most mid-century Asian American literary offerings. For instance, Bulosan's memoir and John Okada's novel No-No Boy (1957) both feature long, uneventful walks through the side streets of major West-Coast cities. This pervading interest in representing ground-level experience is an indication that these protagonists lack a place to settle. They enact Michele de Certeau's maxim: "to walk is to lack a place" (103). When this indication of lack appears in fiction, the result is a reader who is allowed the cosmopolitan privilege to be "a viewpoint and nothing more" (de Certeau 92). This binary of "walkers and voyeurs" is helpful when thinking about Asian American accounts of walking through the city. ${ }^{173}$ As Rita Felski explains, de Certeau's "distinctive logic" of articulating everyday life in the city reveals the "creative and unpredictable ways that individuals negotiate their environment" (611). More importantly, de Certeau counters the "bird's eye view of Left intellectuals who pay lip service to the value of daily life while peremptorily cramming it into the box of a prefabricated political diagnosis" (611). Articulating the dilatory nature of daily life, de Certeau's understanding of walking in the city "offers a form of resistance to strategies of power" (611). Kingston, via Wittman's uneventful strolls, provides a fictionalized representation of the resistances de Certeau delineates. Kingston also offers insight into the way such representations can subvert exploitive reader interests.

For instance, in the third chapter of Tripmaster Monkey, the same chapter wherein Kingston recontextualizes Kerouac, Wittman walks down Market Street, near the bus depot, through the heart of the San Francisco Tenderloin. Famously the place where Kerouac and Snyder used to drink rotgut from paper sacks and pretend to be homeless, the Tenderloin is an area described in tourist guides as "the worst neighborhood in San 
Francisco." It boasts "loads of drug dealers, addicts, prostitutes and mentally unstable street people" but is nevertheless "one of the city's most exciting and diverse locales." From this area of the city, an area wherein the reader might be prone to imagine himself slumming, Kingston envisions San Francisco at large. She does not delineate the plight of the immediate area. From the Tenderloin, Wittman sees all of San Francisco as a twodimensional film set, the type of phony self-representation Sal Paradise encounters in Cheyenne, WY. Noticing how fake the city seems from its poorest place, Kingston's narrator remarks that a "storm will blow from the ocean or down the mountains, and knock the set of the City down. If you dart quick enough behind the stores, you'll see that they are stage flats propped up. On the other side of them is ocean forever" (67). This vision of the city as a Western ghost town, a set of "stage flats," manipulates the point of view of the reader. The reader is not the theater-goer but the stage hand; she is forced to consider what is missing from the city, rather than what amusements and illusions it has to offer. Kingston is here renovating the idea that American cities are at heart selfconscious spectacles, forms of urban experience and of experiencing the urban world wherein the beholder plays witness to an unanswerable performance. This assertion is reminiscent of Alan Trachtenberg's argument in The Incorporation of America that the twentieth-century American city is presented as a "frank illusion" or "an admitted sham" that dislocates any orienting "vision of the real" (231).

To deepen the contemplative moment, Kingston asks and answers an absurd rhetorical question: "And what for had they set up Market Street? To light up the dark jut of land into the dark sea. To bisect the City diagonally with a swath of lights. We are visible. See us?" (67). Kingston is here highlighting the tenuous existence of the Asian 
American in the city. She is also mimicking the blindness that non-Asian American writers have toward the symbolic resonance of the Pacific Ocean. To claim that there is nothing but ocean to the West of San Francisco is to deny the existence of the Pacific Rim. ${ }^{175}$ On the other hand, to signal to the ocean that the city exists is to indicate that there is in fact something/someone West of San Francisco. Kingston is therefore asserting, subtly, that San Francisco is not the last city of the West but the first city of the East. ${ }^{176}$

Since the modern city is the preferred terrain of canonical Western texts, the Asian American presence in it carries some general symbolic prescience, forecasting what Huang calls the "multicultural recanonization" of recent years. Because Chinese Americans were for so long thought of as urban denizens huddled together in the city's excretory zones, its "Chinatowns," Kingston's choice to make fiction from the experience of a Chinese American man walking out of Chinatown and into the city proper also speaks to issues of social and economic mobility. ${ }^{177}$ Ultimately, Kingston's representation of city walking rescues San Francisco from the ephemeral state the Renaissance tried to revise it into. She appropriates the cultural capital often dispersed in canonical city fiction, and flips the directional path of Westward migration. To do this, as I explain in the following section, Kingston engages and updates the codes of representation common to realist city fiction.

\section{V}

In her introduction to the recent $P M L A$ special issue on "Cities," Patricia Yeager contends that the shift from the city as the site of modernist male disillusionment to the site of ethnic identity struggle is complete. As Yeager explains, "one of the urban 
imaginary's tasks" is "to give body and voice to the multiplying subaltern publics that struggle to transform the spatial politics of cities" (21). Advancing this argument, Yeager criticizes Henri Lefebvre, possibly the founding theorist of city space, for denying "the possibility of any working connection between "mental or literary "places"' and space 'of a purely political and social kind" (21). In other words, Yeager claims the city as a trope of literary representation, rather than a psychosocial conundrum to be pondered from a distance. According to Lefebvre, literary texts "can do little to assess the contradictions of place, since, as 'discourse,' literary productions are simply Cartesian grids - topoi removed from lived social space" (21). Yeager disagrees, asserting that "literature has the advantage" in negotiating the politics of city space. The assets of literary meditations/representations of the city include: "The intertwining of codes; the habit of overdetermination; the multiple mapping that accompanies condensation and displacement; the layering that comes with the use of compound plots, points of view, tonality, atmosphere, and meter; and the dense range of figurative speech" (21). In other words, the city needs literature to articulate its fractured realities and multivalent social possibilities.

Yeager's beef with Lefebvre opens a window onto the cosmopolitan/provincial politics of academic discourse about the city. Social critics and theorists such as Lefebvre have the cosmopolitan impulse to separate city spaces into categories: representations of space (manifested through planning and architecture) and representational space (manifested in the activities of inhabitants). The former is, according to Lefebvre's Marxist analysis, a source of oppression, whereas the latter is a site of resistance. Literary critics, on the other hand, tend to conceive of public space as a container of activity that 
changes with the nature of the activity. ${ }^{178}$ This is the "leopards in the temple" analogy drawn, by Joseph Roach and Morris Dickstein, from the Kafka parable to explain some of what is unpredictable about city urban codes. ${ }^{179}$ While Lefebvre agrees that the leopards can rearrange the daily goings on of the temple, their presence doesn't automatically mean that the temple and what it represents dissolves. Such arguments, posed by literary critics, overemphasize the liberatory effect of deviant social behaviors. According to Lefebvre, to think of transgressive social behavior as liberatory is to traffic in a homology that mistakes behavior similar to revolution with behavior actually engaged in synthesizing a contradiction within social codes. Lefebvre's dialectical urbanism, like Jameson's "cognitive map," which stands in for a totalizing view of urban space, emphasizes what Gary Bridge and Sophie Watson call "a conception of the whole city, rather than the specialisms of scientific urbanism" (337). Like Foucault, who understands the administration of public space as dictating urban subjectivity, Lefebvre demonstrates the futile provincialism of such transgressive behavior.

My point in articulating this debate is not to indicate that literary critics are provincial and social theorists cosmopolitan (though the tracks are certainly splayed in a similar pattern). Even if this is the case, it doesn't change the fact that, in recent years, cities in American fiction have become strongholds of realist representation for minority writers. In contrast to the legacy of the disorienting, spectatorial city powerful in American fiction since Sister Carrie (1900), "inner-city" fiction since mid-century reorients the spatial reality of cityscapes. ${ }^{180}$ Ann Petry's The Street (1946), Ralph Ellison's Invisible Man (1952), Saul Bellow's Adventures of Augie March (1953), Harriette Arnow's The Dollmaker (1954), N. Scott Momaday's House Made of Dawn 
(1968), Joyce Carol Oates's them (1969), John Edgar Wideman's Homewood Trilogy

(1981-1983), and Sandra Cisneros's House on Mango Street (1985) are just a few urbanset novels by women and minority writers that present a localized alternative to the modernist city novels of spatial disorientation. These novels suggest that, as a highbrow literary trope, "the city" gives way in the second half of the twentieth century to more socially responsive issues, arguably even producing a new genre of fiction that John Giles and Carlo Rotella refer to as "inner-city" or "urban" literature. ${ }^{181}$

However, it is a mistake to think of recent multiethnic fiction set in the city as an appropriation of a dominant literary trope. In fact, the first major thrust toward thinking of the city as a literary laboratory comes from the work of Robert E. Park, an early collaborator with Booker T. Washington. ${ }^{182}$ As James Kyung-Jin Lee points out in his article "The City as Region," contemporary writers who confront the city revitalize Park's old concept of the "marginal man," "a social type freed from bonds of tradition and custom, enabled by his cosmopolitan vision to observe different cultures and communities without the imprimatur of any one group's social control" (Lee 148). The marginal man is thus liberated from group affiliation, with its various censorships and allowances. The price is his marginalization, or existence outside the official public sphere. The "marginal man" is the missing link between high-intellectual theorizing about the city (exemplified by Lefebvre) and the bean-counting grunt work of literary criticism. It is important to note that he was derived from Park's "investigation of the 'Oriental' and 'Negro Problem'” (148).

In other words, what has become known as the white man's burden of disorientation and identity crisis in the city (cf. Kerouac's " white man' disillusioned") is 
actually a result of sociological inquiry into racial subjectivity. This "marginal man" has since taken "many other names," all of which obscure his origins as a concept used to describe the perceived experience of fitting the racialized otherness into dominant social structures. Lee includes among the marginal man's pseudonyms "Benjamin's flâneur [and] George Simmel's 'stranger"' (148). Both of these figures are pivotal to literary scholarship, providing the psychogeographical vocabulary for understanding the dynamic complications of modern life. ${ }^{183}$ The flâneur helps us understand Baudelaire's genius (including his reasons for translating Poe), Rilke's The Notebooks of Malte Laurids Brigge (1910), and the existential offerings that both inspired, namely Sartre's Nausea (1938) and Camus's The Stranger (1942). ${ }^{184}$ Each of these texts features a "detached walker of the city" through whom a conception of modern urban complexities emerge. According to Lee, this walker:

shares the common attribute of its ability to observe through detachment, to experience the city without falling prey to its forces. He makes uncanny what appears familiar in the mundane life of the urban; he himself is uncanny, a personification of the landscape's repressed, which brings to light the darker forces that gird and energize the city. (148)

In short, the walker is the cosmopolitan perspective personified, another version of Whitman's vagrant cosmopolite, peeking in windows and never being charged. Since Park's conception, though, the marginal man's racial markings have disappeared. Indeed, most of the marginal man's corporeality has disappeared; Malte Laurids Brigge is unmarked save the scuffs he acquires in Paris. However, as Lee explains, Park had originally intended this subject position to be analogous with that of the "urban 
ethnographer," who has "permission to bring objective credence to subjective perception" (149). Interestingly, Park's earlier name for the marginal man was "hobo." His ethnographer's authority was thus not intended to emerge from his detachment and invisibility, but from his ground-level expertise of the nooks and crannies of the city. Not unlike Charlie Chaplin's character in City Lights (1931), who escorts a blind woman around San Francisco, the marginal man was to be a single, solitary person whose life was not (as it had become in the novels of Rilke, Sartre, and Camus) solipsistic. He is at root a public servant, directing traffic and collecting information about the untotalizable landscape. This is his vocation.

Kingston revitalizes this obligation through Wittman, a character who appears to be strictly self-serving but who is at base a cautionary tale teller and a community builder. Hence, Wittman takes to the street. There, he joins in the tradition of young male artists who ponder "what he will do and what he will not do." He "Daedalates," as Kingston's narrator explains in her not-so subtle reference to Joyce's famous artist as a young man (67). But Kingston doesn't allow Wittman the arms of "silence, exile, and cunning." ${ }^{, 185}$ Instead, his job for most of the novel is to worry about "How to make a living. What to eat" (67). Chinese Americans with no trade can work in fast-food, or, "if you're the more imaginative type ... build yourself a cart or stand, sell umbrellas on a rainy day" (67). The option of being a "boulevardier," the option available to most young artists in canonical Western literary narratives, is not allowed to Wittman. The narrator intones in despair, as if for Wittman and others like him: "How am I to be a boulevardier on Market Street? I am not a boulevardier; I am a bum-how, I am a fleaman” (68). ${ }^{186}$ Wittman may not be a man about town, but he can pretend to be one of "Kerouac's 
people, tripping along the street" (69). He can remake his environment by commingling his literary knowledge with local, geographical allusions. Composing San Francisco in this way, Kingston reveals a key reality for the marginal man: the signs that locate one as literate and the signs that locate one as part of a particular identity group are indistinguishable. $^{187}$

Kingston tests this key reality in the first chapter, when Wittman tries to impress a white girl. The entire first chapter of Tripmaster Monkey is divided between Wittman's experience walking the city (an experience I'll discuss at length below) and his experience failing to charm a girl. His usual flirtation tactics are to brag about the unique conditions of his birth. If that fails, he reads poems until the woman submits. As the narrator explains, Wittman enjoyed "taking credit for the circumstances of his birth"; he was "born backstage in vaudeville" and raised in a "theatrical trunk" (13). Born at the site of burlesque comedy, Wittman claims the right to parody his racial identity, or rather, to define the "circumstances of his birth" as he wishes, rather than as his racial markings dictate. Wittman has (or at least pretends to have) the freedom to consider himself to be "burlesque" as much as he is "Chinese." This freedom, Kingston asserts throughout the novel, is uniquely available via the stage. The vaudeville stage offers an opportunity to blend the surrogation of racial traits and the improvisation of the detached artist. ${ }^{188}$ The sensuous presence of the actor is an occasion to consider the slippage between the cultural interactions and the identificatory motifs that produce selfhood. In other words, Kingston pushes Wittman slowly toward the theater and theatricality because, in Wittman's hand, performance signifies a process of standing-in for, and even forgetting, an original conception of the self. As I'll discuss in the final section of this chapter, 
Kingston's elevation of the liberatory theatrical stage is actually the last stage of delocalization, as it presents a generic, movable locale as the terrain upon which the narrative persona gives birth to herself.

\section{VI}

Kingston foreshadows this "final stage" of delocalization as Wittman performs his manic blend of talk-stories and poems for a one-woman audience. In the midst of his recitation, the narrator interrupts: "a door had sprung open before you, and now you were among the alembics in the firelight. ... Your theater came into being" (16). This enigmatic line is actually an uncredited reference to Rilke's account, in The Notebooks of Malte Laurids Brigg, of an unnamed poet turned playwright. ${ }^{189}$ The Rilke quotation, from which Kingston draws the remark about Wittman, is an impressive, ironically romantic, meditation on the importance of realist minutiae. In the passage, Malte Laurids Brigge addresses the burgeoning realist playwright directly:

[S]ince your blood drove you not to form or to speak, but to reveal, ... you made the enormous decision to so magnify these tiny events, which you yourself first perceived only in test tubes, that they should be seen by thousands of people, immense before them all. Your theater came into being. You could not wait until this life almost without spatial reality, this life which had been condensed by the weight of centuries into a few small drops, could be discovered by the other arts ... You couldn't wait for that; you were there, and everything that is barely measurable — an emotion that rises by half a degree; the angle of deflection, read off from up close, of a will burdened by an infinitesimal weight, the slight cloudiness in a drop of 
longing, and that barely perceptible color-change in an atom of confidence — all this you had to determine and record. (Rilke 82-83) In his excitement about small-scale ranges of reference, Rilke's narrator glorifies the unnamed writer's ability to dramatize the scarcely measurable truths of everyday life. The "tiny events" are in effect a positivist condensation of "emotions." The playwright's positivism is a slight caress that makes iridescent the borders of identity. Rilke praises realist art for its use of the increments of "barely measurable," "half a degrees," and "angles of deflection" that are recognizable only at close quarters. This condensation, Rilke implies, is a capsule of tenderness that is available to "the other arts," by which Rilke here (in the middle of his first and only novel) likely means the various literary arts. The unnamed writer's ability to put on the stage these minutiae is applauded by Rilke and will be applauded by Kingston throughout Tripmaster Monkey, via a narrative voice who follows its protagonist's slow transition from an isolated street poet to an energetic stage performer.

Ultimately, as she foreshadows as early as the closing passage of the novel's first chapter, Kingston draws parallels between imagining city space as literary space and dramatizing Chinese American identity. The first chapter ends with Wittman deciding to write a play, a one-man show, for Nanci, the woman who doesn't love him. Kingston's turn to the theater seems like a turn away from realism, or at least a turn toward a literary genre whose "realism" has only a homologous relationship to the realism of fiction. However, in light of the Rilke argument about the potential dramatization of realistic minutiae, playwriting becomes Wittman's form of identity delocalization. It becomes a way of making racial identity into an accident of corporeality, or "angle of deflection," 
rather than a matter of essential reality (Rilke 83). In other words, the fact that the focal point of a one-man show is Chinese American is a matter of physical presence, not a matter established through any script of collective identity. The writer is relieved of the burden of ethnic memory as the burden of recognizing racial identity is transferred to the theater's audience. Ultimately, Kingston's turn to the stage allows Wittman to obscure the precise location of his Chinese Americanness. ${ }^{190}$ Instead of blowing out his brains, Kingston has her protagonist unfold the contents of his brain before an audience.

Wittman's decision to write a play vitalizes his otherwise useless ability to blend local and literary knowledge. Wittman's community-theater becomes a storehouse for his conjoined, democratizing observations. This is Kingston's nod to the New Deal social welfare imagination. In addition to the public readings of Rilke and the "dream" of Whitmanian public transportation, Kingston presents the theater as a branch of public service. Wittman wants to revive "deep-roots American theater" (141). He wants to perform plays that last for days, plays that "leave room for actors to do improv, a process as ancient as Chinese opera and as far-out as the theater of spontaneity that was happening on streets and parks" (141). In other words, Wittman wants to produce plays the way Kerouac and Pollock produce their texts. He wants to do the kind of writing wherein, as Michael Hrebeniak says of Kerouac's writing, "the writer becomes the act of writing" and "the changing stages of the self must be discovered and inscribed as a single action" (150). More importantly, though, he wants to do this kind of writing as though it were a "Chinese" form.

Kingston's blending of American and Chinese aesthetic codes occur throughout Tripmaster Monkey. However, Wittman's vision of the stage as a 
transcultural/transhistorical performative zone takes shape in contrast to what Wittman describes as "red-hot communist Chinese" theater (141). ${ }^{191}$ This distinction is a remnant of the fear among Chinatown residents of being considered sympathizers with the Cultural Revolution. From this fear comes a false conception of a division between spontaneity and political commitment, which ultimately wrecks Wittman's play’s ability to affect a change in his own conception of his individual identity. Wittman thus transforms himself into a one-man show simply to embody the vertical pronoun, or as Wittman calls is, the "bad ass motherfucker personal pronoun of the active voice," which he’s longed to steal from Kerouac and claim for Chinese American art (318). ${ }^{192}$

Therefore, the tension between the call for community-theater and the call for a community to watch one man be a theater constitutes an organizing tension of the second half of the novel. Despite the outcome, which strikes a balance between ensemble and one-man show formats, the focus on theater as the desired cultural form for a 1960s beatnik Chinaman is in keeping with the tension between localization and delocalization that emerges with the ironically place-based fruition of delocalized aesthetics. Wittman wants a WPA-type job as a public servant/artist. But he strikes a telling distinction, namely that there's no longer any such thing as a writer who serves a larger entity such as "the state." He conflates organized writers collectives with those of "corporate playwright” status: “"I'm no playwright who scripts industrial shows and hygiene films for the educational-military-industrial complex"' (239). Wittman is so far removed from large-scale government subsidies for the arts that he sees no possibility of there being a benevolent instructive art. It's not that Wittman doesn't believe in instructive art (see the bus reading fantasy and the Kerouac prose corrections). It's just that at the end of the day 
he doesn't think such a shift is likely. Furthermore, he finds it anachronistic and artless, far from the majestic status he feels his theater arts should take.

Regardless of Wittman's distaste for the art of social welfare, Kingston reveals his social welfare politics in an episode wherein Wittman tries to convince an "old fut in B.V.D. undershirt" (aka, the local Benevolent Association president) that he should allow Wittman to produce his play in the Benevolent Association hall. Wittman argues for the social usefulness of his play. Initially trying to appeal to the old man's Chinese heritage, Wittman translates the Chinese synonyms for "theatrical play," words that signify "To make air. To give to airy nothing a local habitation and a name" (255). Kingston adds to this Sino-centric play on the localization of theater when she gestures to a statue of Gwan Goong, sitting on the Association mantel, explaining that he is the "god of actors and writers and warriors and gamblers and travelers" (255). In apposition, these "occupations" assert that the performance artist and the rootless drifter are the same. Placed in such a horizontal alignment, the actor and writer become synonymous with the Chinese drifters who first came to America. As with all of her gestures at Chinese culture, Kingston does not mystify the status of either Chinese language, mythology, or history. These details emerge in the midst of Wittman's frustrating attempt to convince the "old fut" that his play is appropriate for the Benevolent Association. A ChineseAmerican fraternal society started up by first-generation Chinese immigrants, the Association represents both the antiquated old guard of Chinese American bachelor men and the makeshift ingenuity of Wittman's lot. The Association is a cooperative. Wittman's acknowledgement of the Association's symbolic patronage of such "workers" as himself secures him a place to produce his one-man show. As Wittman asks in broken 
Chinese (rendered in the novel as broken English): "Else, what Association for, huh? Collecting dues? ... You bury old men. You be nothing but a burial society" (255). Without Wittman's generation's fervor to produce public art, the Chinese immigrant experience will amount to a lifeless burial system, a co-op with no socially useful goal save interment. Thus Wittman saves the Association from the very provincial leanings from which Kerouac's delocalization saves American literary regionalism. In other words, Wittman offers a system for honoring diminished things an alternative to its otherwise strictly nostalgic agenda.

In her chapter on the play itself, the last chapter of the novel, Kingston oscillates between Wittman's longwinded logorrhea and the narrator's insights into the larger cultural meaning of his exhaustive delineation of the contents of his training. Wittman's long, improvised soliloquies are peppered by spectacles of racial and cultural parody, including a biracial Cheng and Eng trading vaudeville jokes in Southern and Asian accents, magic tricks, juggling, trapeze artists, and a geriatric cancan performance. As the play reaches its climax, the narrator lists Wittman's “theatrical ancestors," characterizing them as those who "perform without a permit" (301). A nearly 200-person list, this huge, idiosyncratic catalogue includes "filmmakers of tourists, wildcat miners, cigar makers without the white label, ... cubic air breathers, miscegenists, landsquatters ... crowders into single-family dwellings ... un-Americans, red-hot communists, unbridled capitalists ... and exploders of fireworks" (301-302). Everyone in the catalogue is named for the "law" he or she breaks. To think of these lawbreakers as ones who "perform" is to make a bold statement about the nature of post-Civil Rights democratic action. On the one hand, this distinction is absurd, especially since the one principle that holds the list together is 
that the actions named are difficult, if not impossible, to understand as "performances." On the other hand, calling these practitioners of civil disobedience "performers" asserts a common argument in postmodern philosophy, namely that it is impossible to simulate disobedience without making it mistakable for the real thing. As witnessed in Baudrillard's command to "Go organize a fake hold-up," Kingston's semantic play highlights the absolute affront that certain kinds of public performance pose to civil society (Simulacra and Simulations, 408). ${ }^{193}$

Following this inventory of civil disobedience, Kingston's narrator lists tragic fires associated with American theater houses. The paragraph ends with a revolutionary fervor and assumption of collective identity that is noticeably absent elsewhere in the novel: "We'll do anything for lighting, die for it, kill for it" (302). The fire inventory functions quite differently than the performers inventory, as it names facts as facts, rather than interpreting civil disobedience as performance. The fire inventory is less of an affront to polite society than is the inventory of civil disobedience. It names disasters, the destruction of the places of performance rather than the possible innovations one can apply to the very idea of "performance" in democratic social space.

Together, these inventories prove prescient, as Wittman attracts a firetruck after setting off thousands of fireworks. Of course, Wittman's fire is not real, though Kingston's narrator's dedication to thinking that Wittman is a fiery revolutionary is real:

Of course, Wittman Ah Sing didn't really burn down the Association house and the theater. It was an illusion of fire. Good monkey. He kept control of the explosives, and of his arsonist's delight in flames. He wasn't 
crazy; he was a monkey. What's crazy is the idea that revolutionaries must shoot and bomb and kill, that revolution is the same as war. (305)

This passage, and many others like it, figures Wittman as a marionette, or a monkey who dances to his father's concertina and who might "let us tweak [his] ear, and kiss [his] other ear" (340). Kingston establishes dominance over her male artist in this way. She implies that the real writer is the observer of such manic behavior, the one can contextualize it into a larger social and literary history. ${ }^{194}$ What survives this oscillating inflation and deflation of Wittman's presence, especially in the lead up to his one-man finale, is the question of whether or not Wittman's objective is just. Is it right to want to be the first Chinese American playwright to yank an identity from "airy nothing," to overcome racial limitations by sheer emotion and sheer will? Kingston's narrator ultimately answers no, but what is right is the assumption that thinking territorially is another way of thinking about who one is. The placement of the Chinese American artist at the symbolic pivot point of America highlights the slippage between the interior and exterior determinants that mark one as "marginal." Wittman's ability to read the literary past of the San Francisco while existing entirely in the present, and his manner of coloring the landscape with the contents of his own brain places him as a luminous new center of the dividing line between the East and the West. 


\section{Chapter Four:}

\section{Old New England and the New Third World: Russell Banks and the Living Wages of Cosmopolitan Citizenship}

Through the local or regional, through our individual voices, we work to create art that will speak to others who know nothing of us. In our very obliqueness to one another, an unexpected intimacy is born. The individual voice is the communal voice. The regional voice is the universal voice. (Joyce Carol Oates, "My Faith as a Writer")

To us, our knowledge is worth nothing, is merely private information, the names and histories of our family relations, our secret fears and fantasies, our personalities observed obliquely from the inside. We exchange our knowledge for mere survival. (Russell Banks, Continental Drift 242)

The idea that the white working class is unremittingly racist or anything that hampers organization and coalition suddenly dries up when you specify an enemy. (Eric Lott, “The Wages of Liberalism”)

Despite the fact that I argue that Kingston dislikes race-based identity, the point of Chapter Three is not to signal a decline in identity politics in contemporary fiction. In fact, as I will argue in this chapter, identity politics are on the rise, just not in Asian American fiction. As Asian American women writers such as Kingston, Jessica Hagedorn, and Susan Choi enact what Nancy Huston calls the "pulverized writer's 
identity," white male writers such as Russell Banks and Richard Russo rush to inhabit the cramped space of overdetermined, or what Huston calls "polarized," writer's identities (14). ${ }^{195}$ Their objective, according to Mark McGurl, is to draw inspiration from rootedness, or, to use a phrase from Chapter One, to relish the "specific soil" that invigorates the banality of postwar white male identity. Kerouac poignantly sums up this banality as the state of being a "white man' disillusioned" in the city (On the Road 180). Kerouac's narrator in On the Road, Sal Paradise, experiences his classically problematic "wish" to be something other than white (viz., "a Denver Mexican, or even a poor overworked Jap") while walking through "the colored section" of downtown Denver (180). His context reaffirms the idea that localized specificity is what might mark the identities of white male writers. As Sal's disillusionment indicates, delocalization fails as a lifestyle especially for white men. In moments of pause or reflection, delocalization looks too much like the kind of alienation that Kingston parodies in Tripmaster Monkey. In other words, delocalization is dangerously close to one of the most hackneyed of literary themes. The days of individualized concerns taking center stage are over, if for no other reason because of how successful poststructural theory has been at questioning the centrality of the "stage" itself. In this chapter, I will argue that the process of providing substance for what it means to be a "white man" is of a piece with the process of thinking locally. The same calculations and rationality that produce local knowledge also produce what Sally Robinson calls "marked men." ${ }^{, 196}$ It is important to examine the similarities within these two processes because, when coupled, they enact a practical, even provincialized, process of gaining cosmopolitan credentials. Ultimately, this place-based 
process of cosmopolitan orientation humanizes the instrumental rationality of a global imagination the follows closely the logic of multinational capital.

Contemporary writers like Russo and Banks retreat from the alienating and multivalent cityscapes of modern fiction to find in the grain of a traditional American region (New England) the raw materials of world citizenship. Focusing mostly on the blue-collar communities rusting along the fringes of a bucolic region, these writers produce place-based fiction in the tradition of William Kennedy. Their regional foci announce the limitations of their imagination and thus allow for a veritable perfection of the regional narrative voce. By most standards, writers with such limitations on setting and voice seem far removed from international zones of the type of cosmopolitan fiction that writers such as Huston endorse. ${ }^{197}$ Regardless, novels in this mood have recently begun to win Pulitzer Prizes. Of course the Pulitzer, with its stated interest the fiction of American life, is arguably a poor barometer for cosmopolitan credentials. However, considering that it oscillates steadily between regionally themed novels and cosmopolitan themed novels, the Pulitzer does reflect some of the mores and expectations of the popular imagination. ${ }^{198}$ The two regional novels in recent years to earn Pulitzer Prizes, Russo's Empire Falls (2001) and Marilynne Robinson's Gilead (2004), feature a smalltown economic history and a small-town masculine narrative voice, respectively. However, these novels do not signal a return to nostalgic regional fiction. In fact I feel that their accomplishments at the level of plot and voice are enhanced by a sophistication that, especially demonstrable in the case of Robinson's narrative cross-dressing, indicates that the most rewarded American writers are setting their sights on the nuts and bolts of provincial affect, rather than perpetuating sentimental nostalgia for regional America. 
As Russo indicates in Empire Falls, cosmopolitan fantasies vibrate in the minds of those who inhabit the bankrupt economic zones of forgotten Maine. Russo's old men dream of traveling down the eastern seaboard to resort towns in Florida; his complacent diner managers dream of owning bookstores in Martha's Vineyard. Everyone else cycles back to thoughts of the Empire Shirt Factory, which closed down 30 years ago and may magically return any day now. As Horace, the local sardonic newspaper reporter, indicates, the town's collective dream is to see rich businessmen to come reopen the Empire Shirt factory:

They came to invest millions. For a while they were thinking about tech stocks, but then they thought, Hell no, Let's get into textiles. That's where the real profits are. Then, you know what they did? They decided not to build a factory in Mexico or Thailand where people work for about ten bucks a week. Let's drive up to Empire Falls, Maine, they said, and look at that gutted old shell of a factory that the river damned near washed away last Spring and buy all new equipment and create hundreds of jobs, nothing under 20 dollars an hour. (25)

As this theme exemplifies, contemporary writers of provincial affect are not uninterested in global vistas. In fact, they understand globalization through the poor places that modern capital and industry have abandoned.

So, where Kingston finds the seeds of provinciality in the hippest cultural forms of twentieth-century America, these writers find world citizenship in the grainy detail of provincial boondocks. In contrast to Kingston's focus on the interactions between racial identity and so-called "progressive" urban social spaces, such writers as Russo and Banks 
focus on the stasis of unmarked white men amid the decay of America's most storied region, New England. Though these two focal points couldn't seem farther apart, Kingston and Banks do share a basic motivation to represent the stem cells of twenty-first century America, the undifferentiated regions that have yet to stake or renew a claim to a specialized function relative to a body politic. Both writers essentially "think globally and act locally." In Kingston this global consciousness is represented in the relationship her protagonist has with the various histories of the locales he inhabits and in Banks it is present in the tone of "permanent mournfulness" affected by narrators who know personally the waste products of globalization.

"Permanent mournfulness" is a phrase that comes from a passage in Banks's most recent novel, The Darling (2004), in which the narrator reflects on the kind of sensibility that results from having spent one's life on the road of flight from one locale to the next, someone who has successfully resisted the impulse to "take root" (385). It is a timbre in the human voice that mobilizes local knowledge into a matter of characterization and storytelling, rather than a matter of fact and information. This distinction is important for a number of reasons. For one, thinking about local knowledge as something that is used in regional fiction, and not a simple precondition of fiction that gets labeled for one reason or another as "regional," underscores the difference between what we mean by "regionalism" and what we mean by "local color." Banks's fiction reasserts the idea that the former term defines the boundaries of geographical and cultural particularities and the latter defines a representational tool. One chooses a regional subject, but one uses local color. This usability of local color leads to another reason why it's important to strike a distinction between local knowledge as the matter of character or of information. Using 
local color in fiction has become increasingly difficult for a writer wanting currency amid a culture wherein the planet is as easy to navigate as Google Earth. Banks chooses a rudimentary form of localization in order, in his words, to engage a mode of "selfenactment" that allows the working-class writer to resist the conventions of a "bourgeois art form" (1986a). What Banks claims to resist is not the identification of his art as "bourgeois," but the bourgeois idea that art can exist independent of locale. The "self" that is "enacted" in Banks's fiction is one that is indistinguishable from the place from which it speaks. The timbre of Banks's narrative voice is thus made up of local knowledge and is expressed in the manner that mobilizes local knowledge.

Through the mechanism of the narrative voice, Banks tries to accomplish, in a postindustrial setting, what Walter Benjamin calls the preindustrial "institution of social integration and communicative exchange" known as "storytelling" (qtd. in Koepnick 150). Mobilizing local knowledge through the convention of storytelling, Banks resists the tendency of such knowledge to become a kind of information that is saturated with explanation before it reaches an audience. Traditionally in regional writing, local knowledge as information is transmitted to the reader in exchange for the reader's reliance on the verifiability of the knowledge. But knowledge shouldn't work this way, Banks suggests. Knowledge is not information, though it can be used as such. In his essay, "The Storyteller," Benjamin strikes a helpful distinction in the use value of local knowledge:

The value of information does not survive the moment in which it was new. It lives only at that moment; it has to surrender to it completely and explain itself without losing any time. A story is different. It does not 
expend itself. It preserves and concentrates its strength and is capable of releasing it even after a long time. (90)

Banks transmits local knowledge as "story," which has a voice that lives through the act of telling. His story of local knowledge, then, elides one-time exchange value; it treats the textuality of locale as an occasion for transaction rather than transmission. Information, on the other hand, separates itself from the vein of history through compartmentalizing its message into a self-contained unit that can neither be added to nor subtracted from. Benjamin's assertion that the "prime requirement [of information] is that it appear 'understandable in itself" " sounds like an obvious requisite for any place-based text (89). Yet understandability "in itself" requires an initial intelligence into the constraint of explanation. As Benjamin points out, knowledge presented as information "is no more exact than the intelligence of earlier centuries," asserting that storytelling is a replenishment and perpetuation of knowledge, rather than a seizure and encapsulation of it as personal "intelligence" (89).

In this chapter, I will demonstrate that Banks is in fact this complexly reflexive about local knowledge. He is as concerned with these nuts and bolts of provincialism and their roots in the American tradition of realist narrative voices as Kingston is with the essentializing provinciality of contemporary forms of urban cosmopolitanism. Where Kingston's reflexivity universalizes self-enactment, Banks's localizes it so much that it appears at first to be self-destruction. His novels enact a working-class resistance to the provincial/cosmopolitan binary, meaning that his narrative voices handle the unseemly details of provinciality in much the same way a laborer handles rusted industrial materials. This working-class formal agenda merges narrative voices with localizing 
detail, making identity a heavy matter that contains all the weight of provincial materiality. This is why Banks calls his protagonists "wholly reactive" beings, or beings without any primary agency. Banks has described this particular method of characterization as a form of "self-enactment ... a kind of violence [or] heroism" that occasions a battle against the "entropy" that accompanies a working-class writer trying to do the work of another social class (1986a). More than any other writer in my study, Banks is a self-identified as working-class, a writerly identity that has become synonymous with the regional writer, especially when white and male. ${ }^{199}$ In the following section, I will discuss the possible reasons why this parallel currently seems compelling. My sense is that redefining identity categories as literary categories is fairly common practice: African American writers often write African American fiction, Latina/o writers write Latina/o fiction, etc. What's curious about the white male writer writing regional fiction is that the fiction does not take the name of the writer's identity group. Instead, the name of the fiction actually gives the writer a group, gives content to the empty signifier of "white male." 200

\section{I}

\section{Regional Banks}

A 1998 State Department publication entitled "The New Regionalism” celebrates regionalism's “triumphant return in American literature." McGurl, Jonathan Franzen, and other commentators on contemporary fiction also acknowledge this resurgence of regionalism, but with less optimism. Regionalism, Franzen and McGurl claim, is once again central to literary production in America; or, as Franzen bemoans, it "is still

thriving" in the related spheres of American universities and literature $(2002,68) \cdot{ }^{201}$ Its 
one-way transmission of rural culture is now more clearly class-inflected, more of a selfpresentation of class-based identity, as Fred Pfeil has said in his screed against Bobbie Anne Mason's fiction. ${ }^{202}$ In McGurl's conception, the resurgence is spearheaded by men. He points to a slate of successful contemporary male writers, including Wallace Stegner, William Kennedy, and Cormac McCarthy, who "have staged their careers ... in the continuing tradition of literary regionalism" (119). Stegner has not only sustained a long career via the regional tradition, he has also produced a generation of American writers who capitalize on their regional inflections. Having founded and run the Stanford University writing workshop, Stegner shaped the careers of many influential writers, including Edward Abbey, Wendell Berry, Ken Kesey, Thomas McGuane, and Larry McMurtry. McGurl sees these white writers staking claim to the genre because it "has always been cultural pluralist," always "a form of appreciation of diversity" (119). Regionalism, for McGurl, thus allows white men an "alignment by analogy" with some of the more pressing issues of diversity in the literary marketplace (119).

Unlike McGurl, who views the resurgence of regional writing as a reaction to the current premium on diversity in the literary marketplace, Sally Robinson categorizes such gestures toward "marked" embodiment as part of an earnest impulse to register their presence in an era of identity politics, which Robinson and her colleague Peggy Phelan term as "visibility politics" (Robinson 2) ${ }^{203}$ Robinson sees the image of the "disenfranchised white man" as self-imposed by men who oscillate between loving the invisibility that provides them refuge from accountability and envying the "more fully embodied, particularized identity" of those who have benefited from the movement toward valuing diversity (4). No longer the "historical malady of underrepresented 
populations" alone, invisibility is now periodically a legitimate problem for white men (2). As Susan Faludi explains, the 90s man resembles the 50s housewife in that "the empty compensations of the 'feminine mystique' are transforming into the empty compensations of the masculine mystique" (40). As I discussed in Chapter Three, the historical explanation for this phenomenon is that, with the late 1960s wake of the Civil Rights movement and rise of women's and homosexual liberation, white men began to take the role of victim of historical processes. ${ }^{204}$ Robinson agrees with Faludi, adding that from the late sixties to the present, dominant masculinity appears to have suffered one crisis after another, from the urgent complaints of the "silent majority" following the 1968 presidential election, to the men's liberationists call for rethinking masculinity in the wake of the women's movement in the 1970s, to the battles over the cultural authority of "dead white males" in academia, to the rise of a new men's movement in the late 1980s. (5)

McGurl wants to categorize the rise of male-authored regional fiction as a feature of this most recent “men's movement." Even Robinson explains each movement in literary terms, noticing how all manifestations come with a "language of crisis, ... vocabulary of pain and urgency to dwell on, manage or heal the threats to a normativity continuously under siege" (5). ${ }^{205}$ Through this process of reacting to the changing tide, white men have become "marked," or hyper-visible, developing from the "liberal abstractions" that they were assumed to be under New Deal social welfare into a group with special traits. ${ }^{206} \mathrm{In}$ fact, white men are becoming so specialized a group, Robinson says, that the "enduring image of the disenfranchised white man has become a symbol for the decline of the 
American way of life" (2). While still thinking of invisibility as a mode of representation and a category of social citizenship that is "a necessary condition for the perpetration of white male dominance," Robinson and McGurl see recent white masculinity "most fully and convincingly represent itself as victimized by inhabiting a wounded body" (Robinson 20). These "identity politics of the dominant" counteract the invisibility that aids white men politically but prohibits them from affecting change culturally (Robinson 3). By acquiring the "markings" of place-based determinants, the masculine reclamation of regionalism, as both McGurl and Robinson see it, perpetuates the prominence of identity politics by making the survival of difference a key objective of literary production. Marking the otherwise bland experience of the "white man' disillusioned" with a retroactive ethnic mark is supposed to equalize the playing field among diverse authors, as it makes white masculinity another feature of diversity.

In many ways, Banks is symptomatic of this masculinization of regional fiction; he is white and working-class and his use of local color marks his male characters in the same way Sarah Orne Jewett's marked her female characters with what Sandra Zagarell calls a "Nordic" ethnicity. ${ }^{207}$ For instance, in describing the face of Wade Whitehouse, the anti-hero and protagonist of Affliction, Banks evokes an ethnic inflection that borders on ancient inevitability. Wade's face is

shaped by thousands of years peering into firelight, into cold mists rising off salt marshes, into deep waters where huge sturgeon cruise past; a face tightened ... from having pursed thin lips thoughtfully for millennia over animal tracks and droppings. (56) 
Banks here is highlighting Wade's obvious biological ties to a Nordic masculinity, much like Jewett's "Nordicist register" (Zagarell 358, 362). But, although he is one of the more prolific and successful writers for whom regionalism has been a career-organizing category, Banks does not use region only to be competitively multicultural. He does, however, use the logic of thinking about particular similarities and differences to mark whiteness as an ethnic category, or to expose what Pheng Cheah calls the "privative ethnic identity that disguises itself as universalism" (21). In fact, though this passage describes Wade's face as made up of ethnic markings, it debunks the place-based logic of identity that regionalism depends on. Even as Wade's "ancient habits of expression" index Nordic masculinity as a racial distinction made up from millennia of physically intense labor and violent pathologies, his face betrays an "intimacy and a tenderness, a melancholic vulnerability [that] gives the impression of intelligence and sensitivity" (56). The point of noticing the markings of both ancient masculinity and proto-intelligence and sensitivity is to define both as impressions, or markings that aren't totally the property of either the object being described or the writer himself. Rather than trying to forge a place for white men within a marketplace that values diversity, Banks demonstrates the place of provincial self-knowledge in the context of contemporary fiction that is increasingly interested in cosmopolitan affiliations, providing a manner of representing the local in a way that is amenable to the delocalizing thrust of global cosmopolitanism.

Because his region is rural New England, Banks's fiction is in dialogue with the long tradition of New England fiction. In the following section, I will survey Banks's relationship to the enduring value of local color, including his contribution to a now century-old backlash against local color. Thinking that the Jewetts and Freemans of the 
late nineteenth century have given way to the Bankses and Russos of the late twentieth century, I read a general shift in New England fiction toward masculinization, toward male writers who need the markings of diversity that regional knowledge allots. The reason why I look to New England for an example of this shift is twofold. First, since New England regionalism, from its heyday in the late nineteenth century, has been overwhelmingly considered the territory of women writers, the recent proliferation of male writers who have taken root there provides an ideal occasion for reading the contemporary use of regional form. Second, New England is a special site of division between cosmopolitanism and provincialism in America. The onetime site of America's literary renaissance has been, in Dwight MacDonald's words, "pushed aside by history, dwindling to provincial gentility" (34-35). To a large degree, as others have argued often and well, this "dwindling" was accelerated by the widespread popularity of late nineteenth-century regional fiction. A byproduct of this loss of cosmopolitan credentials is an ambivalence regarding the provinciality that shapes the features of the contemporary popular imagination of New England, as the last mainstay of idyllic rurality in America. In the heyday of regional fiction, the preservation of idyllic rurality was legislated by Atlantic-group periodicals as "woman's work." ${ }^{208}$ Taken as a whole, Banks's many New England novels comprise a career-long meditation on the virtues and limitations of the use value of local knowledge. Analyzing two of these novels, Hamilton Stark (1978) and Affliction (1989), I will examine Banks's reiteration of a now century-old tradition in New England fiction of subverting the dichotomizing cultural logic of local color. Originally engineered by Edith Wharton, this tradition (which to my knowledge has yet to be acknowledged as such) of "anti-local color" in New England simultaneously 
represents the violence of rural culture and does violence to innocuous local color. Wharton's intention is to shift readerly and writerly attention away from the backward provinces and toward the backward, but decidedly more cosmopolitan and fashionable, pockets of urban high society. ${ }^{209}$ Banks, on the other hand, criticizes the use value of New England local color but does not propose that writers abandon the local for the urban or the cosmopolitan. Unlike Wharton, he is interested in dramatizing the complexities involved in placing local knowledge in fiction, in calling attention to the love and violence that goes into verisimilitude.

\section{II}

\section{Violence Against New England Local Color}

Late nineteenth-century New England fiction exposes in myriad subtle ways the internal failures and external sentimentalisms of America's most beloved and storied countryside. According to Kent Ryden, typical stories of the period, such as Mary Wilkins Freeman's “The Revolt of the Mother" and “A New England Nun” (1890-91), "explored the tensions hidden beneath the popularly accepted façade of New England village life, offering a harsh critique of the social, imaginative, and emotional stresses and limitations placed upon small-town residents, particularly women" (205). Ryden goes so far as to say that New England local color fiction "prefigured the social criticism" of the post World War I "revolt from the village," as it was the first to recognize the proportionate decline in the region's culture and its agriculture (205). By the 1920s, the representation of decline in New England fiction was matched by cultural commentary, conventional wisdom, and even state policies: 
Regional and national commentators fretted that New England, seen as the cultural hearth of the nation and the repository of national strength and virtue, was losing its vitality and going to seed. ... the remnant rural population came increasingly to be seen as shiftless, inbred, and morally bankrupt, their continued residence in shabby villages now seen as a sign of fecklessness rather then [sic] of incorruptibility. (205) Ryden's historical gloss here runs counter to the understanding of the period usually communicated by critics of literary regionalism. The standard argument among literary regionalist scholars is not whether or not rural New England is portrayed as precious and idyllic, but to what degree and with what specific hues this idyllic landscape is represented. ${ }^{210}$ If cultural decline is discussed at all, the discussion centers around the archetypical "outsider" figure. The most famous outsider of New England local color, Jewett's ornithologist, functions as a mechanism for making the region seem all the more precious. A scientist whose science requires violence against the living ground of New England, the ornithologist needs to shoot and kill the rare eponymous "White Heron" (1886) in order to "preserve" it. As others have argued often and well, this standard form of potential destruction of rural New England usually arrives in the person of the "outsider," who represents national standardization or industrial progress, coming to destroy the virginal sanctity of rural New England. ${ }^{211}$

But, as Donna Campbell has recently argued, the history of local color writing in New England hovers pretty steadily around the twin themes of cultural decline and violence. Campbell uses the example of Rose Terry Cooke, whose stories include "horrifying infant murders, and ... beatings and a suicide" (184). However, Campbell 
recognizes a conspicuous absence of a very specific kind of violence, notably that of "men in groups acting against each other" (21). This is a "suggestive absence," or an absence that evokes the presence of the tyoe of violence that is missing (21). This type of violence is precisely what bubbles up in twentieth-century New England fiction. ${ }^{212}$ Where nineteenth-century local color "purposefully explores ... varieties of absence" in order to set such facts as physical violence into relief, to naturalize them as nonhuman and therefore beyond the reach of rural community responsibility, twentieth-century New England local color highlights the agency that comes with violence. Tearing the world and the self to pieces seems to be the only real kind of authentic self-enactment allotted to New Englanders. This, as writers as early as Wharton and as recent as Banks have asserted, is because the kind of fiction that prohibited violence also produced a sentimental attachment to a New England that never existed but that nevertheless is the inspiration of many small-town social rites. The object of critique of anti-local color is thus the type of provinciality whose myopia denies the existence of destructive impulses that transcend gender roles.

As Campbell explains, the gendered logic of regional fiction was originally shaped via a debate in late nineteenth-century periodicals about the place of masculinity and femininity in a realist tradition. In an 1897 issue of the Atlantic Monthly, Kentucky novelist James Lane Allen defined the "Feminine Principle" and "Masculine Principle" in American fiction. This division, Campbell argues, is similar to the traditional understanding of the split between local color and naturalist fiction. ${ }^{213}$ Young naturalist writers (in which list Campbell includes Wharton alongside the usual suspects: Frank Norris, Theodore Dreiser, Jack London, Stephen Crane) rebelled against the popularity of 
preservation-centered local color. They disliked, among other things, the assumption that it's an inherently good idea to preserve locally variant communities and folkways. They felt this preservation impulse "fulfilled some specific needs of the public — for nostalgia, for a retreat into mildly exotic locales, for a semblance of order preserved in ritual.” Campbell provides an insightful reading of Stephen Crane's story, "The Monster," as fiction that traffics deliberately in local color conventions in order to subvert their conservative logic. Crane's setting, a provincial small town that has lost its economic reason for being, features a self-destructive monster of a man on the verge of disaster, for whom small-town rituals are a source of anger and oppression. As I'll discuss below, Banks's New England fiction has the same characters and contextual features and likewise can be read as a representation of the diminished value of local color. Treating local color this way, Crane and Banks dramatize the violent self-destruction that has long loomed under the surface of even the most innocuous local color narrative of New England.

More important than Crane's brief critique of local color conventions is Wharton's more realized Ethan Frome (1911), which inaugurates a process of localizing New England that conceives of local knowledge as the raw materials of culture, not its quaint trappings. In the famous penultimate scene, Ethan and his star-crossed lover, Mattie Silver, steer their sleigh down a pretty hillside in Starkfield, Massachusetts, straight into an elm tree. This violent suicide attempt marks the beginning of anti-local color counter-narrative to the sentimental local color of provincial New England. It represents, according to Wharton, her effort to "contradict the 'rose and lavender' pages of native writers ... Mary Wilkins [Freeman] and Sarah Orne Jewett" (Wharton qtd. in 
Hamblen 239). Ethan Frome is certainly a "blackly comic joke, a vision of the genre so extreme as to border on private parody" (Campbell 172). By using the standard trappings of New England local color (the sleigh, the snowy hill, the innocent lovers) as the instruments of violence, Wharton "confronts local color fiction on its own terms ... disrupt[ing] and transform[ing] its narrative conventions," and thus revealing a New England crippled by its own apparent quaintness (162). As she explains in her introduction to the novella, Wharton hopes this anti-local color will catch on as the New England fiction writer's "siren-subject"; she hopes local color writers will answer her prefatory call to crash their "cockle-shell to the rocks" (Ethan Frome, vii). In other words, Wharton calls New England local colorists to abandon the woman's work of representing the delicate, irrelevant hues of the region. Her Fromes are deliberately colorless figures whom she describes as "granite outcroppings ... half emerged from the soil and scarcely more articulate" (vii). They are recounted through the detached sobriety of a "looker-on," Wharton's name for the standard outsider narrator, who has "with scope enough to see it all, to resolve it back into simplicity, and to put it in its rightful place among his larger categories" (viii-ix). Wharton thus replaces interest in the delicate, exotic, and endangered details of regional difference (which she found in Jewett and Freeman) with a crude formal essentialism wherein difference is reduced to protoelemental categories like soil and rock. Despite its tragic plot, this novella revitalizes local knowledge, handing it to the fiction writer as an element of the representational palate, or a "siren-subject" that takes shape relative to the fiction writer's individual pursuit, not a nonnegotiable category of reality that must be rendered carefully and verifiably. Judith Fetterley and Marjorie Pryse criticize Wharton for having "treat[ed] 
regionalism with extreme hostility and even fear" (58). While I disagree with the spirit of this critique, I agree that Wharton feared that regional writing was "[s]uffocatingly claustrophobic; utterly regressive; filled with meaningless whining drone voices of women incapable of development" (58).

In short, Wharton was no fan of the "Feminine Principle." This isn't a surprise, especially considering that her strong suit is the big urban social novel. As Fetterley and Pryse imply, Wharton's New England novellas are cautionary tales that warn women writers against the market expectation that they write about rural America. But Wharton's brief relationship with the rural had a research methodology that deserves acknowledgement. In Wharton's words, her anti-local color novellas (which include Frome and Summer [1917]) were intended to "draw life as it really was in the derelict mountain regions of New England" a life that was "utterly unlike that seen through the rose-coloured spectacles of my predecessors" (qtd. in Fetterley and Pryse 58). The revisionist manner through which Wharton draws this life has been a matter of small dispute, mostly by critics of regionalism for whom non-native perspectives are always looked upon with suspicion. Though Wharton has been accused of knowing too little about New England to write about it, she claims that her two New England novellas are the result of ten years of "explorations among villages still bedrowsed among a decaying rural existence" (qtd. in Hamblen 239). Despite what she says, Wharton knew very little about her "hill people." Her ten years in the country were mostly summers and always spent in a fully staffed mansion known as "The Mount."214 Nevertheless, Wharton's criticism of rose-colored New England is valid; her critique is of popular New England literature rather than of verifiable New England and thus is a critique of the kind of 
readerly interest in idyllic representations of New England, representations that find roses and lavender where there is only stark granite. Though her "research" lacks the nativist perspective (let alone affection) required by some critics, the effect of contradicting the “"rose and lavender' pages" of Jewett and Freeman is a critique of fiction that popularizes idyllic assets and eclipses economic liabilities.

In addition to being atypical subject matter for Wharton, whose "rich" characters are usually the lifeblood of her fiction, her deliberately inarticulate and flat as stone characters in Ethan Frome anticipate Willa Cather's modernist call to "de-furnish" the novel. ${ }^{215}$ Wharton does not revere the trappings of regional difference. Instead, she casts them as the props of tragedy. In this way she pushes the remains of rural America toward extinction and puts them in the service of a universalizing tragic vision of localized America. The impact of Wharton's tragic vision is multivalent. Her intention is to devalue fiction about provincial niceties and thus to mobilize the production and consumption of urban social novels. This not-so veiled self promotion seems to have worked, evidenced by the fact that her profound (and profoundly anachronistic) novel of the high-society "tribes"216 of old New York, The Age of Innocence (1920), won the Pulitzer, despite the fact that the jury of readers voted unanimously for Sinclair Lewis's thorough critique of Midwestern provincialism, Main Street, making Wharton the first woman to receive the award. ${ }^{217}$

The opposite effect has also endured: Wharton's heartbreaking hues have inadvertently inspired writers to turn to rural New England for tragic plotlines and even horror (cf. Stephen King's Castle Rock, Maine novels). ${ }^{218}$ According to Ryden, the fictional New England of recent years is that of Wharton, "where moral corruption and 
violence hide behind a static surface and where the hill folk who live above the town are barely civilized" (206). This kind of interest in rural locales turns regional difference into the kind of disparagement that is as acutely legislated as the sentimental narratives about New England. Certainly, Wharton did not intend to replace sentimental fiction about New England with equally problematic horror narratives of New England. Instead, Wharton seems to want to point out that the basic presuppositions of local color fiction are problematic. The fact that an entire (mostly female) faction of writers somehow depend on the survival of regional difference is supremely troubling to Wharton, not just because its fiction has different allegiances than her own, but because it clogs up literary expression, making an inventory of provincial trappings mean as much as, if not more than, the larger cultural or human problems that fiction should address. This "fear," as scholars with affinity for regionalism call it, anticipates Cather's hyperbole: "How wonderful it would be if we could throw all the furniture out of the window," meaning if writers could evacuate the precious details that obscure larger cultural problems (51). A quarter century before Cather makes this call to action, Wharton attempts such an evacuation of New England local color, producing a crushed-bone convalescence that is to survive Freeman's puritan manners and Jewett's botanical exoticisms.

Since Wharton, much has happened to literary New England. ${ }^{219}$ As Ryden notes, New England has most recently become the favorite setting of "neorealists" (viz., Banks, Russo, Hebert, and Carolyn Chute). In Dogs of March (1979), Ernest Hebert produces the prototype of the self-destructive New England everyman in the character Howard Elman. An orphan who chose his own name based on the tree with which he most identified, Elman is a "middle-aged foreman at a textile mill who loses his job when the company he 
works for is bought by a company in South Carolina" (Ryden 209). Ryden describes him as the realistically rendered counterpart to the romanticized Yankee figure; he is "profane and given to drinking, a factory worker who deliberately refuses to farm the fields that he owns, an imperfect father and husband, he is now cut loose in a New England in economic decline, forced to reorder his life as best he can" (209). He has no interest in the physical beauty indigenous to New England, as the conditions of his life do not accommodate the development of a capacity for such appreciation. Hebert figures this lack of expressive forms of appreciation as an essential feature of rural New England. This conception is evident in the novel's culminating scene, wherein Elman's ugly trailer home partially obscures the view of the idyllic countryside that the novel's other main character, an idealistic Midwesterner, had left his life in the Midwest to enjoy. Hebert is thus instrumental in setting the stage for Banks's large-scale renovation of Wharton's anti-local color formal agenda. But his assumption that the beerfat antihero is a matter of fact is as problematic — which is to say, as literary—as the assumption made by last century's local color writers regarding the communal unconscious of rural New England women.

The primary objective of Banks's intervention into this tradition is to introduce a divided narrative sensibility, which wants both to love the monsters of provincial New England and to attain cosmopolitan credentials. Doing this, Banks avoids essentializing the traits of both individuals and the region as a whole. Unlike Wharton's unnamed narrators, whose cosmopolitan credentials are assumed, thereby providing her a standard outsider/insider narrative economy through which to advance her project of distancing herself from the provincial by writing about it, Banks's narrators are never automatically 
assumed to be cosmopolitan outsiders of traditional New England local color. ${ }^{220}$ In fact, they are usually insiders who somehow want to be outsiders. They try to attain cosmopolitan credentials through either becoming novelists and thereby representing their stories of rural New England metafictionally (as does the narrator of Banks's second novel, Hamilton Stark) or by going to college and moving to the suburbs (as does the narrator of Affliction). As Robert Niemi explains, in Banks's career in general (and in his narrative voices in particular) one can read a steady formal shift from metafiction to realism, a shift that constantly registers an "unresolved ambivalence regarding the uses of realism versus metafiction" (17). These early metafictional pretensions, best realized in Hamilton Stark, display a tone of sophistication that stands in "stark" contrast to the crude raw materials of regional difference and destruction that Hamilton Stark focuses so heavily on. This juxtaposition recalls Agee's documentary style, which also prefers fragments to wholes and juxtaposes introspective sophistication against provincial thoughtlessness. But Banks's metafiction is not the play of self-reference that one typically associates with metaficiton. Though referentiality does play into the structure and sensibility of the narrator of Hamilton Stark, the purpose of the novel's "meta-" component is to dramatize the awkward position of a novel writer who chooses to handle local color in the late twentieth-century.

Unlike Wharton, Banks doesn’t simply want to do violence to local color, but to dramatize the relationship between local color and violence. He moves away from the metafictional strategy of dramatizing this relationship because metafiction is ultimately more of a mystification than a dramatization. As the writing process itself takes center stage, the larger cultural point gets subsumed. Therefore, in later novels, Banks 
transforms his original metafictional logic into a processing logic of characters living firmly in the world of the novel. Therefore, Banks begins tell the story of "granite outcroppings" straight. Through this realist method, characters are seen as suffering the same internal familial and cultural failures and external sentimentalisms as do the Fromes. But his narrators aren't detached observers; they are investigators of the wreck, who search the wreckage for evidence of a possible cause of rural self-destruction. ${ }^{221}$ In other words, Banks brings a reconciliatory ethos to Wharton's anti-local color agenda. ${ }^{222}$ His narrator is almost Conradean in his insistence on "immersing" in the "destructive element." In contrast, Banks's protagonists live "wholly reactive li[ves]," which is to say that their agency, however intense, is occupied solely in tasks that respond to their collapsing stability as provincial community leaders (Affliction, 177). In short, Banks treats local knowledge not as a set of disposable facts but as an obstacle that his characters and narrators alike are wholly absorbed in negotiating. For his protagonists, local knowledge overwhelms and is thus a source of pain that "marks" them as distinct and oppressed by external identity determinants. For his narrators, local knowledge is a means of producing cosmopolitan credentials, not for their own sake but in order to gain the evaluative means of explaining why violence is so central to writing about the overlooked sites of America's most beloved countryside.

Ultimately, the divided allegiances of Banks's narrative sensibility have been characterized as "self-consciously postmodern" (Niemi 17). According to Niemi, Hamilton Stark is less of a novel than a "fictive journal about the entire cognitive, emotional, and investigative process of novel writing" (70). Its pastiche of prose styleswhich include formal introduction, self-reflexive digressions, elaborate studies of 
geography and regional history, transcriptions of tape recordings, and various addendais certainly self-conscious in its textuality. But for Banks, the point of metafiction is to represent the nexus between local color facts and cosmopolitan aspirations. For instance, in a chapter titled "The Matrix," Banks attempts a prehistory of New England, elaborating on the "geographic, historic, economic, and ethnic factors" that have produced the colorless figures Wharton characterizes as "granite outcroppings" (Hamilton 21). Here Banks draws complex parallels between the protagonist's violent behavior and the glacial and colonial violence that produced the region and its white communities. He overemphasizes the message that northern New England is "only for tough, heavy-coated, pugnacious, stubborn animals" who submit neither to sentimental fantasy nor to the movement of industrial capital (29). Those who want fantasy and prosperity "inevitably drift[] to the south and west" (30). Unlike Ethan Frome, who can't escape this disparaged provinciality save through smashing himself to pieces, Stark chooses violence as a way of inhabiting provinciality. He relishes his granite features and labors (as a plumber) in filthy working conditions, among "cobwebs, dust, soot, mucky water, shit and garbage" (107). The biographical reading here is clear: both Stark the plumber and Banks the plumber-turned-writer "try to make an old piece of equipment work like a new one," to make literature out of subliterary labor processes and people (107). This understanding of literature as parallel to plumbing, and thus as a kind of labor, is analogous to Banks's plans for local color at large, which he wants to fit to the pipeline of cosmopolitan citizenship. What might look like the wry playfulness of metafiction is thus a concerted effort to revitalize the worn-out properties of a literary genre. 
As opposed to the case of Ethan Frome, Hamilton Stark's life in rural New England is not so quiet and desperate that he attempts suicide. He does, however, intentionally cut himself on the sharp edges of local color. He takes a masochistic delight in, to quote Wharton again, "crashing his cockle-shell to the rocks" (vii). The sharp facts of life at the "craggy head of the robust Appalachian chain" recall Wharton's excited demolition of quaint local color (Hamilton 25). Stark takes pleasure in destroying furniture. After divorcing a wife (he has five in the course of the novel), Stark shoots holes in whatever domestic remains she's left behind. He throws them in a great junk heap, "making bets, and usually winning them, that he could lift and throw a sofa over the fence $\ldots$ or that he could carry a refrigerator in a broken wheelbarrow for a quarter of a mile over a rough surface" (6). Stark here is disposing of sentimental attachment, answering Wharton and Cather's cues to "de-furnish" the novel. Anthropomorphizing Cather's modernist hyperbole - "How wonderful it would be if we could throw all the furniture out of the window"-Banks represents the destructive pleasure of fiction that abandons its realist responsibility of representing material conditions (Cather 51).

As a misogynist monster, Stark is, to say the least, a counterintuitive hatchet man for either Wharton or Cather. Indeed, his violent labor of disposing of the stuff of sentimental fantasy reveals that the idea of ridding local color fiction of its nonessential furnishings is itself fantastic, or at least conceived of without a thought to what a dramatization of such de-furnishing might actually look like. Through his de-furnishing scene, Banks dramatizes shifts in value of nonessential detail, moments wherein local color is violently cycled from useless furniture into fun junk. Stark is a plumber, not a fiction writer. He doesn't have the artistic license to just erase the things he hates. $\mathrm{He}$ 
must make do with unwanted clutter, work to change its formal value, lest the things of his life start to take him over. Banks imposes the same kind of condition on all of his writing about provincial New England: he enters its cramped, dirty spaces and works from there, never discarding the obstacles that threaten to stub his narrative. The very materials Wharton finds claustrophobic and regressive are handled in the text itself.

Banks credits Carl Sauer and William Carlos Williams for his decision to handle local color in this bifurcated (narrator/character) manner. ${ }^{223}$ Sauer's cultural geographies and Williams's modernist localisms "invited" not a cockle-shell crash, but, in Banks's words, "a deep investigation into the "local”" (qtd. in Niemi 69). "By keeping things local," Banks explains, "I could also keep them personal, without being 'autobiographical'” (69). The opposition between the personal and the local is thus "resolved by means of my immersing myself in New England ... history, geology, economics, geography, etc." (69). The result is a "wholly reactive" version of local color writing, wherein the white male writer, in Conrad's tradition, immerses himself in the "destructive element" of his world and through such immersion enables his own subjectivity to take shape. Banks's interest in local color is, he suggests, an interest in dealing with his own past as a union plumber. Unlike the cosmopolitan Wharton, who represents the destructive element of rural New England as evidence for why people should stop caring about provinciality, Banks deals with provincial wreckage as though it were the stuff of autobiography. In this way Banks resembles McGurl's white male regionalist, as region gives Banks a way to "mark" himself as unique.

But I don't find Banks so bluntly opportunistic (especially not when considering that his recent novels have abandoned provincial New England altogether). Even the 
autoethnographic Hamilton Stark signifies a working-class writer's flight into writing, into self-conscious language acts and the kind of structural difficulty that is both a welcome contrast to physical labor and a way of aestheticizing the inelegant details of a laborer's biography. ${ }^{224}$ This metafictional move is not an exploitation of "the continuing tradition of literary regionalism," but a formal manifestation of Banks's trouble representing his "deep investigation into the "local."”

Banks's metafictional approach to local knowledge thus, in terms of blending the factual and biographical elements of local knowledge, reconciles the long division between the cosmopolitan and the provincial. The breach between the two is often so pronounced, such a matter of $f a c t$, that the fog of social relations that usually negotiate the breach is completely lifted, revealing a geography of solid indifference. In stark contrast to the cold facts of setting, the narrator of Hamilton Stark is self-reflexive and introspective. Symptomatic of the standard metafictional narrator, he is a writer trying to write a novel and, in the process, explains the difficulties of writing such a novel. The novel's setting is thus obscured, mostly by the fact that it is difficult to distinguish between the narrator's world and the world he is writing into being. This metafictional form is typical of Banks's writing before the breakthrough success of Trailerpark (1981), a collection of related short stories modeled after Sherwood Anderson's Winesburg, Ohio (1919). In Trailerpark and after, Banks writes in a straightforwardly realistic style. In this new mode, Banks's narrators inhabit the worlds they describe, but at a steady distance. For instance, Rolfe (the narrator of Affliction) has abandoned rural New Hampshire, having gone to college and moved to the Boston suburbs years before the opening of the novel. Rather than giving him the default intelligence and intellectual playfulness of a 
metafictional narrator, Banks makes the narrator of Affliction work for his cosmopolitan credentials. This, as I will argue in the following section, is a process of placing the thumbprint of provinciality onto themes so pervasive as to be, in America at least, thought of as "universal."

\section{III}

\section{Universal Banks}

In Postethnic America, David Hollinger argues that, as ideologies, universalism and cosmopolitanism are basically the same: "cosmopolitans look beyond province or nation to the larger sphere of humankind that is the object of universalists" (84). But Hollinger makes an important distinction between universalism and cosmopolitanism, arguing that "universalists" seek "common ground" and assume that all human beings are essentially the same, whereas cosmopolitans "engage human diversity," value difference, see identity as something that is learned and not inherited (84). This is an important distinction, as it makes the cosmopolitan perspective sound like a vantage from which to see the good in the local. The problem, however, at least as Banks represents it in his fiction, is that local communities aren't thought of as "diverse," or as one of a number of special locations in the grid of the cosmopolitan landscape.

Instead, Banks's would-be cosmopolitan narrators can't see past the shortsightedness of specific provinces, especially not those that are also the narrator's "hometown." As I will argue here, through constructing a cosmopolitan narrator who hates provinciality, he is at once combining the cultural poles and revealing cosmopolitan valuation as a kind of provinciality. It's not too hard to see the irony in my claim that Banks's narrators "won't see past" shortsightedness. What is hard to see is how the 
"universal" category fits into all this as anything but a possible placeholder for a postidentitarian future. Indeed, as I've implied throughout, the impossibility of this category in recent discourse about art and culture in America is what has inspired the resurgence of regional fiction in America. So why, from within the safe haven of specificity, would Banks take a stab at universal themes? On the one hand, it's a natural move, considering his cosmopolitan lineage in the anti-local color tradition. Why else would one critique the sentimental pleasures of minutiae if not to forge a fiction that traffics in broad cultural problems? On the other hand, the move to universal themes is just that, a move. It is culturally informed by a narrator who wants so badly to disassociate himself from provinciality that he conflates cosmopolitan and universalist positions, calling the place from which he speaks a "common ground." At the same time, he calls the place from which the family he has abandoned something completely uncommon, something that is hopefully disappearing.

In short, Rolfe Whitehouse, the narrator of Affliction (1989), tells his story by using universal themes and traits, but speaks from a "subject position" that is uniquely not that of those he describes. As Ernesto Laclau argues in "Universalism, Particularism, and the Question of Identity," the very concept of a "subject position" is logically flawed: it is a "special location within a totality" that must silently presuppose a totality that is the object of an absolute subject (20). ${ }^{225}$ Laclau theorizes universalism in what Eric Lott calls "a radically democratic way, as open and contingent but nevertheless collective" (qtd. in Arthur 192). This radically democratic universalism, this thinking of the universal category as "an empty space that various groups of the aggrieved are always fighting to occupy," is for Lott, "one way to circumvent the postmodernist fancy dance" (192- 
193). ${ }^{226}$ Banks, presumably weary from his own efforts to joind said fancy dance, constructs a narrator who wants universal categorization because it is empty, free from all the seedy particularities of actually having to live the kind of New England that he knows so well. The universal category gives Rolfe's self-reflection on the division between cosmopolitanism and provincialism a refuge. This helps Banks assert the idea that these divisions are in fact the result of mental processes, rather than essential traits of people and groups.

Basically, Banks's recent narrators are former members of provincial America who have decided to better their lot via education and relocation. Their ethos for writing about provincial America remains, though their ambitions and appetites have developed and thus shed new light on the process of thinking about the value of small-town narratives. Their efforts to attain cosmopolitan credentials not withstanding, Banks's recent narrators are subject to the same harsh categories as their characters. As Affliction's Rolfe explains, "I was no more or less adapted than Wade to the soil and climate we were born into — stingy soil, rocky and thin, and a mean climate.... I was as much a tough little lichen as he" (201). Likewise, Banks's new New England novels are written in what Fred Pfeil calls a "steady-sighted, straightforward additive" manner that coldly conflates violent self-destruction with the harshness of locale (78). The difference between this manner of conflation and that in Hamilton Stark is that narrative selfreflexivity isn't so curated or ironically-self aware that the whole text is always on the verge of becoming a meaningless exercise in referentiality.

Banks's "deep investigation into the "local" finally delivers on its promise of being "personal without being 'autobiographical," especially when the immersion into 
New England history, geology, economics, and geography follows an initial splitting of the working-class sensibility into two parts, one an embodiment of provinciality and the other a voice of hard-won cosmopolitanism. This new dynamic frees Banks up to explore the more universal themes that one can deduce from the violent self-destruction of provincial New England. This is not to say that Banks leaves the provincial American reservation. On the contrary, by reifying the signs that signify provinciality and abstracting those that signify cosmopolitanism, Banks starts to fit the two polarities together, asserting that provincial affiliation is tantamount to cosmopolitan citizenship. Unlike Agee's documentarian persona, Banks's self-reflexive narrators have at their disposal not an erudite sensibility or the vocabulary of psychological complexity (which would come in handy considering the steady presence of pathological behavior in Banks's characters). Instead, they have a comprehensive local knowledge of the land that houses the psychological messes. For instance, Banks's narrators speak with expertise of the glacial "moraines" and "monadnocks" (a word favored by both Rolfe and the narrator of Hamilton Stark) that shape the boundaries of rural New England. The raw materials of Banks's narrator's tasks thus appear out of joint with the tasks themselves. The psychological complexities of characters, though vivid and memorable, are not made from the expected materials. They are character portraits in the form of landscapes. Banks asserts that region and regional identity are accidents of geological processes and that communities are basically reactive to these processes. Through experiencing the unavoidable failure of rural communities ("unavoidable," Banks and other contemporary New England writers think, because their economic reasons for being have dried up), 
Banks's readers feel the whole complex of estrangement that comes from a world where fates are determined by the harsh indifference and thoughtless accidents.

For instance, in Affliction, Rolfe describes the regional coordinates of his home state, New Hampshire, as being crudely bifurcated. There is an "unmapped line" between the impoverished rural region of New Hampshire and the suburban fields of Concord and Manchester (61). North of the line, the weather is characteristic of eastern Canada; to the South, it is characteristic of the northeastern US. Rolfe presents the class division the way a weatherman would a forecast:

There are ... two crucially different climate zones that are divided by an invisible line running across New Hampshire, drawn from Vermont in the southwest corner of the state near Keene, through Concord in the center of the state to the lakes north of Rochester in the east and on into Maine. ... The land is tilted higher in the north, is rockier, less arable, with glacial corrugations with heavy-knuckled fingers reaching down toward the broad alluvial valleys and low rolling hills of Massachusetts and Connecticut and the coastal plain of New Hampshire and Maine. (60-61)

The reference to the knuckle-print of glacial violence connotes a class-inflected imagination, a mind that thinks about region by enlarging the scale of thinking about labor. This recalls the intercalary chapters of Steinbeck's The Grapes of Wrath, a novel that (as I discuss briefly in Chapter One) shapes the way many recent white male writers represent the violent earth. But aside from this reference to the narrator's standard working-class imagination, the above description is void of figurative language. The division between the disparaged poor of Rolfe's youth and the affluent suburbanites of 
his adulthood is a fact that doesn't need literary imagination. Natural patterns like the "unmapped line" are readymade; the narrator's only job is to present such found knowledge. The intended effect— to assert that violence and injustice have geological rather than economic origins - is already built into the form. Things are so bad in Rolfe's hometown of Lawford simply because it's too far north for a more amenable clime. No amount of civic effort will overcome the problems plaguing rural New England, at least that's the way Rolfe wants to see it. Rolfe's description of northern New Hampshire is thus an object lesson in how to mobilize knowledge as information that obscures accountability.

Aside from being a manifestation of Rolfe's own desire to distance himself from the place of his story, the nature of the marginality here is of a piece with other, more canonical twentieth-century representations of New England. Like Robert Frost's North of Boston (1914) and Wharton's “North Dormer" setting for Summer (1917) Lawford has a "northness" added to its regional marginality. Unlike the nineteenth-century local color writer, who would treat the zone north of the "unmapped line" as though it were precious and fleeting, Banks (like Frost and Wharton) criticizes the citizens of Lawford for remaining north of this natural(ized) line. His narrator explains that those south of the line "have reflected the generosity and temperance of the climate there" and those north, obviously, "have reflected in their daily lives the astringency ... of the climate there" (61). Banks further demonstrates the danger of thinking regionally, implying how easy it is to enlarge the scale of such dichotomized thinking from region to nation. As Rolfe explains, the split between northern and southern New Hampshire is analogous to "the difference ... between China and Mongolia, or between England and Scotland" (61). 
Differences like these cast regional difference as just a miniature version of national difference. By proliferating these differences, by destabilizing the assumption that northern New Hampshire has more than a tenuous, proximal relation to the rest of its state or country, Banks is doing two things: he is demonstrating an alternative manner of drawing lines of separation among groups of people and he is isolating a problem with regional taxonomies, namely that they fail to politicize divisions that, as in the case of England/Scotland and China/Mongolia, are precisely political.

Having produced a narrator who is a reformed product of destructive provinciality, Banks maps a causality to the perpetuation of the unmapped line. In the case of Affliction, this cause is paternal violence. ${ }^{227}$ With such a universal cause, Banks seems to have finally decided to stop crawling around in local trivialities and start writing about larger cultural problems. As a parable of paternal violence (which it certainly becomes in Paul Schrader's film adaptation, starring Nick Nolte as Wade Whitehouse), Affliction projects itself as a vehicle for a universal theme, and thus as a novel that has abandoned the labor of sifting through local color wreckage. Indeed, Banks intentionally avoids announcing the novel's local color. One sign of this avoidance is that he dropped his original title, "The Dead of Winter," which asserted prominence of the "unmapped line," in favor of a title does not evoke locale at all. A reference to his favorite philosopher, Simone Weil, who supplies the novel's epigraph—“The great enigma of life is not suffering but affliction"- "Affliction" here suggests permanence and omnipresence. These two structuring concepts are antithetical to local color, with its premium on temporality and specificity. With a central theme of paternal violence, Banks evokes an "ancient" tradition of male dominance that has existed independent of locale. 
Indeed, monster Wade "was shrewd and honest enough to know that he would be in his forties and lonely, poor, depressed, alcoholic and violent anywhere" (83, my italics).

But the narrator is Wade's brother and therefore is kin to paternal violence, which means that he has a rarefied perspective that does for the universal theme "paternal violence" what the narrator of Hamilton Stark does for local color: he deconstructs it to its constitutive properties. A formerly abused child (though he never quite admits it), Rolfe has strong negative feelings toward everyone in his story. But he also has the mind of a historian, more specifically the instincts of a historical materialist, which means that his story presupposes that paternal violence has a history and a cause. On the one hand, as evidenced by the "ancient" terminology used to describe Wade and his father, Rolfe blames peasant masculinity. On the other, as evidenced by his insistence on disparaging the provinciality of his hometown of Lawford, Rolfe blames the sentimentality that allows provinciality to house paternal violence. It is through this sober historian that Banks produces his most complex critique of provinciality.

Rolfe is the self-exiled son of provincial America. He insists that the reader understand his status as village rebel: "I despised Wade's life. Let me say it again. I despised Wade's life. I fled the family and the town of Lawford when I was little more than a boy to avoid having to live that life" (4). He has escaped south to a Boston suburb and a safe, callous-free job as a high school history teacher. But the life he left behind, specifically the narrative of his beerfat brother, is the story "that displaces all other stories," that keeps him from moving on with the story in his own life (48). This need to tell Wade's story comes from Rolfe's interest in getting the record straight, in determining causes rather than being determined by their effects. It also comes from an 
interest in the residual value of has-been subjectivities. Wade used to be a high school football hero, and by default the town's virtual savior. His failure to make good signals a problem with small-town culture, specifically its system of value and reward. The fact that his story displaces all others indicates that Rolfe's chances for post-small-town happiness depend in some way on locating the transcendent flaw of provincial culture. In doing this, Rofle unwittingly realizes that what ruins a man in a small town is the same thing that ruins him in the big city.

The stakes of the story are thus pretty high for Rolfe, who is cut from the same "lichen" as his brother Wade, having both clung to the same provincial rock (201). Rolfe marvels at his own ability to thrive in the larger world: "I should have shriveled, should have curled up at the edges and died at the university, as [Wade] believed he would, which is why it never occurred to him to apply to the university" (201). But the reason why Rolfe didn't shrivel is not because of how exceptional he is, but because of how ordinary and deeply channeled his progress narrative is. The extent of his "gifts" is that he left the small town before its systems of value and memory corrupted his ambitions. He found himself a surprisingly easy fit for assimilation into an "affluent suburban town," despite the fact that he "should have been ... merely a curious exhibit of foreign flora at the local museum of natural history or a figure in a diorama depicting life among the less advantaged peoples to the north" (202). Banks is aware here, even if he allows his narrator not to be, that the rules of upward mobility in America actually favor the virtues of displacing oneself from a small place to a bigger city. This move makes Rolfe feel "as if I were Chinese in Switzerland," which is to say that it makes him feel racially different from his suburban neighbors. The irony is that Rolfe also feels that he is the 
typical American Dream story, that his movement to the suburbs was like the rising of "cream to the top" (202). But Rolfe isn't as exceptional as cream, as Banks forces him to discover midway through the novel, when Wade laughingly reveals to him that he is mistaken in assuming that he had never been severely beaten by their father.

Banks thus produces a narrator whose dichotomized sense of provincialism and cosmopolitanism leads him to a false sense of his personal history. The effect is that when Rolfe realizes, however subtly, that he has misinformed himself and his reader that he has always been beyond the reach of his father, he also must acknowledge that he has an idealized conception of his own success. When these mistakes are exposed, Banks is actually exposing the American Dream as a swindle. Banks implies that such progress narratives are not just hackneyed, but are actually a product of the wrong kind of thinking. They designate the successful "dreamer" as an exceptional figure who can overcome big odds and thus remove from his range of concerns the matter of unjust regional bifurcation. Likewise, the point of the typical American Dream narrative is to discover the features of exceptionalism rather than the cultural logic to which the hero is an exception. ${ }^{228}$

Under the logic of the standard American Dream, one is either exceptional or he isn't. Banks's revision asserts that this exception is not an aspect of identity, but of the decision to leave the small town behind. This lack of focus on the transitional status of one who can move from "benighted provincialism" to "benign disinterestedness" is a problem, which is precisely why Banks won't allow Rolfe's story to be more than an aside or byproduct of Wade's story. ${ }^{229}$ The shift from provincial to cosmopolitan credentials, which has dominated Rolfe's adult life, is revealed late the narrative to be an 
established, almost hackneyed, pattern. Rolfe admits that he's nothing unique: "from log cabin to president: it is our dominant myth" (202). Thus Rolfe's American Dream "is not my story," but instead a routinized pattern of upward mobility that has its origin somehow in the life stories of extremely immobile, provincial figures (203).

Unlike George Willard, for whom the abandoned Winesburg, Ohio becomes "the background on which to paint the dreams of his manhood," provinciality is no longer a canvas for the rebel (Anderson 247). Rolfe is no artist nor does he have any pretensions in that direction. His story is troubling for him to write. He has to work at it regardless of whether or not he wants to. As a history teacher, Rolfe relies heavily on sober facts alone to tell even the most personal and traumatic experiences, experiences that include him as a victim of child abuse. ${ }^{230} \mathrm{He}$ recounts Wade's story as though it is a matter of procedure, beginning the novel simply: "This is the story ..." (1). He doesn't mystify, moralize, or reproduce the violence so central to his life. He simply criminalizes it, implying that even the most ancient and enduring form of tragic provincialism is a matter of law enforcement, not some cosmic crutch for the region. Rolfe criminalizes violence not because it is a rich literary enterprise, but because it is a correctable social ill. Violence is not a representational tool, nor is it something a narrator needs to either believe in or denounce; it is simply a misdeed punishable at the civic level.

In short, Banks makes clear the machinations of the mind of an American Dreamer. He thus exposes this mind's exceptionalism as a myth. Rolfe's interest in rules, in interpreting universalized nature as correctable behavior, means that the novel functions formally as a kind of objectifying or reifying exercise. Rolfe gathers information and is reflexive about his gathering process, but since he is a character in the 
story and not an omniscient narrative voice, his self-reflexivity is not metafictional, not the voice of a novelist who is ambivalent about local knowledge. It is, instead, the processing logic of one inside the world of the novel, one who has also been "afflicted" by the paternal violence that goes unpunished in New England. His reaction is sober distance and an objective handling of even the tragic story of a big brother. Therefore, Rolfe's indifference about the frightening manner in which his father and brother have terrorized the New England countryside is a result of the fact that it is a pattern that can be discovered and thereby countered. The real problem, according to Rolfe, is the town itself, which authorizes such terror. Rolfe breaks his disinterested historian's affect when considering the idiocy of a town so poorly run that it appoints its resident monster, Wade Whitehouse, as its sole police officer. Rolfe insults the citizens, whom he calls "remnant people," of Lawford for having stayed in a worthless place, a place that the movement of modern capital has made into a veritable lawless zone of drunken masculinity. He is unsympathetic about the "sad jumble of families huddled in a remote northern valley," hiding from the violent byproducts of their own stupidity (180). But, like the people of any local color narrative, the citizens of Lawford have no interest in being part of the larger nation. Their "willed conservatism," or insistence on remaining where it is no longer lucrative socially or economically, aids provincial stasis by helping rural citizens to "cope with having been abandoned by several generations of the most talented and attractive of its children" (6). Noticing this cultural logic, Rolfe revises the "affliction" of paternal violence from its status as a universal inevitability to a regionally specific type of behavior that the provincial social structure actually in some manner endorses. 
The "bits and shards of social rites that once invested their lives with meaning ... bridal showers, weddings, birthdays, funerals, seasonal and national holidays" become menacingly jagged from Rolfe's detached perspective (5). Except for these "halfforgotten, misremembered ceremonies," the people of Lawford "are no longer a people" (6). Mawkish rites like bridal showers and Christmas dinners "affirm existence, but falsely" (6). They shore up the "rose and lavender" idea of provincial New England, pandering to "the wider, sentimental culture" that sees the rich legacy of New England but never sees the monsters terrorizing its interior (6). Even at the level of word choice, Rolfe indicts Lawford itself for conserving useless social rites while passively accepting criminal violence as though it were some ancient, social inevitability. He describes bridal-shower social rites as "bits and shards," while he describes the evidence of Wade's violence as "bare scraps and bits" $(5,48)$. The former has dangerous ("sharp") edges that can actually do violence, whereas the latter is "bare" and fleshy, more a surface to be scratched than an implement with which to do the scratching. Also, the "bare scraps and bits" are not strange to Rolfe, but pieces of historical knowledge that fit into "coherent, easily perceived patterns" (48). It seems ironic that Rolfe gives sharp edges to seemingly innocuous social rites, and a fleshy innocuousness to violent rampage. The point is not that Lawford's provincialism is worse than Wade's violence. Instead, the point is that violent self-destruction, when seen in its grainy historical detail, can be criminalized and redlined out of provincial New England, whereas seemingly innocent social rites actually have an internal logic that keeps producing the provinciality that drives away those, like Rolfe, whose narrative impulse might remove monsters from America's provincial landscapes. 
A more obvious way that Banks reduces the universal status of paternal violence is by not mentioning Rolfe's father for nearly 200 pages. In an extended flashback about Wade's high school courtship of Lillian, Rolfe recalls that "[i]t was the summer that Wade first spoke of our father's violence" (182). This delay in Rolfe's naming of the arguable source of Wade's “criminal behavior," one might argue, is a symptom of Rolfe's own trauma at having been himself a victim of child abuse. Regardless of whether or not the narrator's own trauma factors into the delay, the fact of the delay unseats paternal violence as the centering theme of the novel. Rather than a universal theme, paternal violence seems either secondary or coequal with other radiant causal factors. The late mention of the father makes for a plot crisis, wherein the reader must apply the new information retroactively to understand all that came before page 182 , casting the 181 pages before this mention into a future anterior state wherein Wade (and eventually Rolfe) always will have been a victim of child abuse. By retroactively fitting of new information onto the rest of the novel's plot, readers run the risk of obscuring most of the complexity of the novel's local color. Nevertheless, this father-centric reading has become dominant. For instance, Schrader's adaptation of Affliction focuses steadily on paternal violence, which feeds into a deer hunting accident/murder mystery plot that is far more central to the film than it is to the novel. All the film's publicity photos, and now all the novel's trade paperback covers, feature James Coburn as Wade's father looming above Wade's shoulder like a diabolical companion and/or reminder of the lineage and inevitability of Wade's violent acts.

Though it's tempting to let the father serve as the organizing center of the novel, his late arrival in the novel produces a large-scale paratactic moment, wherein paternal 
violence arrives as one of a string of horizontally related causes of Wade's criminal behavior. When read this way, the father's tardiness makes paternal violence into another in a series of masculine dilemmas that represent the laboring male at risk. For instance, when Wade's father tries to kill him, Rolfe describes the scene with the same pacing and tone as he describes Wade at work plowing, as though filicide were another kind of labor common to the area. The father's face had "no expression other than one of mild disgust ... of a man compelled to perform a not especially pleasant task, the decision to do it having been made long ago" (342). Then, in the spirit of parataxis, Rolfe catalogues a number of other violent acts of labor:

Wooden mallet to pound a circus tent stake into the ground, to slam the gong that tests a man's strength, to split the log for a house, to drive the spike into the tie with one stroke, to stun the ox, to break the lump of stone, to smash the serpent's head, to destroy the abominable in the face of God. (342)

Fragmenting the signs of ancient inevitability, Banks here and elsewhere disregards the purity of big themes. But he doesn't devalue them. On the contrary, this bricolage (pieced together from the signifiers of a weighty literary theme) both questions the use-value of male violence and disputes its claim to universality.

Instead of assuming its permanence, Banks calls up the assemblage of causes of what looks like a universal inevitability. In doing so, he proves Sally Robinson's point that

"the forced embodiment of whiteness and masculinity is often represented as a violence" (4). When not working or being violent, provincial men have little recognizable value. 
Their corporeality is nearly irrelevant to the process of reproducing the world. Their only natural occupation, in provincial New England anyway, seems to be to destroy the world. This claim is supported by the fact that such destruction is the one form of labor that remains recession-proof in Lawford, as seen in Gordon LeRivier's well-drilling business. "Lawford's only success story,” LaRivier has made his company motto: "OUR BUSINESS IS GOING IN THE HOLE" (11). ${ }^{231}$ The basic metaphor here is that the labor of rural workingmen is a kind of willed, or even cheery, self-destruction, of spending more of oneself than is available_- "going in the hole." Wade's position in the production of holes is key here, since he is the one who drills a lot of the wells in Lawford. Everything about his work annoys him and makes him feel like a boy annoyed by stupid trivialities. For instance, Wade is always worried that he'll not be able to get from his school crosswalk job to the snowplowing job in time to get the good, heated snowplow, rather than the uncomfortable grader. Wade is sore to have to drive the grader, a "huge lumbering ridiculous machine" that "humiliated him" (113). Giving violent manual labor the emotional resonance that comes to a child who is denied his favorite toy, Banks is implying here that provincial masculinity is stuck in a perpetual state of puberty, of having the body of a man but none of the agency.

Another drilling metaphor that registers the wounded state of provincial masculinity comes from Wade's chronic toothache. This injury has an interesting impact on Wade's state of being a male monster, as it is a crippling ache that leaves its victim remarkably unmarked. Wade, as he sees himself in the mirror during an intense fit of pain, notes the weird irony of how normal he looks, how unlike a wounded man he seems to the world. Wade's toothache, along with his employment as a well driller, evokes the 
tradition of American literary naturalism, as a not so veiled reference to Frank Norris's famous tooth-obsessed masculine monster, McTeague. ${ }^{232}$ The reason why teeth and toothaches are important to writers like Norris and Banks is twofold: they dramatize the question of scale in relation to the violence of physical labor and they are virtually invisible.

Wade's physical "affliction" is not something that a totally disinterested observer can see or represent. Wade's painful invisibility is clearly indicated in comparison to, J. Battle Hand, paraplegic divorce lawyer whom Wade visits. As opposed to Wade's internal afflictions, Hand's relation to physical violence (in his case that of a drunk driver) is explicit. As such a symbol, Hand's body confounds Wade, who is the novel's other victim of drunken, physical violence. Hand's body can no longer properly perform physical labor. It is the result of violence but it cannot reproduce violence. Hand's body is thus a version of masculinity that is completely unfathomable to Wade. Through encountering this body, Wade experiences a moment of intersubjectivity, of seeing his own body in apposition to the broken body.

Also in confounding apposition is the version of white-collar work that Hand introduces to the novel, which, because he is a divorce lawyer in rural New England, is arguably a more direct response to male violence than Wade's labor ever could be. Wade can understand the work of a lawyer only as a complicated manipulation of language and abstraction of the historical record that magically leads to the fulfillment of one party's wish to have been a better spouse or parent than s/he actually was. In contrast to Hand's steady grip on the language of law, Wade cannot "find[] the words and then the legal means to articulate the pain he felt at the loss of his child" (158). Wade thus has 
essentially the same agency as does the broken lawyer, that of disability. Going through the formal moves of law is as uncomfortable for Wade as going through the normal moves of daily life must be for Hand. All they can do is adapt themselves to disability's limits and develop "wholly reactive li[ves]" (177).

By the end of the novel, the entire town of Lawford has to learn to react to its transformation from a quaint hamlet into a ski resort town, a reaction that everyone but Wade can execute. As a story told after violence becomes a past tense fact and not an inevitability, Affliction is a process of reconstructing events in a way that deconstructs universal themes. But Rolfe's investigation is not what finally banishes the monsters of provincial New England. Instead, it's the pulverization of local color by global capitalism. A key piece of real estate in Lawford, the 7000-arce "monadnock" of Parker Mountain, ultimately saves the people and banishes the monster (50). ${ }^{233}$ The Abenaki word for erosion-resistant hills that exist independent from the White or Green Mountains, "monadnocks" are for Banks what granite outcroppings are for Wharton. They are geological accidents that somehow become the loadstones of rural New England communities. Disgorged by thousands of years of retreating glaciers, "Parker Mountain" (named after the colonial officer who "bought" it from the Abenakis for some trunks of sundries) was bequeathed to Parker's children, who sold it to a logging corporation and "moved south to Concord and Manchester, where they disappeared into Victorian bourgeois respectability, setting the precedent for a later pattern of migration" (50-51). During the Depression, the corporation went bankrupt, taking from communities like Lawford their economic reasons for being. The aggregate of banks that acquired Parker Mountain auctioned it off "in large slabs for one hundred dollars an acre" (51). By the 
late 1980s, the mountain belonged to a hundred different families "barely aware of the existence of their few acres of useless stony northern New Hampshire countryside except when the tax bill came in" (51). Banks expounds on the fragmented state of this thoroughly foraged piece of landscape:

By now, deed, bills of sale, surveyors' reports, maps and tax assessments were so tangled ... it was difficult if not impossible to ascertain who owned how much of what. Consequently ... more than two centuries after Major Parker's purchase of Parker Mountain from the Abenaki Indians, proprietary rights had come full circle. Once again, ownership of the land was determined more by use than by law. (51)

The irony here, that corporate logic returns the physical world to a pre-colonial primitive state, is compounded by the fact that two shrewd businessmen (Gordon LaRiviere and Evan Twombley) silently buy up the mountain to convert it into a high-end ski resort, turning a provincial small town and its stock characters into the kind of "thriving economic zone" that Wade cannot inhabit (353). This side-plot about the mountain adds to the central theme about the fracturing and gluing of self-destructive masculinity in that, formally at least, it presents a version of local knowledge that, like Rolfe's deconstruction of the "universal" category of violence, renders provinciality into a grainy set of facts that are smaller than the people they destroy and that are always correctable. It thus reimagines manly aggression not as a mode of agency, but as a fixture of non-agency, an internal rupture or reactive impulse, rather than a way of acting on the world.

In short, though paternal violence is an ancient and universal theme, in Banks's representation, it has a face that tells the history that has led to its present state, "a face 
shaped by thousands of years peering into firelight," and a body "evolved over tens of thousands of years of holding the reigns of another man's horse ... the kind of body that made it possible for European princes and popes to wage war" (56-57). By producing a universal theme from a collection of symbols that imply both masculinity and its everdiminishing power, Banks references the current debate about the value of white male fiction in a way that neither mirrors the anxieties of devalued white men nor winks about who is really "holding the reigns" of power. Being another man's horse, the very idea of who has access to power starts to look irrational, as power itself starts to look more like a verb and less like a noun. As Rolfe's disinterested historian's eye marks the fracture points in Wade's constitution, empirical explanations of what we are tempted to think of as inarguable facts gain ground. As explanation becomes the substance of the universal category, the world starts to look like something that can take whatever shape people decide it should. This demystification of the universal is important, even if it is only a figment of Banks's laborer's imagination, as it presents monsters like Wade as potentially disarmable. In fact, in the suburbs south of Lawford, which aren't so in love with nostalgic social rites, Wade falls apart in a stripmall bar and grill. He feels like a "different species," "biologically incapable" of surviving in a world that has sanitized provinciality out of its very physical makeup, a world so replete with consumer amnesia that it is incapable of noticing that there is a violent monster in its midst (164).

Banks is implying here that provincial New England is in such trouble partially because of how afraid of corporate standardization it is. The long tradition of New England local color has produced a place that would rather breed monsters than join a standardized national economic and cultural logic. Banks thus suggests that readers and 
writers of local color should reconsider the tendency to think that standardization is a universally bad thing. The point is not that standardization produces better communities, but that this standardizing logic does root the revenant monsters out from the New England wilderness. In a sense, Banks's corporate deus ex machina reminds regional writers that the old tragedies are being replaced. This is call to face facts is echoed in Bruce Robbins's argument that the problem with the Left's reaction to the end of ideological debate is that it enacts a "romantic localism ... which feels it must counter capitalist globalization with a strongly rooted and exclusive sort of belonging" (3). What's odd is that the willed conservatives residing in the imaginary town of Lawford would probably agree with this left-leaning romanticism and would likely champion the untouched rural.

\section{IV}

\section{World Banks}

The notion that the locales of conservatism are the same as those threatened by the movement of free-market capital is not new. Thomas Frank unpacks this twenty-firstcentury paradox in a well-known book about the growth of conservatism in Middle America, What's the Matter With Kansas? (2004). Frank argues that the paradox is the result of a "backlash" of conservative populism whose public servants have convinced its populace that "culture outweighs economics" (8). These backlash engineers have clogged public discourse with "cultural battles where victory is impossible" while quietly erasing all traces of New Deal national unity (121). ${ }^{234}$ To complement and qualify Frank's position, I will argue here that the paradox of rustbelt love for free-market conservatism 
is an act of cosmopolitan valuation, albeit a misinformed and heinous one that signals a fatal flaw in cosmopolitan valuation in general.

Though Frank never says so, the success of the conservative backlash in the Midwest has a lot to do with the fact that true provincialism has disappeared, that everyone now has at their fingertips the means of cosmopolitan disinterestedness. The problem is that few are using this new global vantage as a way to reconsider the world of work. As a result, few understand that the problems facing the citizens of rural New Hampshire are uncannily similar to those facing men and women in, say, Monrovia.

Banks's recent novel, The Darling, explores this very resemblance of clue-collar America and impoverished zones in the "Third World." The novel's treatment of the global-awareness emerging in the provinces makes palpable the need to represent through literature what can possibly happen relatively soon in reality, namely the dawning of a palpable global collectivity. Banks deals with this possibility in The Darling, a novel about a woman who abandons just about everyone and everywhere she's ever known or been. Told in her own words, the novel is an investigation into what Aihwa Ong calls "flexible citizenship"- a term she uses to refer to "the cultural logics of capitalist accumulation, travel, and displacement that induce subjects to respond fluidly and opportunistically to changing political-economic conditions" (6). Through this concept, Banks continues his project of representing cosmopolitan citizenship as a natural right of small-town dreamers. But, where he dismantles universal inevitabilities in Affliction, in The Darling he explores the idea that abandonment is a characteristic of the kind of cosmopolitan citizenship that actually produces places and families like the Whitehouses. 
For Banks, it's not fleeing, but returning to the site of abandonment— that ethical step that most flexible citizens skip - that should be the moral urge of flexible citizenship.

The theme of abandonment and return develops through the reflections of the narrator, Hannah Musgrave, a former 1960s radical who built and abandoned a chimpanzee sanctuary while in exile in Liberia. The radical opposite of the modern corporation, but ironically following the same flight pattern, Hannah is an old woman whose "permanent mournfulness" makes other forms of globetrotting seem palpable. Her tone casts an air of easy reflection onto even the most nightmarish places and events. Like Robinson's Gilead, but without its homiletic resonance, The Darling captures the intimate drawl of someone at the end of her life. Also like Gilead, the novel is a narrative cross-dressing, or a first-person narrative whose person is not the same gender as her author. Like all Banks's narrators, Hannah's literacy of self is secondary to her literacy of the physical world. In The Darling, this looks like a gender stereotype, to which Hannah herself alludes when she initially reveals her gender to the reader with the sentence, "I sometimes think it's because I am a woman ... that I was able to adapt easily to the pace and patterns and rhythmic repetitions of nature's clock" (4). Though this sounds as though Banks is typecasting Hannah, the truth is that all of Banks's storytellers understand what Hannah calls "the requirements of soil" long before they understand how to tell a descent story. The effect of this multiply displaced intimacy in The Darling is that it localizes cosmopolitan subjectivity through the narrator's very human voice. A one-time revolutionary who knows that the lives of female revolutionaries are, in twentyfirst century America, quaint and popularized stories of "American darlings," Hannah is a test case in the residual value of worn out identities in a global setting. ${ }^{235}$ She knows she 
is past her prime and that her life story is fodder for escapist fun, and it is this acknowledgement of generational division that gives her voice a vitality that makes escape an impossibility for the reader.

It is her voice that unifies an otherwise nonlinear plot, which jumps between her small farm in the Adirondack Mountains to the early 1970s underground to wartime Liberia to its disquieting aftermath. Her voice localizes war-torn Liberia without triggering either xenophobia or xenophilia. This ease and familiarity makes Hannah's cosmopolitan credentials seem like something anyone can attain. Her voice is the ideal post-national sound. She has mastered a series of complicated intersubjective moves, allowing her the ability to give the dark corners of the world an affect of nearness. Through this humanized mechanism of processing the delocalized perspective, cosmopolitanism is no longer a mystifyingly exceptional "subject position." Through Hannah's voice, even the most distant place is a lot like the nearest, most provincial place. It is made of the same basic processes of daily life, what Michel de Certeau calls "les combinatoires d'operations" (xi). Banks's fiction asserts de Certeau's claim that "[m]arginality is becoming universal" (xvii). The boundaries of West Africa, like those of rural New Hampshire, are at some level determined by similar global processes. In short, Banks succeeds via Hannah at denying that cosmopolitanism is simply a privileged category of "world citizen" authorized to claim world citizenship via independent means, expensive tastes, and globetrotting lifestyles. By marrying a periodic interest in postcolonial vistas with a well-seasoned provincial realist mode of narration, Banks makes cosmopolitanism at least sound like something available to us all. ${ }^{236}$ 
This innovative mode of cosmopolitan storytelling, which preserves the "old home" feel, sounds anachronistic, but is actually in line with Amitava Kumar's call for a world literature that doesn't simply showcase the diverse cultures now available as a result of economic globalization, but that "forge[s] new connections and elaborate[s] on ... new coalitions and emergent subjectivities" (Kumar xxiii). ${ }^{237}$ With its setting during the Liberian Civil War (1989-1996) and its narrative prehistory in the Weather Underground, The Darling sketches a rendition of the underground of the first world that looks a lot like the living ground of the third world. Banks's experience with rural New England here helps his West African locales seem real. ${ }^{238}$ His unique handle on the codes and limitations of incorporating local knowledge into fiction suggests that to start depolarizing cosmopolitanism and provincialism, one must frankly portray world vistas, which is to say she should approach to the source of what Americans think of as "diversity" in a way that doesn't assume that cultural difference is precious. Through Hannah, Banks constructs a version of cosmopolitanism that resembles the ideal cosmopolitan citizen, as Ross Posnock describes her in his article "The Dream of Deracination." "Rather preoccupied with opposition and exclusion," Hannah "regards culture as public property and nurtures the capacity for appropriation as a tool for the excluded to attain access to a social order of democratic equality" (Posnock 804). Her process of making her capacity for appropriation into a tool of liberation is the primary action of the novel. In the end, it is the story itself that is the example of what to do with the unique privilege of cosmopolitan appropriation.

Through mobilizing local knowledge via socially integrative and communicative storytelling, Banks elides the one-time exchange value presupposed by other forms of 
local knowledge transmission. Hannah's knowledge of her world is within the grain of history. Not surprisingly, her story ends on September 10, 2001, the day before "the story of my life could have no significance in the larger world," the day before "the history of America" would be rewritten so that her story would seem to be "merely the story of an American darling" (392). She knows that she'll be remembered as just another Patty Hearst, another radicalized daughter from bourgeois liberal stock whose antics entertain more than they affect change. In other words, The Darling is, like most of Banks's work, a meditation on the residual value of has-been identities. By constructing a first-person narrator who knows she no longer has any viable effect on national politics, Banks creates a perspective from which to humanely treat the tender stages of meaningful postnational relations. As a mode of storytelling that blends the worn edges of yesterday's radical alternatives with the literacy of the local colorist, Banks generates possibilities for literature to reappraise what has passed. As with his insistence on handling local color especially after its bankability has dwindled, Banks refuses to ignore the stifling presence of what the mere passage of time has devalued.

The Darling registers the long shadow of yesterday's version of cosmopolitan citizenship through Hannah's father, a thinly veiled Benjamin Spock. He is a physician, best-selling author, and antiwar activist often making the news for having attended protests with the likes of Arthur Miller and the Berrigan brothers (144). Hannah's underground radicalism is a rebellion against his very visible role in a "post-Civil Rights" reclamation of the liberal political space by "arm in arm ... like-minded, earnest white men of a certain age and position" (144). This version of cosmopolitan citizenship is obviously unacceptable to Hannah. As opposed to her father, who "believed in 
nonviolence because he himself was incapable of committing a violent act," Hannah believes in violence because it remake her into a proactive subject rather than the privileged child who could only react to what is granted her (147).

As with Wade Whitehouse and Hamilton Stark, Banks uses Hannah to do violence to the hackneyed narratives that clog up her life's story. Unlike these men, Hannah is not a self-destructive or a solely "reactive" being. She is a narrator; she assumes the position that her voice is as good as any to do the work of freeing her from the oppression of tradition. Like all good left-wing radicalisms, hers is based on a "dream of violence against people and institutions and governments that exploited the poor and the weak" (340). Under her "mask of idealism and ideology" was "the face of the privileged, angry kid who, in the name of peace, justice, and racial harmony, had declared war against the state, the university, and, before long, his parents' entire generation" (47). This version of proactive and constructive violence is new to Banks, whose provincial antiheroes never dreamt of violence as a way of erasing the face beneath the mask. But Rolfe anticipates this kind of class-inflected separation from the provincial figure. His reflection on the oddity of his survival in college, for instance, evokes a mode of introspection that can think of the self in relation to larger systems and concepts. Hannah thus becomes the human voice of post-radical politics, which has adjusted to the reality that her radicalism was authorized by a bourgeois cultural system. Candid about the white middle-class prehistory of her identity as a rebel, Hannah reminisces about her undergrad years:

It was the mid-60s. In our dorm rooms we listened to folk music, Negro blues, and jazz; smoked dope; drank cheap red wine from basket-wrapped 
bottles; and wore black turtlenecks, jeans, and peasant sandals to class, even in winter. ... we loved Goddard and Bergman movies and called them "films," and cultivated what we regarded as morally meaningful alienation from bourgeois society and values. (47)

In short, Hannah admits that her generation's "forms of rebellion" were hand-me-downs from "the Beat Generation and famous European-café existentialists" (47). This tonguein-cheek though poignant account of her early days as a "radical" calls to mind the simple but often neglected fact that authentic relations to roots resistance are hard to come by for one of the white middle class, one who is rarely not already in a dorm room or some other construct designed to elicit a specific version and range of privilege. Because Hannah can recognize these kinds of details about her own biography, it's safe to assume that her handling of the kinds of relations made and remade on a world stage will at least be sincere.

Her talk of west-coast university culture in the 1960s also recaps Kingston's point about the way Beat cultural forms are mismanaged under the consumer logic of "lifestyle" production. Hannah's frank confessions of the embarrassing, even hypocritical, roots to her radicalism comes to a head when accounting for the difficulties of forging productive relations in a nonviolent, nonunderground way. She explains: For years, ever since the Civil Rights movement got taken over by blacks, and the white college kids like me and the white lawyers and clergymen were sent home from the South, leaving us with only the splinters that were left of the antiwar movement ... I'd felt somehow cheated out of my 
true mission, as if in my chosen line of work I'd been deprived of an essential tool, and that tool was black people. (56)

This startling confession implies that racialized thinking is redistributed on the left via the struggle for management and agency in social justice operations. Eric Lott explains this form of leftist racism as the distinguishing characteristic of coalitionism, which "often take[s] the form of the white group going to the black group and asking for help, then articulating demands that the black group never articulated ... it's sadly about opportunistically making use of one group or another for their particular demands."239 This form of political activity, which Lott calls "ungenuine" and "mercenary," is the very kind the Hannah imagines as an undergraduate wishing to direct the registration of black voters in the South during the Freedom Summer of 1961. The fact that adult Hannah winds up marrying a centrist Liberian government official and adopting the surname Sundiata is thus unsurprising not because her Liberian husband is black, but because Liberia is very much like the Old South. ${ }^{240}$

Because of her bipolar dream of social justice and violence, radical Hannah had always been compelled to be in the South. Explaining her "first journey into the American South," Hannah describes herself as a college girl using her summer vacation to register black voters ... an innocent, idealistic, Yankee girl whose vision of the South had arisen dripping with magnolia-scented decay and the thrill of racial violence from deep readings of William Faulkner and Flannery O'Connor. A newly minted rebel, fresh faced and romantic ... confident that we were about to cleanse our parents' racist, oppressive world. (12) 
Thus the South for Hannah, like the South for those readers who popularized the 1960 reprinting of Let Us Now Praise Famous Men, was a mythic terrain wherein white middle-class liberals could indulge in idealism while also gaining the subjectivity of a social justice worker. ${ }^{241}$ Introducing it as an original site of globalized white control of social justice operations, Banks sets up Liberia as a geopolitical machination devised by an antebellum "alliance between northern white Christians and anti-slavery advocates and slaveholders from New York State to Georgia" to "raise government and philanthropic funds to purchase the freedom of enslaved blacks - especially the more troublesome ones" (87). The West African locale was mostly “impenetrable jungle, mangrove swamps, and malaria-infested estuaries, a plot of super-heated, saturated ground that no one wanted" (87). In other words, Liberia was not a place so much as a holding station for people no one wanted to call citizens of the U.S. It was a quick fix for a "race problem" that even abolitionists, who had "noticed the presence of a growing number of ex-slaves on the streets of northern cities," feared (86). In short, Liberia was "the first U.S. colony ... a covert surrogate, clamped tight to the white-skinned leg of its North American founding father" (88). Hannah explains:

By the end of the nineteenth century, just as in parts of the deep South and the Caribbean at the end of the eighteenth, one percent of the population of Liberia ... owned the other ninety-nine percent, and a huge chunk of the profits generated by the back-breaking labor of that ninety-nine percent went straight to the board rooms of America. (89)

But by the mid twentieth century, Liberia's two main imports, rubber and bananas, had been located in developing nations closer to home, meaning that "our man in Africa got 
left behind" (89). Thus the racial injustice of the American South, the "principles of exploitation and use" that undergraduate Hannah felt had been denied her, were crystallized indefinitely into the abandoned socio-political structure of Liberia (89).

The impact of having realized her adolescent dream of helping the disadvantaged quickly reaches a fever pitch for Hannah in Liberia. When she first encounters "poor people eking out their day-to-day livings," she screams internally to be let out of her fiancé's "air-conditioned chariot" (119). She cries, "let me be one of them, not one of $y o u$ ! Let me walk unnoticed with them along this dusty road ... not ride smoothly over it" (119). This spontaneous internal apostrophe to the privileged "you" she'd been running from all her life contains the same basic longing for sensual contact with terrain that Sal Paradise desired in Part One of On the Road. Like Sal, who is to a large degree Hannah's narrative precursor, Hannah needs to run from her privilege, to initiate herself into a vast village of cultural estrangement. ${ }^{242}$ The specific soil of the "dusty road" offers an experiential base inherently more valuable than the "air-conditioned chariot" because it is closer to the physical site of labor and struggle. But Hannah's search for another antebellum American South brings her into close contact with a world of extreme poverty and mistreatment. This contact is made palpable and weighty, too abundant and vast to be overcome. For an instance, upon hearing the chimpanzees who had been caged and mistreated for years before her arrival in Monrovia, Hannah describes the noise they make from their dark confines as a "compulsive, arrhythmic banging" that "had merged and become a congealed and hardened quantity of sound, as if it were an object, a quarried thing, a room-sized block of stone" (95). Also, upon first seeing the native tribespeople who come out from the jungle to see their car pass, Hannah notes that "when 
a human being appeared ... it was as though he or she were emerging from a wall of green water" (122). These two descriptions are typical of Banks, who prefers to transform ethereality into materiality. But, in the context of Hannah's search for another antebellum American South, they register the world of the mistreated as though it is a heavy element too abundant and vast to be overcome.

What's left for Hannah, who sees the granite state of suffering in the places abandoned by the movement of modern capital, is a crippling recognition of her own need for the suffering of others. This is just what happens to Hannah, who, en route to meeting her future in-laws, leaps from the chauffeured car into the face of a frightened goat, an experience that shapes her understanding of her presence in Liberia. The goat's face, its "pathetically scared gaze," becomes "for one brief moment ... the central reality of my world ... it wasn't a symbol of the world that surrounded me; it was the world itself" (120-121). As a "signified" of absolute poverty, the goat here rings with the same awesome shock that Depression-era sharecropper photographers tried to choreograph. Hannah meets the goat while on her way from the big, old city of Monrovia, with its postcolonial glamour of "roads ... built first by Europeans and then Americans," to an Africa that was "as close ... to West Africa as it was when the first Europeans arrived" (124). This is an important aspect of Hannah's identity crisis, as it represents a departure from the safe anonymity of a big city to a communal paradigm heretofore unimagined by a white middle-class girl. In the bush she loses her urban privilege of making herself into whomever she needs to be. Fleeing an air-conditioned chariot is finally not an act of empathy but a way of staving off the inevitable. As the future Mrs. Sundiata admits, "when I fled from the safety and comfort of the ministry car and embraced that poor, 
pathetic, female goat, it was not to comfort her but to induce her to comfort me. To help me believe that what I saw coming towards me would not arrive" (125). Here the identity crisis of the female radical and the pitiful heart of philanthropy merge. Hannah will disappear and the only consolation is that a new person with no identity will emerge to embrace a helpless subhuman version of rural poverty, and therefore be comforted by an action that implies that the one embracing has the agency.

It is not surprising, then, that chimpanzees emerge as her enduring recipient of Hannah's philanthropy. Considering that her travels had opened the door to many so new candidates, it might seem odd that Hannah might choose chimpanzees for the role of most needy figure on the world stage. But, insofar as needy figures have always been misrepresented as unassimilable into mainstream society, the chimpanzee is as good a candidate as any. Like the sharecropper, whose visibility serves to answer the question of who is beyond the reach of New Deal welfare, the chimpanzee is always thought of in terms of its secondary relation to humans. Even its name means “'mock-man' ... derived not from the creature's own nature, but from its relation to us, to humans, as if its essential nature were a lesser version or a negation of ours" (21). As Hannah explains, the chimpanzee is "the only species named in such a purposefully distancing way. ... The not-us" (21). In contrast, the names Hannah gives the chimps come from the fiber of her own voice. She explains that the names "were sounds that for mysterious reasons I liked saying to myself, sounds that were keys capable of unlocking blocked memories, lost sensations, ignored associations" (185). The chimpanzees had always been for Hannah the very disparaged figures she had been hunting for since choosing as an adolescent to care about "the underprivileged." Their names, therefore, come naturally to her, as they 
are both the objects of her life's dream of communing with disparaged soil and the instinctual linguistic compounds of that dream.

With this etymology in mind, Hannah represents the chimpanzees as the beings who both enlarge the population of Liberia (they matter as much as, if not more than, people do for Hannah) and reopen a place within Hannah's dream of deracination for the kind of sentimental affection that used to accompany the presentation of local color. Because Hannah's objects of sentimentalism are othered out of the human species, the affection bestowed on them is not something that can, as in the case of Depression sharecroppers, translate correctable suffering into a foregone inevitability. It almost seems as though Banks is claiming that "animal welfare" is a more realistic cause to back than is social welfare. ${ }^{243}$ Though I'm overstating the case, what makes this misreading seem probable is exactly what makes it important in the context of competing inflections of cosmopolitanism and provincialism. The chimps matter to Hannah because they allow her a scaled-down version of her fantasy to be a manager of social justice. Because she knows that her significance is diminishing, that "when my politics disappeared, my only hope for an autobiographical narrative had disappeared," Hannah knows she has few options outside of the chimpanzee sanctuary (247). Her life without the chimps is punctuated by turns of the knob, frequent acts of abandoning locale. What she learns from the chimps is how to value the stability of confinement, the safe comforts of cramped spaces:

It may seem strange to you, but something about prisons, jails, cages comforts me. All my life I've run from confinement and tried to keep others, even animals, from being imprisoned. Yet whenever I come close 
to an actual place of confinement, whenever I'm physically in its proximity, something inside me clicks off and something else clicks on. (291)

What it is that "clicks on" is the storyteller's excitement at a world that is at once articulable and transcendable. Actual places of confinement confirm locale as something to inhabit and eventually to imagine one's way out of.

Eventually, Hannah's experience with the chimpanzee sanctuary, her earnest effort to treat innocence ethically, yields a fresh articulation of a fairly traditional lesson in tragic thinking. Hannah learns that a principle as reconciliatory as empathy has "builtin limitations" (326). Banks likens this discovery to the "well-intentioned man" who might truly empathize with women but who can never understand injustice locally or spatially, or as Hannah puts it, never know "how the relations between men and women feel to a woman" (326). Though "[i]t's good politics" to empathize with the less fortunate, empathy is essentially another form of oppression, as it champions in the empathizer the main source of feeling that is denied to the empathized and that therefore makes the empathized something worthy of empathy (326). Or, as Hannah puts it, there are useful parallels in the relations between men and women, between whites and blacks, between people without disabilities and disabled people, between human primates and nonhuman primates. We who have more power in the world ... try to experience racism as if I who am white were black, to see the world as if I who am sighted were blind. 
But the point of this discovery about empathy, indeed what may be the point of The Darling as a whole, is that with the expansion of terrain through which to forge cosmopolitan subjectivity, socially conscious American fiction (i.e., fiction that is both responsive to this development and responsible in its treatment of beings that might at first look like disparaged figures in need of aid) should take a better look at the sources of disparagement. Do not do what Hannah warns against and assume that "if I were blind, I'd need me to help me" (326). Instead, Banks reaffirms Agee's assertion that points of contact matter most. The only real way out of the long division between the provincial and the cosmopolitan, Banks seems to say here and throughout his career, is to consider storytelling as the contact zone that gives shape to the experience of relating to a world very different from your own, that negotiates the boundaries between dissimilar objects and subjects.

Overall, Banks suggests that local knowledge is a generative tool, the raw material of an ethically sound twenty-first-century cosmopolitan subjectivity. His unique handle on the codes and limitations of incorporating local knowledge into fiction, as well as his expert understanding of the points of contact between local knowledge and the ethics of cosmopolitan citizenship, suggest that depolarization begins with a frank portrayal of world vistas. This means, as Banks dramatizes through Hannah's difficult journey to the West African location of her own essentialist identity politics, that sources of what Americans think of as "diversity" are in fact the sources of inequality. 


\section{Epilogue:}

\section{War in the Middle West: Jonathan Franzen and Local Affiliations in the Twenty- First Century}

The landscapes offended the eye passively, by disappointing it, leaving unfulfilled the traveler's hope that the opening of the country might, as roads actually did in England and Africa, reveal significant traces of the indwelling spirit. There were, for instance, the zinc-plated standards of exit signs and mileage signs - upright I-beams whose burrs and pits reflected low-cost fabrication, wide tolerances, U.S. government specifications. The structure of each sign was sturdy enough and the design pleasing enough that it teased travelers with the possibility of being appreciated as a less literal sign of place. (Jonathan Franzen, The TwentySeventh City 512)

In this dissertation, I have examined the works of writers who fight against the "location is destiny" maxim that has been developing in American fiction since the Great Depression. Considering this progression, it might be expected that I punctuate my argument here with an examination of fiction that indicates that the fight against false polarities continues and/or is being won in contemporary America. Indeed, it may be true that with the twenty-first century comes a slate of literary fiction that effectively disproves the myth that worldliness and local literacy are opposing conditions. However, because of the omnipresence of locative technologies (e.g., Global Positioning Systems and Wireless-Fidelity), it's no use making this argument. The myth that there is some 
fundamental difference between the provincial and the cosmopolitan is disappearing as fast as small-town adolescents develop online avatars.

In this still young age of "second life" cyber affiliations, the codes that signify what is provincial and the codes that signify what is cosmopolitan are merging together into the codes that signify what is connected. ${ }^{244}$ Indeed, "connectivity" is a word that, had it been in popular use in the mid-century, would have provided a technical vocabulary for Kerouac's delocalization efforts, his efforts to represent multiple simultaneous local affiliations. In a sense, with the cyber revolution comes a sense that the pre-Depression modernist focus on the impossibility of community has evolved into a saturation of communities made possible by the "world wide web," specifically its new language of social integration and communicative exchange. As various geographical zones begin to merge and obscure the distinctions among one another, the obvious question arises: What use can a regional category possibly serve in twenty-first century fiction?

As I discussed in the previous chapter, recent writers such as Russell Banks, Joyce Carol Oates, and Marilynne Robinson assert that the regional category remains valid only to the degree that regional difference can impact the production of the firstperson narrative voice. In other words, self-consciously regional subject matter remains an option only to the extent that first-person narration remains an option. Regionalism, I argued in the previous chapter, is now solely a mechanism to register individualized timbres. Its claims to authenticity have been completely subsumed by artifice, as evidenced by the fact that possibly the two most authentically localized narrative voices in recent fiction - that of Banks's Hannah Musgrave and Robinson's John Ames- have also been examples of narrative cross-dressing (or first-person narration whose person is 
of a different gender than its author). As indicated by these examples, especially by the fact that Robinson's Gilead (2004) won the Pulitzer and the Book Critics Circle Award, American writers are being rewarded for producing a provincial timbre in the narrative voice, rather than for perpetuating sentimental nostalgia for home regions.

Giles Deleuze and Felix Guattari touch on the value of such timbres in their monograph on "minor literature." They begin with the persistent question: "The revival of regionalisms, with a reterritorialization through dialect or patois, a vernacular language — how does that serve a worldwide or transnational technocracy?" (24). On its face, this question seems to discount the usefulness of the regional voice, as regionalism comes across as merely a preservative for vernacular language and other relics of dying cultures. However, as I discussed in Chapter Two, Deleuze and Guattari promote fiction that develops new dialects and vernacular inflections, as these developments expose a language's lack of structural integrity and thus stretch the language to meet the communicative needs of so-called "transnational technocracy" (18). Hence, Banks places his blue-collar voice in the mouth of a female revolutionary and Robinson pushes emotional complexity through the throat of an elderly minister. Their "minor literature" thus passes the no-nostalgia test and gets shelved as serious, place-based literary fiction. But what about what might be called "major literatures," or novels that take on larger, multi-front social constructs such as suburban municipalities and consumer markets? Must a narrative voice have a drawl before it can make any worthy contributions to the depolarization of provincialism and cosmopolitanism? Must provincial figures be the only ones to cross the divide? When will the village rebels come home? 
In this epilogue, I will address a type of American fiction that seems to be in competition with the fiction of provincial affect but that is actually invested in exploring the ramifications of the cosmopolitan/provincial divide. As exemplified in the work of Jonathan Franzen, self-consciously cosmopolitan narratives that acknowledge the coming age of cyber affiliations also acknowledge the coming of a more permanent digital division that will reinscribe socioeconomic (rich/poor) and racial (white/minority) binaries. In the process of revealing this new dichotomizing logic, Franzen's fiction revisits the mechanics of implementing local affiliations in fiction. Franzen differs from contemporaries Banks and Robinson in that he drops both the regional narrative voice and the criterion of place-based verifiability. He produces instead a cosmopolitan narrative voice that reviews the historical and geographical record, finding the root causes of the coming digital divide.

As I discussed in the previous chapter, Franzen is among the recent writers who are pessimistic about the resurgence of regional fiction, as it produces niche readerships whose diminished numbers will in turn diminish the chances that fiction will effect any large-scale social change. According to Franzen, to tag fiction as regional is to attempt in vain to deny the fact that cyber affiliations have swept local variance into a boundaryless ether. In other words, to call a work of fiction "regional" is to provide it with a refuge from the forces of globalization and thus to construct fantasy rather than fiction. By this logic, literature with strong local ties is valuable only when it engages the global networks that influence the nature of local ties.

In what follows, I will discuss how Franzen engages global networks through dramatizing the history of the importance of the Midwest in the tradition of negotiating 
local affiliations through fiction. In section I, I begin by discussing Franzen's relationship to recent developments in Midwest fiction, developments that mirror to some extent the resurgence of regional fiction discussed in the previous chapter. In contrast to this regional resurgence, which represents regions such as the Midwest as though they are foreign lands, Franzen juxtaposes foreign influences into the all too indigenous theme of political conspiracy. He does not exploit the Midwest as a "third world" region, but, in the tradition of Sinclair Lewis, represents the corruption that engenders a new racial and socioeconomic (i.e., urban/suburban) polarity. In section II, I argue that this new polarity requires re-scaling of regional and cosmopolitan paradigms alike. Franzen's geographical and historiographical fictionalization of St. Louis, in his first novel, The Twenty-Seventh City (1988), recommits the polemical sociological gestures of "revolt from the village" fiction to the labor of dismantling regional boundaries. Ironically, by endorsing the disappearance of boundaries, Franzen endorses the very boundary-less Midwestern "empire" that Lewis and other village rebels feared. His first novel's plot, about a failed attempt to merge the wealthy suburbs of St. Louis County and the impoverished inner city of downtown St. Louis, tackles the contemporary sources of the "location is destiny" maxim. In the process, Franzen reveals that the revolt from the village is an outgrowth of a false dilemma.

I will conclude this dissertation by arguing that Franzen's relationship with early twentieth-century literary patterns of addressing the division between provincialism and cosmopolitanism is actually a renewed commitment to "social realism." This commitment is present in his first novel. But it is later galvanized by Franzen's very public dispute with Oprah Winfrey, who chose his third novel, The Corrections (2001), 
for her Book Club and then disinvited Franzen, due to the reservations he expressed at the idea of Oprah's "corporate" endorsement. This dispute is important because the source of the tension between Franzen's elitist conceits and Oprah's populist conceits is a tangible example of the cosmopolitan/provincial polarity that has run through post-Depression literary history. In fact, the dispute signals that the opposition has evolved into a contradiction in need of synthesis. According to a wounded, abashed Franzen, he and Oprah "want the same thing and believe the same thing, that the distinction between high and low is meaningless" (qtd. in Kirkpatrick E1). By "high and low" Franzen means "literary" and "schmaltzy, one dimensional" fiction. If he truly believes that distinction is meaningless, then he must also believe that some truce has been reached regarding the rift. This truce is manifested in the shift from the anti-sentimental antagonism of early attempts to address the cosmopolitan/provincial divide (attempts exemplified by Lewis's Midwestern novels) and the earnest social realism that contemporary writers such as Franzen use to fight the forces of polarization. Franzen's recommitment to social realism has two notable effects: (1) the articulation of a new, urban Midwestern version of the divide (one that is symbolically similar to the digital divide) and (2) the argument that the "revolt from the village" is a source of, rather than response to, cosmopolitan/provincial division.

\section{I}

Franzen's first novel works against the grain of recent Midwestern fiction, which tends to exploit the socioeconomic and racial dividing lines and to present the Midwest as a contemporary no man's land. Typified in Whitney Terrell's first Kansas City novel, The Huntsman (2001) and Michael Collins's rustbelt trilogy, The Keepers of Truth (2000), 
The Resurrectionists (2003), and Lost Souls (2004), the resurgence of regionalism is alive and well in the urban and suburban Midwest. They evoke postindustrial moods and landscapes reminiscent of Banks's blue-collar New England. For instance, both The Huntsman and The Keepers of Truth cast a deliberate third-world shadow over the Midwest. Terrell's novel features a racist Kansas City judge who claims that there is "no difference between [Kansas City] and the most obscure village on the Congo River that Conrad once went past" (341). In other words, both are remote enough to yield lawless megalomaniacs. The Kansas City/Congo conflation is thus "the dream" that corrupt Midwest politicians cling to, as the conflation indicates that corrupt politicians are far from sight; they are the Kurtzes who are "obscure as savages" and therefore free to do as they please (341). In short, Terrell represents his native region as a place to "go native," a U.S. region so inconsequential that it is lawless. Collins, an Irish citizen who has himself gone native in the Midwest, writes literary thriller novels set in generic rustbelt towns. Collins strikes a similar logic of resemblance between the Midwest and the third world. In addition, his narrator in The Keepers of Truth names a major source of the region's economic and civic problems: outsourcing. Collins's Midwestern men embody the typical paradox of guilt and contempt regarding the sweatshop system, a system that simultaneously shuts down Midwestern factories and makes consumer habits less prohibitive. Collins's male characters "long for ... immigrant exhaustion," for the physical byproducts of a vibrant region (173). The broad-shouldered he-men of Collins's fiction are murderous fry-cooks at the local Denny's. Therefore, where Terrell exploits the lawless remoteness of the Midwest, Collins elegizes the vitality that preceded the 
woeful resemblance between the unemployed Midwestern men and the "women and children ... of places without names" (173).

Such narratives have become popular ways of representing the contemporary Midwest. But before Terrell and Collins discovered the third-world hues of the Midwest, Franzen demonstrated that the need for such "foreignness" is of a piece with a need to reinvigorate local affiliations. Near the end of The Twenty-Seventh City, Franzen observes that Midwestern landscapes "offended the eye passively, by disappointing it, leaving unfulfilled the traveler's hope that the opening of the country might, as roads actually did in England and Africa, reveal significant traces of the indwelling spirit" (512). As he makes his way back to St. Louis, back to a failing marriage and ruined public life, Martin Probst-fictional contractor of the St. Louis arch and protagonist of Franzen's novel—finally realizes that no amount of construction work can save him from the banality of his region. In fact, the built environment only adds to said banality: "the zinc-plated standards of exit signs and mileage signs - upright I-beams whose burrs and pits reflected low-cost fabrication" (512). These literal signs and measurements of place are simply too standardized, too unvarying in every way other than their numeric progression, to offer any solace for the fact there is no "indwelling spirit" in the Midwest. Longing for the "thoughtful road experiences in other countries and in his youth," Probst wishes he were "foreign again" (513). As opposed to Terrell and Collins, who expose this need as a trait common to the region, Franzen universalizes this need, making it common to all middle-aged men. The longing to be young and foreign is not localized, as it bespeaks not a place-specific lack, but a universal longing "to live in the world as opposed to merely inhabiting it" (513). As a writer, this drive to "stay foreign" is exactly 
what Franzen attempts to do with his hometown of St. Louis. He populates it with international intrigue, putting its actual history and demographics in relief so that author and reader alike can encounter a familiar place as though it were a foreign place.

To help this fictionalized experience of foreignness, Franzen imports major characters from India, creating a novel that is not so much interested in shining a new light on a familiar region as it is in starkly juxtaposing what is considered banal and Midwestern and what the Midwestern sensibility considers exotic and foreign. The resulting set of images underscores the banality of the Midwest, asserting that not even all the bells and whistles of foreignness will make the place into a foreign country. Franzen's geo-aesthetic argument here, then, seems to be that St. Louis is empirically a boring place. It is so boring that sights as uncommon as "[a]n Indian family of ten ... standing on a traffic island one block east of the Cervantes Convention Center" are easily absorbed into the landscape as "fixture[s] of daily life in the city" (6). The narrator continues to point out new scenes that have resulted from the seemingly random mass migration from the Far East to the Midwest:

Indians were noticed lounging with no evident purpose on the skybridge between Dillard's and the St. Louis Centre. They were observed spreading blankets in the art museum parking lot and preparing a hot lunch on a Primus stove, playing card games on the sidewalk in front of the National Bowling Hall of Fame, viewing houses for sale in Kirkwood and Sunset Hills, taking snapshots outside the Amtrak station downtown, and clustering around the raised hood of a Delta 88 stalled on the Forest Park Parkway. (6-7) 
The presence of Indians here removes Midwesterners from the scene. Grammatically, the past tense passive voice removes the agents - the would-be "noticers" and "observers"from the scene. The Indians "were noticed" and "were observed" by no one in particular, which implies that the observer is either hidden somewhere within the air-conditioned structures between which the Indians crowd or that the observer is herself some such structure. The difference between representing the Midwest as a foreign land and placing the people of foreign lands in the Midwest is thus the difference between exploiting the regional category for the pseudo-ethnicity it provides the author and using fiction as a way to address the civic and, in Franzen's case, municipal injustices that create the very conditions that writers like Terrell and Collins use to flavor this exoticism.

Franzen's interest in getting to the sources of the political corruption and economic plight is clear from the plot of The Twenty-Seventh City. Franzen tells the story of a female police officer from Bombay who, as a result of local partisan deadlock, is elected chief of the St. Louis Police Department. While in office, the "Indian chief" implements a secret plan to merge the St. Louis County and downtown St. Louis, two civic bodies that have been at odds for more than a hundred years. According to the historiography Franzen provides, this city/county divide is the very reason why the onetime "Fourth City" of the U.S. has plummeted to the status of "twenty-seventh city." In its most rudimentary form, The Twenty-Seventh City is a novel about racist municipalization. Seeking an interesting answer to the most asked question about the late twentieth-century urban Midwest-“Why is downtown so dead?"-Franzen cloaks the standard "white flight" answer in a fantastic conspiracy plot against the Midwest city that has most successfully fortified white flight with hard municipal boundaries. 
The novel begins with a hand drawn map of St. Louis, which highlights the city's primary peculiarity: the innumerable municipalities that surround what is, in comparison to the municipal cluster, a small urban center. The peculiarity is no fiction, as any map of St. Louis attests. Franzen's map deliberately draws attention to the peculiarity, as one small area of the map announces that "This region contains 32 municipalities" and many sylvan suburban names (such as Kirkwood, Crestwood, West Wood, Brentwood, Rock Hill, Webster Groves, Richmond Heights, Ladue, Creve Coeur, Frontenac, Des Peres, and Clayton) crowd the page west of the sparse downtown, which is represented as twelve superblocks peppered with "points of interest" to the municipalities, such as the Chase Park Plaza and the Arch. Aside from the thin "River Des Peres," the dividing line between the wealthy, crowded county and the desolate city is entirely unnatural, a fact that is underscored throughout the hand-drawn cartography. The map has the effect of being an introduction to both the novel's setting and plot. It is as though Franzen is asking, "Here is Greater St. Louis, notice anything?"

The novel's first chapter introduces “one S. Jammu,” Franzen's Indian police chief, by combining nonfictional local knowledge and a fictionalized newspaper article (5). This combination establishes the novel's relationship to the real world as partially counterfactual, a viable alternate version of St. Louis, as opposed to either an entirely fantastic or an entirely factual version of the place. Franzen's native knowledge emerges with the observation that with Jammu's tenure begins also the "season of another, more familiar Eastern visitor to St. Louis, the Veiled Prophet of Khorassan" (6). The "Veiled Prophet Organization" is an actual secret society made up of prominent St. Louis business leaders and their families. In this context, the allusion underscores the racial 
hypocrisies of the St. Louis elite. ${ }^{245}$ According to Franzen (as well as to historian Thomas Spencer's study), the Veiled Prophet Organization takes its name from the Thomas Moore poem in Lalla Rookh, titled "The Veiled Prophet of Khorassan" (1817). Franzen quotes a selection from that poem, indicating that the novel's opening night is the same night as the organization's annual debutante ball, an actual annual occurrence that normally follows a lavish parade featuring plenty of "debbing," as well as a veiled prophet (a prominent business leader) and attendants adorned in Persian regalia. The Persian costumes are based on Moore's representation of the historical veiled prophet, alMaqanna, an eighth-century heretical Persian Muslim who wore a veil to shield his holiness from his followers. Franzen's juxtaposition of mass migration of "Eastern visitors" and the annual arrival (at the debutante ball) of an Orientalized Eastern prophet elevates the racist class-inflection of upper-class St. Louisians. The ball takes place in the Khorassan room of the Chase Park Plaza, an old St. Louis grand hotel. Despite the fact that Franzen himself conflates Indians and Persians, his ironic parallel establishes the disconnect between the ballrooms of cosmopolitan ceremonies, wherein Eastern decorum is being preserved, and the train stations, traffic islands, skybridges, and parking lots, wherein similar decorum is being worn down by the road grit of local affiliations.

Franzen begins with the Veiled Prophet reference also in order to establish St. Louis as the fiefdom of the St. Louis County aristocracy. Not only are they partying in the streets of a city that they, by virtue of their municipalization, have little tax obligation to, they are also reincarnating a "prophet" whose claim to fame is that he occasionally raided mosques and towns in Persia. Additionally, the historical "veiled prophet," alMaqanna, espoused a "socioeconomic program [that] stressed the communality of all 
property."246 This program, downplayed in Moore's poem and lost completely on the organizational memory of the secret society, al-Maqanna adapted from a sixth-century heretic named Mazdak, who, in addition to shared property, advocated the heretical doctrine of the transmigration of souls. Though the novel never explicitly revisits the Veiled Prophet Organization, the plot is conspicuously aligned with this historical figure. Specifically, Franzen's Eastern villain, Jammu, works for the same kind of communal distribution of resources that al-Maqanna tried to manifest in his region of Persia. The "veiled" machinations of Jammu, who hopes to foil the hegemony of the business community, are thus unwittingly being evoked by her eventual victims on the night of the novel's opening.

Following this brief, possibly inadvertent reference to the novel's historical parallels, Franzen introduces Jammu through a transcription of a fictional newspaper article. The newspaper article helps Franzen to build his conspiracy alongside an historical footnote on an existing conspiratorial social system (the Veiled Prophet Organization). From the article, the reader learns key bits of nonfictional historical context from which emerges his fictional villain/heroine. For instance, in 1975, Indira Gandhi called "President's Rule" in India and for the following year and a half the Indian constitution was "dispensed with" (9). Police officials were allowed to ferret out and halt economic corruption however they saw fit. Oscillating back to fictional exposition, Jammu is said to have established "Project Poori," a law enforcement program named after a popular Indian fried bread. The article explains that the project was a market initiative designed to "defeat[] corruption on its own terms" (9). The results were immediate and enduring. Bombay has since come to be "known to Western journalists as 
the one city in India where groceries were plentiful and prices uninflated" (9). Franzen thus produces a character whose mission it is to quell corruption by any means necessary. The source of corruption in St. Louis is the county/city divide. Jammu's unification plans constitute the plot's forward motion.

The newspaper is not strictly an exposé of the foreign figure who will eventually almost unify the city, as it also includes some typical Midwestern provincial selfpromotion. For instance, Jammu's very odd appointment is not deemed an opportunity to investigate, but to boast: "St. Louis is now the largest U.S. city to have a female police chief" (11). Franzen's satire of the contemporary Midwestern boosterism is clear. What is odd about the boast is that "progress" (to the extent that the article assumes its readers will recognize female police chiefs as progress) begins in the small town and moves to the city. If St. Louis is "now the largest" city to have a female police chief, then the cities that already have female police chiefs must be considerably smaller. Considering that Franzen is quick to point out how, because of its municipalization of white-flight, St. Louis is demographically smaller than it looks, the cities that already have female chiefs must be quite small on a national scale. What also makes this fact satirical is its temporality. "Now" is a modifier that suggests impermanence; it establishes the fact as dependent on the tenure of a police chief. Local journalists in St. Louis, not unlike the boosters of Lewis's Zenith, will shine the best possible light on facts that might help the city "overcome its image as a 'loser"” (11).

In contrast to this provincial myopia, Jammu views St. Louis not as a city so much as the center of a broader region. In fact, she asserts in a quotation from the newspaper article that the city's criminal element is not an urban problem but "a regional 
problem" that the business community in St. Louis County has a responsibility to address (11). Jammu plans to tackle the crime wave the way she dealt with economic corruption in Bombay, through "appl[ying] a new set of terms to a situation that appeared hopeless" (12). The article anticipates these undertones of martial law, quoting a spokesman of the local ACLU chapter, who "urg[es] that Jammu be dismissed before a 'constitutional disaster' occurs" (12). Well aware of the political leverage she can gain by doing so, Jammu secretly encourages such attacks from "the liberal community," as they help her retain the trust of the business community she plans to liquidate. She publicly accuses liberal Midwesterners of distrusting "the Third World in general," arguing that the Midwestern left wing is a bunch of latently racist knownothings whose assumption that all law enforcement is an affront to minority groups is an unqualified criminalization of such minorities. Rather than follow the ACLU-wary law enforcement protocol of her predecessor, a protocol that "ensures that St. Louis deteriorates in the most orderly possible way," Jammu promises to make the police force a force of proactive production (13).

The "product" she is working toward is the unification of the county and the city. Jammu's chief targets are twelve "chief executives with a strong hold on their stockholders" (29). These so-called "private individuals" are all white and male (30). Together, they "determined the location and tenor of investment" in the county at large. Her method of unification involves lulling these twelve men into "a 'State" in which their "everyday consciousness became severely limited" (30). Jammu induces the "State" in these individuals by preoccupying their minds with personal problems, managerial problems, and most importantly "horribly protracted tax audits" (30). The "State" thus 
works because of its oblique point of entry. As the businessman is preoccupied with what he thinks is his daily life, Jammu manipulates "a quarter of the subject's life unrelated to Jammu ... [unrelated] to the public sphere in general" (30). Jammu indentures her "subjects" to their own character flaws - drinkers of alcohol become alcoholics, men who underpay their laborers become victims of labor strikes. When one's private problems flare up, then his public behavior becomes manipulable. Once in this "State," heads of industry make promises that defy their normal agendas, promises to blend their industrial interests with the interests of urban renewal.

Jammu's ability to control business leaders without their knowing it indicates that the hegemony that authorizes a very few St. Louis county leaders to affect Greater St. Louis policy change also bespeaks a ruling class that is simply too thinly spread to close off all opportunities for insurrection at once. Her subjects impair their control over one relation in order to simply survive the firestorm that another relation devolves into. In this way, a subject "reached a state in which he lived and breathed and dreamed only taxes" (30), and he was less likely to notice that city interests were slowly merging with county interest. The conspiracy thus exploits the multiple affiliations of powerful men, reading these affiliations as a tactical disadvantage, a thinning agent that weakens the barrier powerful people establish around resources.

In addition to instilling the State into St. Louis business leaders, Jammu initiates an aggressive gentrification process, raiding drug houses and derelicts, putting them god knows where (we discover at the end of the novel that she has been depositing evicted African Americans in the undeveloped wasteland, or "Jammuvilles," of East St. Louis). Under various guises, she "buy[s] up the lots as she goes" and then sells them to 
whichever of the twelve county bigshots are the most in need of "blighted area" property tax abatements (68). In other words, Jammu makes it appear as though the bigshots themselves have begun the process of unification. Jammu describes this real-estate inspired subversion as a nonviolent form of terrorism. She claims that the real-estate business is: "[e]ssentially ahistorical. Once it gets going — once we set it in motion—it works by itself and drags politics and economics along after it. Terror works the same way" (76-77). The problem, as the narrator explains, is that a shift in property ownership is not a shift in affiliation. It will thus not effectively merge the county and the city:

She'd hauled the big industrial guns into the inner city and called it a solution, because ultimately it was far easier to change the thinking of a rich white fifty-year-old or to deflect the course of his eighteen-year-old daughter than it was to give a black child fifteen years of decent education. (399)

In other words, Jammu needs to implement a political phase to the unification process. She accordingly begins a grassroots movement that comes to be known as "Urban Hope," which county business and political interests who remain unaffiliated counter with a movement known as "Municipal Growth." Eventually, this rift in municipal reform evolves into a city/county merger referendum and Jammu evolves into an icon of youth culture. Tank tops with her face on it start to appear. She is sure to win the Democratic nomination to the U.S. Senate, whenever she chooses to run: "Youth knew the score" and middle-aged St. Louisians would follow suit (326).

Ultimately, however, the referendum does not pass. Despite all of Jammu's press and popularity, only $15 \%$ of the voting public turns out for the referendum and only $20 \%$ 
of that $15 \%$ actually votes for the merger. The narrator explains the defeat this way: "Threatened with the prospect of thinking and deciding, the body politic had surrendered" (503). In the end, it's too much to ask a Midwestern city to undo a century of self-segregation. The racist municipal logic remains: "No matter how a region was structured, well-to-do white people were never going to permit their children to attend school with dangerous black children" (503). As for youth culture's backing of Jammu, it turns out that the sons and daughters of "well-to-do white people" are simply too enlightened to participate in the democratic process. Indeed, America is "outgrowing the age of action," and its future (in this case young Midwesterners) has retreated from political engagement into the soft forms of Eastern disengagement:

Americans seeking purity wisely left the toxic wastes and consumer complaints and labor unrest and bankruptcies to other nations, or to the remnants of the original merchant caste. The path to enlightenment led through the perception that all communal difficulties are illusions born of caring and desire. It led through non-action, non-involvement, and individual retirement accounts. The new generation renounced the world in return for simplicity and self-sufficiency. Nirvana beckoned. (504)

In other words, the best way to overcome long divisions in America, according to contemporary Midwestern youth, is simply to ignore the division, to assert that it does not exist. This is the assertion that drove the production of white suburbs. Indeed, as Franzen represents them, the suburbs make possible an alternate world of political inaction and "non-involvement," an attitude of daily life that is rewarded with "individual retirement accounts," or the promise of twilight years wherein one can survive despite his own 
noninvolvement and the noninvolvement of his children's generation. It's a perfect noncommunist alternative to democracy, a system wherein mass division dissolves into a unification vis-à-vis innocuous self-expression. In short, this culture of inaction is Jammu's catch-22.

The irony is that Franzen does not exploit this argument into all-out critique of the suburbs. He does not tell his story from the point of cosmopolitan detachment that is required to mount large-scale critiques of the damning safety of suburban America. Instead, he seems almost to signal allegiance with the professional managerial generation that unwittingly gave birth to the enlightened slackers. He channels the xenophobia of this elderly generation into his very narrative voice. For instance, in describing Jammu's progress, the narrator observes: "square miles fenced and boarded, not one man visible, not one family left. The hand that has cleaned this place is no American hand. No American, no Idaho supremacist, no Greensborough Klansman, could have gotten away with this" (256). Such narrative echoes of xenophobia are oddly reassuring, not because they reflect the reader's xenophobia but because they make explicit what otherwise remains the implicit "global" plot and character decisions that Franzen founds his book on. Without overtly racist characters such as General Norris, one of the twelve whose old boy cronyism marks him as the real authorial choice for villain, Franzen's choice to populate his old hometown with sinister Indians would remain bemusing.

The General, a former army general and founder of General Synthetics, both functions as a scapegoat and evokes the Cold War paranoia around which the social conspiracy plot revolves. He reminds the other eleven heads of industry that India is "essentially a Soviet satellite" (37). He also begins his own semi-successful counter- 
surveillance of Jammu. The odd thing about the General's character is that he is a McCarthy-era fossil who actually guesses the plot correctly. He finds to be alarming and significant precisely what is alarming and significant about the plot. In effect, then, his character justifies the paranoid racism typical of the Midwestern business class. There really is an "Indian" conspiracy to subvert the municipal structure of St. Louis. ${ }^{247}$ Rather than follow suit, the other business leaders dismiss the General as an excitable military head case who wants to arrange coincidences into rationales for aggression. The business leaders have thus internalized the habitual political correctness that they had long ago learned to adopt in public matters, a superficial political correctness designed to mask what they really think about women and minorities. No one wants to be the rich white man who levels paranoid accusations at the strong ethnic woman. Even as others of the twelve, Probst in particular, begin to see signs of the conspiracy, they perceive their own recognition as an unsightly outgrowth of their WASP prejudices. They therefore ignore their recognition, stamping back the chauvinist id whispering into their ears that "South Asian lovelies were intent upon staging a real-estate panic in the ghetto" (126).

Probst, after repeatedly noticing evidence that there is a conspiracy, derides himself for noticing. According to the logic of his own paranoia about being racist, it is somehow his fault that "bugs were falling out of the walls, personalities collapsing in the space of weeks, and everywhere Indians - planting bombs, testing executives, dazzling the press and transferring stock and stopping traffic" (217). The fact that there is no escaping the signs of conspiracy means, to Probst, that "[n]othing was safe from his xenophobia now" (217). To call the observation of verifiable phenomena "xenophobia" is to be in full submission to the State. This disorder of perception is partially the result of 
Jammu exploiting the uniquely white male American fear of having his racial prejudices trip up his public progress. But the State is also a metaphysical crisis wherein one loses the ability to accurately acknowledge his own position in the world.

In short, the main difference between being in the State and not is the difference between forgetting and remembering one's local affiliations. In the metaphysical musings of the narrator, it is the difference between confronting a world that was a "spherical enclosing screen on which pictures were projected" and confronting "a collection of objects to which the given person dared to belong" (219). It's almost easier to be in the State, as it smoothes out the grainy incongruities of the realistic acknowledgement of local affiliations. When Jammu convinces her subject that he does not actually inhabit a material world, but rather a bubble of personal space that equalizes his affiliation to everything beyond it, she finds white men to be the easiest to keep within that state, as they have the most to gain from the denial of personal contact with the world they rule. In this sense, Franzen critiques the lamentable condition of municipal segregation in the Midwest, pioneering a theme recently picked up on by Terrell, whose first novel is symptomatic of the regional resurgence that Franzen's fiction works against. Terrell's second novel, The King of King's County (2005), is much more in line with Franzen's project, as the novel is about pre-interstate system land grabbing and boosterism in Kansas City. Terrell traces white flight in Kansas City back to a combination of buying up cheap farmland on the south side and offering cheap mortgages to the black workingclass, allowing them to spread east and, in the process, scares the white middle class into the new suburbs built up from the old farmland. This new historiographical mode of critiquing the Midwest is revolutionary, as it exposes the today's cultural divides without 
also simply fleeing the region. Franzen and Terrell thus symbolize a generation of village rebels who, rather than fleeing, sustain long-term relationships with the home region whose history so troubles them. In the following section, I will discuss how this new mode of village rebellion relates to the politics of parallel traditions of realism and Midwest fiction.

\section{II}

As I demonstrate above, Franzen avoids the banality, not to mention the polarizing politics, of cosmopolitan critiques of the Midwest. He does this without embracing the ethically ambiguous third-world conflations of Terrell and Collins. Instead, Franzen addresses directly the topography of socioeconomic division. This direct treatment, combined with the novel's counterintuitive conspiracy plot, has led critics to place The Twenty-Seventh City under some conflicting labels, perhaps the most inventive of which is Terrence Rafferty's tag "municipal science fiction." But Franzen is a selfdefined "social novelist," which is to say that he is a realist concerned with how social constructs intervene in individual life narratives. Though this concern comes to fruition with his most recent novel, The Corrections (2001), even Franzen's first novel is noticeably realist. Indeed, various new compounds of realism have been developed in recent years to help distance fiction from writers such as Franzen from the vortex tag of "postmodern" fiction. "Crackpot realism" and "hysterical realism" are chief among these new brands of realism.

According to Melvin Jules Bukiet, crackpot realism is recognizable on the level of plot. Plots such as The Twenty-Seventh City carry enough counterintuitive flights of fancy and postmodern irony to mislead readers into thinking that the writer is indifferent to the 
work of representing the real world. The "crackpot realists," who have Thomas Pynchon and Richard Powers as their founding members:

[s]oar[] past the social, the individual, and the imaginative concerns of earlier literary generations, the work of the crackpot realists takes us into an orbit where the imagination changes the political, the emotional, and occasionally, the physical ground rules of existence. ... Such a worldview separates the crackpot realists from their literary contemporaries: beyond the welter of random, inchoate experience, they find pattern and meaning. (Bukiet 14)

This interest in rearranging the "ground rules of existence" into a version of "pattern and meaning" in an otherwise meaningless web of signification is what makes the crackpot realist a "realist" and not a postmodernist. Such writers as Pynchon, Powers, and Franzen answer postmodern semantic play with an equally playful assertion of systematic integrity. They are the scientists of the literary world; they enjoy the technical challenges of intuiting and developing the minutiae of complicated fictional worlds such as a Midwest overrun by seemingly sinister Indian nationals.

They are to postmodern fiction what first-wave village rebels are to high modernism, fellow innovators whose innovations are aimed at reimagining the living grounds of local affiliations. Just as Lewis approaches his Midwestern boomtowns from "the perspective of an investigator who views his own culture not as an unquestionably natural given but as a set of social and economic conventions that the investigator must newly define and explain because the popular and accepted explanations of them are mere rationalizations" (Hilfer 160-161), Franzen approaches St. Louis as though it were a 
foreign country. His formal innovations signal a camaraderie with his contemporaries and his "imaginative concerns" signal a link to previous generations. Rather than enacting the outright abandonment of tradition called for by John Barth or (more recently) by Ben Marcus, the crackpot realists remain in "orbit" around the realist tradition, answering Barth's claim that "the novel, if not narrative literature generally ... has by this hour of the world just about shot its bolt" with an exacting account of the bolt's interstellar whereabouts (Barth 71). ${ }^{248}$

Of course, Franzen's first novel is grounded in history and geography of a specifically Midwestern place. Therefore, his fiction has more of a tangible relationship, less of a comparative literary-historical relationship, to the revolt from the village. Specifically, Franzen's deliberate meditation on the social structures of Midwesterners calls for a reassertion of the idea that Lewis set the stage for this type of large-scale critique of Midwestern social structures. In fact, one might argue that, in literaryhistorical terms, Franzen's St. Louis resembles Lewis's “Zenith,” but after its boosters were beaten out by the logic of safe economic prosperity. Like the Zeniths and Gopher Prairies of Lewis's fiction, Franzen's late-twentieth-century St. Louis exists under the same "philosophy of dull safety" that so offended Carol of Main Street (235). ${ }^{249}$ Furthermore, like Lewis's cities, Franzen's St. Louis is represented amid extensive historical and intellectual context. This context is designed to critique the American middle-class ideal as it is played out in the so-called "heartland." The difference between Lewis and Franzen, however, is that Lewis's fiction insists that Midwestern culture is a mode of "empire" and Franzen's presents it as a mode of self-segregated provincialism in need of a mode of empire. Lewis's narrator in Main Street predicts that Midwestern 
culture will not be "satisfied until the entire world also admits that the end and joyous purpose of living is to ride in Fords, to make advertising pictures of dollar watches, and in the twilight to sit talking not of love and courage but of the convenience of safety razors" (238). Indeed, this satirical representation of the perils of Midwestern-model standardization is echoed transnationally in the 1920s. Upon having had to engage so many Midwesterners in Paris coffee shops, Ford Madox Ford proclaims that "Middle Westishness" was "in fact a world movement, the symptom of an enormous disillusionment" (qtd. in Hoffman 369). Indeed, the scholarly concept of the "revolt from the village" has engrained this phenomenon in literary history, establishing the idea of the Midwest as a major exporter of cosmopolitan modernists.

Franzen redresses this conception somewhat when he asserts the need for an internationally engineered movement toward unification of the region. Rather than promoting abandonment, Franzen's model seems to invite national, even international, interests back into the onetime "Fourth City" of the nation. Like the Time magazine journalist who interviews Probst the night before the merger, Franzen is interested in stories that reveal a "new federalism" in America (411). The Time reporter assigned to Probst is not interested in asking questions about the polarization on the merger referendum because, in the reporter's words, "it's mainly news because it's divided the region, not because it's united it. And what we're interested in are forces of unity" (411). In an age of "up-and-coming cities" such as Knoxville, Salt Lake, Tampa, and WinstonSalem, Time finds newsworthy that which connotes a sense of national unity. By equating the success of something like the county/city merger with a spirit of "new federalism," Franzen reminds his reader of the potential larger national sway that comes from a 
unified regional authority. The fact that no one in the novel except a journalist for a soft news national magazine (and of course Jammu) notices the potential for the merger to have national ripples bespeaks an internalization of the idea, initiated by the revolt from the village, that what the Midwest has to offer, the rest of the nation must refuse.

Regardless of what threatens those who inhabit the Midwest, whether it is the dull safety epidemic or the soul deadening nature of comfort and convenience, the agenda of Midwest fiction since the heyday (i.e., since the "revolt from the village") has been to represent the Midwest as a silent, smiling threat. Franzen reinforces this notion only on an aesthetic level. He disagrees with the idea that Midwestern provincialism is the cause of so many ills in national culture. Plotting the invasion of the Midwest by sinister, international forces, Franzen invites interpretations wherein the Midwest is figured as a victim of conspiracy, rather than being itself one giant conspiracy. The international force, a group of Indian Marxists, invades St. Louis to reestablish the very logic of "empire" that Lewis once saw growing naturally by the acre in the vast Midwest. In contrast to this conception of the Midwest as a massive empire, Franzen represents St. Louis as a city composed of multiple divisions. A union of communities, the very union that Lewis deemed as an inevitable and frighteningly standardizing force in the American Midwest, is precisely what Franzen implies is the most just and least racist model of Midwestern community. The "threat" posed by the Indians is thus the possibility that the city's longtime municipal segregation might be replaced by the very standardized vast region that so devastated Lewis's wannabe-cosmopolitan protagonist, Carol Kennicott. In this sense, Franzen upends the agenda of the village revolt. He introduces the idea that, as a municipal principle, "dull safety" engenders division rather than, as Lewis 
feared, standardization. Franzen's villain-heroine, S. Jammu, injects a fair amount of standardization into the greater St. Louis area, actually succeeding to some degree at redistributing some of the wealth that had been horded in the county for a hundred years. In other words, Franzen reveals that it is easy to misconstrue Lewis's fear of Midwestern standardization as a fear of a diminishing gap of economic disparities in the Midwest. Indeed, as Tony Hilfer argues, Lewis's fiction eventually “retreated ... to a glorification of banality," wherein the larger questions of socioeconomic equality are skirted in favor of empty satire (221).

The Midwest has thus long since offered the unique opportunity to tackle both the urban theme of municipal management and the rural theme of small group dynamics. Franzen, a committed "social novelist," participates in this tradition of writing about the Midwest in an inherently depolarizing manner. The agendas of social novelists such as Franzen differ from those of regional novelists such as Terrell and Collins in that Franzen's authorial urge seems to be to explain the current states of affairs, not to explore the various ways that such states can be made to appear different, diverse, or, of late, "foreign."

Hence, when Franzen places foreign nationals at the center of his city's politics, he does so not to make the region appear foreign, but to induce the reader's need for an historical explanation of the city's municipal policies. Therefore, Franzen introduces his plot's peculiarity as a way of introducing long passages of historiography. These passages limn a phenomenon that is central to Lewis's founding vision of fiction about Midwestern provinciality: the rise and spread of Midwestern boomtowns. The second chapter of The Twenty-Seventh City recounts the past hundred years of the national 
reputation of St. Louis. In 1870, it was “America's Fourth City ... a booming rail city, the country’s leading inland port, a wholesaler for half a continent. Only New York, Philadelphia and Brooklyn had larger populations.” (24). In recounting these facts, Franzen alludes to the same fact-bending rationalizations of the boosters Lewis critiques in Babbitt (1922): ${ }^{250}$

Granted, there were newspapers in Chicago, a close Fifth, that claimed the 1870 census had counted as many as 90,000 nonexistent St. Louisans, and granted, they were right. But all cities are ideas, ultimately. They apprehend themselves, and the rest of the world apprehends them or ignores them as it chooses. (24)

But the problem with St. Louis's ascent, according to Franzen, is not the dishonesty of boosters. It is the artificial division between city and county, which the boosters tried to repair. In fact, boosters were positive forces in trying to reduce the sinister influence of the county over the city. They tried to bypass the county's "archaic administration" and court system, whose "“judges' were notoriously corrupt and insensitive to urban needs" (24). Franzen details a "secession scheme" in which the city offers to let the county buy its way out of thinking about "urban matters." The price: forty acres of farmland for "tomorrow's parks and industry" (25). The scheme passed and the County Court dissolved. Forty acres, however, proved to be nowhere near enough land and "[a]s early as 1900 the city was running out of space" (25). As a result, industrial interests fled and new industries settled in the county. In the 1930s, suburban white flight began as "poor black families arrived from the rural South, hastening the migration of whites to the suburbs" (25). In the 1940s, the city's tax base dwindled to next to nothing. The housing 
projects of the 1950s (most famously Pruit-Igoe) "failed spectacularly" and imploded in the 1960s (25). By the 1970s, St. Louis had entered its "Era of the Parking Lot" (25). By the early 1980s, the time of the novel, the city's population was half of what it had been in 1930. This recap of the city's post-Depression decline presents St. Louis as a good setting for a social novel concerned with the sources of socioeconomic and racial polarization in America.

Franzen claims allegiance to the realist tradition, but not because of any politicalscientific interest in social systems. Instead, in an interview just preceding what's come to be known as his "Oprah debacle," Franzen explains his anachronistic interest in the "social novel." ${ }^{251} \mathrm{He}$ concedes that Philip Roth was right to pronounce the "death of the social novel" in 1961. But Franzen points out that the validity of Roth's pronouncement comes from the fact that late 1950s novelists have staged "a voluntary withdrawal of interest ... from some of the grander social and political phenomena of our times" (Roth 180). Of course, Franzen agrees. Muckraking "exposé fiction" is certainly dead, partly because, in Franzen's words, “[o]ther media simply do social realism much better." It's no use waiting for another Dreiser or Norris in the technocratic twenty-first century. But the social novel does have a chance of survival, especially if that genre can be stretched to include such a novel as Catch-22, also published in 1961. This American classic is a social novel, if for no other reason, because, according to Franzen, it "cut deeply enough into the country's consciousness to create its own dictionary entry." According to Franzen's timeline, if Catch-22 is social realism, then Roth declares the genre dead in the very year that it escaped down a new, fertile tributary. Franzen wants to correct Roth's hasty generalization, and he does so by both writing the widely read literary novel, The 
Corrections (2001), and, unintentionally, having it thrust into public discourse as a novel whose very status as "literary" raises big questions about the role of self-consciously literary fiction in contemporary American social life. In the wake of shunning Oprah, the question has emerged as to whether Franzen wants to be an accessible novelist or a "status model" cosmopolitan writer whose literary difficulty must be endured. ${ }^{252}$

The fact that Oprah chose to intervene into the public life of the novel actually helps to frame the way we think about this question. It's almost as though, if Oprah picked it, it can't be one of those esoteric, William Gaddis inspired, "status model" novels. However, there's no denying that The Corrections is very different from the type of novel that her readers had come to expect from her Book Club. Combined with the fact that Franzen expressed enough reservations to earn himself a disinvitation, the exceptionalism of The Corrections adds up to the very kind of fracas worthy of a great social novel. ${ }^{253}$ In effect, the Oprah debacle reminds readers of all stripes that what Jerry Heron calls "human-scale literary activity" has actually spread through the American public, thanks in large part to Oprah's Book Club. Because of the Book Club, “[m]ore people are reading more books than at any time in American society, without any contact with the so-called authorities." ${ }^{, 54}$ In addition, the Franzen debacle was big news, reported everywhere from Yahoo News to The Chronicle of Higher Education, from The New York Times to Raritan. It garnered 999 (and counting) amazon.com reader reviews, far greater than the number of reviews normally accompanying a "literary fiction" title. Indeed, Oprah's choice seems to have enacted in the literary marketplace the very depolarization of the provincial/cosmopolitan divide that heretofore has been relegated to the pages of certain literary fiction. 
Before it included The Corrections, Oprah's book list was dominated by domestic fiction uncritically rooted in a specific local affiliation. ${ }^{255}$ Since its inception in the fall of 1996, the Book Club has frequently selected regional fiction by contemporary women authors. In a sense, the Book Club is the popular manifestation of the female-centered regional fiction championed in the scholarship of Judith Fetterley, Marjorie Pryse, and others. Oprah's Book Club does some of the same cultural work as this scholarly endeavor. As Foote argues, the "feminist retrievals" of the 1970s and 1980s construct an "alternative literary tradition" that values community over alienation, nature over urban zones, and the values of "cooperation, communication, and a tradition of feminine knowing" (Foote 2001, 33). Oprah's Book Club is a similar and more popularly effective engine of public opinion that values feminine community over masculine alienation. By elevating regional settings and identities as discrete from society at large, however, Oprah's Book Club also threatens to re-inscribe counterproductive cultural divisions. The promotional apparatus of the Book Club, namely the system of web pages devoted to descriptions of Oprah authors and works, deliberately highlights the local affiliations of pre-Franzen Oprah authors. For instance, the biographical information for Jane Hamilton, who has twice been chosen for the Book Club (for The Book of Ruth and A Map of the World), informs the reader that "Hamilton lives, works, and writes in an orchard farmhouse in Wisconsin." Titles and description highlights from the Book Club's first full year include: Marry McGarry Morris's novel, Songs in Ordinary Time (1995), which takes place during "the summer of 1960 in Atkinson, Vermont" and stars a "strong but vulnerable divorced woman"; Ernest J. Gaines’s A Lesson Before Dying (1993), “a wrenching story of death and identity in a small Cajun Louisiana community in the late 
1940s"; and Kaye Gibbons's A Virtuous Woman (1989), a “young North Carolina writer's" novel of "two richly cadenced Southern voices.",256

Oprah's obvious preference for novels that express strong local affiliations was complicated somewhat in the following year, 1998, when she chose Toni Morrison's brand new novel Paradise (1998), a violent, powerful mystery of racial discord. In the same year, Edwidge Danticat's Breath, Eyes, Memory (1994), a novel about the violence and injustices suffered by Haitian women, is chosen. The Book Club thus started to show preference for overtly globalized themes of female suffering and subsequent courage. In this year, Oprah's Book Club started to reflect the cosmopolitan reach of its corresponding talk show host. Rather than choosing books whose communal architectures are inherently self-contained and intimate, which is to say inherently bookclub-like, the Book Club list began to move away from the excessive localism of the its past year and a half. However, it was in this same year that Oprah announced two of the titles Franzen later called "schmaltz": Chris Bohjalian's Midwives (1997) and Billie Letts's Where the Heart Is (1995).

Based on his well-publicized comments, Franzen hesitates to embrace his inclusion on this list not necessarily because he is a snob, but because the list includes enough nostalgic regionalism to dampers his own novel's social realist ambitions. To accept his place alongside Bohjalian and Letts is to undercut his own advances in the realm of depolarization. ${ }^{257}$ It is to allow the earmarks of domestic fiction present in The Corrections - the empty nest plot, the sibling rivalry, the "I'll be home for Christmas" ending - to overcome the complexities of the novel's delocalized relations and its engagement with the digital divide of modern America. In order to enhance the reader's 
ability to connect to the hearthstone of Middle America carried by Enid, the Lambert family matriarch, the Book Club may have set aside the corresponding themes of market evolution and psychotropic drug revolutions. Considering Franzen's pitch line for The Corrections - "a family novel about three East Coast urban sophisticates who alternately long for and reject the heartland suburbs where their aged parents live"-it's easy to see why he would worry that his non-domestic themes might decrease in value ("Meet Me in St. Louis" 289). The irony is that, in order for The Corrections to be the perfect social novel, Franzen needed both to own the domestic pitch line and to resist the type of public life that the novel would have had had it hit the stands branded with a corporate logo. ${ }^{258}$ In the process of expressing ambivalence about the Oprah logo, Franzen alienated many potential readers. The world will never know what an Oprah discussion of The Corrections might have consisted of. According to Franzen, an Oprah Book Club producer once told him that The Corrections "is a difficult book for us ... I don't think we're going to know how to approach it until we start hearing from our readers" (289). In other words, the novel's meaning would have been decided initially by feedback from anonymous "readers." The novel's public life, then, would have been more a matter of populist consensus than the literary fiction apparatus normally allows its National Book Award candidates to become. Whether it is true or not, Franzen's fiction seems to have gained entry into a global network through having first denied the allegiance of the "general reader." As he demonstrates in his first novel, and again in his public commentary about The Corrections, his third novel, Franzen is able to trace, if not transcend, the crucial dividing lines in contemporary America. If nothing else, his persistent interest in Midwestern cultural shortcomings, even those that might or might 
not exist in a nationally syndicated club to which he was dared to belong, helps forecast the reconciliatory potential of social fiction in the twenty-first century. 


\section{Notes}

${ }^{1}$ This Dissertation is prepared according to the Modern Language Association style, as specified in the MLA Handbook for Writers of Research Papers, $6^{\text {th }}$ edition.

2 I use the term "nativism" instead of "patriotism," the term commonly supposed to be in opposition to cosmopolitanism, because nativism has more currency in discussion of American literary modernism, especially after Walter Benn Michaels’s Our America (1995). In Our America, Benn Michaels argues that nativism and modernism are twin "efforts to work out the meaning to the commitment to identity" (3). In other words, the question of what is American and what is un-American is common to both nativism, the “social movement," and modernism, the "aesthetic movement" (2).

${ }^{3}$ Chabot argues that both the aesthetics and actual publication outlets of U.S. modernism suffered as a resul of the First World War. The "cultural purpose" of modernism, as envisioned by the editors of The Seven Arts (James Oppenheim, Waldo Frank, and Van Wyck Brooks), which published the early works of such U.S. modernists as Sherwood Anderson, Amy Lowell, Robert Frost, and John Dos Passos), “did not survive World War I" (17). A “casualty of war," The Seven Arts never established itself as the engine of cultural unification that it had been envisioned as (30).

${ }^{4}$ According to Thomas Bender, "Young Intellectuals" was the name for early twentiethcentury New York intellectuals who, like Brooks, represented "the first generation to come of age within a bourgeois culture that had consolidated itself. . . they rejected both the personal values represented by the Victorian family and the public culture of their parents" (New York Intellect 229). 
${ }^{5}$ See T. J. Jackson Lears's No Place of Grace (1983), especially his discussion of Henry Adams as a representative "antimodern modernist," for a more fully developed discussion of the problems modernist intellectuals and artists had with the pitfalls and uneven development of industrial progress (286-298).

${ }^{6}$ Steinbeck describes migrants farmers in racial terms beginning in the first installment of his Harvest Gypsies article series, published in the San Francisco News (October 5-13, 1936). Steinbeck claims white migrants have "strong blood"; "[t]hey are descendents of men who crossed into the middle west, who won their lands by fighting ... [t]hey are gypsies by force of circumstances" (22). Multiple times Steinbeck refers to the migrant farmer as a "new race."

${ }^{7}$ For a full discussion of Michaels's intervention into the culture wars, see Bill Brown's “Identity Culture," in American Literary History 10.1 (1998): 164-184. For a full discussion of his intervention into modernist criticism, see the panel on "Our America and Nativist Modernism" in Modernism/Modernity 3.3 (1996) 97-126. Included are short essays by leading modernist critics such as Marjorie Perloff, "Modernism Without the Modernists: A Response to Walter Benn Michaels" and Charles Altieri, "Whose America is Our America: On Walter Benn Michaels's Characterizations of Modernity in America." To get a sense of the "post-identity politics" debate, see the "Post Identity Politics" special edition of New Literary History (31:4, Autumn 2000).

${ }^{8}$ Need footnote about Hegeman's criticism of Benn Michaels.

${ }^{9}$ Patricia E. Chu takes Hegeman and Benn Michaels, as well as Michael Szalay, to task for being too nationalistic. Chu argues that more "culturally and historically focused studies" such as Hegeman's and Benn Michaels's are symptomatic of both the de- 
emphasis on modernist formal innovation, brought about by "the feminist and cultural studies-led move," and an "increasing nationalization Anglo-American modernist studies" (164). Chu thus warns that it is easy to overlook the internationalism of modernism when viewing modernism through these critics' studies. This is an important warning, especially in that it reminds us that the localized thinking of modernists and modernist critics alike betrays a contradiction between place-based exceptionalism and cosmopolitan ambitions.

${ }^{10}$ Hegeman alludes to this debt when she explains that "the Midwest's literary sons were quick to understand the complexities of their, and their region's, provincialism ... writers like Theodore Dreiser, F. Scott Fitzgerald, Sinclair Lewis, and Sherwood Anderson, tended to emphasize the dynamics of modernization, placing the Midwest in a relational drama of rural and urban, East and Midwest" (135).

${ }^{11}$ This interest in mid-America became pervasive among New York intellectuals. Edmund Wilson indicates the centrality of the Menckenean taxonomy in his tongue-incheek endorsement: "Mencken's boob is as ideal a monster as Swift's Yahoo" (qtd. in Hilfer 130).

${ }^{12}$ See Mark McGurl's article “Understanding Iowa: Flannery O'Connor, B.A., M.F.A.,” for an extended discussion of O'Connor's prominence in current creative writing programs.

${ }^{13}$ In Reading for Realism, Nancy Glazener uncovers the conglomeration of magazines responsible for constructing and maintaining the dimensions of realism. The Atlantic group, as she calls it, "shared contributors ... endorsed each other's authority, and based that authority in similar understandings of class-inflected cultural trusteeship" (257). 
Glazener convincingly reads meta-editorial chatter among these magazines, bent on distinguishing Anglophone literature written in America as uniquely "American.” A byproduct of this nationalizing effort, argues Donna Campbell, is what the an 1897 editorial in the Atlantic Monthly terms the "Feminine Principle" and "Masculine Principle" in American fiction. This division, as Campbell argues, is similar to the traditional understanding of the split between local color and naturalist fiction (Campbell 1-13). See below for my discussion of how this slip in principle is played out in contemporary fiction.

${ }^{14}$ The arts division of the Works Progress Administration (WPA), known as Federal One, was the collective name for a group of five arts-based projects: Federal Writers' Project (FWP); Historical Records Survey (HRS); Federal Theatre Project (FTP); Federal Music Project (FMP); Federal Art Project (FAP); and the Federal Writers' Project (FWP).

${ }^{15}$ Many regionalist stories and novels are told from the first-person point of view of a cosmopolitan urban visitor whose perspective is far from stable and rarely reliable. Unlike the collective "we" of William Faulkner's famous third-person story "A Rose for Emily," the visitor/narrators of such texts as Sarah Orne Jewett's Country of the Pointed Firs (1891) and Edith Wharton's Ethan Frome (1911) do not determine how readers understand the culture represented. Instead, the narrator introduces a "cosmopolitan flavor" to the rural culture she encounters. This means that the narrator's process of blending into the culture becomes a process of balancing different perspectives on culture, thus a process of actually acting out on culture as a cosmopolitan rather than just looking or acting descriptively cosmopolitan. 
${ }^{16}$ See the first chapter of Christine Bold's book The WPA Guides: Mapping America (1999) for a full discussion of the aesthetics and "cultural work" of the WPA State Guides Series (3-18).

${ }^{17}$ Incidentally, his forthcoming novel, The Reserve (2008) is a "slightly obsessive, mad love story" set in the Adirondacks during the Great Depression.

${ }^{18}$ Chabot refers to the prominence since the 1970 s of fiction by minority writers, "the novels and stories published by Toni Morrison, Ishmael Reed and Alice Walker; by N. Scott Momaday, Louise Erdrich and Sherman Alexie; by Julia Alvarez, Sandra Cisneros and Junot Diaz; by Amy Tan, Gish Jen and Chang-Rae Lee,” arguing, alongside Jay Clayton, that "the range and vitality" of this fiction "is the single most important fact about contemporary American fiction" (10).

${ }^{19}$ I include the scare quotes around "spontaneous prose" both because it is a welldelineated category of writing pioneered by Jack Kerouac and because On the Road is generally not considered a work that features the form in its most fully-developed stage. Instead, the style of the novel is commonly thought of as precursor to "spontaneous prose," a prose style that looks like it is spontaneous but that isn't. Maybe "prespontaneous" is the right, although perhaps absurdly ironic, term.

${ }^{20}$ Such writing reached its pinnacle in the late nineteenth century, when American literary periodicals, such as The Atlantic Monthly (1857-present) and Harper's Monthly (1850-present), began to publish a steady stream of local color stories. The most popular setting for early dialect writing was the American South. Beginning with an exposé titled "The South As It Is," published in The Nation just months after the end of the Civil War, stories featuring Southern settings and dialects became a national phenomenon. 
${ }^{21}$ Likewise, certain racial and ethnic classes speak in thick dialect and thus seem ignorant and unassuming. For instance, Joel Chandler Harris's Uncle Remus, the title character/storyteller of Harris's many fictionalizations of African American fables, embodies the minstrel motif of the docile Negro. Walt Disney's adaptation of Remus, portrayed by James Baskett in Song of the South (1946), testifies to the endurance of this motif. Charles W. Chesnutt, a contemporary of Harris, uses dialect to subvert this same motif. Chesnutt's ex-slave character/storyteller is a "trickster"; he speaks in a remarkably dense dialect and has the familiar name "Uncle Julius," but he is smarter than he lets on. Through Julius, Chesnutt exposes the racist social hierarchy embedded in dialect speech, wherein dialect speakers appear less worldly, more inescapably bound to backwards folkways, than do non-dialect speakers.

${ }^{22}$ From Haraway’s essay “Situated Knowledges, (“Situated Knowledges: The Science Question in Feminism and the Privilege of Partial Perspective" Feminist Studies 14.3 (1988), 575-599)

${ }^{23}$ The current scholarly debate about cosmopolitanism is actually split into two semisuperable strains, one that has mainstream public appeal and one that appeals only to academics. The first strain, inaugurated by Martha Nussbaum's controversial essay "Patriotism and Cosmopolitanism" (1994), concerns the place of moral philosophy in the shift from national to global models of affiliation. The second strain regards the politics of cultural studies. The first strain examines the nature of human affiliation with land and with other human beings, periodically grazing naïve totalization with such phrases as "man has always" and anachronisms such as supposing that Diogenes the Cynic has anything to teach contemporary Americans. ${ }^{23}$ Nussbaum boldly renews the old Stoic 
economy of concentric circle affiliation. The second examines the ideological import of cultural studies. The fact that these two strains are not acquainted with one another is a helpful indication that the act of "thinking globally" occurs local to "the community of human argument" (Nussbaum 7). While certainly cosmopolitan in their departures from local concerns, discourses on the global reach of cosmopolitanism are ironically mired in particular, local conditions.

${ }^{24}$ The most famous response to this counterargument, so-called "compassionate conservatism," soon emerged, thanks to the work of Marvin Olasky, who invented the doctrine in his Renewing American Compassion (1996).

${ }^{25}$ I'm not overstating Nussbaum's totalizing rhetoric here. As a moral philosopher, Nussbaum fears not the royal "we" of transcendental humanity. She thus leaves herself open for any number of attacks on her "Sunday school" rhetoric (McConnell 84).

${ }^{26}$ Jackie Robinson signed in 1945. Roy Campanella signed in 1948.

${ }^{27}$ To begin his essay, Dirlik evokes Local Hero (1983), a humorous Scottish film about an American oil company looking to buy an all-too-eager-to-sell village on the Scottish coast. What saves the village is not the efforts of the villagers, but oil company's eccentric CEO's fascination with discovering and naming his own comet. The view of the night sky from the Scottish coast proves optimal, and therefore the village is "saved." Dirlik's anecdote illustrates the futility of local resistance, a phenomenon that nonetheless informs much of the left's coalitionist agenda is recent years.

${ }^{28}$ James Clifford claims that this kind of denial is a feature of contemporary ethnography, which overlooks the "transnational political, economic, and cultural forces that traverse and constitute local and regional worlds" $(1997,27)$. Clifford argues that the majority of 
the places in the world that we think of as the untouched "local" actually are "discrepant cosmopolitan" zones. Studying remote regions as such, anthropologists avoid the "excessive localism of particularist cultural relativism" as well as "overtly global visions of capitalist or technocratic monocultures" (36).

${ }^{29}$ In November 1998, the State Department issued a curious report, Outline of American Literature. The final section dealt with "The New Regionalism," claiming that regionalism is making "a triumphant return in American literature, enabling readers to get a sense of place as well as a sense of time and humanity" (Outline). On a more literary, but far from scholastic, front, Joyce Carol Oates has called for a conflation of the regional voice and the universal voice. Her sketch "My Faith as a Writer" (now an occasional piece printed on the covers of her current lecture tour pamphlets) elevates the universality of the "regional voice":

Through the local or regional, through our individual voices, we work to create art that will speak to others who know nothing of us. In our very obliqueness to one another, an unexpected intimacy is born. The individual voice is the communal voice.

The regional voice is the universal voice. (2)

${ }^{30}$ I owe these thoughts on Tan to Jeremy Reed. His paper, "Same Stories, New Places: The Joy Luck Club and American Individualism" (delivered at the 2007 International Conference on Narrative), shaped the way I think about local affiliations in The Joy Luck Club.

${ }^{31}$ As I explain in Chapter Three, "multicultural recanonization" comes from Yunte Huang's argument in Transpacific Displacement (141). 
${ }^{32}$ Leopards in the Temple is an emended version of Dickstein's Cambridge History of American Literature, Volume 7, 1940-1990.

${ }^{33}$ See Cox "Regionalism: A Diminished Thing," in the Columbia Literary History of the United States, edited by Emory Elliott. The Frost poem from which Cox gets is title is “The Oven Bird" (1920).

${ }^{34}$ In 1939 Hicks resigned from the party and in the 1950s he was a cooperative witness before the House Committee on Un-American Activities. In 1946 he publishes his classic defense of provincial life, Small Town. In 1970, he introduces the Wright Morris Reader. ${ }^{35}$ In 1976 the University of Nebraska-Lincoln established its Center for Great Plains Studies. This regional research center, the first in an American university, centers on the extensive Wright Morris archives. The 1999 NEH “Regional Humanities" initiative christened ten universities as flagship institutions for a revised taxonomy of American regions. For more information on the initiative, including a list of the winning universities and the new taxonomy of American regions, see $<$ http://www.neh.gov/news/archive/20000724.html $>$.

${ }^{36}$ Morris discusses Norman Rockwell as the mid-century artist to most successfully evade this reality. Rockwell's representations of innocent provinciality are figments of the artist's imagination, as such patterns of everyday life from the places Rockwell claims that they are. Rockwell is the artist who provides mid-century America with "the raw material that appeals to us ... the black-eyed tomboy, the hopeless, lovable pup, the freckled-faced young swain on his first date, the kid with white flannels at his first prom" (1958, 117-118). In short the raw materials of mid-century America are "seldom raw at all" but "cliché" (117). 
${ }^{37}$ Trachtenberg's illuminating essay "Home Place" discusses the different principles of combination in Morris's two 1940s "photo-texts," The Inhabitants and The Home Place. Trachtenberg has written two articles about Morris's photo-texts, one in 1996 and one in 2006. In the interim, with the exception of an anomalous article titled "Wright Morris and the Jews," there have been no scholarly articles on Morris that were not published in the Midwest Quarterly. The fact that Morris is discussed only by scholarly conversations self-identified as "regional" obscures his cosmopolitan techniques.

${ }^{38}$ Though Morris claims that "I am not a regional writer," he admits that "the characteristics of this region [the rural American community] have conditioned what I see, what I look for, and what I find in the world to write about" (qtd. in Hicks xii). Furthermore, his very prose style is shaped by his region. Morris thus thinks that the contentual grounds upon which he is categorized as a regionalist, the "plains" of his writing, are actually formal grounds. The Midwest provides a unique vernacular that Morris strives to formalize throughout his fiction.

${ }^{39}$ Of course, farm ownership is not a key characteristic of the New York intellectual. However, Mark Van Doren (arguably a founding New York intellectual) did have a farmstead in Cornwall, Connecticut.

${ }^{40} \mathrm{~A}$ lean-to is a structural extension of an original structure, such as a house. It's different from an "addition" in that doesn't share interior space.

${ }^{41}$ One of the prose passages in "Inhabitants," titled "Kirby Lee," voices the kind of illusive moment that is unavailable to either photographs or poetry. The voice (apparently that of "Kirby Lee") explains, via a colloquial wisdom that borders on incoherence, that "it ain't the thing, its what comes over it. Its like a no account scene just before somethin 
happens when you know somethin is bound to happen there" (151). The voices that are, for lack of a better preposition, "next" to the photographs are firmly in media res: boys in the midst of a complex masquerade game, conversations overheard, a note left for a son who may or may not return to a home from which the family has long since moved. This last scenario, the only one accompanied by a city-set photograph, is reminiscent of William Carlos Williams's “This is Just to Say."

${ }^{42}$ Laughlin was obviously overstating his claim to this emergent literary form. In fact, he might have been reacting to a market trend. As John Tagg explains in his excellent essay on the "Melancholy Realism" of post-New Deal photo-texts, Life magazine had already begun to incorporate WPA innovations in photography into its "pictorial journalism" aesthetic (Tagg 4-10). This private-sector interest in the photography produces what Tagg calls "new economy" of visual, social, and political meaning. Tagg explains that the "moment at which new technologies of photomechanical reproduction enabled a further quantum leap in the proliferation and social dispersion of photographic images, crossing a threshold" marked the emergence of this new economy (3).

${ }^{43}$ If anyone had single-handedly bridged New Deal photo-text and private photo-texts, it was MacLeish, whose documentary photo-book Land of the Free was published, with Roy Stryker's blessing, in 1938. As Tagg explains, MacLeish's goal in Land of the Free "was to find ways to shape public opinion through the direct and public use of poetry, hybridizing his writing with forms drawn from mass media" (31). MacLeish describes the accompanying poems in Land of the Free as a "choral voice," an overbearingly populist mix of what tag refers to as "Southern Agrarian themes of the betrayal of Eden with quasi-Marxist themes of capitalist exploitation in a way that seemed convincing at the 
time to so many east coast intellectuals" (31). According the Tagg, MacLeish's project was to establish a "metaphoric unity" among photographs for photographers who had no idea of the "metonymic realism of their archival project" (32).

${ }^{44}$ See Granville Hicks's Literary Horizons, specifically his introductory paragraph in his chapter on Morris, in which he explains Morris's insistence that Works of Love be included in its entirety in a Wright Morris Reader that Hicks was compiling. ${ }^{45}$ Lionel Trilling coined this phrase in the title of his first essay collection, The Liberal Imagination (1950), which established him as the next generation of New York literary critic similar to Edmund Wilson but markedly different in his focus on (usually Freudian) modes of introspection.

${ }^{46}$ Trilling represents this very convalescent self in his one novel, The Middle of the Journey (1947). The novel (often referred to as a "novel of ideas") features a troubled protagonist, John Laskell, who recovers from an awful illness caused in part by the death of his lover. From his convalescence in rural Connecticut, Laskell recognizes that the New York intelligentsia (many of whom are summering with Laskell) is hollow and replete with betrayal. In short, Laskell is on his own.

${ }^{47}$ Solomon draws from a number of critics to form this list, including Peter Cosgrove, Fredric Jameson, Miles Orvell, Paula Rabinowitz, and T. V. Reed. ${ }^{48}$ This is Dos Passos's conclusion/concession after meditating on the extreme national bifurcation over the issue of Sacco and Vanzetti's execution. In a recent editorial on the current political bifurcation of red-state/blue-state America, The Nation editor Katrina Vanden Heuvel reapplies this term of twenty-first-century America. 
${ }^{49}$ The language of newness is all over the article series later bound as The Harvest Gypsies. In its first installment, Steinbeck introduces the "new kind of migrant," proclaiming that "this new race is here to stay. Again, Steinbeck explains that "with this new race the old methods of repression ... are not going to work: these are American people" (993-994).

${ }^{50}$ The phrase "children of crisis" comes from Robert Coles's five-volume study of the same name (1967-1977). Volume two, which along with volume three won the Pulitzer Prize for general non-fiction in 1973, was titled Migrants, Sharecroppers, and Mountaineers (1971). The volume is a multi-generation study of east-coast migrant farmers, southern sharecroppers, Appalachian mountain dwellers, and the "rural mind" in general.

${ }^{51}$ See Coles's book Doing Documentary Work (1997), which is based on a series of lectures he gave at the New York Public Library, for an extended discussion of the pedagogical virtue of Praise.

${ }^{52}$ See WJT Mitchell for an extended discussion of Praise as a prototypical "photo-essay" that foregrounds "the dialectic of exchange and resistance between photography and language" $(289,290-300)$.

${ }^{53}$ As I mentioned in the introduction, MacLeish's goal in Land of the Free (1938) was to shape public opinion through combining poetry and mass media aesthetics of photography (Tagg 31). MacLeish describes the poems in his phototext as a "choral voice," an overbearingly populist mix of Agrarian and Marxist themes. According Tagg, MacLeish's project was to establish a "metaphoric unity" among photographs for photographers who had no idea of the "metonymic realism of their archival project" (32). 
${ }^{54} \mathrm{Du}$ Bois was fond of the mock dignity of the French word for sharecropper (Souls; 146, 156-158; The Negro; 132, 134). Du Bois uses the word to refer to black sharecroppers, tenants, and wage laborers. His preference for the French word is an interesting early use of juxtaposition of polarities. Also Du Bois's interracial definition of sharecroppers, or métayers, contrasts with Agee's subject, which is conspicuously white. The white washing is partly, Agee informs us, the result of editorial direction. As Agee repeatedly reminds his reader in the preface, the aim is for "white tenants." Agee repeats this condition when he describes the landlord's chauffeuring he and Evans around rural Alabama, who know none of their black tenants will cooperate with documentarians and are therefore dauntingly of "no use" to Agee.

${ }^{55}$ However, Agee often dispels myths about the sharecropper. He is uneasy with even the most innocent conflation of the terms "sharecropper" and "tenant." In his extensive "Notes and Appendices," Agee distinguishes sharecropper from tenant, explaining that "One name for the other chief sort of tenant, the man who, owning neither mule nor implements, must be furnished these as well as land and shelter, and must pay the owner half his cotton and a third to half of his corn, is sharecropper" (402). The word tenant, therefore, is "inaccurately used save where it is indigenous." (403). Both are "dialect word[s], to which a conscientious 'educated' person knows he has fortified the right" (403). Agee undermines his purist posturing, however, offering a dadaist list of a few hundred "anglosaxon monosyllables" that disarm his otherwise strict preoccupation with semantic meaning (403-405).

${ }^{56}$ But Agee's dismissal of vernacular transliteration also marks a shift not only in documentary art, but in other literary modes of regional representation. In the wake of 
John Dos Passos's newsreel verisimilitude, efforts toward the vernacular realism that dominated nineteenth-century regional writing had simply been replaced by a less ventriloquial technique of reportage, of, in Alfred Kazin's words, "getting down the facts of human existence in the twentieth century" (267).

${ }^{57}$ See Nichols's "Documentary Film and the Modernist Avant-Garde" for his argument about that documentary techniques and modernist techniques are the same. The original version of Nichols's argument appears in Kees Bakker's collection, Joris Ivens and the Documentary Context (1999). This collection of essays examines the "crossover" career of Ivens, a Dutch avant-garde filmmaker who directed many 1930s documentary films, including The Spanish Earth (1937), which was narrated by Ernest Hemmingway, and the New Deal documentary promotion of rural electrification, Power and the Land (1940). See Doss's Benton, Pollock, and the Politics of Modernism: From Regionalism to Abstract Expressionism (1991) for a compelling argument about the continuities between Thomas Hart Benton's politics and aesthetics and those of his protégé, Jackson Pollock. ${ }^{58}$ A one-time Stalinist, Macdonald became a Trotskite following the 1939 Hitler-Stalin Pact. A dedicated contrarian, Macdonald declared himself a pacifist after the onset of WWII, and an anarchist in the 1960s.

${ }^{59}$ In the early 1950s, Agee wrote the screenplays for African Queen (1951) and Night of the Hunter (1955). In 1937, Agee published a stylized screenplay, "Notes for a Motion Picture: The House." ${ }^{60}$ This haunting rhetorical question, "How was it we were caught?," begins in the mouths of sharecroppers, drawling out of an inconsequential conversation, but evolves into the arresting words of the Agee himself. The question means a number of things, but most 
immediately it is an inquiry into how his sharecropper gained some depth of understanding about the ethics of documentary work and about their position as amusement. They have discovered that they are cast in a voyeur's wet dream and, Agee fears, they will soon desert him to sober isolation.

${ }^{61}$ The Vital Center is also, according to Courdileone, "one of the most oft-cited and rarely scrutinized books in American historiography ... [it] tends to be discussed in passing, particularly by intellectual historians on their way to the more ideologically provocative left-to-right odysseys of the New York intellectuals" (4).

${ }^{62}$ Michael Denning's great study of the "Popular Front" 1930s, Cultural Front, is largely to blame for this neglect of interest in literary innovations. However, Michael Szalay's New Deal Modernism (2000) has inaugurated a renewed interest in the formal politics of the literature of social welfare. Among the offshoots of the Szalay strand of the debate are Christine Bold, whose book WPA Guides (1999) is a good study of the aesthetics of a WPA guidebooks, a study that hasn't been attempted since William Stott's mid 1970s ambitious study of Depression-era documentary work at large.

${ }^{63}$ Similarly, Coates and Farooq explain that New Deal products such as the WPA state guides promoted "regional self-awareness and introspection" (83).

${ }^{64}$ Incidentally, Fortune is the second longest running business magazine in the U.S. it was founded by Henry Luce shortly after the stock market crash in 1929.

${ }^{65}$ Agee was slow to get started with the manuscript for Praise. He writes to Evans, more than two years after the sharecropper assignment, that he is "trying to start a book on the Alabama trip, having a bad time of it” (1938). 
${ }^{66}$ As Coats and Farooq explain, the TVA was lauded by "many regionalist contemporaries [as] the greatest regionalist experiment" of the New Deal (81).

${ }^{67}$ Cordell Hull was Roosevelt's Secretary of State, and a Tennessee native.

${ }^{68}$ The first quote, from Agee, is a self-description intended to differentiate himself from “conservative Southerner" Donald Davidson (1945). The second quote similarly is a way of differentiating himself from self-identified communists whose commitment is less a deliberate and vocational matter than it is a condition of socialization in intellectual and artistic circles in the 1930s (Praise 220).

${ }^{69}$ The more accurate translation is: "The proletarians have nothing to lose but their chains. They have a world to win. Working men of all countries, unite!"

${ }^{70}$ In another passage, Agee directs the reader to put an ear next to a phonograph blasting at full volume either Beethoven's Seventh or Schubert's C-Major Symphony.

${ }^{71}$ I use "disparagement" here and below to mean the not-necessarily malicious act of belittling a person or entire cultural group with the purpose of seeming superior. But the old English legal term of the same name might also apply. Essentially a law against marrying down, "Disparagement" used to signify the injury sustained by comparing two things of disparate value.

${ }^{72}$ Aside from Amity Shlaes's reactionary The Forgotten Man: A New History of the Great Depression (2007), which actually defends the laissez-faire government that allowed the easy-money policies, credit expansion, and installment buying that lead to the 1929 Stock Market Crash, most economists and historians agree that commercial and consumer debt, specifically the corporate trend of purchasing businesses and factories on 
credit and the consumer trend of buying cars with home mortgages, is the Depression's primary causal factor.

${ }^{73}$ According to Jonathan Harris, Federal Project One was "the collective name for the visual art, music, theater and writing projects created by the Works Progress Administration. The Federal Art, Music and Writers' Projects became part of the Works Projects Administration" (130-131).

${ }^{74}$ For instance:

The major lines of the structure, each horizontal of each board, and edge of shingle, the strictness yet subtle dishevelment of the shingles, the nailheads, which are driven according to geometric need, yet are not in perfect order, the grain, differing in each foot of each board and in each board from any other, the many knots in this cheap lumber: all these fluencies and irregularities, all these shadows of pattern upon each piece of wood, all these in rectilinear ribbons caught into one squared, angled, and curled music, compounding a chord of four chambers upon a soul and center of clean air: and upon all these masses and edges and chances and flowerings of grain, the changes of colorings of all weathers, and the slow complexions and marchings of pure light. (126)

Of this 132-word sentence, there are five are verbs, two of which are linking, two present participles, and one past tense.

${ }^{75}$ See Paul Foreman's "Sharecropper Novels" for a complete discussion of the sharecropper novels from the 1930s and other periods. One 1930s author that Foreman 
does not mention, however, is Charlie May Simon, a popular children's author published a popular piece of adolescent fiction titled The Share-Cropper (1937).

${ }^{76}$ The New Deal never directly helped sharecroppers. It employed huge numbers of jobless industrial laborers (who produced 650,000 miles of new road, 125,000 public buildings that employed 8,500,000 people, numerous airports, small dams, hospitals, libraries, parks, power flumes, sewers, schools, and cement and steel playgrounds). But with this unprecedented growth in national infrastructure came stiff farming regulations. The Agricultural Adjustment Administration (AAA) initiated sweeping production controls. A provision for crop reductions known as "domestic allotment" allowed "producers" (i.e., sharecropper landlords) to decide on production limits for their crops. The AAA then paid landowners subsidies for the land left idle. However, since they owned no land, sharecroppers had no say in what land or crop was cultivated and what remained barren. Since these decisions were left up to absentee landlords, they were often the wrong decisions. The most woeful byproduct of these long distance anti-deflationary crop reductions was the large-scale destruction of crops and livestock at a time when many sharecropper families were starving.

${ }^{77}$ As Rothstein's later explained, "I found a sun-bleached skull and photographed it against the cracked earth... I took many pictures and then moved the skull about 10 feet to a grassy spot near some cactus where I could get another effect" (43).

${ }^{78}$ James Curtis argues that for certain photos in Praise Evans rearranged the domestic interiors in order to construct formally harmonious scenes. For instance, he pushed a bed out from the wall to create a diagonal form and he removed a dirty white suit from a wall hook. For another photograph Evans apparently cleaned the kitchen table of all but a 
lamp and propped up a butter churn in the background. See the second chapter of James Curtis's study of FSA photography.

${ }^{79}$ Evans's most famous sequence is "New York City Block." Compared to standard FSA sequences like Lange's "Migrant Workers," Rothstein's “Tenant Farmers" and "FSA Migratory Labor Camp," Evans's photography seems entirely unrelated FSA standards. ${ }^{80}$ The encountering self is to be distinguished from the simple first person narration. For one, Agee is not writing fiction, but documentary prose, so his persona is always some version of his actual person. The "encountering self" is actually involved in events and observations as they occur, rather than reflecting and retelling of events and observations that have all already occurred.

${ }^{81}$ As Richard Brodhead, Stephanie Foote, Nancy Glazener and others have argued, late nineteenth-century regionalism actually erases the vitality of the cultures it represents. What Brodhead calls the "cultural elegy" function of regionalism actually helped to "memorializ[e] a cultural order at the moment passing from life and [to] fabricat[e] ... a mentally possessible version of a loved thing lost in reality" (1994, 154-155). Foote concurs, claiming the regionalism "represented various sections of the consolidating nation to an audience that was conscious of itself as a national elite" (4).

${ }^{82}$ Mary Louise Pratt coined this term in her 1994 lecture "The Arts of the Contact Zone." Pratt defines the term as "social spaces where cultures meet, clash, and grapple with each other, often in contexts of highly asymmetrical relations of power, such as colonialism, slavery, or their aftermaths as they are lived out in many parts of the world today" (607). ${ }^{83}$ The phrase comes from the title of David Farber's history of America in the 1960s. 
${ }^{84}$ As Susan Hegeman notes, Praise became "legendary" in the 60s, "a book that young college students took south with them during the Freedom Summer of 1961" (178).

${ }^{85}$ See T. C. Boyle's The Tortilla Curtain (1995) as a direct descendant of Grapes. The novel's subject, illegal immigration in Southern California, bears strong relation to Steinbeck's, especially considering Steinbeck's own conception of the transhistorical lineage of immigrant laborers in the California farm fields. The novel also evokes Grapes in its epilogue: “They ain’t human. A human being wouldn't live like they do. A human being couldn't stand to be so dirty and miserable."

${ }^{86}$ According to Charles Wollenberg's introduction to Harvest Gypsies, as Steinbeck's article series came to be called, Steinbeck "mined" [Collins's] reports for material for The Grapes of Wrath" (ix). These reports, portions of which had already been published in the San Francisco News, "included social and cultural observations on migrant life and individual anecdotes sometimes told in "Okie" dialect" (ix).

${ }^{87}$ According to Wollenberg, long before the 1930s, big agribusiness was "an already established fact of life in California" (x).

${ }^{88}$ In Denning's words: "the best known Popular Front genre is probably the 'grapes of wrath,' the narrative of the migrant agricultural workers in California ... [it] remains one of the most striking examples of a Popular Front narrative becoming a part of American mass culture" (259).

${ }^{89}$ Sean McCann's Gumshoe America explores in detail the way New Deal patterns of liberalism play out in such popular literary genres as hardboiled crime novels. 
${ }^{90}$ Agee takes specific aim at Edwin Locke, a writer and amateur photographer who began his career as Roy Stryker's assistant at FSA (1935-1937). Agee references almost exclusively Locke's laudatory review, "Adaptation of Reality in The Grapes of Wrath." ${ }^{91}$ Agee kept at least seven journals of notes on Praise. The journal I refer to above is the sixth, which he began after Harper and Brothers rejects "Cotton Tenants: Three Families," Agee's revision and expansion of the original sharecropper article, commissioned and later refused publication by Fortune. Agee was reviewing books for Time when began the journal cited above.

${ }^{92}$ In his unpublished review, Agee derides Edwin Locke's review, “Adaptation of Reality in The Grapes of Wrath."

${ }^{93}$ For instance, the film completely erases the lascivious young Al Joad, Casey's seedier motives for leaving the pulpit, not to mention the sexist vulgarities spoken by Tom Joad himself. This sexist ethos is a feature, Steinbeck argues, of impoverished migrant masculinity, a feature that is in conflict with the more Ma's aggressive domesticity and Rose of Sharon's submission to a maternal form of public aid.

${ }^{94}$ Walter Benn Michaels's new book, The Trouble with Diversity: How We Learned to Love Identity and Ignore Inequality (2007) argues that Americans value of diversity at the expense of acknowledging the fixability of poverty. Michaels argues that the celebration of "difference" masks a national neglect of a vast and growing economic divide. Because diversity offers a stable vision of social justice, it has a "sacred cow" in contemporary America, one that costs middle-class Americans nothing.

${ }^{95}$ Agee begins reviewing films for Time and The Nation fulltime in 1941. 
${ }^{96}$ Szalay claims that the nursing scene at the end of Steinbeck's novel signifies that "the once virtuous and compassionate heroine of the nineteenth-century sentimental novel emerges in Steinbeck as a symbol of contested intersection between private interest and public aid, a pedagogical subject in need of moral reeducation" (171). Szalay thinks that Steinbeck punishes Rose (with a miscarriage and a dirty old man) for being too interested in her baby.

${ }^{97}$ Critics have often (and in my estimation) wrongly assumed this companion to be Walker Evans. Not only is there a poverty of evidence that Agee's companion here is in fact Evans, critics' assumptions confirm Agee's own woeful suspicion that the men and women he tries so diligently to "praise" will, despite his efforts, remain churls with next to no intellectual capacity. However, in these critics' defense, Agee makes no effort to identify the rest of the group constituting the "we" of "On the Porch 3." The only other prevalent instance of Agee using the pronoun "we" occurs in the third section of "A Country Letter," when Agee repeats the ominous rhetorical question "How was it we were caught?" (72 and 81). This "we" is likely Evans, if not the equally snoopy reader. The only indication that the other half of "we" in "On the Porch 3" is in fact Evans comes when Agee notes that the animal making the mysterious sound has "become a searcher with whom we had identifies ourselves" (411). But assuming the companion is Evans based on this evidence assumes that "searchers" are by default documentary intruders, thus stripping the Gudgers of the very acquisitive capacity that Agee tries to keep alive in their represented selves. 
${ }^{98}$ Spiegel's study of Agee, James Agee and the Legend of Himself (1998), presents a convincing portrait of a writer who situated himself within an "emotional geography" rather than an actual local dynamic.

${ }^{99}$ Henry Wallace coined this phrase in a famous speech on agrarian economy first given in May of 1942.

${ }^{100}$ See the Library of America edition of Agee's Film Writing and Selected Journalism (2005), which begins with W. H. Auden's letter to the editors of The Nation, praising Agee's movie column as "the most remarkable regular event in American journalism today."

${ }^{101}$ Lhamon describes the characteristic offering of a deliberate speeder as a text that thus flows like rapids, with eddies that turn back against its current and whorls within larger whorls that gesture like earlier sequences and will be echoed later. Its achievement is to be as turbulent as the real world with as much order cohabitating with its disorder. (128)

Lhamon applies this comment to the sequencing logic in Robert Frank's photography book Americans (1959). However, it is applicable to Kerouac's aesthetic as well.

${ }^{102}$ In order to mount this critique, however, critics have to overlook the fact that Kerouac is a working-class immigrant from French Canada.

${ }^{103}$ As Ginsberg recalls this as Kerouac's career-long mantra, and perhaps the mantra of the Beat generation at large. The quote originally appears in Kerouac's novel Visions of Cody (1959). Ginsberg's reminiscence appears in the documentary What Happened to Jack Kerouac?. 
${ }^{104}$ One can see Agee's self-reflexive structural inertia in such loose, baggy monsters as David Foster Wallace's Infinite Jest (1996) and David Eggers's A Heartbreaking Work of Staggering Genius (2000).

${ }^{105}$ I use the language of topography here to underscore the fact that, in Kerouac and Agee both, the act of inscribing the specificity of place is similar to inscribing the specificity of an identity type. See chapter three for one contemporary writer's critique of this conflation.

${ }^{106}$ Kerouac mimics this song’s refrain, "mañana, mañana, mañana is soon enough for me," in his description of the Mexican workers Sal lives with for a time. Knowing no Spanish, Sal decides that "mañana" must be Spanish for paradise: "It was always mañana. For the next week that was all I heard-mañana, a lovely word and one that probably means heaven" (79). For more discussion of Kerouac's appropriation of popular stereotypes of Mexican peasantry, see Mark Richardson's “Peasant Dreams: Reading On the Road."

${ }^{107}$ Incidentally, Agee's one successful novel, A Death in the Family (1957), was published posthumously the same year that On the Road was published. It is similarly autobiographical and set in the writer's hometown; it won the Pulitzer Prize. ${ }^{108}$ See Morris Dickstein's chapter "On the Off the Road," in Leopards in the Temple for an exhaustive discussion of the road motif in mid-century fiction.

${ }^{109}$ This passage reminds me of one from Sherwood Anderson's great work of village rebellion, Winesburg, Ohio (1919). In the story/chapter titled "Sophistication," George Willard (the village rebel and hero of Winesburg) first engages in introspection, what Anderson divisively terms the "backwards view of life" (145). George's pensively 
reflects on "the countless figures of men who before his time have come out of nothingness into the world, lived their lives and again disappeared into nothingness," as the "sadness of sophistication" seizes him (145). The important difference between George's and Sal's experiences is that the former is prompted by introspection and reflection on the past, something Sal is never willing to do (Notice that the opening line of On the Road refers to an ex-wife who is never again evoked, 3). Sal's panic is a surprise, almost literally waking him up. What separates Sal from George, and by extension what separates Kerouac from Anderson, is that George is still meditating on departure from provincial restraints, whereas Sal has completed his separation from it. ${ }^{110}$ Although Sartre's novel was published in 1938, Nausea was not translated until 1949. See George Cotkin's Existential America (2003) for further discussion of the impact of Sartre and other French existentialist on mid-century American fiction. Cotkin describes the ways existential texts and cultural interactions between French intellectuals and American popular culture played out in the late 1940s and early 1950s (91-133). See Bill Brown's brief discussion of the Nausea as the most famous modernist instance of literature that animates the physical environment to emphasize the radical otherness of physicality (8).

${ }^{111}$ Ultimately, though, Dean relies on empty platitudes of hip-ness like "We only live once" and "Yes, yes" (125).

${ }^{112}$ See Making It (1967) for evidence of Podhoretz's conspicuous interest in rising to power among New York intellectuals.

${ }^{113}$ Blue Highways opens with this explanation: "On the old highway maps of America, the main routes were red and the back roads blue" (1). 
${ }^{114}$ I am thinking specifically of the branch of local color made popular by Bret Harte's popular Overland Monthly stories of poems, published from 1869-1870), all featuring sentimental depictions of gangs of noble gambler and prostitutes. As Elizabeth Ammons notes in her introduction to the Penguin anthology of American Local Color Writing, local color in this vein, though "preventionist, reactionary ... [and] touristic," "has the ability to challenge and deconstruct monolithic national, imperial, and racial agendas" (xvii). Kerouac, or at least Sal, had similar ambitions in his narrative of the West. See my next chapter for a discussion of Bret Harte's racism, especially in terms of his Chinese characters.

${ }^{115}$ Morris Dickstein refers to Adventures of Huckleberry Finn as the "ur-text of the postwar fiction" (90).

${ }^{116}$ The river becomes an exceptional locale where an unlikely community (Huck and Jim) can critique the society that will not endorse their friendship.

${ }^{117}$ In the sentence just before the one about the Mississippi, Sal admits that "I'm not much of a driver" (15).

${ }^{118}$ See David M. Wrobel's The End of American Exceptionalism: Frontier Anxiety from the Old West to the New Deal (1993). Wrobel argues that, when New Dealers imposed comprehensive government regulation on the "frontier economy," the goal was to create the "moral equivalent" to the standard view of the frontier as an "equalizer" of economic class.

${ }^{119}$ See Robert Holton for a discussion of this and other scenes in On the Road as representations of a burgeoning postmodernist landscape. Robert Holton characterizes the 
Wild West Week episode as a "manifestation of postmodern history ... a parody of the past, a consumer spectacle without depth" (272).

${ }^{120}$ See Jonathan Harris for more discussion of the New Deal "citizen-artist," specifically the way in which "the [Federal Art] Project employed artists as wage laborers, in the same way that other agencies employed plumbers, engineers or lumberjacks" (9).

${ }^{121}$ It's noteworthy that Sal repeatedly sees "Indians," especially in Cheyenne, who "watched everything with their stony eyes" (35). Holton notes that this "[o]ne curious and repeated detail" suggests an "impenetrable depth wholly absent" from Cheyenne as well as from most of Sal's cohort (272). Holton thinks of these Native Americans as one of Kerouac's "fellahin." See below for a discussion of this category of socially disparaged figure, which Kerouac means to represent a more authentic subjectivity, but which he always essentializes.

${ }^{122}$ As Ann Douglas explains of Kerouac, he always "meant his work to be in some sense verifiable" $(2000,12)$.

${ }^{123}$ Back in Harlem, Carlo rededicates himself to place-based melancholy, writing "Harlem Doldrums" in the place of the "Denver Doldrums" he wrote in Denver (47). ${ }^{124}$ See Jo Freeman (aka Joreen) “The Tyranny of Structurelessness," for a fuller discussion of the pros and cons of CR, in Quiet Rumours: An Anarcha-Feminist Reader San Francisco: Dark Star, 2002.

${ }^{125}$ The name of the suburb is obviously important here, as Arcadia was the bucolic Grecian landscape that inspired pastoral poetry, whose celebrations of virtues of rural life previews the agenda of much American regional fiction. 
${ }^{126}$ In addition to the Beat Superman, Sal while in Central city imagines moving "over the Plains ... an old man with white hair ... walking toward us with the Word" (55).

${ }^{127}$ The irony is that Kerouac, in biographer Ann Charters's estimation, is an "ethnic writer" reared in French Canada, for whom English is a second language.

${ }^{128}$ In "The Know-Nothing Bohemians," Podhoretz argues that "spontaneity is a quality of feeling, not of writing: when we call a piece of writing spontaneous, we are registering our impression that the author hit upon the right words without sweating, that no 'art' and no calculation entered into the picture" (314). As for Capote, he famously said that Kerouac was not a writer but a typer.

${ }^{129}$ In Reading for Realism, Nancy Glazener implies that a false polarity in American letters began in the late nineteenth century, from the efforts of a conglomeration of literary institutions. The "Atlantic group," as Glazener calls it, "shared contributors ... endorsed each other's authority, and based that authority in similar understandings of class-inflected cultural trusteeship" (257).

${ }^{130}$ See K. A. Cuordileone's chapter on "Postwar Liberalism and the Crisis of Liberal Masculinity" (1-36) for more discussion of the fear surrounding this supposed "doctrine." ${ }^{131}$ Also noteworthy here is the recent reemergence of the Buckley interview. It is featured in multiple documentary films, including What Happened to Kerouac? (1986, redistributed 1998). Most interestingly, however, the avant-garde theater group, Elevator Repair Service, has recently produced (to rave reviews) a performance titled "No Great Society" that reenacts verbatim the interview transcript. (See Jason Zinoman's review for The New York Times.) 
${ }^{132}$ As Harry Frankfurt explains in his treatise On Bullshit, a bullshitter is he whose claim to be "sincere" is based on that fact that he is "[c]onvinced that reality has no inherent nature" (65).The sincere appreciator of the Beats, indeed the one who has misunderstood delocalization as erasure of reality, retreats from the business of trying to "arrive at accurate representations of a common world, [and] turns toward trying to provide accurate representations of himself" (65).

${ }^{133}$ I use the word "territory" here the way Yoon Sun Lee uses it, to refer to "a trope for a fixed system of signification ... a realm within the customary forms ... organized into knowledge and elicit standard affective responses" (473). In fiction, territory functions as a spatial signifier wherein "norms" are reified and organized. "Deterritorialization," as Deleuze and Guattarri have articulated, is the disorganization and destandardization of spatial order. "Delocalization," by comparison, is similar in its seductive stirring of distinctions, but it is not the same thing as deterritorialization in that it refers specifically to narrative positionality.

${ }^{134}$ Kingston's two well-known works to precede Tripmaster, Woman Warrior (1976) and China Men (1980) are classified as memoirs. They both won major prizes in nonfiction categories.

${ }^{135}$ The above quotation comes from Michael Davidson's Ghostlier Demarcations (1997) (xii). See Davidson's San Francisco Renaissance (1989) for a detailed discussion of the sociocultural milieu of San Francisco from the mid-1950s to the mid-1960s.

${ }^{136}$ Regardless of how we define the category, when we talk about multicultural fiction we talk about fiction that uses individual character identity to negotiate the tensions among variously situated group identities. 
${ }^{137}$ Viet Thanh Nguyen recognizes a racialized artistic sensibility similar to that of the Black Arts Movement, especially in its use of theater groups as means of expressing racial identity, emerge in the West Coast in the late 1960s. Nguyen argues that, having witnessed the many militant violations and versions of human rights and social justice, these Chinese American writers appropriated the rhetoric of counterculture into what some critics think of as counter-hegemonic literary narratives. As Nguyen explains, "1968 signaled a change in consciousness for Chinese Americans, as many of the younger generation in college became radicalized around the antiwar and antiimperialism movements, and began to connect those issues with the cause of domestic racial empowerment" (130). The culture wars were only beginning in 1968, as indicated in the famous conclusion from the Kerner Report on the race riots of the previous year: "Our nation is moving toward two societies, one black, one white, separate and unequal." The Kerner Report was a response to the race riots of 1967. Race riots continue to erupt in many U.S. cities (including Baltimore, Boston, Chicago, Detroit, Kansas City, Newark, and Washington, D.C.) in the wake of Martin Luther King, Jr.'s 1968 assassination. Chicago police enforce "shoot to kill" orders for putting down its riots. The FBI issues a "Counter-Intelligence Program" against Black Nationalist "hate-groups." Meanwhile, the Civil Rights bill is signed into law. Incorporating the embers of riotous anti-segregation into their agendas and writing styles, writers such as Frank Chin, Gus Lee, Jeffery Paul Chan, and Lawson Fusao Inada, replaced the disparately related midcentury Asian-American writers, such as John Okada and Toshio Mori, as a generation unique in their collective literary militancy. According to Jonna Mackin the premises of this group of, mostly male and mostly Chinese American, writers include: "(1) promoting 
Chinese American cultural hegemony; (2) engaging in an aggressive war of position with another Chinese American author; and (3) asserting gender dominance" (514). Nguyen isn't alone when he claims that 1968 as an inaugural year of a "generation" of militant Asian American writers. In "The Fate of '68," Eric Lott reminds us that "[Paul] Berman and [Todd] Gitlin turn '1968' into a trope for What Went Wrong-in Berman's work [A Tale of Two Utopias: The Political Journey of the Generation of 1968 (1996)], political authoritarianism and black criminal-leftism; in Gitlin's [The Twilight of Common Dreams: Why American is Wracked by Culture Wars (1995)], a fracturing of the left into newer social movements - a.k.a. identity politics — that are no longer enraptured in the early- and mid-'60s idea of the New Left"' (26).

${ }^{138}$ To date Charters is the one Beat critic to translate Poteet into English. Her repeated attempts to popularize his argument have been all but ignored.

${ }^{139}$ The name likewise evokes the local color tradition in the West, which to some degree typecasts Chinese American figures. The reference to Whitman is clear enough, not only in the protagonist's homophonic name but also in the novel's chapter titles, three of which are phrases from "Song of Myself." The first two chapters are titled "Trippers and Askers" and "Linguists and Contenders." A later chapter is titled after another Whitman poem "A Song For Occupations."

${ }^{140}$ When originally published in the Overland Monthly, the poem was titled "Plain Language from Truthful James" (1869). It was pirated under the title "The Heathen Chinee." It tells of a gambler who attempts to cheat at cards against the Chinese character Ah Sin. The poem defends the Chinese minority in California, but is often read as a polemic against Chinese presence there. 
${ }^{141}$ See A. Noelle Williams's article on "Parody" for a detailed discussion of Kingston's referentiality as particularly "modernist."

${ }^{142}$ Nussbaum uses this language in her essay "Patriotism and Cosmopolitanism" (1994). According to Nussbaum, what makes cosmopolitanism both appealing and unappealing is its tendency to prioritize the universal similarities among all human beings, such as the capacity for reason and the justice, rather than to highlight the particulars of smaller group memberships.

${ }^{143}$ In 1862, California legislators passed the Anti-Coolie Act, which restricted the increase of Chinese "coolie" (or unskilled) labor and thus discouraged Chinese emigration to California.

144 "Cultural capital" is a Bourdieuean sociological concept that comes to literary studies via John Guillory. Bourdieu and Jean-Claude Passeron first used the term in Cultural Reproduction and Social Reproduction (1973). It is a form of currency that, in Guillory's well-known words, "can be displayed upon request and ... thereby entitle[] its possessor to the cultural and material rewards of the well-educated person" (ix). Very simply, cultural capital is similar to but distinguished from economic capital or social capital. Its assets aren't directly exchangeable for cash or status. Instead, cultural capital must be used in much the same way that it is acquired, via the mental labor of acquiring and retaining knowledge of the Western canon. As many of us know, possession and use of cultural capital doesn't easily or ever translate into economic benefit. In layman's terms, then, cultural capital is the form of knowledge or skill that comes from a liberal arts education and often goes nowhere. In what Bourdieu calls its "embodied state," cultural capital is a matter of individual possession, both the inherited and acquired properties of 
one's knowledge of sweetness and light. By inheritance, Bourdieu does not mean the genetic sense, but rather the sense of the culture and traditions that one receives via family and socialization.

145 This is underscored by Sal's experience of disorienting panic upon awaking in a cheap hotel and feeling as though he is "somebody else." Sal describes this "one distinct time in my life" as a form of profound panic: "I was far from home ... hearing the hiss of steam outside, and the creak of old wood of the hotel, and the footsteps upstairs, and all the sad sounds, and looked at the cracked high ceiling and really didn't know who I was for about fifteen strange seconds. I wasn't scared; I was just somebody else” (17).

${ }^{146}$ While marooned in San Francisco for ten weeks, Sal develops uncharacteristic, sociopathic impulses to shoot out jewelry store windows or frighten "queers" in "bar johns" with his nightwatchman's pistol. Sal confesses: "I've never understood why I did that ... It was just San Francisco and the fact that I had a gun" (73). Incidentally, the San Francisco chapter (Part One, chapter 11) is uncharacteristically long, at twenty pages (5979).

${ }^{147}$ Wittman and Taña do, however, take a trip top Reno to find Wittman's adopted grandmother.

${ }^{148}$ In "The Difficulty of Imagining Other People," Elaine Scarry argues that the failure to imagine the "full weight" of others is to make violence possible:

The difficulty of imagining others is both the cause of, and the problem displayed by, the action of injuring. The action of injuring occurs precisely because we have trouble believing in the reality of other persons. ... the injury itself makes visible the fact that we cannot see the reality of other persons ... we come out of the 
opera, absorbed with compassion for those on stage, not seeing the cabdriver and horses who are freezing from their long wait to carry us home. (102-104) When we seek equality through "generous imaginings," Scarry argues further, "we start with our own weight, then attempt to acquire knowledge about the weight and complexity of others" (105).

${ }^{149}$ Later in this chapter, I will discuss the WPA presence in San Francisco, which initially brought Rexroth to the city.

${ }^{150}$ The word "racinate" comes from the following line from Tripmaster Monkey: "we make theater, we make community - the stage writer doesn't have to 'racinate' anybody" (318).

${ }^{151}$ Even Marshall Berman applauds Woman Warrior. In his classic study of nihilism and modernity, All the is Solid Melts into Air (1982), Berman explains that Woman Warrior became "[t]he single most impressive exploration of ethnic memory in this period" (334). Kingston is haunted by victims' ghosts, by family members who did not survive the days before the Cultural Revolution nor the move to the New World. Considering Kingston a true modernist, Berman describes her writerly stance as that of one who is haunted by ancestral nightmares that it will take her whole life to wake up from: she sees herself metamorphosing into a ghost, losing her embodied actuality even as she learns to walk tall in the ghost world, "to do ghost things even better than ghosts can"- to write books like this. (334) Berman's articulation of Kingston's scepter-like influence both explains her rapid canonization and her discomfort at being celebrated for disappearing into dead cultures. 
${ }^{152}$ Recall Kerouac's depiction of he, Neal Cassady, and Allen Ginsberg “danc[ing] down the streets like dingledodies," remarking with characteristic enthusiasm that "the only people for me are the mad ones, the ones who are mad to live, mad to talk, mad to be saved, desirous of everything at the same time, the ones who never yawn or say a commonplace thing" (On the Road 8).

${ }^{153}$ Two Kingston articles refer to the passage as "Kerouac's actual verse" (Royal 2004) and "his poem" (Maini 259); one article claims that "Kerouac listed the figures he saw on a San Francisco street" (Lowe 118). Likewise, a recent dissertation devotes an entire chapter section to investigating Kingston's interrogation of "a poem by Kerouac" as a "negative script of collective identity" (Durso, 1997 191-205).

${ }^{154}$ Because of the permanent "peasant" status that Asian immigrants in California endure, Bulosan is forced to see only the materiality of the local. From this perspective of ownership and use, developed in the first part of the book, develops an explicit identification of capitalism as the enemy.

${ }^{155}$ What Kingston doesn't indicate is that Kerouac calls attention to the fact that he attaches the adjective "little" to the Asian American characters of the novel: "I keep saying 'little' George and 'little' Arthur but the fact is they were both small anyway" (99). If nothing else, this recognition demonstrates that Kerouac had some clue about the diminutive effect of his modifiers.

${ }^{156}$ It's important to note, however, that Kingston's use of "Canuck" constitutes a rare reminder that Kerouac was not an all-American writer, but an immigrant from French Canada. Kingston's treatment of Kerouac thus validates Maurice Poteet's neglected 
argument about Kerouac's "bilingualism" and "ethnicity." The gist of Poteet's argument is that Kerouac's experimental style helped him to:

build bridges to and from a number of inner and local realities which might not 'become' American at all. In other words, spontaneous writing and effect are one answer, at least, to an ethnic situation that in many ways resembles the 'double bind' of psychology: if a writer cannot be himself in his work (a minority background) he is lost; if he becomes an 'ethnic' writer, he is off on a tangent. (qtd. in Charters, xxv)

Poteet reminds us that Kerouac is an immigrant from French Quebec, an "ethnic" writer. This fact is hard to swallow, considering that Kerouac's image has been adopted as the all-American visage. Regardless of whether or not Poteet's argument is valid, his articulation of the difficulty of being an "ethnic writer" is helpful in the context of Kingston's prose. As will become clear below, the struggles Poteet attributes to Kerouac are similar to the struggles Kingston attributes to Wittman. But she resolves the double bind of her protagonist's identity by locating the source of his identity trouble in the cultural materiality of his city at the "end of the road."

${ }^{157}$ Herbert Hunke, the most famous of the Times Square underground, reportedly coined the term "beat."

${ }^{158}$ See Ann Charters's biography of Kerouac (360).

${ }^{159}$ Sanders affection is notable elsewhere in the 1968 episode of William F. Buckley's "Firing Line." He shows tender deference toward an extremely drunk and hostile Kerouac, who harangues Sanders's "hippie" politics and lifestyle. Sanders's responds sincerely: "You're a great poet, it's your fault" (qtd. in Lerner). 
${ }^{160}$ David Sterritt's Mad to be Saved: The Beats, the '50s, and Film is a good study of the Beat presence in pop culture. Also Regina Weinreich's “The Beat Generation is Now About Everything" and Allan Johnston's article, "Consumption, Addiction, Vision, Energy: Political Economies and Utopian Visions in the Writings of the Beat Generation," further explore Sterritt's claims.

${ }^{161}$ The Dharma Bums (1958) is where Kerouac tells the story of the West-Coast branch of the Beat movement. But even in this novel, which centers on a Japhy Ryder, a Zen Buddhist character based on Gary Snyder, thinks about Eastern modes of belief as vacuums void of every kind of influence, acultural solitude. Likewise in Big Sur (1962) and the first half of Desolation Angels (1965), Kerouac represent the West Coast as the edge of the world, the place near which to sit and reflect.

${ }^{162}$ Portions of the following paragraph from the introduction to $A$ Thousand Plateaus (1980) appears in Marco Abel's article "Deleuze Meets Kerouac On the Road," as well as in Michael Davidson's chapter on "California Orientalism" in Guys Like Us.

${ }^{163}$ Though he dislikes novels, claiming their readers are "women and men under thirty," Rexroth enjoys McTeague for Norris's obvious interest in "mining" beneath "surface phenomenon."

${ }^{164}$ The entire Stein quotation is of note, if only to compare Stein's attitude toward local affiliation with that of the following generation of West-Coast American writers: "What was the use of my having come from Oakland it was not natural to have come from there yes write about it if I like or anything if I like but not there, there is no there there" (289). ${ }^{165}$ In a sense Kerouac reinforces Rexroth's nativist pride. As Michael Davidson claims, Kerouac's circum-continental road narratives represent multiple attempts to escape from 
"the pressures of East Coast sophistication and privilege" $(2004,86)$. This "exodus from the East [Coast] to California" becomes a celebration of "heterosexual male community" (86). As Rexroth puts it bluntly, "get out of New York before it kills you" (180). In literary historical terms, Kerouac's denial of sophistication becomes a denial of his early influence, Thomas Wolfe, Hilfer's most proficient village rebel. Kerouac abandons his labored imitation of Wolfe after the publication of The Town and the City (1950), favoring from then on more experimental forms of prose that emulates movement. Although this central Beat stylistic is figured by critics (though most famously by Truman Capote's pithy remark) as an example of their overarching dilettantism, spontaneous prose is a controlling principle for a literature that has resolved the tension between cosmopolitan introspection and provincial parsimony. Where aesthete rebels like Agee are effective at advancing the need for attacking the polarity of these cultural attitudes, Kerouac produces an example of what post-village rebellion literature might actually look like. In short, Ginsberg's poetry and Kerouac's prose offer a tangible (albeit amateurish) option of what can come after the successful coupe against both provincial and cosmopolitan small-mindedness.

${ }^{166}$ For more on Rexroth's efforts to engineer the San Francisco Renaissance see Hamalian's own A Life of Kenneth Rexroth.

${ }^{167}$ In The San Francisco Renaissance (1989), Davidson focuses on the problems inherent in present academic constructions of the Renaissance. He claims that all twentiethcentury literary "movements" are composed around "luminous centers" or "inaugural moments" that "galvanize public attention" to the movement described and give "the illusion of purpose and direction" to those who construct and maintain the chronological 
and biographical apparatus of the works of the movement $(1989,1)$. Specifically concerned with subtracting "enabling fictions of origin" from the study of literary movements, Davidson criticizes narratives of the San Francisco Renaissance. He claims that the common denominator of all anecdotal or comprehensive accounts of the Renaissance — that it "began" on October 13, 1955, at the Six Gallery Reading — rally around a moment that obscures the "social materiality" of the movement, "the urban spaces in which alternative communities and constituencies are formed" (1997, xii). Thus, Davidson hopes to prove that the purpose and direction of the laundry list of historical narratives that surround both the Renaissance and the Beats neglects what he deems the paramount social effect of the San Francisco Renaissance: the establishment of a clandestine community of readers whose relationship with City Lights publications is based on the type of reader/writer intimacy sought by the Beat aesthetic, rather then on the voyeurism of the post-historical-narrative readership. Davidson is striving to bring a social materiality back into the discussion of poetry. As his later work on modern poetry and the material world explicates, Davidson wants to restore poetry a "critical and political potential that earlier Marxist critics such as Raymond Williams, E. P. Thompson, and Theodor Adorno granted it" (1997, xii).

168 A long list that includes Gary Snyder, Robert Duncan, Philip Lamantia, Philip Whalen, Ginsberg, William Everson, Robin Blaser, Jack Spicer, Lawrence Ferlinghetti, Bruce Boyd, Kirby Doyle, Richard Duerden, Philip Lamantia, Ebbe Borregaard, and Lew Welch.

${ }^{169}$ Though some would argue that Madeline Gleason and Helen Adam had a heavy hand in engineering the movement, I would argue that their influence was muted by the more 
aggressive voices of Rexroth and relegated to the neo-traditional task of design caring about the design of public events. Adams is a "collagist" first and a poet second. Her labor of production has been largely eclipsed by the more high-profile labor of Lawrence Ferlinghetti, who produced the publishing house that bound and distributed all his old boys.

${ }^{170}$ See Juliana Chang's "Melancholic Dreams" for a comparative reading of Bone and Eat a Bowl of Eat.

${ }^{171}$ Huang here implies that canonical Asian American writers are canonical precisely because they enact positivist techniques. Frank Chin makes a similar argument, which I'll discuss below.

${ }^{172}$ Yoon Sun Lee is currently finishing a book on the construction of the everyday in Asian Pacific American literature and history.

${ }^{173}$ Part III of The Practice of Everyday Life, "Spatial Practices," includes a section titled "Voyeurs or Walkers."

${ }^{174}$ See the travel guide section of the San Francisco Chronicle (SFGate): sfgate.com/traveler/guide/sf/neighborhoods/tenderloin.shtml. The Tenderloin's neighborhoods include Mid-Market, Civic Center, Theater District, Lower Nob Hill, Polk Gulch, and Little Saigon. The words "The Tenderloin" almost never appear in real-estate listings.

${ }^{175}$ See Arlif Dirlik's What is a Rim? for a detailed discussion of this geographical category.

${ }^{176}$ This is the same argument that, elsewhere, Frank Chin makes more forcefully. A fellow Berkelean and Chinese American who came of age in the late 1960s, Chin is 
Kingston's militant opposite. He is part of the aforementioned radicalized generation of Chinese American writers that Viet Thanh Nguyen claims emerged in 1968 on the West Coast. These writers appropriate the militancy enacted in city space in the 1960s. In his lengthy essay, "Come All Ye Asian American Writers of the Real and the Fake," Chin claims that Kingston, Tan, and Hwang are popular "among whites" because they make the militancy of Chinese culture look "icky-gooey evil" (2). Despite the bravado of Chin's remonstrations, he has a point when he suggests that Chinese literature should claim America on its own terms and in its own genres. By Chin's account, the Pacific is the Chinese Atlantic, San Francisco the Chinese Ellis Island, and "non-Christian bachelor Chinamen" who built the transcontinental railroad the Chinese pilgrims ("Come All Ye"). Chin celebrates the fact that "before the 1960s, the majority of Chinese Americans were non-Christian bachelor Chinamen" (xii). In 1965, immigration reform brings new Asian immigrants to America for the first time since The Chinese Exclusion Act restricted immigration from Asia from 1882 until 1943. Increasing numbers of Asian immigrants began arriving after the INS Act raised the quotas set by the Magnuson Act (a provision to allow Chinese emigration as a consolation for allegiance with the US during World War II), renewing Asian communities that had nearly died out. The 1980 census reports 62.1 percent of Asians are foreign born. This migration narrative is obscured by the Eurocentric cartography of literature about the American West.

${ }^{177}$ The American Chinatown has always been perceived as what Braman refers to as " $\mathrm{a}$ geographic and cultural body that is separate from the civil body of the city and as a site where the physical body can degenerate physically and morally" (141). Evidence of the degenerative capacity of Chinatown was generated, among other places, via Jacob Riis's 
fixation on the opium dens of New York's Chinatown, in How the Other Half Lives (1890) and turn-of-the-century cartography of San Francisco, which depicted the city "as a white city in which Chinese-occupied cells stand out, like cancer" (Moy 65). This fixation on Chinatown not only facilitates anxiety about moral deterioration; it ensures that the Chinese American will exist in the popular imagination as a ghettoized figure, rather than as the virile, bachelor laborers who built the transcontinental railroad. It sets the topography of what Frank Chin calls the "racist love" commonly bestowed on Chinese Americans, and his literature is designed as a corrective to this misrepresentation.

${ }^{178}$ Richard Lehan's The City in Literature (1998) offers the most exhaustive study of the city as a backdrop for white male soul searching. Lehan argues that the city is an "unreal" cite of high modernist innovation, a shape-shifting backdrop upon which the psychological crises of modern subjectivity are staged. For instance, in Lehan's last chapter, Thomas Pynchon is discussed as a writer who undoes the "wasteland myth" of the modernist city. Deconstructive theory, another key player in undoing this myth, has articulated the poststructural zeitgeist that gives rise to two major themes in postwar urban literature: the self-referential city and the disoriented self trying to relate. Lehan claims that Jean Baudrillard's celebration of simulacra and pastiches of collapsed traditions marks the end of "liberal tradition and its trust in the individual" and gives rise to a bricoleur materialism that sees the city not as the debris of a once golden age, but as only emptied objects and the relations among them. Lehan describes Pynchon as the latest in a series of "major figures" to address the city, a figure who prefigures a new perspective on the built environment. Ultimately, then, Lehan's interest in the city is 
reducible to the common interest in this literary trope, to endorse "major figure" taxonomies, if not also to continue the list of "genius" men-of-letters into contemporary literature.

${ }^{179}$ Dickstein published an emended version of his Cambridge History of American Literature, volume 7, a study of American fiction from 1945 to 1970, Leopards in the Temple (1999). Four years before Dickstein's book, Joseph Roach references the parable in Cities of the Dead (1996), to discuss those who, like the Zulu crew in New Orleans Mardi Gras, interrupt performances of origin and supremacy and resists the comfort of selective amnesia.

${ }^{180}$ Since the late nineteenth century, roughly since the "White City" exhibit at the 1893 Chicago World's Fair, American cities have been represented as self-conscious spectacles, forms of urban experience and of experiencing the urban world wherein the beholder plays witness to an unanswerable performance which (s)he has no hand in producing. Alan Trachtenberg argues that the twentieth-century American city is presented as a "frank illusion" or "an admitted sham" that dislocates any orienting "vision of the real" (231). Since then, the city has become the preferred production site for modernist fiction writers. This vision of the city overlooks the fact that recent cityborne genres, such as noir fiction, inner-city memoirs, and immigrant narratives, are illogically segregated from discussions of another as well as from the discussions of city fiction.

${ }^{181}$ Note on James Kyung-Jin Lee's Urban Triage: Race and the Fictions of Multiculturalism, which discusses multicultural fiction in the context of urban redevelopment in the 1980s. 
${ }^{182}$ Park coauthored The Man Farthest Down (1912) with Washington. He also served as Tuskegee's publicist and, in 1912, organized an International Conference at Tuskegee on "the Negro."

${ }^{183}$ The term "psychogoegraphy" comes from Guy Debord's “Introduction to a Critique of Urban Geography.”

${ }^{184}$ Walter Benjamin has written much about the flâneur. See specifically the first chapter of Charles Baudelaire and the Arcades Project sketch "Paris - Capital of the Nineteenth Century" (1938).

${ }^{185}$ I believe that the Joyce allusion stops there. A. Noelle Williams, believes that Joyce is "the second most alluded to author within the pages of Tripmaster Monkey"(90). Williams's vague, unsubstantiated claim that "Joyce's visible influence flows into the text particularly when the young artist ... is discussing his own artistic imperatives, or when the narration follows Wittman and his thoughts through the streets of San Francisco" has become symptomatic of critics rushing to make sense of Kingston's unorthodox referencing logic (90).

${ }^{186}$ When Wittman visits his mother, she also refers to him as a "bum-how": "He read books when he was three years old. Now look at him. A bum-how" (184). I'm not sure if the word is a phonetic spelling of a Chinese word or simply slang. Regardless, both seem to refer to the colloquialism "bum," as both uses name a Wittman who is not gainfully employed.

${ }^{187}$ This near conflation and race is unique to Asian American literary studies, as David Li indicates when he claims in recent Asian American scholarship “" $r$ r]egion” seems to have overridden 'race,' and the 'global' seems to have overtaken the 'local' in the ongoing 
disciplinary redefinition of 'Asian America(n)"' (1). The first part of Li's claim implies that the spatial coordinates of "Asian American citizenship" are now more important standards of inquiry than are questions of racial make up. The second part suggests that this shift from race to region is of a piece with the inductive forms of belonging engendered by recent debates about cosmopolitanism.

${ }^{188}$ This language comes from Joseph Roach's Cities of the Dead, which defines "surrogation" as the act of placing an object or image in for an original.

${ }^{189}$ In the footnote to his translation of the novel, Stephen Mitchell indicates that the unnamed poet turned playwright is intended to be Henrik Ibsen.

${ }^{190}$ It is outside the bounds of this project to compare Kingston's decision to have Wittman be a playwright and the oftenicited similarities between Wittman and Frank Chin. However, Wittman's final one-man show can be seen as a form of ventriloquism, wherein Kingston does for the militant Chinese American writer what he is unable to do for himself. However, Chin's Chickencoop Chinaman (1972) and Year of the Dragon (1981) are fairly well done meditations on the very identity questions Kingston has Wittman wrestle with.

${ }^{191}$ For a detailed discussion of communist Chinese theater, See Xiaomei Chen's study of the emergence of the "model theater" of the Cultural Revolution, in Acting the Right Part.

${ }^{192}$ This homoerotic lust for the vertical pronoun is a continuation of Whitman's virile delineation of the reciprocity between the body the poet sings electric and body politic of America at large. Kingston thus reveals the provincial scope of the all-male aesthetic alternatives promoted by both Kerouac and Chin. 
${ }^{193}$ In this context, Tripmaster Monkey dramatizes the spectacular intricacies and effects of problematic seizures of the public sphere. As W. J. T. Mitchell has suggests in his essay, "The Violence of Public Art," in the year 1989 there was a spike of interest in representing "public sphere" debate and political activity. Commonly referred to as the "Year of Miracles," 1989 bore witness to both the end of the cold war and the Tiananmen Square protests. In the same year, Tripmaster Monkey was published and Spike Lee directed a comparable version of a racially charged, potentially violent public sphere, $D o$ the Right Thing (1989). Habermas defines the public sphere as a collection of "private people come together as a public" who collectively assert a legitimacy at least horizontal to that of "public authorities"(27). The point of the public sphere is to "engage [these authorities] in a debate over the general rules governing relations in the basically privatized but publicly relevant sphere of commodity exchange and social labor" (27). This type of public debate about legitimacy "problematized" social relations "that until then had not been questioned" (36). This "civil society," however, "the private people for whom the cultural product became available as a commodity profaned it inasmuch as they had to determine its meaning on their own (by way of rational communication with one another), verbalize it, and thus state explicitly what precisely in its implicitness for so long could assert its authority" (37). It is this loose-canon, collective lowbrow authority that intrigued artists like Kingston and Lee, whose art argues dramatizes public sphere debate without also perpetuating Habermas's fallacy that the unsteered masses will misunderstand art. Indeed, as I will discuss shortly, Tripmaster represents an innovative application of eclectic "cultural products." 
${ }^{194}$ In this sense, Kingston's narrator on Tripmaster Monkey is much like Sal Paradise, the narrator in On the Road, who asserts that he's rambled all his life "after people who interest me" (8).

195 Of “polarized” writers, in which list she places Toni Morrison, Russell Banks, John McGahern, Huston says that these writers

have nothing to prove and nothing to teach; their attachment to a specific group or land is not conflictual in any urgent, present way; simply, within their local universe, they have discovered all the wealth and complexity and contradictions of the human soul, and can therefore go on exploring this universe forever, without inflicting boredom on either themselves or their readers. (14)

${ }^{196}$ In Marked Men (2000), Sally Robinson discusses how, after the advent of identity politics, white masculinity has forded off the disadvantages of invisibility by acquiring "markings," usually in the form of imperial or post-imperial wounds, that require that he no longer be "hidden by history" (1).

${ }^{197}$ I call Huston "internationalist" not only because of such international credentials as a being a Canadian-born novelist and essayist who writes in French, or because she holds an MA in social sciences (supervised by Roland Barthes) from the École des Hautes Études in Paris, or because she's won numerous French literary awards, or because her husband is Tzvetan Todorov, but also because she is so detached from any specific group or place that she honestly thinks that Toni Morrison is a regional writer, or a writer with a "local universe" (14). 
${ }^{198}$ The tension between these two polarities, a tension that arguable spawned this oscillation, exists as early as 1921, when Edith Wharton's decidedly cosmopolitan The Age of Innocence (1920) won the Pulitzer despite the fact that the jury of readers voted unanimously for Sinclair Lewis's thorough critique of Midwestern provincialism, Main Street (1920). The motivations of the Columbia University trustees, which issued the award, for overturning the jury's unanimous verdict are ambiguous. The wild popularity of Main Street may have contributed some to the trustee's mistrust of the novel. As "the most sensational event in twentieth-century American publishing," the runaway popularity of Main Street was a first in America. Main Street sold close to three hundred thousand in its first year and over two million within two years. The fact that a tedious novel about a humdrum Midwestern town (Gopher Prairie) would win the hearts of such a broad cross-section of America indicates that national culture may have been more interested in confronting the prominence of small-town provincialism than the gatekeepers of cultural capital may have wanted them to be. Wharton later admitted that Lewis should have received the award. Grateful, Lewis dedicated his next novel, Babbitt (1922), to her. See Robert Coard's Modern Fiction Studies article “Edith Wharton's Influence in Sinclair Lewis" for a more detailed discussion of the crucial relationship between the early twentieth-century's most cosmopolitan and most provincial novelist. See John Hohenberg's The Pulitzer Diaries for a more detailed history of the award. ${ }^{199}$ His early book blurbs all end with the assertion that "he grew up in a working-class environment, which has played a major role in his writing." 
${ }^{200}$ Barry Chabot writes in a forthcoming book on contemporary American fiction that contemporary regional writing is "ethnicity for white folks, who are able to use in their writing being from Kentucky or Kansas as others use being from Korea" (Chabot 2007) ${ }^{201}$ By "regional" Franzen means fiction that "feeds on specificity" and finds "the manners of a particular region ... fertile ground" (68). This is how Franzen sees regionalism "thriving" at universities, as a mode of identity politics. "In fact," the antiacademic Franzen snorts, "it's fashionable on college campuses nowadays to say that there is no America anymore, there are only Americas; that the only things a black lesbian New Yorker and a Southern Baptist Georgian have in common are the English language and the federal income tax" (68-69).

${ }^{202}$ According to Fred Pfeil, Mason is a throwback to heyday regionalism who "allows upscale readers to savor the narrative as a virtual transcription of likeable, down-home stupidity" (76). Mason's career even mimics the economy of late nineteenth-century regional writers. After leaving the academy in 1979 to become a full-time writer, Mason wrote short stories of working-class life in the "New South," which were published mostly in The New Yorker and the Atlantic Monthly. These stories, which were later collected in Shiloh and Other Stories (1982), disparagingly feature the trappings of "white trash" culture (its strip malls, fast-food, and bad TV) for a reader who is supposed to read on in condescending amusement.

${ }^{203}$ Using regional writing as a way of breaking into the literary market is not a new tactic. As Richard Brodhead reminds us, all major late nineteenth-century authors, with the exception of Henry James and WD Howells, succeeded through regional form (viz., George W. Cable, Sarah Orne Jewett, Mark Twain, Charles W. Chesnutt, Mary Wilkins 
Freeman, Abraham Cahan). According to Brodhead, "authors in this [regional] mode typically had their first efforts published" $(1994,117)$.

${ }^{204}$ See Susan Faludi's Stiffed: The Betrayal of the American Man for a deeply researched historical study of this phenomenon.

${ }^{205}$ Fred Pfiel's White Guys is the best book to elicit this counterintuitive victimization and its reactionary backlash.

${ }^{206}$ See Szalay for a discussion of the white masculinity of liberalism, which imagines "abstract persons whose very nonspecificity masks a world of hegemonic norms and values" (21).

${ }^{207}$ See Sandra Zagarell's article "Crosscurrents: Registers of Nordicism, Community, and Culture in Jewett's Country of the Pointed Firs."

${ }^{208}$ See Introduction, note 12.

${ }^{209}$ See Tom Lutz (119-123) for a more detailed discussion of Wharton's cosmopolitan ambitions.

${ }^{210}$ I am thinking specifically about the agenda-setting book-length works, such as Josephine Donovan's New England Local Color Literature (1983), which discusses local color in New England fiction as though it were homosocial, an early manifestation of feminist community building. Elizabeth Ammons, Nancy Glazener, and Sandra Zagarell, have all written articles more recently that treat to some degree the economic and social decline of rural New England, even as it exists amid the enabling fiction of all-female utopia.

${ }^{211}$ See Stephanie Foote (17-37) and Brodhead (142-176) for good discussions of this topic. Basically, both Foote and Brodhead view the virginal status of regional fiction as a 
projection from bourgeois readers and literary institutions onto the regions. Nancy Glazener contributes to this discussion in her conception of the "Atlantic group" of publishing institutions, which originally asserted the long division between cosmopolitan and provincial cultures. According to Glazener, the projection of virginal status onto rural spaces of the US aided the development of a "nationalizing sectional identity" that holds provincialized regions at arm's length from their cosmopolitan readership (260). ${ }^{212}$ For the record, though, one of Celia Thaxter's first Atlantic Monthly publications was an essay, published in May of 1875, on the brutal murder of two women, which supposedly occurred literally on her doorstep in Smuttynose Island off the Maine coast. ${ }^{213}$ See Campbell's Resisting Regionalism (1-13). ${ }^{214}$ Abigail Ann Hamblen's 1965 article in the New England Quarterly first expressed these inadequacies in Wharton's manner of gathering material for Ethan Frome and Summer ("Edith Wharton in New England"). In it, Hamblen criticized Wharton of knowing too little of rural New England to make any proper representation. This may be true, but as I try to prove above, Wharton's agenda is not verisimilitude but a formal register of the crude essentialism presupposed in all local color regionalism.

${ }^{215}$ Which she lays out in "The Novel Démeublé," in her essay collection, Not Under Forty (1936).

${ }^{216}$ See Clair Preston's book length study of Wharton's "Social Register," in which Preston uses the term "tribes" to describe the social apparatus that structures and confines individuals in Wharton's novels, namely The Age of Innocence.

${ }^{217}$ The motivations of the Columbia University trustees, which issued the award, for overturning the jury's unanimous verdict are ambiguous. The wild popularity of Main 
Street may have contributed some to the trustee's mistrust of the novel. As "the most sensational event in twentieth-century American publishing," the runaway popularity of Main Street was a first in America. Main Street sold close to three hundred thousand in its first year and over two million within two years. The fact that a tedious novel about a humdrum Midwestern town (Gopher Prairie) would win the hearts of such a broad crosssection of America indicates that national culture may have been more interested in confronting the prominence of small-town provincialism than the gatekeepers of cultural capital may have wanted them to be. Wharton later admitted that Lewis should have received the award. Grateful, Lewis dedicated his next novel, Babbitt (1922), to her. See Robert Coard's Modern Fiction Studies article “Edith Wharton's Influence in Sinclair Lewis" for a more detailed discussion of the crucial relationship between the early twentieth-century's most cosmopolitan and most provincial novelist.

${ }^{218}$ Even the State Department publication has taken note of this phenomenon in new regionalism, citing Joyce Carol Oates's "haunting works" of the northeast US whose “obsessed characters' attempts to achieve fulfillment within their grotesque environments lead them into destruction" (Outline). The publication also notes the fact that Stephen King "generally sets his suspenseful page-turners in Maine -- within the same region." Also in Maine, recent novelist G. K. Wuori has started to receive due recognition for his novel, An American Outrage (2000), and story collection, Nude in the Tub (1999), about the bizarre north woods of Quillifarkeag, Maine. ${ }^{219}$ It has been represented through Robert Frost's poetry as the site of "the social and emotional costs of living in a poor and declining part of the country" and allegorized by Thornton Wilder's Our Town (1938) as "the imaginative property of the entire nation" 
(Ryden 206, 208). But anyone who's read Stephen King's Castle Rock novels knows that the unseemly side of rural New England has reemerged in the late twentieth century. King's New England horror follows that of H. P. Lovecraft, who drew extensively from his native New England for the settings of his horrific and fantastic science fiction. Lovecraft, like King, makes use of numerous real historical locations and several fictional New England locations. Lovecraft first used a New England setting for his short story "The Terrible Old Man" (1920). Key recurring fictional cities in Massachusetts include Arkham and the Miskatonic Valley, both of which appear in "The Picture in the House" (1920). Lovecraft explains his interest in New England as a setting for weird fiction by claiming the "night-black Massachusetts ... is material for a really profound study in group neuroticism; for certainly, none can deny the existence of a profoundly morbid streak in the Puritan imagination." (qtd. in Joshi and Cannon, 2). King, Banks, Russo, and lesser-known contemporaries like Ernest Hebert and G. K. Wuori, likewise flock to New England settings. But this "group neuroticism" has retreated into a set of individual personal crises, and the fiction of isolated, self-destructive blue-collar males is on the rise in New England. Whether probing the interior psychic contours of self-destructive men or writing plainly of the topology of rural New England, contemporary writers whose fiction is local to New England always claim that there is a self-evident correspondence between the region and its wrecked lives. Tragic antiheros are matters of fact, lives that, like Puritan culture, have already ended and are told just to get the record straight, to revise the large-scale denial of the violent impulses of the American grain out of that region of the American landscape. 
${ }^{220}$ Wharton's narrator is in Starkfield on business, where he has been sent from the city on a kind of consultantcy mission to a "power-house" somewhere in the hinterlands of northern New England.

${ }^{221}$ The major plot arc of the novel, or at least the major occasion for referencing the world outside of the world that the narrator/novelist is trying to produce, involves the narrator searching for the man who Stark the character is based on, a man who has gone missing and who appears to have been murdered.

${ }^{222}$ Banks's career has long been seen in Conradean terms, or at least to masculine intrusions metaphors. The lead blurb for his most recent novel, The Darling, written by J.M. Coetzee, claims that Banks's Liberia “is as hellish a place as Joseph Conrad's nineteenth-century Congo.” Though I think this understanding of Banks as a reincarnation of Conrad is redundant, Banks, like all honest regional writers, immerses himself in the "destructive element" of storytelling that elevates the centrality of socially disparaged figures.

${ }^{223}$ Sauer was a geographer and professor for over 50 years at the UC Berkeley, where he built a distinguished graduate school. A great influence on a generation of geographers, Sauer sought to unify the areas of physical and human geography through an essentially historical methodology. He advocated a "humane" use of the environment, pointing to ancient and modern rural cultures as examples. Among his 21 books and monographs are Agricultural Origins and Dispersals (1952) and Northern Mists (1968).

${ }^{224}$ In "Arts of the Contact Zone," Mary Louise Pratt talks about "autoethnography" as "a text in which people undertake to describe themselves in ways that engage with representations others have made of them" (586). 
${ }^{225}$ Laclau also explains that the so-called "death of the subject" heralded by poststructural theorists "has been succeeded by a new widespread interest in the multiple identities that are emerging and proliferating in our contemporary world" (20). This is important because, as I'll discuss below, the concept of multiple identities has a tricky way of rebirthing the subject as something that is so available that it is no longer the property of human being alone.

${ }^{226}$ See Lott's new book, The Disappearing Liberal Intellectual for an extended discussion of what he calls the "return of universalism," one prominent feature of which is that it inaugurates an era of radical democracy that the watch and guard of left-leaning intellectualizing had not anticipated.

${ }^{227}$ The choice of paternal violence is not as arbitrary as I might imply. The novel is dedicated to Earl Banks, Banks's abusive father, whom Banks has mentioned in interviews he was thinking quite clearly of while writing the novel.

${ }^{228}$ See the first three pages of Walter Benn Michaels's The Trouble With Diversity for a brief and effective discussion of this same kind of critique of the American Dream myth in F. Scott Fitzgerald's famous novel The Great Gatsby. Michaels describes Fitzgerald's conception in the same way that Banks reveals Rolfe's, in that he wants to think of the rich as somehow another, exceptional race, or as Fitzgerald himself calls then, a "special glamorous race."

${ }^{229}$ This is Ralph Ellison's language, from the introduction to Invisible Man, a novel that is more about the long division between the provincial and the cosmopolitan than is currently discussed (xi). 
${ }^{230}$ Indeed, Rolfe is a victim of abuse. The reader learns through a phone conversation with Wade that what Rolfe misremembers as an Oedipal story featuring Wade, who peeked at his nude mother was beaten within an inch of his life, was actually part of Rolfe's own life story, part that Rolfe the narrator never fully acknowledges.

${ }^{231}$ The other profitable act in Lawford is to sell it to investors looking to open a ski resort. This venture is successful, temporarily sustaining the town economically and, as I'll discuss below, banishing monsters like Wade to some point father north on the "unmapped line."

${ }^{232}$ Though I can't do it here, the connection between McTeague and Affliction is worth exploring. Not only are teeth and drilling prominently featured as supplementary symbolics for violent masculinity, but both Mac and Wade spiral out of control in near proximity to sources of capitalist logic. McTeague spends his childhood as a "car-boy," for an unidentified, subterranean "ore" (Norris 2). Upon his mother's death, he gains an inheritance sufficient enough for him to leave the Big Dipper Mine in Placer County and enter the free-market economy as a dentist. Yet, as the constant presence of his pet canary implies, McTeague never quite abandons his miner subjectivity. His canary accompanies him as he mines the mouths of San Francisco. McTeague eventually returns to Placer County, to "the same work he had so often performed in his 'Parlors,' only magnified, made monstrous, distorted, and grotesqued, the caricature of dentistry" (217). Where McTeague the miner draws gold from the earth and introduces it into the economy, McTeague the dentist draws the gold back out of the economy—using comparatively similar tools, "queer counterparts" of his mining drills (217). He'd squandered gold through placing it in people's mouths and out of circulation and thus returned to his other 
occupation as a miner, as a brutishly masculine worker of the raw materials of capital. Likewise, Affliction can be read as an allegory of the labor that goes into the production of capital. Lawford eventually transforms itself into a resort town reminiscent of Bretton Woods Mountain Resort (located very near where Banks placed Lawford), where the International Monetary Fund was born in 1944. The Bretton Woods system was based on a fundamental agreement that the dollar was to be considered literally "as good as gold," meaning that gold (of which the US possessed about a third of the world total) was the guarantee of the power of the dollar. Also, the Bretton Woods system was a fundamentally new arrangement because, unlike previous international monetary systems (notably the British), which had been firmly in the hands of private bankers, Bretton Woods gave control to a series of governmental and regulatory organizations, including the International Monetary Fund, the World Bank, and ultimately the U.S. Federal Reserve.

${ }^{233}$ Banks enjoys the word "monadnock," using it to describe significant geological formations of in both Affliction and Hamilton Stark. In Hamilton Stark, the narrator describes the landscape of rural New Hampshire as consisting of "deep furrows and mile high moraines ... here and there an isolated monadnock" (27). In The Darling, he starts to favor the word monad, which I'll discuss below is important to him as a way of reconceiving of individuality.

${ }^{234}$ Frank elaborates in this in this historicizing vein in his introduction:

Having rolled back the landmark economic reforms of the sixties (the war on poverty) and those of the thirties (labor law, agricultural price supports, banking regulation), its [the conservative backlash's] leaders now turn their 
guns on the accomplishments of the earliest years of progressivism (Wilson's estate tax, Theodore Roosevelt's antitrust measures). With a little more effort, the backlash may well repeal the entire twentieth century. (8)

${ }^{235}$ In the larger context of contemporary American fiction, Banks's choice of narrator speaks to a recent trend, arguably made famous by Julia Alvarez's In the Time of the Butterflies (1995), of partly pseudo-historical narratives about "women revolutionaries." Recently, this category of fiction has exploded, even earning its own Library of Congress subject heading. A short list of American fiction catalogued under the "Women Revolutionaries" heading includes: Erased Faces by Graciela Limón (2001), L.C. by Susan Daitch (2001), No One To Trust (2002) by Iris Johansen, Blood Diamonds (2002) by Jon Land, The Maquisarde (2002) by Louise Marley, American Woman (2003) by Susan Choi, The Wild Irish by Robin Maxwell, The Tree Bride by Bharati Mukherjee, and Rosa by Jonathan Rabb. This list represents a fairly even sample of popular historical fiction, crime fiction, romance novel, and "literary" fiction, further marking "women revolutionaries" as a bountiful category. An interesting offshoot of the "women revolutionaries" category is the recent boon of novels featuring the kidnapping of Patty Hearst. In addition to Choi's excellent novel, Christopher Sorrentino's Trance (2005) and Diana Spiotta's Eat the Document (2006) have meditated on the generation of American radicalism that spawned some of the more spectacular gestures at cosmopolitan belonging.

${ }^{236}$ Banks once remarked on the presence of a "bipolarity" in his oscillating interests in New England and the tropics (Brown 68). Three of Banks's books are at least partially set in the Caribbean: The New World (1978), The Book of Jamaica (1980), and Continental 
Drift (1985). Most of the stories in The New World were written while on an 18-month stay in Jamaica and take as their organizing metaphor the Americas as they were when "discovered." The Book of Jamaica and Continental Drift both feature, on cultural and individual levels alike, the struggles of Jamaicans and Haitians must make to yield a humane existence.

${ }^{237}$ In the first documented use of the word "cosmopolitanism," Thomas Carlyle wrote, in an 1828 letter: "A certain attenuated cosmopolitanism had taken place of the old home feeling."

${ }^{238}$ Banks never stepped foot in Liberia. As he explains in an interview for Guernica: "I went to West Africa. I tried to get into Liberia ... I did an awful lot of prep work beforehand, library, reading, talking to people who had spent time there, Peace Corps volunteers, Liberians living in the United States and so on. I even spent an entire weekend with an old CIA hand who'd been stationed in Liberia” September 2005, (www.guernicamag.com/interviews/81/telling_details).

${ }^{239}$ The above Lott quotation is drawn from an unpublished portion of an interview I conducted with him, an interview that appeared in the minnesota review.

${ }^{240}$ A lot of the reason why this is true in Banks's depiction is because, as he explains in an interview with identity theory, "the whole theme of Liberia ... became important to me when I was researching Cloudsplitter ... I got into the early history of the antislavery movement and the creation of Liberia and its intimate and ironic connection with American racial history" (www.identitytheory.com/interviews/birnbaum156.php).

${ }^{241}$ As I noted in Chapter One, Susan Hegeman notes that Praise became "legendary" in the $60 \mathrm{~s}$, "a book that young college students took south with them during the Freedom 
Summer of 1961" (178). Also, the "disembodied liberal abstractions" language comes from Michael Szalay, who uses this phrase to describe the intended recipient of New Deal social welfare (Szalay 21).

${ }^{242}$ Despite all the personal problems Banks has with Kerouac, his methods of representing working-class masculinity owe a lot to Kerouac's influence. In his “Art of Fiction" interview with Paris Review, Banks characterizes Kerouac's narrative voice as imbuing a "rough personalism ... [that] reinvoked a Whitmanesque perspective and texture" (54). It is this tradition, or "stream," of "rough personalism," that the "'High Modernists' affection for formalism" had all but dammed out of American literature (5455). Kerouac's rejection of modernist sophistication "opened up the old current" of rough personalism, linking himself to the larger-scale American literary tradition of autodidactic authorship. Marco Abel calls this "rough personalism" a "minoritarian" poetics that "demarcates a new form of writing: not the slow, deliberate sentence of the dominant modernist tradition, but the speedy, visceral, combinatory, over-exuberant conjunction of words that form sentences radically different from their predecessors" (232). Kerouac's style reminds Banks of Whitman's intimate address and exuberant transcendence of the stationary. Kerouac's belching, ranting corporeality, on the other hand, reminds Banks that the master/apprentice model of influence is bankrupt. Banks's obsession with the masculine stream of American literature is not reducible to identity politics. Like Kingston, Banks understands Beat style as a means of depolarizing cosmopolitan and provincial sensibilities. Like Kingston, who uses Beat style to overcome the limitations of writing from within a specific racial category, Beat style is a model for coming to terms with the shock and humiliation of being the "token poor kid" 
in a "bourgeois art form" (Banks 1986a). Where Kingston gravitates to Beat style for a way out of the constrictions of ethnic stereotypes, Banks finds in Kerouac's writing, an example of how to bypass both literary sophistication and the myopia of working-class regional narratives.

${ }^{243} \mathrm{I}$ 'm probably overstating the case here. However, Banks does seem to have a very earnest affiliation with the SPCA and a collection of various other NGOs dedicated to "saving chimpanzees from medical experimentation, abused as entertainers and pets, and outright extermination" (The Darling, "Acknowledgments," 393).

${ }^{244}$ See Irene Sege's article "Leading a Double Life" or James Harkin "Get a (Second) Life" for interesting discussions of Second Life, a virtual reality community in which users create their own identity, meet people, buy land and build homes and cities. Known as a "massively multiplayer online role playing game" (MMORPG), Second Life offers users freedom to create and interact with an alternate reality that consists of the same daily operations of this reality, including mortgages.

${ }^{245}$ The Veiled Prophet Organization is known primarily for its annual festival and debutante's ball. The "Veiled Prophet Festival" was renamed Fair St. Louis in 1992. The debutante's ball, or "Veiled Prophet Ball," still occurs under that name, but in December, rather than autumn (which is when it takes place in Franzen's novel). For more information on the Veiled Prophet secret society, see Thomas M. Spencers' The St. Louis Veiled Prophet Celebration (2000).

${ }^{246}$ The above information on the historical Veiled Prophet is found in the online Encyclopedia of World History: Ancient, Medieval, and Modern, 6th ed. (2001). 
${ }^{247}$ The racist connotation of "Indian" also applies here, as Jammu engineers a series of Xerox flyers from supposed "Osage Warriors" calling for "Death to Gentials! [sic]" and "Free the Land!" and "God is Red!" (81).

${ }^{248}$ The above quotation comes from Barth's famous Atlantic Monthly article "The Literature of Exhaustion" (1967). Barth attributes the sentiment about narrative literature to Leslie Fiedler.

${ }^{249}$ The difference is that, rather than living on the distant farms and commuting into the city center as "hired girls" and boys, the minority groups of Midwestern cities in the late twentieth-century live only in the city centers.

${ }^{250}$ Lewis describes Zenith, the city setting of Babbitt, as a boomtown, a city of office building "grotesqueries ... built—it seemed—for giants" (1-2). It is full of small Babbitts, or white-collar workers who make nothing in particular, "neither butter nor shoes nor poetry," but who hold fervent opinions about everything from settlement-work and socialism, to entrepreneurialism and British entitlement (2). Zenith is a prison of contradictions, where men sneak sly looks at every naked female ankle but where the "moral indignation with which males ruled the world" somehow still rules the roost (93). Its parochialism is marketed to the rest of the Midwestern metropolises, fixing the patterns that lead contemporary Midwestern writers to assert that the economic agenda of Midwestern metropolitan areas is antithetical to the promise of cosmopolitanism.

${ }^{251}$ The interview quoted in this paragraph is entitled "Mainstream and Meaningful" and appeared in The Atlantic Online on October 3, 2001 (http://www.theatlantic.com/doc/200110u/int2001-10-03). All of the quotes from Franzen in this paragraph come from this interview. 
${ }^{252}$ Franzen uses a "contract vs. status" polarity when discussing the relationship between the writer and reader of literary fiction. Franzen argues that "status" authors see themselves in the modernist mold, as crafters of prose who are indifferent to their audience's interests and desires. Though he'd probably rather not, Franzen considers himself a "contract" author whose primary allegiance is to the relationship between his narrator and his reader. It from this commitment that one can consider himself a "social novelist."

${ }^{253}$ Oprah chose the novel nearly a month after its publication. However, most of the major reviews of the novel were already in print before Oprah made her decision public. ${ }^{254}$ The above quotation from Heron comes from a forum in The Chronicle of Higher Education, titled "A Novelist, a Talk-Show Host, and Literature High and Low" (2001). ${ }^{255}$ Of course, after The Corrections, unquestionably canonical works of literary fiction (three words: "Summer of Faulkner") became the norm. ${ }^{256}$ Other notable pre-Franzen Oprah regional titles include Bret Lott's Jewel (1991), set in the backwoods of Mississippi, Melinda Haynes's Mother of Pearl (1999), also set in a small Mississippi town, Robert Morgan's Gap Creek (1999), set in the Appalachian high country, Tawni O'Dell's Back Roads (2000), set in mining towns of western Pennsylvania, Barbara Kingsolver The Poisonwood Bible (1998), set in a small town in Georgia (and the Congo), Christina Schwarz's (2000), set on Wisconsin's Lake Nagawaukee, Joyce Carol Oates's We Were the Mulvaneys (1996), set in the rural community of Mount Ephraim, New York. Gwyn Hyman Rubio's Icy Sparks (1996), set in the hills of Kentucky in the 1950s. 
${ }^{257}$ Of course, in order to have this fear, Franzen needs to have overlooked Oprah's preference for Morrison and Danticat.

${ }^{258}$ Many thousands of the novel's first editions did, however, hit the stands with the logo. 


\section{Works Cited}

Abel, Marco. "Speeding Across the Rhizome: Deleuze Meets Kerouac on the Road." Modern Fiction Studies 48.2 (2002): 227-256.

Agee, James. "Tennessee Valley Authority." 1933. Film Writing and Selected Journalism. New York: Library of America, 2005. 631-646.

---. Letter to Archibald MacLeish. 18 November 1937. James Agee Collection. Box 11, folder 16. Harry Ransom Research Center. U of Texas, Austin.

---. Letter to Walker Evans. 1938. James Agee Collection. Box 2, folder 5. Harry Ransom Research Center. U of Texas, Austin.

---. “Colon.” New Directions in Prose \& Poetry, 1940. New York: Kraus Reprint Corp., 1967. 181-192.

---. Review of Grapes of Wrath. 1940. James Agee Collection. Box 6, folder 10. Harry Ransom Research Center. U of Texas, Austin.

---. “A Preface to a Decision.” 1945. James Agee Collection. Box 1, folder 1. Harry Ransom Research Center. U of Texas, Austin.

---. “J 6.3: LUNPFM Drafts: Introduction.” James Agee Rediscovered: The Journals of Let Us Now Praise Famous Men and Other New Manuscripts. Eds. Michael A. Lofaro and Hugh Davis. Knoxville: U of Tennessee P, 2005. 143-155.

Agee, James and Walker Evans. Let Us Now Praise Famous Men. 1941. New York: Mariner, 2001.

Altieri, Charles. "Whose America is Our America: On Walter Benn Michaels's Characterizations of Modernity in America.” Modernism/Modernity 3.3 (1996): 107-113. 
Ammons, Elizabeth. Introduction. American Local Color Writing, 1880-1920. New York: Penguin, 1998.

Anderson, Amanda. The Powers of Distance: Cosmopolitanism and the Cultivation of Detachment. Princeton: Princeton UP, 2001.

Anderson, Sherwood. Winesburg, Ohio. 1919. New York: Penguin, 1987.

Arthur, Jason: "The Wages of Liberalism: An Interview with Eric Lott.” the minnesota review 63-64 (Spring-Summer 2005): 179-193.

Austin, Mary. "Regionalism in American Fiction." The English Journal 21.2 (1932): 97107.

Banks, Russell. 1978. Hamilton Stark. New York: Perennial, 1996.

----. "The Trailerpark Tales: Notes and Synopsis.” Russell Banks Collection. Box 30, folder 6. Harry Ransom Research Center. U of Texas, Austin.

----. Trailerpark. 1981. New York: Perennial, 1996.

----. Continental Drift. New York: Harper, 1985.

----. Success Stories. New York: Harper, 1986.

----. Interview with Kay Bonetti. Columbia: American Audio Prose Library, Rec 1986.

----. "Research Materials for Affliction." Russell Banks Collection. Box 2, folder 6. Harry Ransom Research Center. U of Texas, Austin.

----. Affliction. 1989. New York: Perennial, 1990.

----. Interview with Robert Faggen. “The Art of Fiction CLII.” Paris Review 147 (1998): $50-88$

----. The Darling. New York: HarperCollins, 2004.

----. Interview. "Road Signs” 29 March 2000. 12 Aug. 2006 
$<$ http://indyweek.gyrobase.com/gyrobase/Content?oid=14223>.

Barber, Benjamin. "Constitutional Faith." For Love of Country?. Ed. Joshua Cohen. Boston: Beacon, 1994. 30-37.

Barth, John. The Friday Book: Essays and Other Nonfiction. New York: Putnam, 1984. Baudrillard, Jean. "Simulacra and Simulations." Trans. Paul Foss, Paul Patton, and Philip Beitchman. Modern Criticism and Theory. Eds. David Lodge and Nigel Wood. New York: Parson, 2000. 404-412.

Bender, Thomas. New York Intellect: A History of Intellectual Life in New York City, From 1750 to the Beginnings of Our Own Time. New York: Knopf, 1987.

Benjamin, Walter. "Author as Producer." Reflections: Essays, Aphorisms, Autobiographical Writings. Trans. Edmund Jephcott. New York: Schocken Books, 1978. 220-238.

---. Illuminations. Ed. and trans. Hannah Arendt. New York: Schocken Books, 1978. Berman, Marshall. All That is Solid Melts into Air: The Experience of Modernity. New York: Simon and Schuster, 1982.

Berman, Paul. A Tale of Two Utopias: The Political Journey of the Generation of 1968. New York: Norton, 1996.

Bold, Christine. The WPA Guides: Mapping America. Jackson: UP of Mississippi, 1999. Boyle, T. C. The Tortilla Curtain. New York: Viking, 1995.

Bridge, Gary and Sophie Watson. "Introduction: Reading City Publics.” The Blackwell City Reader. Eds. Gary Bridge and Sophie Watson. Malden: Blackwell Publishing, 2002. 
Brodhead, Richard. Cultures of Letters: Scenes of Reading and Writing in NineteenthCentury America. Chicago: U of Chicago P, 1993.

---. "Regionalism and the Upper Class." Rethinking Class: Literary Studies and Social Formations. Ed. Wai Chee Dimock and Michael T. Gilmore. New York: Columbia UP, 1994. 150-174.

Brooks, Van Wyck. The Ordeal of Mark Twain. New York: Dutton, 1920.

---. The Pilgrimage of Henry James. New York: Dutton, 1925.

Brown, Bill. "Identity Culture.” American Literary History 10.1 (1998): 164-184.

---. A Sense of Things: The Object Matter of American Literature. Chicago: U of Chicago P, 2003.

Bukiet, Melvin Jules. "Crackpot Realism: Fiction for the Forthcoming Millennium." Review of Contemporary Fiction 16:1 (Spring 1996): 13-22.

Bulosan, Carlos. America Is in the Heart: A Personal History. Seattle: U of Washington P, 1973.

Caldwell, Erskine and Margaret Bourke-White. You Have Seen Their Faces. 1937. Athens: U of Georgia P, 1995.

Campbell, Donna. Resisting Regionalism: Gender and Naturalism in American Fiction, 1885-1915. Athens: Ohio UP, 1997.

Cather, Willa. Not Under Forty. 1936. Lincoln: U of Nebraska P, 1988.

de Certeau, Michel. The Practice of Everyday Life. Berkeley: U of California P, 1984.

Chabot, C. Barry. Writers for the Nation: American Literary Modernism. Tuscaloosa: U of Alabama P, 1997. 
Chan, Jeffery Paul, Frank Chin, Lawson Fusao Inada, and Shawn Wong. The Big Aiiieeeee!: An Anthology of Chinese and Japanese Literature. New York: Penguin, 1991.

Charters, Ann. Kerouac: A Biography. New York: St. Martin’s P, 1973.

---. Introduction. On the Road. New York: Penguin, 1991. vii-xxx.

Cheah, Phang. "Introduction Part II: The Cosmopolitical—Today." In Cosmopolitics:

Thinking and Feeling Beyond the Nation. Eds. Bruce Robbins and Pheng Cheah. Minneapolis: U of Minnesota P, 1998. 20-41.

Chin, Frank. "Come All Ye Asian American Writers of the Real and the Fake." The Big Aiiieeeee! 1-92.

Chin, Frank and Jeffrey Paul Chan. "Racist Love.” Seeing Through Shuck. Ed. Richard Kostelanetz. New York: Ballantine Books, 1972. 65-71.

Chu, Patricia E. Race, Nationalism and the State in British and American Modernism. New York: Cambridge UP, 2006.

Clifford, James. Predicament of Culture: Twentieth-Century Ethnography, Literature, and Art. Cambridge: Harvard UP, 1988.

---. Routes: Travel and Translation in the Late Twentieth Century. Cambridge: Harvard UP, 1997.

Coard, Robert L. "Edith Wharton's Influence on Sinclair Lewis.” Modern Fiction Studies $31: 3$ (1985): 511-527.

Coats, Lauren and Nihad Farooq. "Regionalism in the Era of the New Deal." $A$ Companion to the Regional Literatures of America. Ed. Charles L. Crow. Malden, Blackwell P, 2003. 74-91. 
Coles, Robert. Migrants, Sharecroppers, Mountaineers: Volume II of the Children of Crisis. 1967. Boston: Atlantic Monthly P, 1971.

---. Doing Documentary Work. New York: Oxford UP, 1997.

Collins, Michael. The Keepers of Truth. New York: Picador, 2000.

Cox, James. "Regionalism: A Diminished Thing," Columbia Literary History of the United States. Ed. Emory Elliott, 761-84.

Cotkin, George. Existential America. Baltimore: Johns Hopkins University Press, 2003.

Crump, G. B. The Novels of Wright Morris: A Critical Interpretation. Lincoln: U of Nebraska P, 1978.

---. “A New Regionalism in American Fiction.” Unpublished essay, 2006.

Cuordileone, K. A. Manhood and American Political Culture in the Cold War. New York: Routledge, 2005.

Curtis, James. Mind's Eye, Mind's Truth: FSA Photography Reconsidered. Philadelphia: Temple UP, 1989.

Davidson, Michael. The San Francisco Renaissance: Poetics and Community at MidCentury. Cambridge: Cambridge UP, 1989.

---. Ghostlier Demarcations: Modern Poetry and the Material Word. Berkeley: U of California P, 1997.

---. Guys Like Us: Citing Masculinity in Cold War Poetics. Chicago: U of Chicago P, 2004.

Debord, Guy. The Society of the Spectacle. Trans. Donald Nicholson-Smith. New York: Zone Books, 1994. 
Debord, Guy, et al. "Introduction to a Critique of Urban Geography." Les Levres Nues 6 (1955). <library.nothingness.org/articles/SI/en/>.

Deleuze, Gilles and Félix Guattari. Kafka: Toward a Minor Literature. Trans. Dana Polan Minneapolis: U of Minnesota P, 1986.

Deleuze, Gilles and Félix Guatarri. A Thousand Plateaus: Capitalism and Schizophrenia. Trans. Brian Massumi. Minneapolis: U of Minnesota P, 1987.

Denning, Michael. The Cultural Front. New York: Verso, 1997.

Dickstein, Morris. Leopards in the Temple: The Transformation of American Fiction 1945-1970. Cambridge: Harvard UP, 1999.

Dirlik, Arlif. "The Global in the Local." Global/Local: Cultural Production and the Transnational Imaginary. Eds. Rob Wilson and Wimal Dissanayake. Durham: Duke UP, 1996. 21-45.

Dos Passos, John. USA. 1936. New York: Library of America, 1996.

Doss, Erika. Benton, Pollock, and the Politics of Modernism: From Regionalism to Abstract Expressionism. Chicago: U of Chicago P, 1991.

Douglas, Ann. Introduction. The Dharma Bums. 1958. New York: Penguin, 2007. viixxviii.

---. “Telepathic Shock and Meaning Excitement': Kerouac's Poetics of Intimacy." College Literature 27.1 (2000): 8-21.

Du Bois, W.E.B. The Souls of Black Folks: Essays and Sketches. Chicago: A. C. McClurg \& Co., 1903.

---. The Negro. New York: Henry Holt and Company, 1915. 
Durso, Patricia Keefe. Crossing Cultures, (Ex)Changing Stories. Unpublished Dissertation. http://blake.montclair.edu/ dursop/pkd_cv_2_18_03.pdf>. Eisinger, Chester E. Fiction of the Forties. Chicago: U of Chicago P, 1963. Ellison, Ralph. Invisible Man. 1952. New York: Vintage, 1990.

Frank, Thomas. What's the Matter With Kansas?: How Conservatives Won the Heart of America. New York: Henry Holt, 2004.

Faludi, Susan. Stiffed: The Betrayal of the American Man. New York: Perennial, 2000.

Farber, David. The Age of Great Dreams: America in the 1960s. New York: Hill and Wang, 1994.

Felski, Rita. "Introduction.” New Literary History 33.4 (2002) 607-622.

Ferlinghetti, Lawrence. “Thus Spake Ferlinghetti.” Exquisite Corpse 8 $<$ http://corpse.org/issue_8/critiques/ferling.htm $>$.

Fetterley, Judith and Marjory Pryse. Writing Out of Place: Regionalism, Women, and American Literary Culture. Urbana: U of Illinois P, 2003.

Fisher, Philip. "Democratic Social Space: Whitman, Melville, and the Promise of American Transparency" Representations 24 (1988): 60-101.

Folks, Jeffrey J. "Let Us Now Praise Famous Men.” The Literary Encyclopedia. 14 pars. 7 July 2001. The Literary Dictionary Company. 24 October 2005. $<$ http://www.litencyc.com/php/sworks.php?rec=true\&UID=4015>.

Foner, Eric. The Reader's Companion to American History. New York: Houghton Mifflin, 1991.

Foote, Stephanie. Regional Fictions: Culture and Identity in Nineteenth-Century American Literature. Madison: U of Wisconsin P, 2001. 
Foreman, Paul. "Sharecropper Novels.” Southern Exposure 9.2 (1981): 107-110.

Frank, Robert. The Americans. 1959. New York: Grossman P, 1969.

Frank, Waldo. Our America. New York: Boni and Liveright, 1919.

Frankfurt, Harry G. On Bullshit. Princeton: Princeton UP, 2005.

Franzen, Jonathan. How to Be Alone. 2002. New York: Picador, 2003.

---. Twenty-Seventh City. New York: Picador, 1988.

---. The Corrections. New York: Picador, 2001.

Freeman, Jo. "The Tyranny of Structurelessness." Quiet Rumours: An Anarcha-Feminist Reader San Francisco: Dark Star, 2002.

Gitlin, Todd. The Twilight of Common Dreams: Why America is Wracked by Culture Wars. New York: Metropolitan Books, 1995.

Glazener, Nancy. Reading for Realism: The History of a U.S. Literary Institution, 18501910. Durham: Duke UP, 1997.

Gordon, Mary. "Introduction." Woman Warrior and China Men. New York: Knopf, 2005. ix-xvi.

Guillory, John. Cultural Capital: The Problem of Literary Canon Formation. Chicago: U of Chicago p, 1993.

Habermas, Jürgen. The Structural Transformation of the Public Sphere: An Inquiry into a Category of Bourgeois Society. 1962. Trans. Thomas Burger. Cambridge: MIT Press, 1995.

Hamalian, Linda. A Life of Kenneth Rexroth. New York: Norton, 1991. 
---. "Regionalism Makes Good: The San Francisco Renaissance." Reading the West: New Essays on the Literature of the American West. Ed. Michael Kowalewski. New York: Cambridge UP, 1996.

Hamblen, Abigail Ann. "Edith Wharton in New England." New England Quarterly: A Historical Review of New England Life and Letters 38:2 (1965): 239-44.

Haraway, Donna. "Situated Knowledges: The Science Question in Feminism and the Privilege of Partial Perspective." Feminist Studies 14.3 (1988): 575-599.

Harkin, James. “Get a (Second) Life.” Financial Times. 17 (November 2006).

Harris, Jonathan. Federal Art and National Culture: The Politics of Identity in New Deal America. Cambridge: Cambridge UP, 1995.

Hegeman, Susan. Patterns for America: Modernism and the Concept of Culture. Princeton: Princeton UP, 1999.

Hicks, Granville. Small Town. 1946. New York: Fordham UP, 2004.

---. "Introduction." Wright Morris: A Reader. New York: Harper and Row, 1970. ixxxxiii.

---. Literary Horizons: A Quarter Century of American Fiction. New York: New York UP, 1970.

Hilfer, Anthony Channell. The Revolt from the Village 1915-1930. Chapel Hill: U of North Carolina P, 1969.

Hohenberg, John. The Pulitzer Diaries: Inside America's Greatest Prize. Syracuse: Syracuse UP, 1997.

Hollinger, David. Postethnic America: Beyond Multiculturalism. New York: Basic Books, 1995. 
Holton, Robert. "Kerouac Among the Fellahin: On the Road to the Postmodern.” Modern Fiction Studies 41.2 (1995): 265-83.

Howe, Irving. "Mass Society and Post-Modern Fiction.” Partisan Review 26 (1959): 420436.

Hrebeniak, Michael. Action Writing: Jack Kerouac's Wild Form. Carbondale: Southern Illinois UP, 2006.

Huang, Yunte. Transpacific Displacement: Ethnography, Translation, and Intertextual Travel in Twentieth-Century American Literature. Berkeley: U of California P, 2002.

Huston, Nancy. “The Decline of Identity?” Salmagundi (Winter/Spring 1999): 10-22.

Jacobs, Jane. The Death and Life of Great American Cities. 1961. New York, Modern Library, 1993.

Johnston, Allan. “Consumption, Addiction, Vision, Energy: Political Economies and Utopian Visions in the Writings of the Beat Generation." College Literature 32.2 (2005): 103-126.

Jones, Gavin. "Poverty and the Limits of Literary Criticism." American Literary History 15.4 (2003): 765-792.

Joshi, S.T. and Peter Cannon. More Annotated H. P. Lovecraft. New York: Dell Pub, 1999.

Kazin, Alfred. On Native Grounds: An Interpretation of Modern American Prose Literature. 1942. Garden City: Doubleday, 1956.

Kerouac, Jack. The Town and the City. 1950. New York: Harcourt, 1970.

---. On the Road. 1957. New York: Penguin, 1991. 
---. "Essentials of Spontaneous Prose." Evergreen Review. 2.5 (1958): 72-73.

---. Big Sur. 1962. New York: Penguin, 1992.

---. "From the Journals: 1949-1954." Road Novels: 1957-1960. Ed. Douglas Brinkley. New York: Library of America, 2007. 775-834.

Kingston, Maxine Hong. Tripmaster Monkey: His Fakebook. 1989. New York: Vintage, 1990.

---. The Woman Warrior and China Men. New York: Knopf, 2005.

Kirkpatrick, David D. ““Oprah' Gaffe by Franzen Draws Ire and Sales.” New York Times, 21 Oct. 2001: E1.

Koepnick, Lutz. Walter Benjamin and the Aesthetics of Power. Lincoln: U of Nebraska P, 1999.

Kowalewski, Michael. "Contemporary Regionalism." A Companion to the Regional Literatures of America. Ed. Charles L. Crow. Malden, Blackwell P, 2003. 7-24. Kumar, Amitava. "Introduction." World Bank Literature. Minneapolis: U of Minnesota P, 2003. xvii-xxxiii

Laclau, Ernesto. On Populist Reason. New York: Verso, 2005.

Lears, T. J. Jackson. No Place of Grace: Antimodernism and the Transformation of American Culture, 1880-1920. New York: Pantheon Books, 1981.

Least Heat-Moon, William. Blue Highways: A Journey Into America. Boston: Little, Brown, 1983.

Lee, James Kyung-Jin. "The City as Region." A Companion to the Regional Literatures of America. Ed. Charles L. Crow. Malden, Blackwell P, 2003. 74-91. 
Lee, Yoon Sun. “Kingston's China Men: Circumscribing the Romance of Deterritorialization." The Yale Journal of Criticism 11. 2 (Fall 1998): 465-484.

Lehan, Richard. The City in Literature: An intellectual and Cultural History. Berkeley: U of California P, 1998.

Lerner, Richard and Lewis MacAdams, dirs. What Happened to Kerouac? Ingram Home Entertainment, 1986.

Lhamon, W. J. Deliberate Speed: The Origins of a Cultural Style in the American 1950s. Washington: Smithsonian Institution Pr, 1990.

Li, David. Imagining the Nation: Asian American Literature and Cultural Consent. Stanford: Stanford UP, 1998.

Lin, Patricia. “Clashing Constructs of Reality: Reading Maxine Hong Kingston's Tripmaster Monkey: His Fake Book as Indigenous Ethnography." Reading the Literatures of Asian America. Eds. Shirley Geok-lin Lim and Amy Ling. Philadelphia: Temple UP, 1992. 333-48.

Locke, Edwin. "Adaptation of Reality in The Grapes of Wrath." Films 1.2 (1940): 49-55.

Lott, Eric. The Disappearing Liberal Intellectual. New York: Basic Books, 2006.

Lowe, John. "Monkey Kings and Mojo: Postmodern Ethnic Humor in Kingston, Reed, and Vizenor." MELUS 21:4 (1996): 103-26.

Lutz, Tom. Cosmopolitan Vistas: American Regionalism and Literary Value. Ithaca: Cornell UP, 2004.

Macdonald, Dwight. Against the American Grain. 1962. New York: De Capo P, 1983. 
Mackin, Jonna. "Split Infinities: The Comedy of Performative Identity in Maxine Hong Kingston's Tripmaster Monkey.” Contemporary Literature 46.3 (Fall 2005): 511 534.

Mailer, Norman. "The White Negro" http://www.dissentmagazine.org/article/?article=877.

Maini, Irma. "Writing the Asian American Artist: Maxine Hong Kingston’s Tripmaster Monkey: His Fake Book.” MELUS 25.3/4 (2000): 243-64.

McCann, Sean. Gumshoe America: Hardboiled Crime Fiction and the Rise and Fall of New Deal Liberalism. Durham: Duke UP, 2000.

McClure, Michael. Lighting the Corners: On Art, Nature, and the Visionary. Albuquerque: U of New Mexico P, 1994.

McConnell, Michael. "Don’t Neglect the Little Platoons.” For Love of Country?. Ed. Joshua Cohen. Boston: Beacon, 1994. 78-84.

McGurl, Mark. "The Program Era: Pluralisms of Postwar American Fiction.” Critical Inquiry 32 (2005): 102-129.

---. “Understanding Iowa: Flannery O’Connor, B.A., M.F.A.” American Literary History 19.2 (2007): 527-545.

Michaels, Walter Benn. Our America: Nativism, Modernism, and Pluralism. Durham: Duke UP, 1995.

---. The Shape of the Signifier: 1967to the End of History. Princeton: Princeton UP, 2004.

---. The Trouble With Diversity: How We Learned to Love Identity and Ignore Inequality. New York: Metropolitan Books, 2006.

Mitchell, WJT. Picture Theory. Chicago: U of Chicago P, 1994. 
---. “The Violence of Public Art: Do the Right Thing." In Spike Lee's Do the Right Thing. Ed. Mark Reid. New York: Cambridge U, 1997.

Morris, Wright. "Inhabitants." New Directions in Prose \& Poetry, 1940. New York:

Kraus Reprint Corp., 1967. 145-179.

---. "from The Territory Ahead." In Wright Morris: A Reader. New York: Harper and Row, 1970. 636-648.

---. The Territory Ahead. New York: Harcourt, Brace, 1958.

---. The Works of Love, 1949. Lincoln: Bison, 1972.

Moy, James. Marginal Cites: Staging the Chinese in America. Iowa City: U of Iowa P, 1993.

"The New Regionalism." Outline of American Literature. Ed. Kathryn VanSpanckeren. 1998. US Department of State, Washington. 12 June 2005 $<$ http://usinfo.state.gov/products/pubs/oal/lit8.htm\#regionalism>.

Nguyen, Viet Thanh. "The Remasculinization of Chinese America: Race, Violence, and the Novel." American Literary History 12.1 (2000): 130-157.

Nichols, Bill. "Documentary Film and the Modernist Avant-Garde." Critical Inquiry 27.4 (2001): 580-610.

Niemi, Robert. Russell Banks. New York: Twayne, 1997.

Norris, Frank. McTeague. 1899. Ed. Donald Pizer. New York: W. W. Norton \& Company, 1977.

"A Novelist, a Talk-Show Host, and Literature High and Low." The Chronicle of Higher Education 30 November 2001: B4. 
Nussbaum, Martha. "Patriotism and Cosmopolitanism." For Love of Country?. Ed. Joshua Cohen. Boston: Beacon, 1994. 2-20.

Oates, Joyce Carol. The Faith of a Writer: Life, Craft, Art. New York: HarperCollins, 2003.

O'Connor, Flannery. Mystery and Manners: Occasional Prose. Eds. Sally and Robert Fitzgerald. New York: Farrar, Straus \& Giroux, 1969.

Olasky, Marvin N. Renewing American Compassion. New York: Free P, 1996.

Ong, Aihwa. Flexible Citizenship: The Cultural Logics of Transnationality. Durham: Duke UP, 1999.

Perloff, Marjorie. "Modernism Without the Modernists: A Response to Walter Benn Michaels." Modernism/Modernity 3.3 (1996): 99-105.

Perry, George Sessions. Hold Autumn in Your Hand. New York: Viking, 1941.

Pfeil, Fred. "Beating the Odds: The Brechtian Aesthetic of Russell Banks." In Another Tale to Tell: Politics and Narrative in Postmodern Culture. New York: Verso, 1990.

Pinsky, Robert. "Eros Versus Esperanto." For Love of Country?. Ed. Joshua Cohen. Boston: Beacon P, 1994. 85-90.

Podhoretz, Norman. “The Know-Nothing Bohemians in Partisan Review, Spring 1958: 305-318.

---. Making It. New York: Random House, 1967.

Pollack, Oliver B. "Wright Morris and the Jews" Shofar: An Interdisciplinary Journal of Jewish Studies 20.4 (2002): 18-35. 
Posnock, Ross. "The Dream of Deracination: The Uses of Cosmopolitanism.” American Literary History 12.4 (2000): 802-818.

“Post Identity Politics.” New Literary History 31.4 (2000).

Pratt, Mary Louise. “Arts of the Contact Zone." Ways of Reading. $5^{\text {th }}$ edition. Eds. David Bartholomae and Anthony Petroksky. New York: Bedford/St. Martin's, 1999. 605-619.

Rexroth, Kenneth. "Disengagement: The Art of the Beat Generation.” New World Writing 11 (1957): 28-41.

---. "San Francisco Letter." 1957. San Francisco Stories: Great Writers on the City. Ed. John Miller. San Francisco: Chronicle Books, 1990.

---. “Afterward." McTeague. 1899. New York: Penguin, 1964. 340-348.

Richardson, Mark. "Peasant Dreams: Reading On the Road." Texas Studies in Literature and Language 43.2 (2001): 218-242.

Rilke, Rainer Maria. The Notebooks of Malte Laurids Brigge 1910. New York: Vintage, 1990

Robbins, Bruce. "Introduction Part I: Actually Existing Cosmopolitanism." Cosmopolitics: Thinking and Feeling Beyond the Nation. Minneapolis: $\mathrm{U}$ of Minnesota P, 1998. 1-19.

Robinson, Sally. Marked Men: White Masculinity in Crisis. New York, Columbia UP, 2000.

Rodriguez, Richard. "Late Victorians." Days of Obligation: An Argument with my Mexican Father. New York: Penguin, 1992. 26-47. 
Rosenblum, Naomi. A World History of Photography. $3^{\text {rd }}$ ed. New York: Abbeville P, 1997.

Roth, Philip. "Writing American Fiction." Reading Myself and Others. 1975. New York: Penguin, 1985. 173-91.

Rothstein, Arthur. "The Picture that Became a Campaign Issue.” Popular Photography (1961): 42-43, 79 .

Royal, Derek Parker. 'Literary Genre as Ethnic Resistance in Maxine Hong Kingston’s Tripmaster Monkey: His Fake Book.” MELUS 29.2 (2004): 141-56.

Russo, Richard. Empire Falls. New York: Knopf, 2001.

Ryden, Kent C. "New England Literature and Regional Identity" A Companion to the Regional Literatures of America. Ed., Charles L. Crow. Malden: Blackwell P, 2003.

Savran, David. Taking it Like a Man: White Masculinity, Masochism, and Contemporary American Culture Princeton: Princeton UP, 1998.

Scarry, Elaine. "The Difficulty of Imagining Other People” For Love of Country: Debating the Limits of Patriotism. Ed. Joshua Cohen. Boston: Beacon P, 1996. 98-110.

Schlesinger, Jr., Arthur M. The Vital Center: The Politics of Freedom. 1949 New Brunswick: Transaction P, 1998.

Sege, Irene. "Leading a Double Life." The Boston Globe. 25 October, 2006.

Shlaes, Amity. The Forgotten Man: A New History of the Great Depression. New York: HarperCollins, 2007.

Simon, Charlie May. The Share-Cropper. New York: E.P. Dutton, 1937. 
Skenazy, Paul. "Kingston at the University." Conversations with Maxine Hong Kingston. Eds. Paul Schenazy and Tera Martin. Jackson: U of Mississippi P, 1998. 118-158. Solomon, William. "Wound Culture and James Agee." Arizona Quarterly 58: 4 (Winter 2002): 81-105.

Sontag, Susan. “Godard.” A Susan Sontag Reader New York: Vintage, 1982. 235.

Spencer, Thomas M. The St. Louis Veiled Prophet Celebration: Power on Parade, 18771995. Columbia: U of Missouri P: 2000.

Spiegel, Alan. James Agee and the Legend of Himself: A Critical Study. Columbia: U of Missouri P, 1998.

Stein, Gertrude. Everybody's Autobiography. 1937. New York: Cooper Square Publishers, 1971.

Steinbeck, John. The Harvest Gypsies: On the Road to the Grapes of Wrath. 1936. Berkeley: Heyday Books, 1988.

Sterrit, David. Mad to be Saved: The Beats, the 50s and Film. Carbondale: Southwestern UP, 1998.

Stott, William. Documentary Expression and Thirties America. 1973. New York: Oxford UP, 1973.

Szalay, Michael. New Deal Modernism: American Literature and the Invention of the Welfare State. Durham: Duke UP, 2000.

Tagg, John. "Melancholy Realism: Walker Evans’s Resistance to Meaning." Narrative 11.1 (2003): 3-77.

Terrell, Whitney. The Huntsman. New York: Penguin, 2001. 
Trachtenberg, Alan. The Incorporation of America: Culture and Society in the Gilded Age. New York: Hill and Wang, 1982.

---. Forward. You Have Seen Their Faces. 1937. By Erskine Caldwell and Margaret Bourke-White. Athens: U of Georgia P, 1995. v-viii.

---. “Home Place.” Raritan 26.1 (2006): 64-87.

Trilling, Lionel. The Middle of the Journey. New York: Viking Press, 1947.

---. The Liberal Imagination: Essays on Literature and Society. Garden City: Doubleday, 1950.

Tytell, John. Naked Angels: The Lives \& Literature of the Beat Generation. New York: McGraw-Hill, 1976.

Wakoski, Diane. "The Birth of the San Francisco Renaissance: Something Now Called the Whitman Tradition." Literary Review 32.1 (1988): 36-41.

Wald, Alan. The New York Intellectuals: The Rise and Decline of the Anti-Stalinist Left from the 1930s to the 1980s. Chapel Hill: U of North Carolina P, 1987.

Watson, Stephen. The Birth of the Beat Generation: Visionaries, Rebels, and Hipsters, 1944-1960. New York: Pantheon, 1995.

Weinreich, Regina. "The Beat Generation is Now About Everything." College Literature 27.1 (2000): 263-268.

Wharton, Edith. Ethan Frome. 1911. New York: Charles Scribner’s Sons, 1987.

---. House of Mirth. 1905.

Wheeler, Elizabeth. Uncontained: Urban Fiction in Postwar America. New Brunswick: Rutgers UP, 2001.

Whyte, William H., Jr. The Organization Man. Garden City: Anchor, 1956. 
Williams, A. Noelle. "Parody and Pacifist Transformations in Maxine Hong Kingston's Tripmaster Monkey: His Fake Book. MELUS 20.1 (Spring 1995): 83-100.

Wills, Garry. Nixon Agonistes: The Crisis of the Self-Made Man. New York: Signet, 1971.

Wilson, Edmund. Boys in the Back Room: Notes on California Novelists. San Francisco, Colt P, 1941.

Wollenberg, Charles. "John Steinbeck: On the Road to The Grapes of Wrath." The Human Tradition in California. Clark Davis and David Igler, eds. Wilmington, Del: SR Books, 2002. 135-146.

Wolfe, Tom. The Electric Kool-Aid Acid Test. 1968. New York: Bantam, 1999.

Wrobel, David M. The End of American Exceptionalism: Frontier Anxiety from the Old West to the New Deal. Lawrence: UP of Kansas, 1993.

Wuori, G. K. Nude in the Tub: Stories of Quillifarkeag, Maine. Chapel Hill: Algonquin Books, 1999.

---. An American Outrage: A Novel of Quillifarkeag, Maine. Chapel Hill: Algonquin Books, 2000.

Wydeven, Joseph J. "Photography and Privacy: The Protests of Wright Morris and James Agee Source.” Midwest Quarterly: A Journal of Contemporary Thought 23.1 (1981): 103-115.

Xiaomei Chen, Acting the Right Part: Political Theater and Popular Drama in Contemporary China. Honolulu: U of Hawaii P, 2002, 17-72.

Yeager, Patricia. “Introduction: Dreaming of Infrastructure.” PMLA 122.1 (2007): 9-26. 
Zagarell, Sandra A. "Crosscurrents: Registers of Nordicism, Community, and Culture in Jewett's Country of the Pointed Firs." Yale Journal of Criticism 10.2 (1997): $355-370$.

Zinoman, Jason. “On the TV: Re-enacting Kerouac Interviews.” New York Times (11 February 2006). 3 December 2007 $<$ http://theater2.nytimes.com/2006/02/11/theater/reviews/11elev.html\#>. 


\section{VITA}

Jason Arthur is the youngest of four children born to Gene and Joyce Arthur. He enrolled in graduate school in 1999, received his MA from Creighton University in 2001, and his PhD from MU in 2007. He currently serves as Visiting Assistant Professor at Central Methodist University, where he teaches courses in American literature and film. He is the only one of his siblings who is not self-employed. 